\title{
Social Learning in Community Forests
}

\author{
Edited by \\ Eva Wollenberg \\ David Edmunds \\ Louise Buck \\ Jeff Fox \\ Sonja Brodt
}

A Joint Publication of CIFOR and the East-West Center

2001 
Cover design adopted from traditional Dayak

Kenyah (East Kalimantan) "saung seling" weaving

(C) 2001 by Center for International Forestry Research

All rights reserved. Published in 2001

Printed by SMK Grafika Desa Putera, Indonesia

\section{ISBN 979-8764-77-3}

\section{Published by}

Center for International Forestry Research

Mailing address: P.O. Box 6596 JKPWB, Jakarta 10065, Indonesia

Office address: JI. CIFOR, Situ Gede, Sindang Barang,

Bogor Barat 16680, Indonesia

Tel.: +62 (251) 622622; Fax: +62 (251) 622100

E-mail: cifor@cgiar.org

Web site: http://www.cifor.cgiar.org 


\section{Table of Contents}

Contributors ix

Acknowledgements xiii

Foreword $\quad x v$

\section{Chapter 1}

Social learning in the collaborative management of community forests: Lessons from the field

Louise E. Buck, Eva Wollenberg and David Edmunds

\section{Chapter 2}

Facilitating viable partnerships in community forest management in Cameroon: The case of the Kilum-ljim Mountain Forest Area

Christian A. Asanga

\section{Chapter 3}

Platforms for learning:

Experiences with adaptive learning in Nepal's

Community Forestry Programme

Ghanendra Kafle

\section{Chapter 4}

Seva Mandir: A learning organisation

Rukmini Datta 


\section{Chapter 5}

Institutional collaboration and shared learning for forest management in Chivi District, Zimbabwe

Nontokozo Nemarundwe

\section{Chapter 6}

Rethinking the role of consensus in pluralism:

Learning from community-based forest management in Yunnan, China

Cao Guangxia and Zhang Lianmin

\section{Chapter 7}

External donors and community-based management of Mgori Forest, Tanzania: What happens when

the donors leave?

Edward Massawe

\section{Chapter 8}

Model forests: A partnership-based approach to landscape management

Ron D. Ayling

\section{Chapter 9}

Learning how to devolve: The Social Forestry Project, Malakand, North-West Frontier Province, Pakistan Haider Ali Khan

\section{Chapter 10}

Beyond rhetorical success: Advancing the potential for the community forestry programme in Nepal to address equity concerns

Bishnu Upreti 


\section{List of Figures, Tables and Boxes}

\section{Figures}

Figure 2.1 The Kilum-ljim forest area, North West

Province, Cameroon

Figure 2.2 Community members of one of the forest adjacent villages (Simonkoh) are carrying out fire tracing along their forest boundary

Figure 2.3 A time line exercise is being carried out with men of Mboh community

Figure 3.1 The NUKCFP experiential learning cycle

Figure 3.2 Project sites

Figure 3.3 Women engaged in discussion about future forest needs and indicators

Figure 4.1 Position of Rajasthan in India and of Udaipur district in Rajasthan

Figure 4.2 Paraworkers facilitating tree planting 71

Figure 4.3 Training for village women 76

Figure 5.1 Location of the Romwe catchment in Zimbabwe

Figure 5.2 Institutional framework for woodland management in Romwe catchment

Figure 5.3 Degraded gully to be reclaimed

Figure 5.4 Grass donated after the visit to Kuturaya project

Figure 5.5 Attempts to reclaim gully with vetiver grass

Figure 6.1 Location of three villages in Yunnan province, China

Figure 6.2 The village forest addresses villagers multiple needs

Figure 6.3 The local worship under the divine hill in Tangdui village

Figure 7.1 Location of Mgori forest in Singida regions (Tanzania) 
Figure 7.2 Boundary marker between two villages Nduamughanga and Mughunga

Figure 7.3 Mgori Forest coordinating committee meeting, including project technical advisor

Figure 7.4 Local patrolmen with their traditional weapons 137

Figure 8.1 Model forest network

Figure 8.2 Partnerships can be rich associations of personalities, and are dynamic and evolving relationships (Waswanipi Cree Model Forest)

Figure 8.3 Public participation and sharing of information are essential ingredients of an effective model forest (Western Newfoundland Model Forest) 162

Figure 9.1 Social Forestry Project in Malakand Agency 176

Figure 9.2 Village plantation on communal hillside $\quad 178$

Figure 9.3 WO members also contribute in the preparation of village management plan

Figure 9.4. VDC members prepare village management plan

Figure 10.1 Community managed forests: hope for future 193

Figure 10.2 Location of the research area 194

Figure 10.3 Community members are planning a community forestry activity

Figure 10.4 Women are the principal user of forest

\section{Tables}

Table 3.1 Characteristics of and factors that promote good collaboration

Table 5.1 Women's ranking of importance of institutions operating in the Romwe catchment area

Table 6.1 Location, population, and forest information for three case study villages in Yunnan Province

Table 9.1 Stages of terms of partnership agreements

Table 10.1 Overview of the strengths, weaknesses, opportunities and challenges of community forestry in Nepal 


\section{Boxes}

Box 2.1 Practical evidence of overlap between community use objectives and conservation objectives in Kilum-ljim area

Box 3.1 Appreciative inquiry: A forward-looking approach

$\begin{array}{lll}\text { Box } 4.1 \quad \text { Shyampura village } & 73\end{array}$

Box 4.2 Nayakheda hamlet 74

Box 5.1 Mr. Jonasi Dube's case 95

Box 5.2 Successes and challenges of the kuturaya project

Box 7.1 Improving fire management in Mgori Forest 139

Box 7.2 Establishing a forum for community-based forest management in Tanzania $\quad 145$

Box 8.1 Development of a Representative Board for the Chihuahua Model Forest, Mexico 161

Box 8.2 Experimenting with partnership building in the Gassinski Model Forest, Russia 
Photographer: $₫$ David Edmunds and Louise Buck, page xii Christian A. Asanga, page 28, $29 \backsim$ Ghanendra Kafle, page $53 \backsim$ Rukmini Datta, page 71, $76 \backsim$ Nontokozo Nemarundwe, page 101, 102 Cao Guangxia and Zhang Lianmin, page 115, 119 -Edward Massawe, page 133, 135, 137 Model Forest Network, 159, 162, - Haider Ali Khan, page 178, $181 \backsim$ Bishnu Upreti, page 193, 196, 198

viii 


\section{Contributors}

Christian Asanga is the Senior Minister, Ministry of the Environment and Forestry Counterpart and Site Manager (Kilum) of the Kilum-Ijim Forest Project in Cameroon. Born in 1962 in Bambili, North West Province, Cameroon, Mr. Asanga obtained a B.Sc. in forestry at the University of Wales at Bangor in 1988 and an M.Sc. in Resource Management at the University of Edinburgh in 1989. Upon his return to Cameroon, he worked as senior forestry staff member at the office of the Conservator of Forests, South West Province Cameroon for two years before taking up his current position with the Kilum-Ijim Forest Project.

Ron Ayling is a consultant on integrated resource management, with an emphasis on forestry and agroforestry in developing countries. He has a B.Sc. (forestry) from the University of Toronto, Canada and a Ph.D. from the Australian National University in Canberra. He has worked for over 20 years internationally in forestry and rural development, including 15 years with Canada's International Development Research Centre (IDRC) in East and Southern Africa, South East Asia and parts of Latin America.

Louise Buck is a Senior Associate at the Center for International Forestry Research, based in the Department of Natural Resources at Cornell University, and associated with the Cornell International Institute for Food, Agriculture and Development. Her research interests are in participatory and social learning strategies for the management of protected areas and agroforestry. She holds a Ph.D. in Natural Resources from Cornell University, and earned her M.Sc. in Natural Resources Planning and 
Management from Colorado State University. Her work has been primarily in East Africa, Madagascar and northeastern North America.

Cao Guangxia is an associate professor at the Institute of Community and Environment, Southwest Forestry College. He holds a B.S. in Botany and M.S. in Ecology from Lanzhou University. He also received a certificate in community forestry from the Regional Center for Training in Community Forestry in Bangkok in 1991. He is working on issues of adaptive management, conflict, negotiation, participatory learning and local consensus building in community forestry. He also acts as the facilitator for promoting community-based collaborative management projects in Yunnan and other provinces of China.

Rukmini Datta is currently employed with the Village Development Fund programme of Seva Mandir, a non-governmental organisation working on community upliftment in tribal villages in Udaipur, India. She holds a post-graduate diploma from the Institute of Rural Management in Anand, India, and a Bachelor of Arts in Sociology from St. Xavier's College, University of Bombay, Mumbai. She was born in 1973.

David Edmunds is research fellow (sponsored by the Rockefeller Foundation) at the Center for International Forestry Research in Bogor, Indonesia. He received a Ph.D. in Geography from Clark University in 1997. Mr. Edmunds has spent five years in Uganda, Benin and the Democratic Republic of Congo, (then Zaire) working on community-based resource management. He now works on a number of projects related to multistakeholder negotiations and devolution policy.

Ghanendra Kafle is the Community Forestry Advisor with the Nepal/United Kingdom Community Forestry Project in Nepal. He has worked in community forestry in Nepal for more than a decade, managing projects, facilitating stakeholder collaboration in community forestry and assisting in creating enabling environments at the implementation and the policy levels. His earlier work experience included teaching high school students and school administration, socio-economic survey and research work, action research and teaching Nepali as a foreign language to non-native speakers.

Haider Ali Khan is currently Manager of the Support Organization (NGO) closely working with Social Forestry Project in the Malakand and Dir districts of the NorthWest Frontier Province, Pakistan. He holds Master's and Bachelor's degrees in Forestry 
from the University of Peshawar, Pakistan (1978), and received a Master's degree from the University of Missouri, USA, in 1991 with specialisation in Social Forestry. He has many years of experience in social forestry, community organisation and village land use planning. He is the author of three books and several articles relating to forestry.

Nontokozo Nemarundwe (née Nabane) is a sociologist with eight years' experience in rural development, specifically on gender and institutional issues in communitybased natural resource management. She worked as a research fellow under the Centre for Applied Social Sciences (CASS) at the University of Zimbabwe for six years (1992-1997). Currently she is a research associate with the Institute of Environmental Studies and is undertaking research on institutional dynamics in woodland management. Ms. Nemarundwe holds a Master's degree in Social Studies from the University of Zimbabwe (1997). She attended a one-year graduate course in natural resource management at Oregon State University in the USA in 1993/94. Ms. Nemarundwe was born in Plumtree district, Western Zimbabwe.

Edward L. Massawe is a Divisional Forest Officer for Mgori Forest and Mgori Forest Liaison Officer of the Tanzania Forestry and Beekeeping Division, where he has facilitated community-based forestry among the five villages of the Mgori Forest Reserve since 1995. Born in 1955 in the Moshi Kilimanjaro Region in Tanzania, Mr. Massawe worked with the Tanzanian Government's Forest Utilization Research Section in Moshi from 1978 to 1980 . He completed a Certificate Course in Forestry in the Olmotonyi Forestry Training Institute in 1983 and a Diploma in Forestry in 1994. Mr. Massawe's other community forestry experience includes working from 1984 to 1992 in Ilongero in the establishment of village and individual woodlots and tree planting in the Ilongero Division.

Bishnu Raj Upreti is a Sociologist and Agricultural Extensionist by training and has worked in community development and natural resource management in Nepal for the last 19 years. Mr. Upreti completed his Ph.D. on conflict management in natural resources at the Wageningen Agricultural University, the Netherlands and is currently a Research Fellow at the Centre for Environmental Strategy, University of Surrey, UK. He has helped design and evaluate several integrated development projects, studies and action research and worked in the Department of Irrigation, Agricultural Development Bank, Department of Agriculture, UNDP, FAO, SNV, SDC and UMN. 
Eva (Lini) Wollenberg is a researcher at the Center for International Forestry Research in Bogor, Indonesia. Before joining CIFOR in 1994, she was with the Ford Foundation's Asia Rural Poverty and Resources Program. She received a Ph.D. from the University of California, Berkeley in 1991. Her current research focuses on social learning among stakeholders and means for empowering forest communities, especially in the tropical regions of Asia.

Zhang Lianmin is an Assistant Professor at Southwest Forestry College. She is currently pursuing a Ph.D. at Yunnan University. In her Ph.D. study, she is looking at the interface between local ecology and economy and its implications for conservation policy in Yunnan Province.

Participants of the workshop entitled "Sharing Innovations: Methods for Multiple Stakeholder Management of Community Forests" at East-West Center, Honolulu, Hawaii, 26 July - 20 August 1999

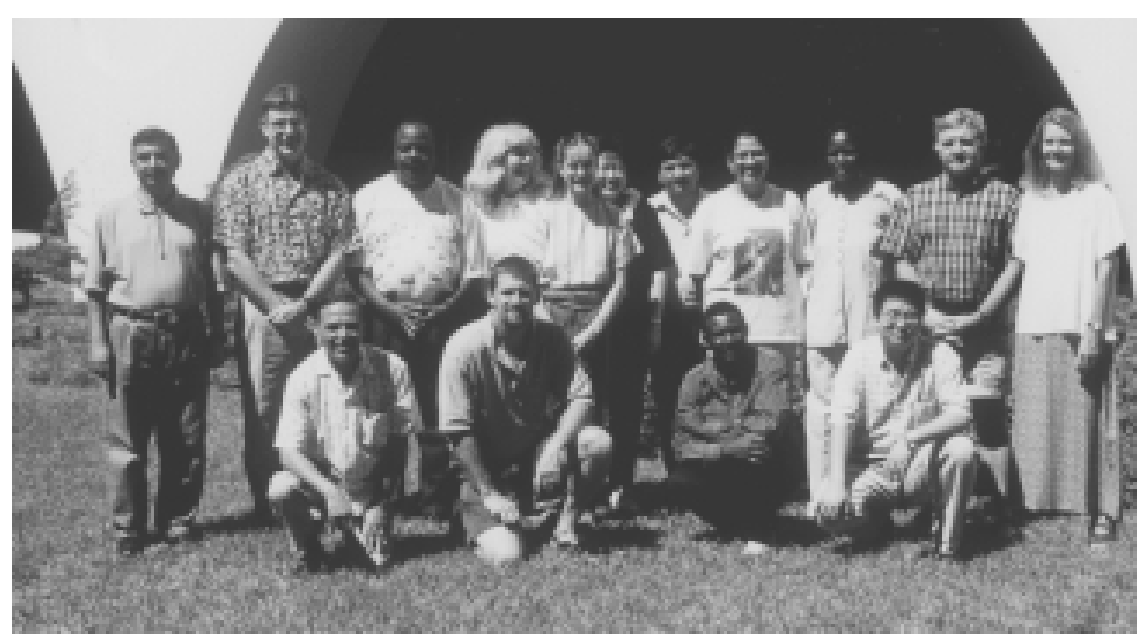




\section{Acknowledgements}

The editors express their most sincere thanks to everyone who helped with writing workshop and this publication. We especially thank the nine participants of the workshop-Christian Asanga, Ghanendra Kafle, Rukmini Datta, Nontokozo Nemarundwe, Cao Guangzia, Edward Massawe, Ron Ayling and Haider Ali Khanand their colleagues at home that contributed to the information for the papers. Louise Buck, David Edmunds, Sonja Brodt and Jeff Fox worked enthusiastically with the participants in Honolulu to develop and edit their papers. Bruce Campbell and Niels Röling reviewed earlier drafts. We are grateful to Dina Hubudin for her tireless assistance in handling administrative aspects of the project from Bogor, and to June Kuramoto, Mary Abo and Glenn Dolcemascolo for their efficient assistance in Hawaii. Sally Wellesley, Gideon Suharyanto, Eko Priyanto and Dina Hubudin completed the final round of editing, cover design and layout.

The work was supported by a grant from the International Fund for Agricultural Development, and with contributions from CIFOR and the East West Center. 


\section{Contributors}




\section{Foreword}

The chapters of this volume were produced at a writers' workshop entitled Sharing Innovations: Methods for Multiple Stakeholder Management of Community Forests. The workshop was hosted by the East-West Center in Honolulu, Hawaii on 26 July28 August 1999 and designed and supported through the Center for International Forestry Research (CIFOR). It brought together professional practitioners in the field of community forestry to articulate their experience with collaborative approaches to forest management and their relationship to social learning.

CIFOR initiated the workshop as part of a larger project on Creating Space for Local Forest Management, coordinated by David Edmunds and Eva Wollenberg. This project aimed to assess the impacts of forest devolution policies, while also indicating directions for future support of local forest management. One of our observations in this work was that local forest management required collaboration among different groups to exchange views and information as well as to adapt to changing conditions. We were therefore interested in documenting innovative approaches that encouraged learning among multiple stakeholders.

To this end, Eva Wollenberg and David Edmunds organized a global competition to identify people with experience in social learning, who could come together for four weeks to exchange their experience, advance thinking about social learning and document their insights. We compiled a set of readings on social learning and 
stakeholder collaboration as background material that was later distributed to the selected participants.

We selected nine participants through the competition. Applicants represented government as well as non-government organisations (NGO's), universities and research institutions. Although we aimed to draw participants from geographically diverse backgrounds, the case study writers were mainly from Africa and Asia. All were active in natural resources management and conservation-related programmes. Participants were selected who appeared able to offer insights on the role of learning in collaborative approaches, not because their experience in community forestry necessarily offered success stories by conventional measures. The workshop therefore raised issues related to these learning processes based on varying degrees and qualities of social learning.

The workshop was held at the East-West Center, where Jeff Fox and Sonja Brodt brought considerable experience in conducting writing workshops and editing. Workshop sessions included discussion and exchange on varied aspects of social learning, collaboration and adaptive management. Weekly seminars were framed around the readings that were selected to represent current thinking on key themes of the workshop. Sonja also conducted technical writing seminars. Louise Buck was the lead thematic resource person for the workshop. She designed the thematic seminars and facilitated the seminars to assist participants in linking their practice with emergent theory through summary presentations and reflections on the readings, as well as group discussion. Louise, David, Jeff and Sonja worked closely throughout the workshop to design a program that would best meet the needs of the participants.

As the workshop progressed, participants were challenged to share their ideas as they evolved through the seminar format. Each paper was open to periodic input from the group. Differences of opinion concerning the interpretation of certain concepts or events sometimes raged. Often these had to do with culturally -rooted perspectives, or the 'political climate' for forest management. Eventually most differences were 'negotiated' into a common appreciation for the perceptual or contextual basis of the impasse. Facilitation and time were required to achieve such understanding, and participants demonstrated great patience, curiosity and drive to succeed as a group. Eventually we all came to understand that crafting the papers was a form of social 
learning, benefiting each piece individually while also improving the group's grasp of key concepts.

In addition to group activities, participants were paired with an advisor who provided daily assistance in the tasks of conceptualizing and organizing the writing. Sonja Brodt, Louise Buck, David Edmunds, and Jeff Fox worked with each writer one-onone several times a week to produce their papers. Eva provided comments on the papers from Bogor. Louise, Eva and David wrote an introductory article as a synthesis of the main points emerging from the workshop and the papers. The papers were then edited, first by Sonja for English, then by Eva for content, then by the authors themselves to review changes, and finally by Sally Wellesley for copy editing. Eva, with assistance from Dina Hubudin and Gideon Suharyanto, then coordinated reviews by Bruce Campbell and Niels Röling, final revisions and publication.

The result of this creative team effort was a set of ten papers quite different from most workshop proceedings. The papers reflect the shared development of thinking among fourteen colleagues. They push hard at seeking to link frsthand practice to concepts and in doing so carefully ground an emerging framework of social learning with empirical experience. They move beyond rhetoric and seek to share practical insights. We have found this project to be inspiring both for the promise of the methods it suggests, as well as for the learning that each of us has embarked upon along the way.

The Editors 


\title{
Chapter One
}

\section{Social learning in the collaborative management of community forests: Lessons from the field}

\author{
L.E. Buck, E. Wollenberg and D. Edmunds
}

\begin{abstract}
Community forest management worldwide has involved diverse types and varying levels of success in social learning, yet little effort has been made to analyze these experiences and link them to emerging social learning theory. This chapter is a synthesis of the contributions of the workshop participants to indicate what social learning is and how it could be enhanced. The most notable contribution of chapters was in making learning phenomena more visible and giving people the concepts and labels with which to analyze their experiences. Important institutional arrangements underlying social learning were facilitation and the platforms around which stakeholders met and learned. Different types of learning, the avenues for learning and the factors influencing learning are reviewed. Any endeavor to learn jointly must be assessed and implemented with sensitivity and strategic thinking to who can or should be participating and how.
\end{abstract}


SOCIAL LEARNING

\section{INTRODUCTION}

Learning how to manage forests to meet multiple demands-from local people concerned with making a livelihood to more distant communities interested in ecological functions and revenues-is a critical challenge of our time. Forests are increasingly contested properties where different groups aim to make use of the forest in often incompatible ways or struggle to be the first to acquire finite benefits. To balance these multiple interests, there have been growing efforts to develop strategies and mechanisms that promote collaboration among different interest groups in forest management (Anderson et al. 1999; Fox et al. 1997, Western 1994).

Yet collaborative management of forests has fallen short in effectively bringing together the knowledge and capacities of different groups. Coordination among different interest groups has often been less than desirable. Too frequently, interest groups become deeply attached to their partial, time-bound perspectives (Saigal 1997, Kalyawongsa 1997). Collaboration based on one-time agreements or contracts loses its relevance as even the slightest conditions change. The assumptions and perspectives of the most powerful actors often prevail. The static quality and polarity of such collaboration leads to suboptimal decisions and undermines the potential for creative problem solving and innovative outcomes.

It follows that collaborative management may improve when interest groups attempt to engage in an ongoing and evolving process of understanding each other's knowledge, goals, interests, capacities and actions. Collaboration can also be improved by ensuring that no one group's views or knowledge dominate this process. Joint or social learning seeks to achieve this more dynamic mutual understanding. Joint learning acknowledges that interest groups bring different knowledge (including values, capacities, perspectives, methods of learning, stores of historical experience) to the collaborative process. This knowledge and experience can be an asset to problem solving if shared, and a detriment if ignored. Joint or social learning also fosters perceptions of interdependence and mutual appreciation. As such, it facilitates working together toward agreed-upon goals, generating confidence in further efforts at collaboration. The emphasis on learning also helps stakeholders address the dynamism of social and environmental systems. 
A key question to unlocking the potential for improved multistakeholder management of forests is therefore, how to foster joint learning that improves collaboration in forest management? In turn, how can collaborative institutions and agreements be designed to improve joint learning in forest management? This volume addresses these questions by exploring interdependencies between learning and collaboration in pluralistic forest management settings.

Our purpose with this volume is to expand ideas and applications for shared learning by building on lessons learned from initiatives in collaboration and linking current practice within a common framework. One of the motivations for developing the material for this publication was that we felt there is much relevant experience in multistakeholder community forestry that is not yet recognized under the label of social learning. We expected that important lessons could be drawn by articulating and sharing field-based practice. Our contribution with this work is to offer some concepts and labels around which others can organise reflection, evaluation and documentation of present and emergent practice. We expect that the innovations and syntheses presented here represent the tip of an iceberg of rich experience in social learning.

\section{Social learning: The concept}

What then is joint or social learning? We use the terms interchangeably, recognizing that social learning has been used more frequently in the literature, yet noting that joint learning may have a more intuitive meaning in community forest contexts. Maarleveld and Dangbégnon (1999) provide the best current overview of what social learning is and its related literature. They characterize social learning in natural resource management as a continuous dialogue and deliberation among scientists, planners, managers and users to explore problems and their solutions (p. 269). Communication together with experimentation enables adaptation among the relevant actors to adjust and improve management.

We further define the concept of social learning by examining the multiple dimensions of what is meant by 'social'. Lee (1993: 8), for example, describes social learning as the combination of (1) adaptive management, involving conscious learning from policy experiments, and (2) politics, defined as bounded conflict among forest stakeholders. Daniels and Walker (1999: 42-48) similarly use 'collaborative learning' to refer to a 
framework for public policy conflict management and decision making. By emphasizing the political processes related to conflict among interest groups, these interpretations reflect the importance that conflict and power relations play in natural resource management discussions. The focus on politics is useful for addressing questions about, for instance, the strong inequities that exist among stakeholders in most community forest settings. Other aspects of the interactions among people when they learn together can also be important, however.

Daniels and Walker (1999: 38), for example, describe 'mutual learning' as a process for exchanging perspectives between clients and professional planners or managers to transform everyone's understanding of problem situations. Social learning acknowledges that interest groups bring different knowledge to the learning process, including knowledge in the form of values, capacities, perspectives, methods, and stores of historical experience. Such knowledge and experience, effectively shared, are critical assets in solving forest management and related problems (Maarleveld and Dangbégnon 1999). Another important dimension of social learning is therefore knowledge sharing, which emphasizes the diversity and complementary nature of different social groups' knowledge.

Central to both the political and knowledge sharing aspects of social learning is the idea that constructive interaction among interest groups can be encouraged by lifting barriers to communication to make it more open and responsive (Steins and Edwards 1999:246). Social learning facilitates joint problem solving by fostering perceptions of interdependence, trust and mutual appreciation. It demonstrates to actors that they can benefit from working together toward agreed-upon goals, and generates confidence in further efforts at collaboration. There is thus a communication and relationshipbuilding aspect of social learning that results in sharing of knowledge and enhanced capacity for action.

Social learning also can refer to the collective process of accumulating new knowledge by a particular social group. For example, 'community learning' frames an approach to education and community development that emphasizes participatory, experiential capacity building activities (Steele et al. 1999: 153-180). This collective aspect of social learning stresses how knowledge is developed and shared among a given group to help construct new motives for action and patterns of interaction. 
We suggest that each of these dimensions of social learning is important in collaborative forest management: conflict mitigation and political decision making, innovation and problem solving, communication and relationship building, and capacity building and community or organisational development. We are just beginning to better understand that these four aspects of social learning are not easily divisible and involve interactions among each other as well. By encompassing these four dimensions, social learning begins to get at a broader set of processes about more transparent, engaged and democratic collaboration among stakeholders. In seeking to improve social learning, we are then concerned with enhancing the four aspects of social learning as a set, rather than one by one.

The four dimensions of social learning can be jointly improved by developing strategies, mechanisms and conditions that enable actors to creatively collect, analyze and act on new information together (Woodhill and Röling 1998). These strategies, mechanisms and conditions are most effective when they are sensitive to the power differences among stakeholders, build on complementarities in their knowledge, and are designed to enhance interactions. Röling and Jiggens (1998) thus articulate the need for new platforms and communication processes for facilitating social learning in complex networks of interdependent actors.

Social learning can also advance by understanding more about the learning process itself. Maarleveld and Dangbégnon (1999) identify learning loops, in which learning takes place not only about social and environmental facts (single loop learning), but also about the theories and methods for observing the world (double loop learning) and, even more fundamentally, the importance of learning in the first place. These complementary perspectives paint a theoretical 'way out' of the dilemmas that so often wind up in polarity and impasse: development versus conservation; industrial versus artisinal use; foreign versus local authority. They challenge us to focus on evolving knowledge systems (Röling 1994) that constitute the 'fit' between human perception and reality, and to offer leadership in reconstructing these around current ecological, social and institutional imperatives.

The concepts related to social learning are still young and in need of testing and development. It was with this goal in mind that we were curious to see what social learning looked like in the field. The chapters in this volume are the result of that search. We aimed to document practical experiences that would stimulate a deeper 
understanding of social learning in practice and in doing so, further the development of social learning theory.

\section{'SHARING INNOVATIONS': A WRITERS’ WORKSHOP}

\section{Insights into social learning}

The most notable and catalytic contribution of the workshop and resulting papers undoubtedly was in 'making things visible'. Phenomena that tended to be hidden, or taken for granted, were brought to consciousness and made explicit. Learning, to most participants, had been a second order, background activity that occurred subliminally without substantial thought as to whether or how it occurs in projects. As it was made more explicit, the power of learning and the effects of different modes of learning on environmental management and social change started becoming evident. The group began to appreciate that the way learning is organised and how people organise to learn can affect behavioral, institutional and policy outcomes.

The group found, however, that most of us lacked adequate conceptual language to describe social learning. Language characterizing collaboration and partnership formation was certainly familiar. During the past decade terms such as negotiation, cooperation, accommodation, mutual adjustment, agreement, consensus building, and collective decision making have entered the lexicon of environmental managers. What was missing was conceptual language describing the role of learning in collaboration. It was this sort of language that was introduced at the workshop, and compared against our experiences. Concepts such as learning groups, learning platforms, discovery groups, discovery learning, group experimentation, double loop learning, appreciative inquiry, facilitation of platform processes, ecological knowledge systems, collective learning in actor networks and others helped us appreciate how learning is organised to support collaboration, and how people organise collaboratively to learn.

Through our discussions we discovered that in practice there was insufficient shared learning among community forest management institutions. While single institutions exhibited considerable learning, usually through project reporting of various types, it tended to occur independently of other stakeholders. At the same time, few collaborative arrangements, be they formal agreements or informal consultative 
processes, established explicit mechanisms for group learning. Numerous opportunities for joint learning may have been present, but generally were overlooked or foregone.

Workshop participants discussed several explanations for this limited level of social learning. Insufficient trust and transparency among partners was thought to be a common barrier to social learning. Participants also appreciated that joint learning and collaboration posed threats to existing power structures. Until there are compelling incentives for dominant organisations to change they are likely to resist the calls for shared learning. Finally, potential facilitators of multiple stakeholder learning processes were simply invisible or inaccessible to the actors who might have benefited from shared learning. The catalyst for the process was missing.

Where joint learning did occur, it was often confined to the biological and infrastructural dimensions of projects. Rarely did it extend into institutional relations or the human dimensions of management. There was frequently joint monitoring of tree cover, for example, but much less ongoing monitoring and evaluation of decisionmaking processes and relations among stakeholders. Limiting the scope of shared learning to biological and infrastructural issues made collaboration vulnerable to misunderstandings and conflicts in stakeholder relations continued to evolve.

The limited demonstration of shared learning among the projects and activities we discussed did not discourage the workshop participants, but stimulated thinking on how to take concrete steps to improve practices. We provide a flavor of the participants' insights below.

\section{INSTITUTIONAL ARRANGEMENTS FOR BRINGING COLLABORATORS TOGETHER}

Our analysis centered on two themes. First, we examined what kinds of institutional arrangements brought collaborators together and underlay social learning. We grouped these broadly into the roles of facilitation and the 'platforms' or opportunities for collaborators to come together to learn. Analysis of these arrangements provided insights about the appropriateness of different kinds of social learning for different kinds of actors and the possibilities for some groups to dominate the process. 
SOCIAL LEARNING

\section{(1) Facilitation}

Facilitation was vital in promoting social learning, particularly in cases of intense competition or conflict among stakeholders, or when stakeholders had very different knowledge systems. Röling and Jiggens (1998) also found from their experience that facilitation was 'the crucial factor in adaptive management'. Facilitators are often the catalysts for joint learning. They bring stakeholders together in various configurations to plan, coordinate, demarcate, monitor, reflect, and learn and to act together in other ways.

The papers by Nontokozo Nemarundwe, Cao Guangxia and Zhang Lianmin, Edward Massawe, Christian Asanga, Ron Ayling and Bishnu Upreti discuss facilitation at length, while each author in the volume identifies its centrality to social learning. A key issue concerns the feasibility and effectiveness of facilitation by internal, local actors versus external, 'project-supported' actors. The papers by Massawe and Asanga indicate that external facilitators can be effective in dealing with macro-level constraints on collaboration, such as formal government policy or project finance. Nemarundwe's work suggests, however, that external facilitators run the risk of excluding or misinterpreting the interests of important local actors and may not be sustainable. Cao and Zhang's paper demonstrates the importance of the initiative of local leadership. The conclusion we drew from these experiences was that internal and external facilitation each serve their different purposes, but local processes should become more prominent over time through training, institutional development and imaginative financing. Upreti argues that all stakeholders in social forestry need to learn effective facilitation.

The papers (see especially Asanga) also indicate that facilitators, external or internal, need to be sensitive to and strategic about existing relationships among actors. These sensitivities refer particularly to the political aspects of social learning. This means taking account of stakeholders' historical relations with each other, their different interests in the collaborative process, styles of learning and existing knowledge. Facilitators can use this information to make a plan for what groups to get together when, and what issues to focus on within each meeting. They are likely to structure shared learning through a number of steps and build collaboration over time, with plans revised in response to the outcomes of early steps. 
Khan's paper shows that effective learning experiences stemmed from facilitating the involvement of private sector organisations with public sector agencies, generating notable 'ah-ha' moments when conventionally powerful stakeholders appreciated that alternative approaches could work better. Learning about stakeholders (stakeholder analysis) helped parties adjust to new roles and responsibilities. Khan advises that community involvement in multistakeholder processes requires constant internal negotiation and compromise, and the same holds for forest departments since neither are homogenous organisations. Bishnu Upreti describes how community forestry in Nepal became more sensitive to gender and equity issues among stakeholders over time and has tried to deal with them more directly in current projects.

Asanga's case indicates how facilitation requires often step-wise treatment of different stakeholders. He elaborates how collective leadership in a community forest management project in Cameroon coordinated actors over the course of ten years . Actors were brought together in various configurations at different times to discuss forest management. The process was sensitive to the logistical and political impracticality of encouraging all stakeholders to act together simultaneously. The collective leadership's commitment to responsiveness and participatory action research assured that the strategy for bringing different actors together evolved over time.

\section{(2) Platforms}

A metaphorical space, if not a real one, needs to be constructed so that stakeholders can interact and learn together. Röling and Jiggins (1998:301) call such spaces platforms for resource use negotiation. Platforms can be one-time meetings, elected committees, formally appointed boards or councils or even government bodies. An important issue is how key stakeholders are represented in the platforms and how representatives are held accountable to their constituencies. Another is how to generate an open and free discussion among numerous actors without bringing the platform to a total impasse of immobile positions (Röling and Jiggins 1998: 301). Finally, how platforms interact with conventional decision-making bodies needs to be examined to assure that the platform has legitimacy and efficacy.

Papers in the volume highlight the variety of platforms that have emerged to involve multiple stakeholders in the management of community forests. A number of community forestry projects represented at the workshop constituted such platforms. 
Ghanendra Kafle provides examples from experience in Nepal that include: loosely configured self-evolved networks of forest user groups; user group-based committees for participatory planning, implementation, monitoring and evaluation; and workshops encompassing representatives of local NGOs, federations of forest users, a district office of a women's organisation, and district forest officers. Kafle discusses how platforms evolved around problems faced by institutions concerned with a management problem, or were created by projects. Self-evolved platforms were more likely to be sustainable.

The paper by Ayling discusses some of the potential benefits of creating platforms on larger scales, as well as some of the challenges to doing so. Forest managers increasingly argue that forests must be managed as landscapes, and not as small fragments under the unique control of a single company or community. Fragments are not isolated from one another and a collaborative agreement in one can be undermined by activities in another. Scaling up shared learning to a point where decisions are made about the forest as a landscape should bring substantial benefits to the forests and its stakeholders. As Ayling points out, however, scaling up intensifies the problems associated with representation and accountability, bridging the divide among knowledge systems, and addressing inequalities in political power. Based on cases from the International Model Forest Network, he suggests strategies for overcoming some of these problems, including innovative leadership, risk-taking and more informal, face-to-face interaction among stakeholders.

\section{LEARNING PATTERNS}

The second theme of our analysis was to characterize the type of learning that occurred, the avenues for learning and the factors influencing learning. We examined what triggered social learning and motivated people to engage in the extra effort and cost of learning together. We reviewed the diversity of different avenues and styles of learning and the potential benefits of using multiple avenues. We also looked at how learning occurred about joint learning, or what is referred to as double loop learning (Hamilton 1998: 186). The overarching theme here is the need for learning styles and approaches to themselves be responsive to stakeholders' preferences, culture, and changes in management needs. Multiple approaches are likely if the goal is to reach all the necessary parties and to be relevant to changing conditions over time. 


\section{(1) Conditions that stimulate learning}

Joint learning generally occurs in fits and starts, and does not proceed at a consistent, predictable pace. Typically a bounded, but persistent conflict among stakeholders triggers collective learning, which then focuses on negotiating ways out of a dilemma (Lee 1993.) The authors bring forward various examples of impasses that were reached before stakeholders turned to negotiated approaches. One-time events however, often lead to ongoing processes as key actors in the management system recognize the value of negotiation, informed by collaborative learning. Initial attempts at collaborative learning frequently require outside facilitation to overcome issues of mistrust and misunderstanding among groups. The sustainability of the collaboration, however, may depend on the stakeholders themselves taking on more of the facilitation role.

Khan illustrates a case in Pakistan on learning how to devolve management authority from government authorities to local civil groups. A sequence of learning experiences based on continuous conversation between the stakeholders, which he characterizes as messy and contested, enabled the project to make progress in developing collaborative management practices between the forest department, communities and NGOs.

Upreti offers another example from his experience with the Community Forestry Programme in Nepal. He characterizes a study that was undertaken to help understand and overcome the social equity limitations of the programme. The study revealed how an effort by a powerful politician to attempt control of a long standing common pool resource for his personal benefit stimulated the resource users to analyze the problem and form a Protection Committee to negotiate the conflict by exerting social pressure through parents, schools and elders rather than pursuing a legal solution. A long-term, self-facilitated process ensued that has resulted in the forest becoming a locally recognized symbol of socially just forest management.

\section{(2) Avenues for shared learning}

Rukmini Datta's case study from India highlights the value of distinguishing various avenues for learning and allowing each its legitimate space to grow. These included learning from: feedback from the field, process documentation, research studies, training programmes, organisational self-reflection (internal feedback) and interactions 
with the state. One of Datta's conclusions was that multiple avenues of learning were helpful for organisations. She suggests that efficiency of information exchange may sometimes be at the cost of not getting information out to everyone who needs to have it. The strategy of using multiple channels for learning is consistent with Lee (1993:102) who maintains that deliberately fostering diversity by catalyzing learning in many different places, each supported in a different way, enhances chances that important lessons can be learned somewhere.

All the papers also refer in some way to the importance of learning by doing as the key avenue of change. This thinking is consistent with Borrini-Feyerabend and colleagues (2000) who illustrated how the type of learning we refer to in collaborative management is commonly based on experience. The cases describe how the simple act of sharing key activities such as developing indicators for self-monitoring, conducting participatory mapping or evaluating potential roles in collaboration can result in joint learning. What was learned is often not explicit, however-and therefore not shared as clearly - unless more structured approaches are taken to evaluating experience.

Participatory research can stimulate social learning by bringing different groups together through a conscious and deliberate cycle of inquiring, observing, reflecting, planning and acting. Nemarundwe's experience in Zimbabwe with participatory research and experimentation by landowners highlights key elements and potential outcomes of this approach. Landowners realized that they needed to understand and share views about the dynamics of their environment, and that the dynamics might best be understood through repeated experimentation.. The group used resource management experiments that formed the basis for joint monitoring and evaluation. Other joint learning tools included community workshops, field days, the use of metaphors and folklore, and group 'look and learn' visits. The latter evolved into learning platforms rooted in village-to-village interactions, which fostered local collaboration by generating trust and understanding of problems faced by different interest groups. The participatory approach helped to generate means of communication and learning that were appropriate for the collaborators.

The way these experiences are structured can foster more effective learning. For example, Khan's paper reminds us of the importance of introducing small-scale pilot applications of programme activities. Once proven successful it is applied on a larger 
scale. Thus a continuous process of learning from success and failure at low-cost levels of intervention plays an important role in the devolution of forest management.

One key to making these avenues effective over the longer run is to institutionalize them within a project or organisation. Asanga discusses the use of action research as the foundational modus operandi of the Kilum-Ijim Community Forestry Project in Cameroon. He characterizes action research as an overarching methodology for project implementation. It served to make things visible and created shared understandings about resources among stakeholders.

\section{(3) Learning Styles: consensus and conflict}

Learning styles can differ among countries and stakeholders. In particular, the way that different groups treat the roles of consensus and conflict, individual rights and group harmony, open discussion or quiet diplomacy can be very different from place to place, and influence how social learning takes place. Tools, platforms, and other mechanisms of facilitating social learning must be developed to support these different learning styles if collaboration is to be effective.

Cao and Zhang illustrate the point with their case from Yunnan, China. They point out that encouraging open expression of individual perspectives, and the conflict that might ensue, is not as likely to lead to effective collaboration in China as some authors suggest (Lee 1993). They argue that in Yunnan, group harmony and consensus set the stage for effective collaboration, and that informal, behind-the-scenes consensus building was necessary. In such situations, the importance of local leaders, who carried the authority and knowledge to help build the consensus, were more important than outside facilitators.

Cao and Zhang believe that even communities that encompass diverse interests in forest resources can be effective in uniting under common cultural values, reaching consensus on plans of action.

Ayling shows that sensitivity to different styles was important in acknowledging value differences among partners from different cultures in Canada. He believes these differences affected the willingness and capacity of actors to collaborate, and most 
importantly the feasibility of reaching consensus, the idealized form of decision making to which the Model Forest Program aspired. Communication and education approaches that helped to foster the participation of reluctant collaborators included the use of direct, verbal communication rather than printed or electronic media, workshops, presentations, strategic planning initiatives, public consultations and other activities that promote social interaction. Studies of resource values among different actors were conducted as well, to help explain limited progress in partnership formation. It was necessary in some model forest projects to change decision-making rules such that consensus was not the goal.

Upreti demonstrates that conflict was not always disruptive, but could lead to innovation and had important transformational potential. His case illustrates how conflict and negotiation were integral parts of an inclusive community management process. The key to success in his estimation was facilitation and platform processes that encouraged the involvement of marginal groups.

\section{(4) Double loop learning: learning how to foster learning among collaborators}

In forest management, no single avenue or tool for joint learning will remain valid for long. The methods used to support shared learning must themselves be updated regularly in light of new experiences and stakeholders. People collaborating in forest management must periodically turn their attention to how they learn, as well as what they learn. This is a process known as double loop learning.

Double loop learning incorporates feedback from experience into the planning process to challenge underlying assumptions. It requires examination of the purpose of the programme in light of its achievements and constraints, such that the value of theoretical assumptions is clarified (Lee 1993; Maarleveld and Dangbégnon 1999). By passing through a continual process of learning and cognition, actors can adapt management to changing environmental and social circumstances. Datta uses the concept of double loop learning to describe a 'learning organisation'; an organisation that is self-reflective with respect to how it gathers information about the world around it. Nemarundwe's case from Zimbabwe also suggests that creating platforms for double loop learning can help institutions adapt by facilitating periodic and systematic evaluation of their fundamental principles and habits of doing work. 


\section{WHERE THEORY AND PRACTICE MEET-THE MEANING OF SOCIAL LEARNING IN COLLABORATIVE FORESTRY AT PRESENT}

We concur with Parson and Clark (1995) that the term 'social learning' conceals great diversity and that the uses of the concept by different researchers have not revealed a common theoretical perspective (p. 429). In producing this synthesis, we have tried to bring more coherency to the concept as an approach and a philosophy that focuses on participatory processes of social change (Woodhill and Röling 1998: 53). Though social learning theory is at a youthful stage of development, it offers us a compelling framework for sharing experience and ideas for how to improve collaboration in natural resources management to foster institutional adaptiveness and ecological sustainability. While a social learning approach will not be appropriate everywhere and under all circumstances, the material in this volume suggests that social learning has high potential to foster better collaboration among local institutions (horizontal integration) and vertical links among forest departments, NGOs and local community groups without losing sight of equity issues related to gender, culture or poverty.

Social learning is distinctive in that it requires giving attention simultaneously to how to bring interest groups together, as well as to which learning patterns to employ. The intersection of collaboration and learning is what makes social learning different from simple learning by one actor or collaboration that does not involve conscious learning. The most important implication of this overlap is that any endeavor to learn jointly must be assessed and implemented with sensitivity and strategic thinking about who can or should be participating and how. This involves attention to the four dimensions of social learning referred to earlier. Sensitivity and strategic thinking are required in considering political relations and conflict among actors, in considering how to bring together complementary knowledge, in developing trust-building interactions and in deciding how to create collective understanding.

Social learning therefore suggests the need for facilitators with strong sensibilities about relationships among interest groups and a repertoire of multiple platforms and avenues of learning to meet the diverse learning styles and preferences of different interest groups. Multiple platforms and avenues are needed to be able to work with different types of stakeholders or groups of stakeholders. Multiple avenues are also 
needed to deal with different types of issues that will arise over time among different groups of stakeholders. Determining which types of learning to use with which people where and when constitutes the art of effective facilitation of social learning. Learning from the case study experiences we can make the following initial observations to help guide that process:

A long-term strategy for information sharing is necessary that is suitable for all key collaborators.

There should be a means of recording lessons learned and the reasons why subsequent actions were taken to ensure institutional memory. This record should also be broadly available to all stakeholders in an appropriately accessible form and place.

Learning avenues and platforms need to be matched to the needs of the people implementing the activity who stand to benefit from the lessons learned. These avenues will often involve multiple steps and different constellations of stakeholders interacting at different times.

Strategic attention needs to be given to arranging learning avenues and platforms in a way that enables the knowledge and capacities of less powerful stakeholders to genuinely be heard by more powerful stakeholders and to develop the synergies that enable problem solving.

The costs of learning should be allocated in such a way that recognizes the relative capacities and incentives of different stakeholders to bear that cost. In this way the learning is more likely to be sustainable.

Reflection about the role of the facilitator and their own objectives in bringing people together for learning can help indicate biases about the learning approaches and indicate how some collaborators are not involved effectively.

Social learning of course is not possible or desirable in all settings. There can be significant costs and limitations. The limiting factors in social learning, based on participants' experiences, were meeting time commitments, developing facilitation capacities, working with cultural diversity, overcoming power relations and covering material costs. Social learning is a lengthy, multistage process that can be expensive. 
Learning at larger scales (such as over landscapes), commonly needed in forest management, poses particular problems, especially related to transaction costs, dealing with group diversity, employing appropriate communication strategies, building and maintaining trust and so on.

In addition to practical concerns of cost, time and ingenuity, there are limits to the roles that learning and collaboration can play in advancing sustainable forest management. To accomplish certain objectives, patterns of negotiated conflict and compromise inevitably must be allowed to give way to legally mandated authority and rules. In certain settings it may be strategic to embrace differences, and even limited conflict, among stakeholders rather than attempting to 'neutralize' them through collaboration. Knowing when and how to apply respective strategies requires political savvy on the part of stakeholders, a sound intervention theory, and extraordinary communication expertise. The combination of external political pressures and internal performance demands should warn us against placing unrealistic levels of hope and confidence in social learning approaches to resolving management dilemmas.

\section{ORGANISATION OF THE CHAPTERS}

To convey the experiences of the case studies, yet also draw out the themes discussed above, we have arranged the chapters in the following way. The first three chapters, by Asanga, Kafle and Datta, provide an introduction to common approaches for improving social learning. These authors examine, respectively, three foundational elements of social learning: the building of strategic partnerships, the use of multistakeholder platforms, and organisational (double loop) learning. Through the retelling of their own experiences in community forest management in Cameroon, Nepal and India, each author provides an account of the range of techniques used and their strengths and weaknesses or the appropriateness of the technique under varying conditions.

The next six chapters highlight specific issues related to the practice of social learning. Nemarundwe raises the issue of how institutional design principles for the management of common property can themselves be flexible and adapted to conditions of change in Zimbabwe. Cao and Zhang question conventional thought in pluralism theory about the impossibility and undesirability of consensus. They show that in 
practice, consensus is highly valued in China and essential to understanding multistakeholder processes. In Tanzania, Massawe indicates the costs and skills necessary to facilitate social learning and raises the practical issue of how social learning will be sustained after the donors leave. Ayling looks at large forests in Canada to highlight the difficulties of fostering social learning at larger scales. Khan describes the difficulties encountered by the Pakistan government in reaching out to other organisations and creating genuine collaborative relationships. Upreti reflects on attempts in Nepal to adjust community forestry programmes to be more equitable.

Together, the chapters show the many dimensions of the social relations involved in community forest management and the difficulties of fostering learning across relationships. They paint a picture that is often messy, complex and not always successful. They show where theory is difficult to implement. It is precisely these experiences that we hope will advance the development of the concepts of social learning and ultimately its practice.

Social learning in multistakeholder community forestry offers an approach for spawning a new generation of initiatives rooted in collaborative relationships. The cases we present are all works in progress. None is conclusive about the effects of social learning processes on community forest management objectives. Part of the power of social learning seems to be in generating optimism that situations can improve by modifying perspectives, trying new approaches, seeing what works and trying again. As we can attest from our collective experience through these chapters, a social learning perspective can release social actors from long-standing habits to enable the emergence of astonishing innovation.

\section{LITERATURE CITED}

Anderson, J., Clemant, J. and Crowder, L. V. 1999 Pluralism in sustainable forestry and rural development: an overview of concepts, approaches and future steps. In: FAO. Pluralism and Sustainable Forestry and Rural Development. Proceedings of an International Workshop, 17-28. Food and Agriculture Organization, Rome.

Borrini-Feyerabend, G., Farvar, M. T., Nguinguiri, J. C. and Ndangang, V. A. 2000 Co-management of natural resources: organizing, negotiating and learning-bydoing. GTZ and IUCN, Heidelberg, Germany 
Daniels, S. and Walker, G. 1999 Rethinking public participation in natural resources management: concepts from pluralism and five emerging approaches. In: FAO. Pluralism and Sustainable Forestry and Rural Development. Proceedings of an International Workshop, 9-12 December 1997, 29-48. Food and Agriculture Organization, Rome.

Fox, J., Fisher, L. and Cook, C. (eds.) 1997 Conflict and Collaboration: Eighth Workshop on Community Management of Forest Lands. Program on Environment, East-West Center, Honolulu, Hawaii.

Hamilton, G., 1998 Co-learning tools: powerful instruments of change in Southern Queensland, Australia. In: Röling, N. G. and Wagemakers, M. A. E. (eds.) Facilitating Sustainable Agriculture, 172-190. Cambridge University Press, Cambridge.

Lee, K. N. 1993 Compass and gyroscope: Integrating science and politics for the environment. Island Press, Washington D.C., USA.

Maarleveld, M. and Dangbégnon, C. 1999 Managing natural resources: A social learning perspective. Agriculture and Human Values 16: 267-280.

Parson, E. A. and Clark, W. C. 1995 Sustainable development as social learning: theoretical perspectives and practical challenges for the design of a research program. In: Gunderson, L. H., Holling, C. S. and Light, S. S. (eds.) Barriers and Bridges to the Renewal of Ecosystems and Institutions, 428-459. Columbia University Press, New York, NY.

Röling, N. G. 1994 Communication support for sustainable natural resources management. In: Davis, S. (ed.) Knowledge is Power? The Use and Abuse of Information in Development. IDS Bulletin Vol. 25 (2): 125-133.

Röling, N. G. and Jiggins, J. 1998 The ecological knowledge system. In: Röling, N. G. and Wagemakers, M. A. E. (eds.) Facilitating Sustainable Agriculture, 281307. Cambridge University Press, Cambridge.

Saigal, S. 1997 Beyond experimentation: emerging issues and conflicts over joint forest management in India. In: Fox, J., Fisher, L. and Cook. C. (eds.) Conflict and Collaboration: Eighth Workshop on Community Management of Forest Lands, 1-26. Program on Environment, East-West Center, Honolulu, Hawaii.

Steele, R., Nielson, E. and Mboji, E. 1999 Community learning and education in a pluralistic environment: implications for sustainable forestry, agriculture and rural development. In: FAO. Pluralism and Sustainable Forestry and Rural Development. Proceedings of an International Workshop, 153-180. Food and Agriculture Organization, Rome. 
Steins, N. A. and Edwards, V M. 1999 Platforms for collective action in multiple use common-pool resources. Agriculture and Human Values 16: 241-255.

Western, D. 1994 Natural Connections. Perspectives in Community-Based Conservation. Island Press, Washington D.C., USA.

Woodhill, J. and Röling, N. G. 1998 The second wing of the eagle: the human dimension in learning our way to more sustainable futures. In: Röling, N. G. and Wagemakers, M. A. E. (eds.) Facilitating Sustainable Agriculture, 46-71. Cambridge University Press, Cambridge. 


\title{
Chapter Two
}

\section{Facilitating viable partnerships in community forest management in Cameroon: The case of the Kilum-ljim Mountain Forest Area}

\author{
Christian A. Asanga
}

\begin{abstract}
Conventional forest conservation measures in Cameroon have had little success in protecting forests, largely due to lack of community involvement. BirdLife International, a partnership of conservation organisations, began to consult with local community members in setting forest boundaries in 1987. This chapter describes the ongoing participatory action research being conducted by BirdLife International as a facilitator of a collaborative forest management project involving local communities, traditional authorities, and government. The chapter presents lessons learned thus far about methods and the challenges of involving all stakeholders, building trust and communicating with all parties involved, facilitating joint action, managing and resolving conflicts, and finding convergence between conservation objectives and those of local resource use. It concludes that there is growing acceptance of the need for community participation in forest management and that collaborative approaches based on an adaptive social learning process offer ways of achieving this.
\end{abstract}




\section{INTRODUCTION}

The need for greater involvement of local people in forest management is increasingly recognised in Cameroon. Over the present decade, there has been growing interest within the country in community participation in natural resource management for biodiversity conservation. It has generally been recognised that more conventional protection measures such as creating forest reserves and policing have had little success and that one major factor in this failure may have been the lack of community involvement.

The recognition of the need to involve local people has grown out of an awareness that the conservation of natural resources cannot take place in isolation from economic development, especially where people depend upon it for their livelihood. Fisher (1995: 2) states that 'collaborative approaches to forest management have clear advantages in their potential to provide benefits to local people in exchange for the costs of conservation. They accomplish this by providing continued access to forest products, or income generation. At the same time, they have the potential to contribute to conservation'. The Kilum-Ijim Mountain Forest area in Cameroon is an example of a site where the local people depend heavily on the forest for their wellbeing and represents one of the first places in Cameroon where attempts have been made to achieve conservation and community use objectives through collaborative forest management.

Since its creation in 1987, the project facilitated community participation in forest conservation with a series of consultative meetings and informal dialogues. By early 1994 it had initiated work with communities around the forest to develop community forest management. The project developed a conceptual framework based on community forestry interventions in Nepal, which were seen as highly successful and relevant to the Cameroon setting. Project staff refined the approach used by bilateral donor projects such as the Nepal-Australia Community Forestry Project through the use of their own internal planning and reflection. The key elements of this framework were: (i) an institutional three-way partnership among traditional authorities, local communities and government, with the project acting as a facilitator or catalyst for collaboration and (ii) the presence of enabling policy through the new forestry law that allows for devolution of management authority from central government to local communities. 
In this chapter, I present some of the lessons learned from practical experience with collaborative forest management by the Kilum-Ijim Forest Project. I examine methods, situations and events within the project that enable us to draw conclusions about learning processes in resource management. These conclusions indicate directions for new governance and management procedures that may be useful elsewhere in Cameroon and throughout the world. The paper demonstrates that accommodating international objectives for biodiversity conservation and local objectives for sustainable use of forest resources is possible if appropriate steps are taken. I conclude that there is a growing acceptance of the necessity for community participation in forest management and that collaborative approaches that are rooted in an adaptive social learning process offer ways of genuinely achieving this for the benefit of biodiversity conservation in Cameroon.

Information for this chapter is drawn from my own experience working in the KilumIjim Forest Project, having played a leading role in the team implementing the processes described since March 1993.

\section{BACKGROUND}

The Kilum-Ijim Forest Project is an initiative of BirdLife International and the Government of Cameroon through the Ministry of the Environment and Forestry (MINEF). BirdLife International is a UK-based international partnership of conservation organisations, which focuses on birds as indicators of the health of ecosystems. Cameroon's Ministry of the Environment and Forestry is in charge of formulating policy that governs the management of the country's forest, wildlife and fisheries resources, as well as other aspects of environmental management.

The Kilum Mountain Range and the Ijim Ridge are in the part of the Western Highlands of Cameroon commonly referred to as the Bamenda Highlands. The Kilum range (also known as Mount Oku) is situated in Bui Administrative Division in the North West Province. The Ijim ridge stretches northwest from Mount Oku, starting from the west side of Lake Oku to Kom in Boyo Division. The contiguous Kilum and Ijim Mountain Forests (now known as the Kilum-Ijim Forest) are located between latitude $6^{\circ} 07^{\prime} \mathrm{N}$ and $6^{\circ} 17^{\prime} \mathrm{N}$ and longitude $10^{\circ} 20^{\prime} \mathrm{E}$ and $10^{\circ} 35^{\prime} \mathrm{E}$ (see Figure 2.1). 
FACILITATING VIABLE PARTNERSHIPS

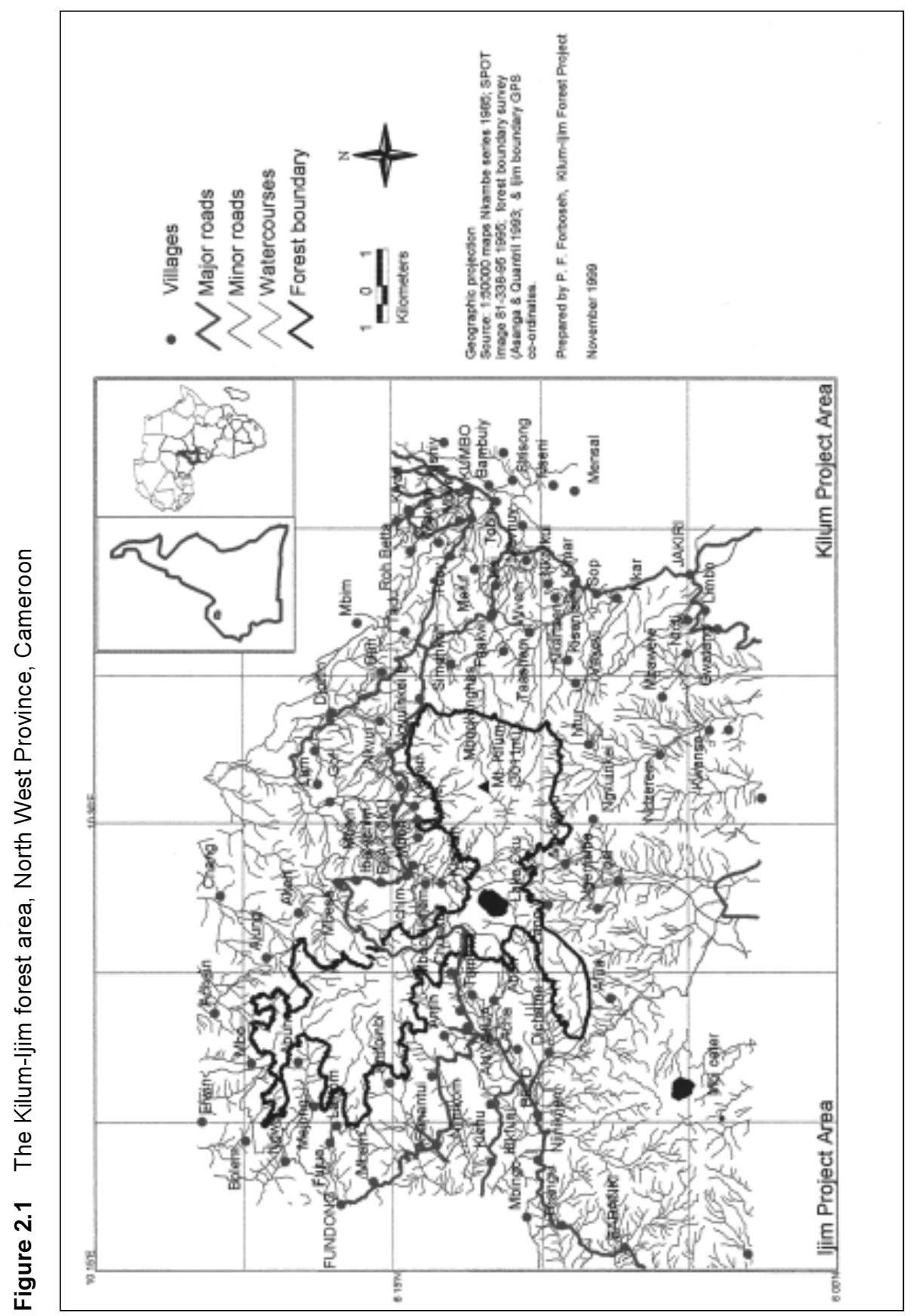


This forest constitutes the last significant remnant of an endangered ecosystem that is of global significance for conservation. The total area of the remaining forest is approximately 20000 ha. The flora and fauna are unique. Rich in Podocarpus and bamboo (Arundinaria alpina), the forests most resemble those in the highlands of East Africa. Fifteen montane bird species endemic to Cameroon are found in the Kilum-Ijim Forest, and for two of them, the Bannerman's Turaca (Tauraco bannermanni ) and Banded Wattle-eye (Platysteria laticincta), this forest almost certainly represents the last possibility for their continued survival (Collar and Stewart, 1985). There are also endemic species or subspecies of amphibians, reptiles and mammals as well as a larger number of endemic and near-endemic plants.

The forest is extremely important to the local population. The Project's rapid assessment data show that over 200000 people depend on it, first as a source of water, firewood, building and craft materials, honey, medicinal plants, carving wood, bush meat and other products and secondly for its role and value in local traditions and culture. Several ethnic groups use the forest: the Oku and Nso people on the Kilum side and the Kom people on the Ijim side.

There are many threats to the conservation of the area. Between 1963 and 1987, over $50 \%$ of these forests were destroyed or severely degraded, mostly by fire and clearance for agriculture. It is estimated that over $80 \%$ of the forest's Prunus africana stock has been lost due to destructive harvesting, mostly by illegal exploiters. This tree species is exploited commercially for its medicinal properties. Its bark contains a complex of compounds used in the treatment of ailments of the prostate gland.

The Government of Cameroon has long recognised the need to conserve this forest. The Ministry of the Environment and Forestry made several attempts - the first in 1963 and the last in the mid 1970s - to limit encroachment by marking a boundary with the intention of gazetting it as a state forest reserve, but the retreat of the forest continued. Therefore, in 1987 BirdLife International started the Kilum Mountain Forest Project, with headquarters in Elak-Oku. Its first priority was to set an effective boundary through agreement with local people and the authorities. The process was not fully participatory, but the forest destruction was so severe that the project members felt that urgent action was needed. There was, however, consultation and a degree of participation through commissions consisting of representatives from traditional and government authorities, as well as community members and project staff. The boundary 
was agreed upon in 1991 and has since been largely respected by the community. Without this action the forest would have almost completely disappeared by now. In 1992, a sister project was started at Ijim with the same aim of agreeing upon a boundary to gazette the whole forest as a state reserve. This boundary has also been agreed upon and is holding. The two projects are now working as one with two sites at Kilum and Ijim.

Although local people have strong reasons for maintaining the forest, the shortage of cropland and other economic and social factors lead to pressure to convert the forest to farms or to overexploit it in other ways. In this context, the only viable strategy for protecting the forest is to work in close partnership with the local communities who consider the forest their own. To be successful, any strategy for forest conservation would have to view local people as the frontline managers and allow them to meet their needs from the forest. In 1994 the new forestry legislation gave local people an opportunity to do exactly this through the establishment of community forests. The project immediately started working with the communities surrounding the forest to establish community forests. The Kilum-Ijim area presented a promising test case, with communities already using indigenous practices to manage the forest (Nurse et al. 1994). It is envisaged that, in the end, the Kilum-Ijim Forest will be a series of community forests managed by the surrounding communities.

In accordance with the new legislation, a community forest is 'a forest which is covered by a management agreement between a village community and the Forestry Administration. Management of such forests is the responsibility of the village community concerned, with the help or technical assistance of the Forestry Administration' (Article 3 [16] of the Decree of Application, 1995). 'Forest products of all kinds resulting from the management of community forests shall belong solely to the village communities concerned' (Section 37 [5] of the Law, 1994).

The policy requires the negotiation of a written forest management plan with the responsible community-based institution. In the North West Province of Cameroon, the Fon (a traditional ruler of an ethnic group or a fondom) and Kwifon (the Fon's Council of Elders) have traditional custody of forests and de facto ownership ${ }^{1}$. In practice, therefore, community forest management in the Kilum-Ijim area was to be enabled through the support of an institutional three-way partnership among the traditional authorities (represented by the Fon, Kwifon and village heads), the local 
communities (represented by user groups at Kilum and management committees at Ijim) and government (through the MINEF).

Traditional authorities would have the role of coordinating the activities of the user groups and of resolving conflicts between user groups or members of the same user group. A coordination and conflict resolution role was also to be played by the government. The government's other key role was to create the enabling policy environment for community forestry through legislation and technical assistance. The project's role was to act as a facilitator or a catalyst.

\section{The project}

The Project used participatory action research (PAR) at all stages of the intervention. Action research is the process of integrating research with action through a conscious and deliberate cyclical process of observing, reflecting, planning and acting (Jackson 1993). 'Action research provides a way of working which links theory and practice into the one whole: ideas-in-action' (Kemmis and McTaggart 1998: 1). At KilumIjim, four phases were identified as important in the process of setting up community forest management: investigation, negotiation, implementation and monitoring/review. The Project sought to support, initiate and facilitate a continuous process of change through learning and action through these phases. What is learned at each stage is continuously fed iteratively into the project cycle. Careful documentation facilitated the learning.

\section{Interim management arrangements}

In practice, the stages described above have overlapped with each other as well as with action begun before community forestry legislation was enacted. For example, bans on fire, farming and grazing within the forest were already agreed upon before 1994. These actions provided some interim control before communities could take formal legal control of the forest as a community forest. The disadvantage of these earlier actions was that decisions were not always participatory, and this may have affected subsequent results. In this interim phase before official recognition of the community forest is received, the communities are taking increasing responsibility for forest management with the support of local MINEF officials. This includes fire prevention and fire fighting (Figure 2.2), vigilance against illegal exploitation of forest 
Figure 2.2 Community members of one of the forest adjacent villages (Simonkoh) are carrying out fire tracing along their forest boundary. They do this by clearing a 4-metre band between the forest boundary and the farms to prevent the entry of fire into the forest

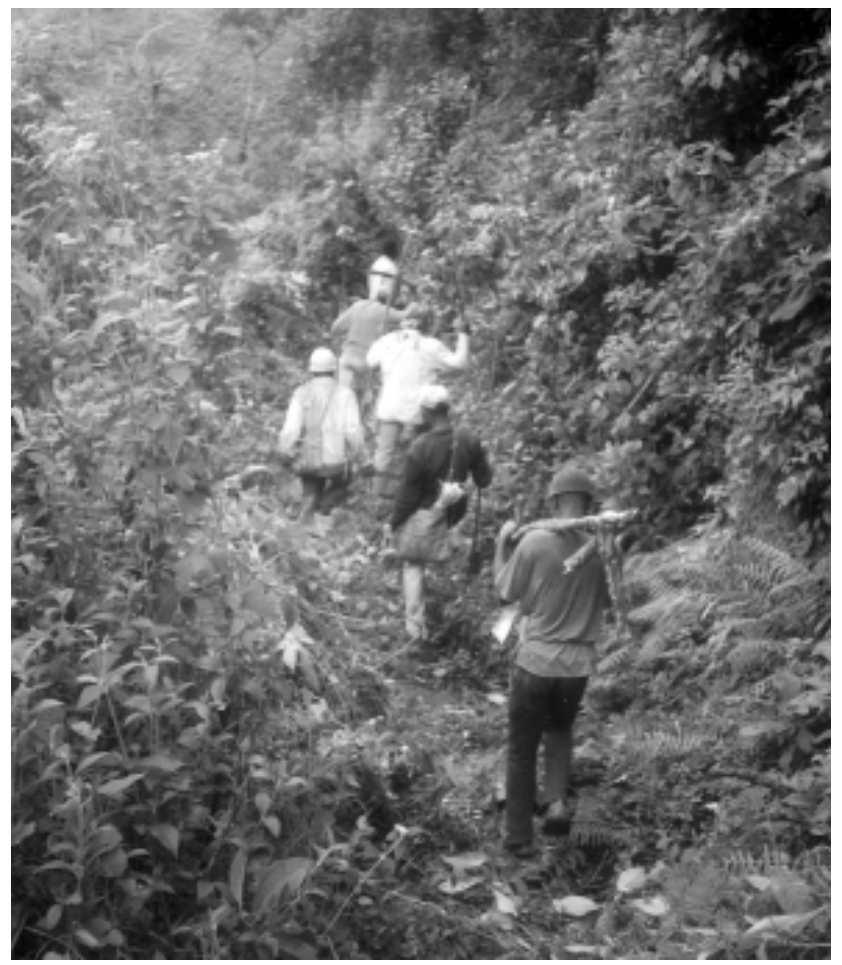

resources such as Prunus africana bark and the planting of forest boundary markers. The traditional authorities are handling most minor cases of forest encroachment. Thus, there is at present an agreed-upon interim management system.

\section{Investigation phase}

Much of the project's experience thus far has been with the investigation phase, making use of a variety of participatory rapid appraisal tools (Figure 2.3). Investigation activities have been ongoing since the beginning of the community forestry process in 1994 and have been completed in all but one community around the project area. In this one 
Figure 2.3 A time line exercise is being carried out with men of Mboh community

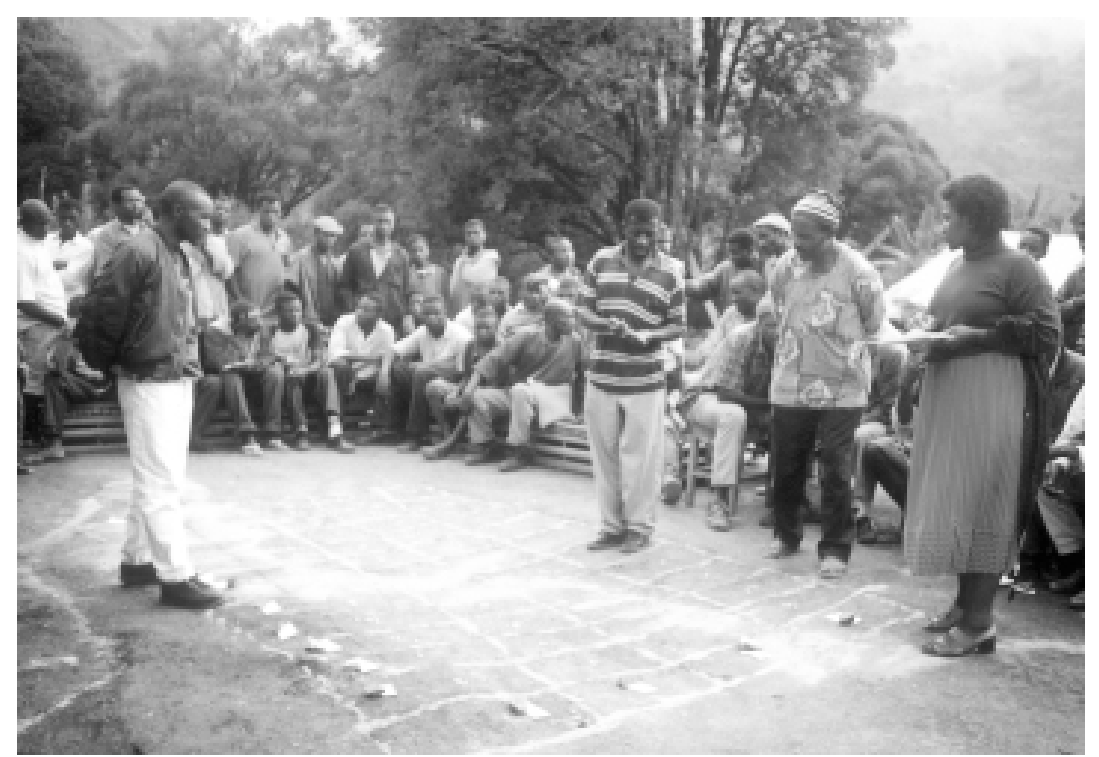

community (Djichami on the Ijim side), there is an internal leadership dispute that is making any kind of community work difficult. A total of 40 forest-adjacent village communities have been involved. Rapport was built with the villagers and information was gathered on the existing use patterns and rules of access and use rights, as well as the needs and problems of interest groups using the forest. At this stage, in Kilum the forest user group was identified as the locally appropriate institution while that for Ijim was the forest management committee ${ }^{2}$. In one community (Djichami on the Ijim side), there is an internal leadership dispute that is making any kind of community work difficult. A total of forty forest-adjacent village communities have been involved.

\section{Negotiation phase}

The negotiation phase has been recently initiated in all but one community. This phase has been carried out in accordance with the negotiation phase trial framework that was developed by the project at the beginning of 1998 in line with the new forestry law (1994) together with its decree of application (1995) and the government's community forest management procedures manual (1998). It has been tested in the 
communities and modified as necessary. The framework involved the creation of a legal entity for forest management and the demarcation of forest boundaries. An inventory and management plan is being negotiated as part of the communities' application process. The plan will take into consideration the indigenous management system and will aim to meet both conservation and use objectives.

In May 1998 the project finalised its conservation objectives document for the KilumIjim Forest. The document serves as a set of guidelines, outlining the desired states of habitats and species in the forest as defined by extent, quality and number (Maisels $e t$ al. 1998). The broad conservation goals are as follows: (i) the extent and quality of the montane habitats, for which the Kilum-Ijim Forest is of outstanding conservation interest, is improved or maintained; (ii) the key species important for ecological processes within each habitat, such as forest regeneration and food webs, are maintained; (iii) the populations of the rare species of the Kilum-Ijim Forest are maintained, and, if appropriate, increased to carrying capacity, where known. The project is facilitating the negotiation of management plans to safeguard conservation objectives while meeting the aspirations of the local communities. Evidence suggests that there is enough overlap between conservation and communities' use objectives that both can be met if the process is carefully carried out (Box 2.1). Negotiation is thus crucial to the process.

Implementation of the negotiation framework has reached different stages in different communities. Over the past year, activities have focused mainly on creating legal entities and marking community forest boundaries. Some progress was also made in discussing rules for forest management.

\section{Formation of forest management institutions}

Following the advice of the community forestry unit of MINEF, the project has been advising communities to form Common Initiative Groups (CIGs). A Common Initiative Group can be formed by one or more user groups or management committees. The most advanced forest user group in the project area is the Bihkov group, which brings together forest users from six villages located on the southeastern side of the Kilum Forest to manage one area of forest. Other communities and their user groups have followed the example of Bihkov and made efforts to form forest management institutions among multiple villages. Joining together to make one community forest 
Box 2.1 Practical evidence of overlap between community use objectives and conservation objectives in Kilum-ljim area

Project Purpose: The biodiversity, extent, and ecological processes of the Kilum-ljim Forest are maintained and the forest is used sustainably by the local communities. Example 1. Beekeeping: There is a large number of beekeepers in the area who have traditionally used the Kilum side of the forest for pitching thousands of beehives. They depend on a healthy and rich forest for the nectar, which is produced from a variety of trees and other plants. This clearly converges with the broad conservation goal of the project. If all montane habitats are maintained or increased in area and the plant list includes all plants characteristic of the habitat, the conditions are ideal for beekeeping. Bees as pollinators also contribute positively to ecological processes of the Kilum-ljim Forest. The beekeepers are often the most vigorous fire fighters as they are not only concerned with the health of the forest but for the safety of their beehives. Example 2. Rat trapping: This trade obviously depends on the existence of a forest cover, with no grazing or farming activities which are clearly incompatible with the breeding of rats. The forest cover might not necessarily be a rich one as in Example 1 because even degraded forest and thick undergrowth can fully support this activity. But the starting point here is that forest cover is preferred to clearing for farming or grazing. Maintenance of montane forest habitat as required by the conservation objectives clearly overlaps with this activity. Example 3. Prunus africana bark: Many members of the communities are bitter about the severe loss of Prunus africana trees from their forest. What happened had been largely out of their control as licensed buyers and harvesters came from outside and destroyed the resource, leaving few benefits for the communities. Community members are now aware of the financial benefits in protecting the Prunus trees and harvesting the bark sustainably. They are even prepared to include enrichment planting in their management plans. This is compatible with the conservation objective concerning the maintenance of species characteristic of montane forest habitats. Example 4. Traditional medicine: Traditional healers around the forest collect small quantities of materials from a wide variety of plants within the forest. The harvesting is not destructive as they depend on the continued survival of these plants for their trade. Maintenance of healthy natural montane forest habitats is consistent with conservation objectives and supports abundance of medicinal plants.

rather than manage small portions individually makes management of the forest easier and reduces the legal and bureaucratic overheads involved in establishing a community forest. Seven institutions have been formed on the Kilum side, representing a total of 22 village communities covering the entire Kilum side of the forest. Forest management 
institutions have also been formed in all but two forest-adjacent communities in the Ijim area. Some of the management institutions have been legally constituted and registered with the government while others are at earlier stages of organisation such as membership campaigns or drafting of articles of association.

\section{Marking of community forest boundaries}

The negotiation and demarcation of boundaries for the individual community forests is a critical part of the negotiation phase. Community forest management boundaries between a number of communities were completed after numerous exchange visits. The Divisional Delegate of MINEF was present during all the boundary marking exercises. In each instance he placed paint marks on points agreed on by the two communities.

\section{Common rules for forest management}

A significant development in the negotiation phase was the adoption of common rules for forest use by representatives of the three fondoms (Oku, Kom and Nso) in the project area. The process started with the development of a project proposal for common forest use rules that project staff judged necessary to ensure that the conservation objectives for the forest would be met. Then project staff proceeded to organise and facilitate separate fondom level meetings that culminated in a meeting bringing together all three fondoms. In each fondom, a meeting was held of representatives of all the forest management institutions, representatives of the traditional authorities and MINEF staff to develop forest use rules for that fondom. The project proposal was not presented at these meetings, but was used by staff only as a reference to ensure that no important aspects were left out of the discussion. Typically, the rules developed in these meetings were similar to or stronger than those developed by project staff. At the fondom meetings, representatives were elected to attend a three-fondom meeting at which agreement would be sought on a set of rules to be applied throughout the forest. This two-day meeting was an unqualified success. For the first time ever, representatives of the three fondoms met together to discuss how to look after the forest. Consensus was reached on a set of rules which is now being sent to the traditional authorities and MINEF for endorsement. These rules will be used as the basis of each community's forest management plan, on which rules and actions particular to a specific locality can be built. 


\section{Development of review phase methodology}

Once communities begin implementing their community forest management plans, they need to review progress periodically. At the Kilum-Ijim Forest Project, two methods of review are envisaged. First, the project's ecological monitoring programme is expected to continue indefinitely through the establishment of a trust fund, as a way to help the outside world keep an eye on the condition of the forest. Secondly, communities should also be able to monitor the condition of their forests, as well as the condition of their forest management institutions. In a workshop held in February 1999 with project and MINEF staff of the project area, indicators were produced for monitoring the state of the forest and the state of the forest management institution. In a later workshop that also included representatives of traditional authorities, the practical application of these indicators was discussed. These indicators will be tested with the implementation of the management plans.

\section{LESSONS LEARNED SO FAR ABOUT MULTIPLE STAKEHOLDER MANAGEMENT AND PROJECT LEARNING}

The implementation of the various phases of the collaborative forest management process at Kilum-Ijim has been a continuous learning process. Key project management actors like senior community forest management staff and project managers meet periodically and synthesise the lessons learned. Project workshops are also held periodically to review progress and reflect on methodology. Lessons learned are continuously being fed into the project planing cycle and field activities are adjusted accordingly.

\section{Involvement of all stakeholders}

In the pluralistic environment in which the project is operating, the collaborative management process is that of multiple stakeholder management. Many authors stress the importance of multiple stakeholder approaches to natural resource management (for example Grimble et al. 1995, Ramirez 1999, DFID 1998). Grimble et al. (1995) outline the steps and tools in stakeholder analysis. The Kilum-Ijim Forest Project did not undertake formal stakeholder analysis as described by these authors, but came to identify the 
stakeholders through experience in the field and has worked with them throughout the process. The application of action research as the modus operandi of the project embraces this multiple stakeholder approach. 'Action research benefits from synergy between the stakeholders: researchers, users and local officials. The research process must involve all stakeholder groups to ensure that all views are heard and compromises, if necessary, are agreed before implementation' (DFID 1998: 9).

As far as the Kilum-Ijim Forest is concerned, stakeholders are found within the local communities, the government, traditional authorities and the international community. In facilitating collaborative forest management, the project has had to support contacts and discussions among the stakeholders. This has not been by bringing all stakeholders together in one forum to take management decisions. In the early days of the project, such a forum of all stakeholders was considered, but due to the complex socio-political context and the large number of people with an interest in the forest, it was judged to be risky. Bringing so many stakeholders together would lead to power struggles and head-to-head confrontations, with little chance of properly resolving the issues. Such polarisation would spoil, rather than help the process. Another risk would be lack of effective representation of all sectors. Rather, the project has been taking iterative action by facilitating discussions and joint action among the various stakeholders in a decentralised way. The project acts as a focal point. Project staff meet various actors separately and actions are initiated. Various communities are also visited separately and from time to time different combinations of the various actors are brought together as appropriate. The following sections further illustrate the practical use of the project's decentralised approach to multiple stakeholder management.

\section{Building trust}

The project has recognised that one of the keys to multiple stakeholder management lies in establishing an atmosphere of trust among the parties. The project has had to facilitate the building of trust among partners. When the community forest management process first started at the Ijim site, for example, the traditional authorities were hesitant to deal with MINEF. The mistrust between traditional and government authorities had less to do with how the forest was to be managed and more with the long history of interaction between the two and the current political environment. These are issues over which a conservation project has little influence. However, as the forestry law requires the involvement of MINEF in the creation of community forests, this mistrust 
clearly had to be overcome. The kwifon first proposed the idea of a ceremony at which the traditional authorities, MINEF and the project would all sign a document stating their intention to work towards a system of community forest management. This ceremony was duly held at the Fon's palace and in this instance the public declaration of intent was sufficient to encourage the traditional authorities to start working with MINEF.

As the underlying problem was much larger than the management of a forest, it is not surprising to find that the impact has gone beyond the creation of community forests in the Ijim Forest. For example, the Fon of Kom has given the Divisional MINEF Delegate the honorary traditional title 'Bo-Akuh' (Keeper of the Forest) and made him a member of the Kwifon and the two now work together on a range of matters, some related to the forest and others not. The process of community forest management is thus one of community development in the broad sense and is not just about conserving a forest.

\section{Facilitating joint action among actors}

The project has been facilitating joint action among the actors in the collaborative forest management process. As an example, I focus on forest fires. During the dry months of the year the Kilum-Ijim Forest is under severe threat from fire. Technical advice gained through meetings with MINEF, traditional authorities and the communities, and sometimes in joint meetings with different combinations of these actors, considerably influenced the agreement by all to take joint action to protect the forest against fire. At Ijim, MINEF and the traditional authorities have cooperated to urge communities to take action. At Kilum, traditional authorities have happily resumed their authority in conducting on-farm and community-level fire campaigns. The frequency of occurrence of fires within the forest has been drastically reduced and when they do occur, they are quickly put out.

Another example concerns the illegal exploitation of Prunus africana bark that has been posing a serious threat to the health of the Kilum-Ijim Forest. On the Kilum side, the communities felt powerless to oppose the corrupt practices of some administrative officials and their confidence in the collaborative management process was almost completely eroded. To foster confidence in the process, the Divisional MINEF Delegate for Bui joined forces with the communities to counter the corrupt 
action of these administrative authorities. He authorised the communities to conduct seizures of Prunus bark and keep it under their custody. He also worked very closely with traditional authorities. The communities consequently gained more confidence in MINEF. The MINEF, traditional authorities and communities now work more closely together. All three parties are necessary to make the collaboration successful.

\section{Clear communication}

In a project workshop held in February 1997, participants identified the need for information on all aspects of community forest management to reach all actors in the communities. Yet in this complex environment, not everyone supports community forest management. There was evidence that some people tried to cause confusion in the communities, either by generating rumours or by misinterpreting messages. After several instances in which statements were changed as they were passed on, staff now more fully appreciate the need to state things very clearly and in several different forums to reduce possibilities for misinterpretation. To be successful in any kind of extension work, one needs to be honest and straightforward and deal with people in a transparent way. When the process is a highly political one, as community forest management tends to be, this need is even more evident and the risks of not being transparent are even greater.

One example illustrates the kind of problem that may arise. When the community forest management process began in Kilum in 1994, project staff decided that the interests of graziers who keep livestock in the forest illegally should be taken into account when negotiating a forest management plan. It was felt, however, that the graziers themselves should not be included among the decision makers. Later it was accepted that the exclusion of an interest group, albeit one acting illegally, was not

appropriate. Furthermore the project staff agreed to investigate the possibility of allowing limited legal access for livestock into the grassland areas within the forest in the forest management plan. Unfortunately, both these reconsiderations seemed to reach the community in a rather confused form and led graziers to take more livestock into the forest. In other words, they thought, or wanted to think, that they were being invited to graze in the forest, whereas they were actually being invited to participate in decision making. One lesson here is that it is essential to anticipate that people can misinterpret messages, and may actually choose to do so, especially if it suits their interests. 
When the process began at Kilum, information was being passed on to communities in the course of investigation work, while at Ijim there was a separate information phase, plus further information before the investigation meetings. During the workshop cited above staff realised that this aspect might have been taken for granted at Kilum, and so special information packages were prepared and delivered to groups representing all sectors of the communities, traditional authorities and government around the project area. Making sure that all sites receive equal information is therefore important.

\section{Conflict management and resolution}

At Kilum-Ijim, conflict was of course expected and resolutions have been sought along the way. With experience it has become clear that conflict identification and resolution are not side activities to be undertaken in order to return to the main process. Rather they are central to the process itself. Our experience so far is that the process moves forward most significantly at points where diverse interests meet and differences are resolved. An unresolved conflict can lead to a stalemate among groups with divergent interests, even if the differences are small when compared with what the groups have in common. Resolving the conflict removes the blockage and opens the way to action driven by convergence of interests. Furthermore, the resolution of conflicts often has implications beyond the immediate effect on community forest management, so that the process of conflict resolution becomes a process of community development.

\section{Conflicts among interest groups}

The relations among woodcarvers, beekeepers and the MINEF provide a good example of conflict among interest groups and its management. Woodcarvers are a significant interest group in all the user groups in Oku. They produce carvings of a variety of objects including masks, statues and furniture, which they sell both within and outside Oku. The most preferred tree species for their trade is Polyscias fulva. This tree has been overharvested to such an extent that middle to large diameter trees are hard to find within the Kilum forest. Some carvers now depend on buying Polyscias trees from outside the forest, but many resorted to cutting down other trees, especially Schefflera abyssinica, which is most preferred by the beekeepers. The nectar from 
this tree gives the special white honey that is popular throughout the country and that the beekeepers of the area are particularly proud of. Therefore, the beekeepers were unhappy, and they complained to MINEF and the project about the carvers' activities. MINEF staff viewed the carvers as posing a great threat to the forest and punished the carvers by seizing their carvings. This resulted in the carvers' suspicion and fear of MINEF and even of the project.

It became difficult to call meetings with the carvers. They were never present in the user group and community meetings. Attempts by the project to call meetings with the carvers failed. The carvers feared that if they showed up for a meeting they would be arrested. The project then embarked on working with MINEF to allay their fears. Invitations were sent to all the carvers throughout Oku and the MINEF Delegate sent word to the villages assuring the carvers that they were only being called to a meeting to discuss their problems and seek solutions. A successful meeting was convened with the carvers and fruitful discussions were held. Repeated meetings were held and methods of responsible resource management were discussed. They agreed to a moratorium on cutting Polyscias from the forest and decided instead to purchase trees from private owners outside the forest. They have now joined the user groups and their interests are discussed along with other issues. Many of them have set up tree nurseries and are requesting assistance from the project. While the problem of indiscriminate felling of trees in the forest for carving has not totally disappeared, it has been drastically reduced. This example provides a clear illustration of the integral aspects of resolving conflict, building trust and involving stakeholders in the collaborative forest management process. It is never sufficient to wave aside one stakeholder group after a single attempt to involve it. Putting more time and effort into building trust (especially where there has been long-term mistrust) often results in eventual success in bringing stakeholders together.

\section{Emerging conflicts and resurfacing of old conflicts during the negotiation phase}

As communities negotiate forest use limits with the government and forest management boundaries with one another, conflicts of interest have emerged. During boundary negotiations at Kilum, a disagreement between two of the communities arose that caused the postponement of the exercise twice before it was finally completed. Initially, the MINEF Delegate and the project did not know the origin 
of the disagreement as neither community revealed the actual problem. On further investigation it was discovered that both communities had an eye on a rich patch of forest further up the mountain. The Divisional Delegate was then able to propose a boundary through the middle of the patch of forest in question, which both communities then agreed to. The case illustrates the beneficial role of the government in identifying a conflict and playing the role of diplomat to resolve it. Old cases of tribal boundary conflicts also have been resurfacing. In the North West Province of Cameroon, tribal boundary disputes are long standing and are mostly beyond the control of a conservation project or a single government department. The project has tried to work around this type of conflict, rather than to try to resolve it. It has stressed the benefits of putting aside differences and working for the health of the forest. MINEF made its position clear to the communities that it is working with the communities to set forest management boundaries, not tribal boundaries. Through project facilitation, different fondoms have thereby been able to agree on forest boundaries that they consider have nothing to do with tribal boundaries. In this case, conflict management occurs even if conflict resolution does not. While it is essential to identify and resolve conflicts in the CFM process, it must also be recognised that not all conflicts can be resolved before the process moves forward. A project should be able to facilitate cooperation between conflicting partners without necessarily resolving a long standing conflict between them.

\section{Conflicts beyond negotiation}

A classic example of a conflict that has gone beyond the point of being managed or negotiated is illegal grazing in the Kilum Forest. As has been discussed, the graziers have chosen not to cooperate with the project. They showed that even if allowed limited legal access to areas within the forest they would not restrict themselves to those areas. Instead of attending forest user group meetings and discussing forest management options with them, they chose to stay away and continued to send more livestock into the forest. They have been responsible for many fires and for clearing patches of forest to expand grassland. In spite of this lack of cooperation, the project has, over the years, facilitated meetings between them and government as well as traditional authorities. In all these meetings the illegality of their activities has been stressed and opportunities were given to them to remove their animals from the forest and keep them in alternative grazing lands outside the forest. The project's livestock programme and local officials of the livestock ministry promised to help them set up and manage their activities outside the 
forest. As they find the forest the easiest place to allow their livestock to range freely, they refused to cooperate with all efforts to negotiate alternative grazing areas and better livestock management systems with them. The only option left was litigation and at this moment they are answering charges in court.

At this point, it is worth examining the legitimacy of these graziers as stakeholders within the forest. Clearly, accommodating conflicting interests in forests is central to the collaborative forest management approach, especially in a pluralistic environment in which the Kilum-Ijim Forest Project finds itself. As stated by Anderson et al. (1998: 3), "pluralism describes situations where distinct groups are actively autonomous and independent, but often interdependent, with legitimate claims and different positions on critical substantive issues'. But who determines legitimacy? Is it enough for people to walk into and claim a resource to become legitimate stakeholders? Then it is worth asking if farmers are not also stakeholders? When the present boundary was marked, thousands of farmers and most livestock owners gave up their activities within the forest and left. This core group of graziers, who are clearly a minority, have fought for grazing rights within the forest to the point of litigation, only because they could afford the means to carry on the fight. If their interests prevailed, it would result in the transfer of resources from the weak to the powerful. The project decided not to support the short-term self interest of the powerful graziers at the cost of long-term conservation goals that clearly overlap with community use interests.

\section{The strategic role of the project as facilitator}

Perhaps the central lesson learned in the collaborative forest management process is the strategic role played by the project in facilitating the three-way partnership. Project staff have taken up the role of convenors and in many cases have found themselves playing the unaccustomed role of diplomats. They pull all the partners into the process by listening to everyone and providing feedback. Staff convene both formal and informal meetings and facilitate cooperation among various groups.

Project staff work with subgroups to initiate discussions and action and then convene larger groups in different combinations as appropriate. In so doing, the facilitation role permeates everywhere and shared meanings arise among stakeholders. It brings partners together to share ideas and to carry out joint planning and action. Attention is paid to getting everyone's opinion. The facilitation role has led to the partners 
finding, in most cases, an acceptable middle ground between the tension that inevitably exists between international conservation objectives and local sustainable use objectives.

When the community forest management process began in 1994, project staff recognised that project-driven subsidies and other forms of direct sponsorship did not work out as hoped. With these activities, the ownership of the problem rested with the project and not other stakeholders. Staff subsequently shifted to an advisory role, providing support in the form of logistics and materials, such as providing transportation to meetings, field per diems, stationery for forest management institutions and boundary marking/mapping equipment. Where possible, the project has encouraged the actors to initiate and carry out activities, while it steps aside. Project staff have revised these roles through field experience and training sessions.

\section{CONTINUITY}

The Kilum-Ijim Forest Project started in 1987 with a heavy expatriate presence, which has since been phased out gradually. At present, there is a single expatriate position of project manager, with most of the work being managed and carried out by Cameroonians. However, resources for the work are still being provided by external funding agencies. To ensure continuity when external funding phases out, BirdLife International is supporting the establishment of a permanent forest management unit in the area in the form of a Technical Operations Unit (TOU) as prescribed in the new MINEF organogram. The proposed mandate of the Kilum-Ijim TOU is (i) to continue and complete the process of assisting the communities around the forest to acquire community forests; (ii) to monitor the implementation of forest management plans by the communities, and (iii) to periodically review each management agreement, as provided by the law. As mentioned above, the project team is planning a separate, permanent ecological monitoring unit to be financed by a trust fund. This unit would continue systematic data collection and produce regular reports on the condition of the forest that would be provided to all stakeholders. The detailed structure of the TOU has not yet been determined, but it is envisaged that the unit will be supported by external funding for the first few years. 


\section{CONCLUSIONS}

Our experience with community forest management at Kilum-Ijim Forest Project is incomplete as there is no official community forest yet. We are still in the process of implementation. We are in the midst of the negotiation phase in which the communities are working with each other and with government and traditional authorities to agree on sustainable systems of managing their community forests. The evidence so far suggests that the process is working and that the communities are enthusiastic about the opportunities they have through the new legislation to participate in natural resource management.

The project's conceptual framework has worked so far. Necessary adjustments have been made to the Nepal model to suit the Kilum-Ijum area of Cameroon. Although the issues are certainly familiar to many, we think we have gained insights that may be useful to experienced practitioners, as well as those just about to start the process. These include the constraints on working with all stakeholders, the importance of clear communication, the central nature of conflict management and the role of the project as a facilitator of a three-way set of relationships. The process has been complex. One needs to be constantly attuned to what is happening in the communities and why it is happening to be able to respond flexibly to changing circumstances or new information. Participatory Action Research, which stresses experiential learning, has provided a methodology that is conceptually and operationally consistent with our collaboration objectives. Through PAR many lessons have been learned on multiple stakeholder management. Through the application of collaborative adaptive management there has been shared learning among the actors.

While the local communities are showing enormous enthusiasm for community forest management and there is apparent consensus to conserve the forest, the question is whether this momentum will be maintained when external interventions are phased out. We hope to face these questions by implementing the remaining phases of the process, consolidating what has been achieved, and applying the lessons learned to achieve community forests in most of the communities before the project phases out. We believe the process will continue to foster interdependence between conservation and use, so that by the time the project phases out, there should be enough convergence between the two objectives for the communities to want to continue managing and conserving their forests. Capacity should have been built among the various actors for them to continue to play effective roles in collaborative forest management. 


\section{ACKNOWLEDGEMENTS}

I wish to acknowledge the support from the Center for International Forestry Research (CIFOR) and the East-West Center, especially to June Kuramoto, Mary Abo and Glenn Dolcemascolo, and to Jefferson Fox, David Edmunds, and Sonja Brodt. I wish especially to thank Louise Buck for all her editorial inputs on the paper throughout the workshop. My discussions with her were very enriching and her suggestions and contributions were invaluable in the completion of the paper.

Anne Gardner, Project Manager of Kilum-Ijim Forest Project, deserves special thanks, not only for the great job she is doing in leading project work, but for the special contributions she made towards the development of this chapter in her discussions with me before I attended the workshop. All staff of Kilum-Ijim Forest Project, particularly the CFM teams, are acknowledged for their participation in the collaborative work with all the partners in the field. Much of what is reported in this chapter is drawn from their experiences. Past and present project managers and staff are all gratefully acknowledged. Past and present project reports have been closely consulted during the preparation of this chapter.

Finally, I am grateful to all the participants at the workshop. Throughout the workshop we shared experiences and exchanged ideas that contributed positively towards the writing of this chapter.

\section{ENDNOTES}

${ }^{1}$ Each ethnic group is made up of villages that are managed by village heads and village councils. These all report to the Fon and Kwifon. Most of the village heads are members of the Kwifon.

${ }^{2}$ In Kilum the people traditionally had a closer relationship with the forest than in Ijim, using the forest for such purposes as beekeeping, rat trapping, cutting of wood for carving and collecting medicinal plants, so user groups were easily identified. Such indigenous uses are not as common on the Ijim side, so when they embraced community forest management, they had to form forest management committees consisting of members from all sectors of the community. 


\section{LITERATURE CITED}

Anderson, J., Clement, J. and Crowder, L. 1998 Accommodating conflicting interests in forestry-concepts emerging from pluralism. Unasylva 194 (49): 3-10.

Collar, N. J. and Stewart, S. M. 1985 Threatened Birds of Africa and Related Islands (Part 1). ICBP/IUCN Red Data Book. Third Edition. BirdLife International.

Department for International Development (DFID) 1998 Action Research for Community Forestry. Sharing Experience From Nepal.

Fisher, R. J. 1995 Collaborative Management of Forests for Conservation and Development. IUCN/WWF.

Grimble, R., Chan, Man-Kwun., Aglionby, J. and Quan, J. 1995 Trees and trade-offs: a stakeholder approach to natural resource management. Gatekeeper Series No. 52. IIED, U.K.

Jackson, W. J. 1993 Action research for community forestry: The case of the Nepal Australia Community Forestry Project. Discussion Paper 3/93. NACFP, Nepal.

Kemmis, S. and McTaggart, R. (eds.) 1998 The nature of action research. the action research planner.

Maisels, F., Allport, G., Anders, S., Asanga, C., Bibby, C., DeMarco, J., Forboseh, P., Gardner, A., Gartlan, S., McKay, C., Nkengla, J. and Thomas, D. 1998 In: Maisels, F. (ed.) Kilum-Ijim Forest Project Conservation Objectives.

Ministry of the Environment and Forestry (MINEF) 1998 Manual of the Procedures for the Attribution, and Norms for the Management, of Community Forests.

Nurse, M. C., McKay, C. R., Young, J. B. and Asanga, C. A. 1994 Biodiversity conservation through community forestry, in the Montane forests of Cameroon. Paper presented in BirdLife International XXI World Conference: Global Partnership for Bird Conservation, Rosenheim, Germany, 12-18 August 1994. ODI Rural Development Forestry Network Paper No. 18d.

Ramirez, R. 1999 Stakeholder analysis and conflict management. In: Buckles, D. (ed.) Cultivating Peace: Conflict and collaboration in natural resource management, 101-126. IDRC/World Bank, Ottawa, Canada, Washington, USA.

Republic of Cameroon 1994 Law No. 94-01 of 20 January 1994 to lay down forestry, wildlife and fisheries regulations.

Republic of Cameroon 1995 Decree No. 95-531-PM of 23 August 1995 to determine the conditions for implementation of forestry regulations. 


\title{
Chapter Three
}

\section{Platforms for learning: Experiences with adaptive learning in Nepal's Community Forestry Programme}

\author{
Ghanendra Kafle
}

\begin{abstract}
Despite the overall success of community forestry in Nepal, local forest user groups still face problems relating to accountability and responsiveness to stakeholders, intraand intergroup conflict management, and establishment of equitable relationships with outside organisations. As a result, several attempts are now being made to build stronger multistakeholder partnerships within and among forest user groups. Using case study material, I describe three different approaches to involving multiple stakeholders, ranging on a continuum from an entirely self-evolved forest user group network, to a selfmonitored forest user group facilitated by an externally funded project, to an entirely outside-initiated workshop for networking stakeholders. Case material is drawn from my experience of working with the Nepal/United Kingdom Community Forestry Project (NUKCFP). I analyse the opportunities and limitations of each approach and suggest which factors are most important for building effective platforms for institutional learning that will lead to improved multistakeholder participation and empowerment in community forestry.
\end{abstract}




\section{INTRODUCTION}

Academics and resource managers frequently cite community forestry in Nepal as a programme that successfully empowers local communities to manage forest resources sustainably. The success of community forestry in Nepal, however, has resulted in a multitude of second-generation problems associated with the constantly changing context and complexities of community-based resource management. These problems also require appropriate responses. One such problem is that when local communities successfully increase their control over nearby natural resources, organisations and local institutions beyond the community become increasingly interested in influencing the setting and the dynamics of resource management (Ramírez 1999). More equitable relations with outside organisations would help communities retain their control. Intra- and intergroup conflict management and the accountability and responsiveness of forest user groups (FUGs) ${ }^{1}$ to stakeholders have also emerged as key areas for improvement of FUGs.

In Nepal, we have attempted to address these problems through the establishment of partnerships among multiple stakeholders. Partnership and collaboration among multiple stakeholders have become a broader issue of contemporary concern not only within projects, but throughout the country. Many approaches for involving multiple stakeholders are being tried by external agencies supporting the community forestry programme, as well as by local communities themselves.

Röling 1996 (cited in Röling and Jiggins 1998: 301) suggests that stakeholders using the same natural resource for various purposes are discovering that they are interdependent. They argue that this requires 'scaling up human agency to a level of social aggregation which is commensurate with the level of the ecosystem perceived to be in need of interactive management.' Röling and Jiggins refer to these aggregations of human agencies as platforms, which can be in the form of 'one-time meetings, elected committees, formally appointed boards or councils or even government bodies' (Röling and Jiggins 1998: 303). An important issue is how to achieve the representation of key stakeholders and the accountability to constituencies without bringing the platform to a total impasse of immobile positions. These authors also state that collective learning is an essential element in platform building. While the focus of platforms is often on social processes such as conflict mediation, institutional development and leadership, experience also makes clear that the stakeholders need to construct a shared understanding of the resource and its complex dynamics (Röling and Jiggins 1998: 304). 
This chapter describes three different means or platforms that have emerged to involve multiple stakeholders in the management of community forests. I examine the processes followed and tools used in the three examples and discuss the implications of these processes for collective learning. The three approaches are: (1) a self-evolved forest user group (FUG) network; (2) the self-monitoring and participatory planning process of a forest user group facilitated by the Nepal/United Kingdom Community Forestry Project (NUKCFP) at the request of the group; and (3) a workshop for networking multiple stakeholders facilitated by the NUKCFP. This chapter also examines what the project has learned about the use of facilitation in establishing effective multiple stakeholder involvement in community-based resource management.

I work for the NUKCFP and this chapter is based on my close association with people involved in these projects, as well as my knowledge of internal project materials, field reports and related literature. The three case studies are all in districts supported by the project. One premise to understanding NUKCFP's work is that it seeks to be a learning organisation that emphasizes a learning cycle of modelling, planning, action and reflection as shown in Figure 3.1. The project therefore seeks to create learning opportunities through the platforms that it has helped facilitate.

Figure 3.1 The NUKCFP experiential learning cycle

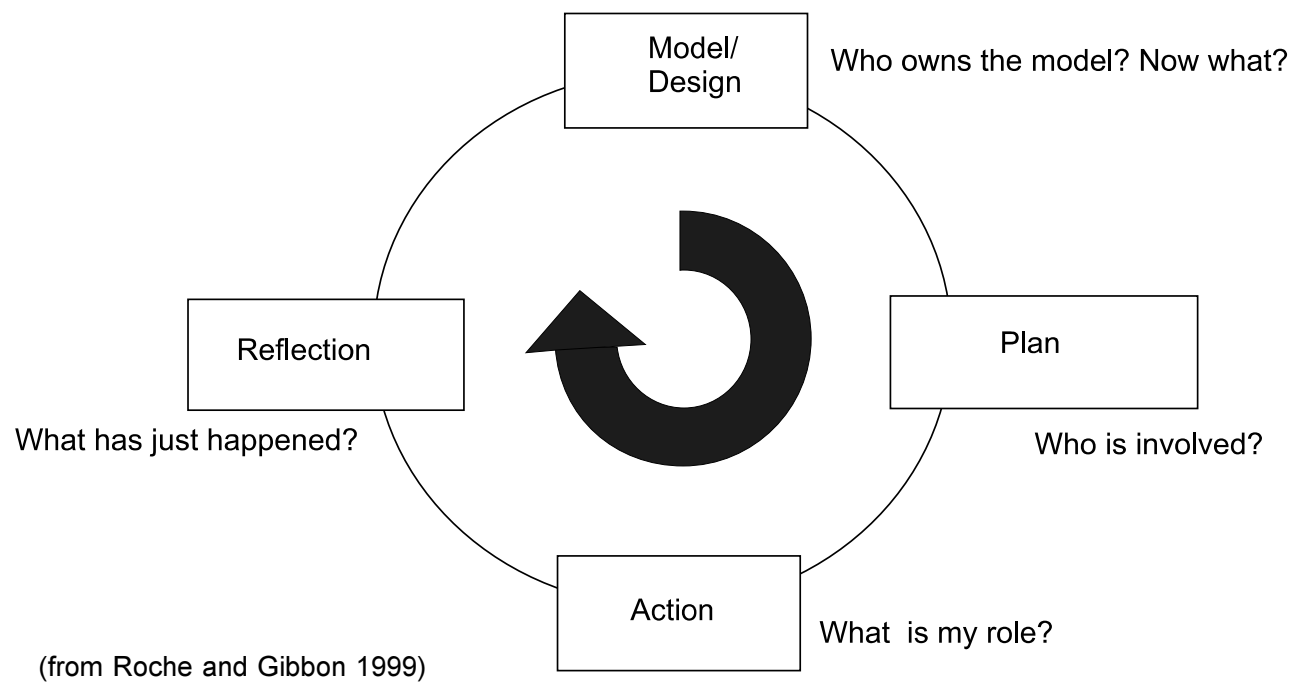




\section{THE CASE STUDIES}

\section{Case 1: The Bokhim Forest User Group Network}

The Bokhim Forest User Group (FUG) Network is a loose, self-evolved network of 17 forest user groups in the Bokhim Village Development Committee of Bhojpur District, one of seven districts supported by the project (SAGUN 1999) (see Figure 3.2). The network evolved in late 1996 in response to conflicts faced by forest user groups. Because most of these conflicts were related to boundaries or land tenure issues, forest users were faced with difficulties in extracting forest products. In a training programme organised and facilitated by the District Forest Officer (DFO), representatives from the forest user committees of the Bokhim Village Development Committee noted a need for a mechanism for resolving these conflicts among user groups. Representatives from the 17 user groups therefore formed a committee comprised of 11 people to resolve local conflict by coordinating and interacting with stakeholders and concerned parties. Network members work on a voluntary basis.

To date, the Bokhim FUG network has mediated conflicts between groups as well as between individuals and groups. The network sometimes works as an advocate, putting pressure on parties in the conflict, or by giving information to the courts and land registration office to assist government civil services to settle disputes. This advocacy role has empowered less advantaged groups and prevented the local elite from dominating the mediation of land conflicts. One example of the network's labour is a district court case filed by an individual against the Athaise FUG. In this case the individual claimed that the forest land managed by the FUG was his personal property inherited from his family. With moral support and backstopping.provided by the DFO, the Bokhim FUG network was able to provide evidence to the judge, who eventually ruled in favour of the FUG.

The network has also helped to resolve disputes outside of the formal judicial system. Their approaches have included interacting with both parties separately, as well as hosting joint meetings of the parties with network members serving as mediators. When conflicts are related to boundaries and land tenure, in addition to dispute resolution, the network assists the affected parties to fix their boundaries with the help of the District Land Survey Office, the Village Development Committee(s) and DFO staff 
Ghanendra Kafle

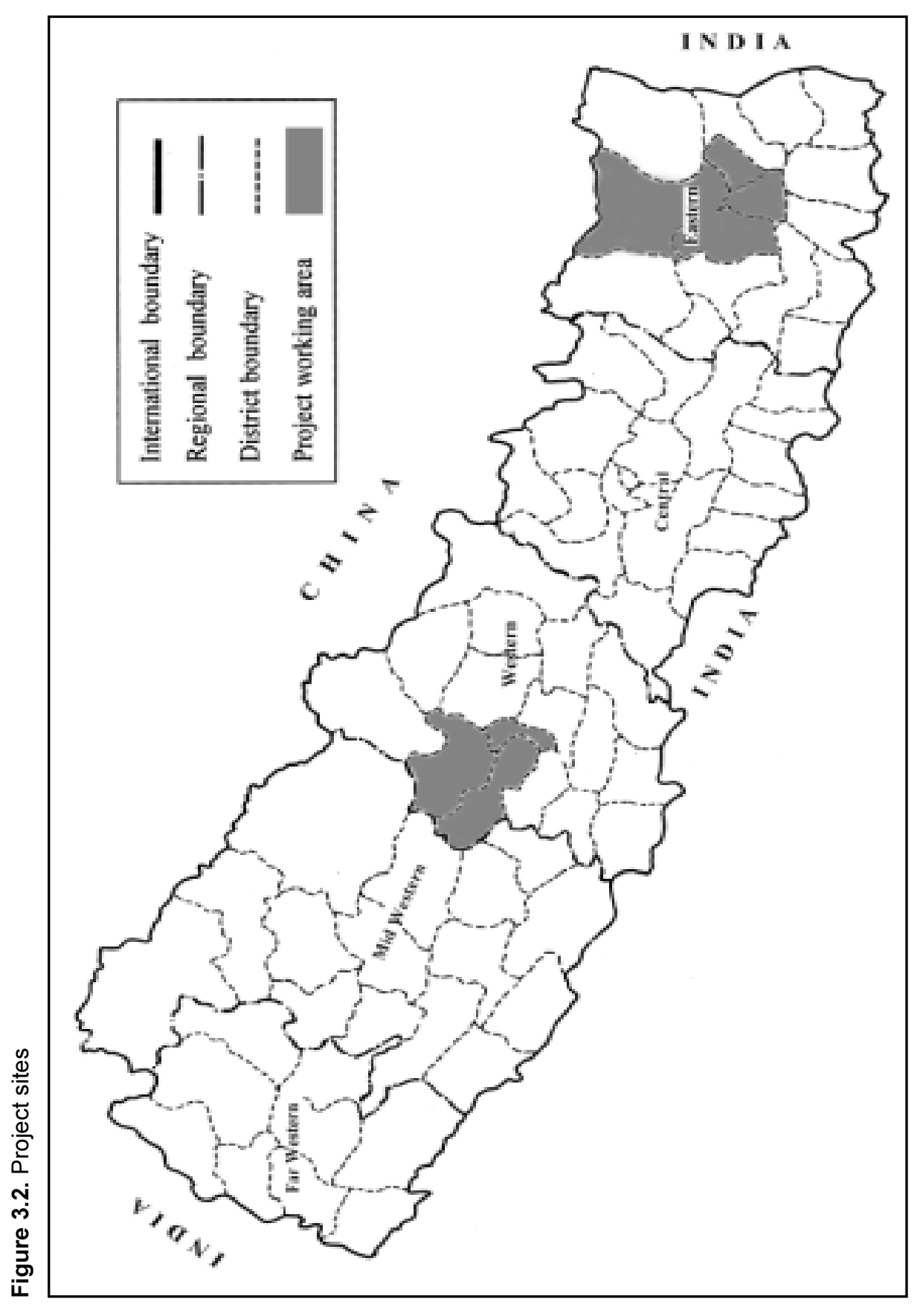


members. Although the Bokhim FUG network was self-initiated, the collaboration with these other organisations has been key to their effectiveness in resolving conflicts.

Aside from their conflict resolution work, the Bokhim FUG network is also attempting to assist individual forest user groups to strengthen the institutional structure, accountability and responsiveness of their organisations. The network assists groups in improving their methods for financial accounting, increasing participation in decision making and institutionalising interactions among users and committee members. It also coaches committee members on how to facilitate meetings, raises issues for discussion in meetings and assemblies and shares learning with other network members. In one case, the network assisted a FUG in overcoming the problem of its executive committee misusing the group's funds by helping the FUG to institutionalise an auditing system. The network provided the pressure for transparency and change that made this development possible. Another achievement of the Bokhim network includes the creation of new platforms for stakeholders to interact and learn through the sharing of experiences, and to undertake coordinated and collaborative activities. The network, in collaboration with the Bokhim Village Development Committee, recently organised a three-day interactive workshop to raise the awareness of private and public organisations interested in community-based forest management. These organisations include groups such as the Small Farmers Development Program, vegetable growing groups, seed development groups, mothers' Groups, Village Development Committee representatives and representatives from the Soil Conservation and District Forest Offices. The members of some of these groups are already forest user group members. The network used the workshop to share experiences among these groups and to gain their support in resolving outstanding issues related to community forestry. Through activities such as this the network is gaining recognition in the district.

According to its chairperson, the network intends to conduct an interactive workshop, in collaboration with the local Village Development Committee, for district-level stakeholders, including non-governmental and community-based organisations. The workshop will seek to share experiences and issues on community forestry and to develop new ideas for partnership with the NUKCFP. To date, the partnership with NUKCFP has taken the form of an NUKCFP-hired animator, who acts as a change agent or facilitator in the community and has been assigned to work with the network. 
The network's committee holds regular monthly meetings to reflect upon the progress the network has made and the learning gained. The committee also prepares work plans for the coming month in response to the demands put forth from forest user group members.

\section{Case 2: Self-monitoring and participatory planning by the Dhungedhara Thulopakha FUG}

This case study refers to a process of self-monitoring and participatory evaluation in the Dhungedhara forest user group, Sankhuwasabha District (see MAP). The process was initiated and facilitated by NUKCFP staff in January 1998, together with staff members from the DFO and Range Post (Raya 1998). The project aimed to establish monitoring and evaluation systems starting with top-down, non-participatory approaches that gradually become more bottom-up, user-initiated and participatory. This change has gradually empowered users to manage the FUG better by bringing them together around a common learning platform.

One key turning point for bottom-up monitoring and evaluation occurred when DFO staff and the project staff members worked together to develop criteria for assessing the health of a FUG. A Dhungedhara Thulopakha committee member of the FUG ${ }^{2}$ explained: 'the committee was being blamed by many users for our inability and inefficiency to communicate with them and to undertake things properly. Despite our good intentions and enthusiasm, we were not able to satisfy the users' expectations and interests. One day we asked DFO staff members the criteria on which they evaluated the FUGs for the annual award. This was the start of a dialogue for developing the pictorial self-monitoring and participatory planning process used by the group.' Project and DFO staff members, at the request of the committee, had a series of meetings with committee members that clarified and identified concepts, processes and methods of facilitation, and envisaged possible impacts of self-monitoring and participatory planning.

A jointly planned exercise was subsequently carried out to develop indicators for self-monitoring with the Dhungedhara Thulopakha FUG. The committee divided group members into ten small subgroups according to caste or household size with a view to involving at least one member from each household in small group discussions. Realizing a need to develop understanding of the process of self- 
monitoring, small group discussions used role plays and exercises to clarify concepts. For example, the game of looking in a mirror gave a clear picture of what selfmonitoring is.

A second exercise encouraged participants to think about the group and its forest situation in the coming ten years. This exercise led to setting indicators for monitoring. For example, the group envisioned the ideal future situation as sufficient timber and fuelwood for users, construction of a user group's office and equal participation by disadvantaged users in decision-making processes. Suggestions that were not forestryrelated included the construction of a water pipeline for kitchen gardens, loans for undertaking income generating activities and skill development opportunities. The users' committee considered it important to use the group's fund for such activities, provided the users' assembly accepted the proposal.

Users were then asked to draw pictures of indicators that could show that these objectives were being successfully achieved. Despite some initial reluctance and hesitation, especially by illiterate people, they did draw. This session was very interactive and participatory, irrespective of class, gender and educational background. Each group then confirmed whether the drawing conveyed the intended meaning. Even illiterate people found the pictures easy to understand (Figure 3.3).

The next step was to assess the current situation against the indicators of the desired situation the groups had previously set. Symbols of the four phases of the moon were used in this exercise. Indicators were arranged in a vertical column and symbols of the phases of the moon were placed in a horizontal row. A full moon symbolized the desired state, a black or new moon meant the work had not yet started, a one-third or crescent moon meant activities were just getting started, and an image of a two-thirds moon meant that $60 \%$ of the work had been completed. This exercise was also done in a participatory manner. After completing the exercise, participants started to say, 'Oh, we have a lot to do to bring the indicators to the full moon.'

Finally, committee members and representatives from each small group, with the support of project and DFO staff members, compiled the indicators. Committee members presented the results to the users' assembly. The assembly endorsed the indicators with a few amendments. As a result of this process, the user group developed a forest management plan that focused more attention on poorer women and disadvantaged 
Figure 3.3 Women engaged in discussion about future forest needs and indicators

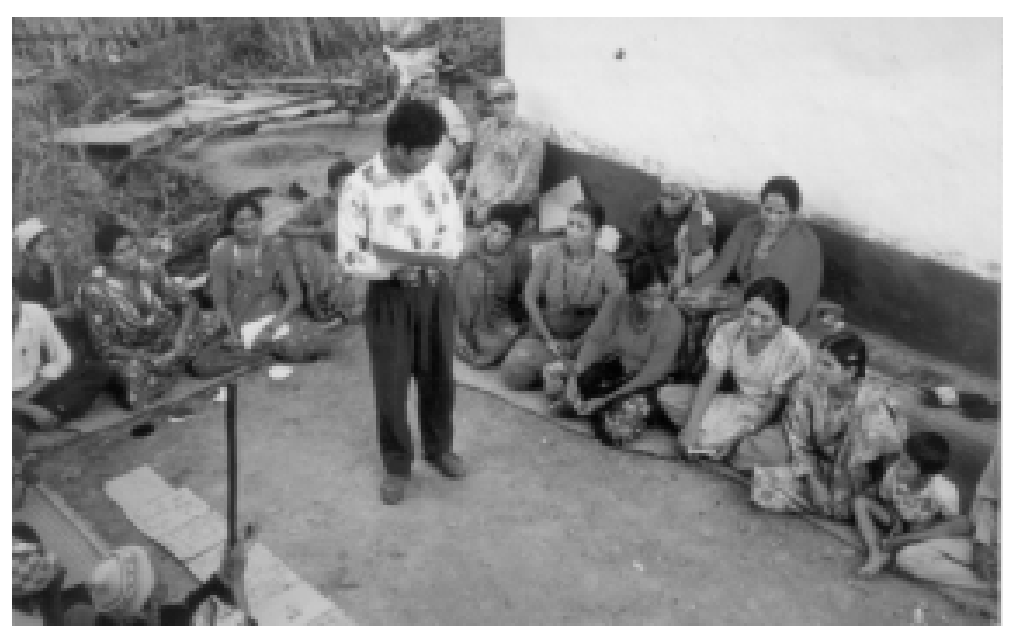

households within the group. The user group used this exercise as a benchmark and has recently completed its second annual assessment and planning exercise on its own.

Some committee members from the Dhungedhara Thulopakha user group are now sharing their learning with the nearby Archale FUG. These members have facilitated a similar process for the Archale group on request. Thus, new resource people are also being produced at the local level.

\section{Case 3: Initiation of Multiple Stakeholder Collaboration through a Workshop}

A workshop initiated and facilitated by the NUKCFP in western Nepal exemplifies efforts to use workshops as tools for facilitating collaborative learning among multiple stakeholders for sustainable forest management (Maskey et al. 1999). Twenty-five representatives from local nongovernmental organisations, the Federation of Forest Users, a district office of the South Asia Women's Organisation and DFOs participated in the workshop. The workshop sought to lay a foundation for collaboration by developing a common understanding among participants of the organisational strengths and constraints of each group and to identify potential areas for collaboration. 


\section{PLATFORMS FOR LEARNING}

The workshop followed a process that logically assisted participants to see possibilities for collaboration, and to become motivated to then collaborate with one another. The approach was positive and forward looking, focusing on examples of what worked best in the past and rather than on what did not work (see Box 3.1). Based on current successes, the workshop identified possible opportunities for collaborative work.

Workshop participants first set the objectives and desired outcomes of the workshop. They then agreed to an operational definition of the conceptual terminology used to describe multiple stakeholders working together. Organisations shared their missions,

\section{Box 3.1 Appreciative inquiry: A forward-looking approach}

NUKCFP has been following an appreciative inquiry approach to facilitating communitybased resource management for the last two years. Srivastva and Cooperrider (1990) explain appreciative inquiry by saying that people get what they are searching for. The questions people ask determine what they get, hence the more positive questions people ask, the greater the likelihood they will obtain positive responses.

The approach has three basic principles:

1. The Constructive Principle. Organisational development depends on constructive thinking and involving people towards constructive actions;

2. The Simultaneity Principle. Inquiry and change are interlinked. The questions we ask set the goal we want to achieve and what we discover leads to our constructed future.

3. The Positive Principle. The more positive questions people ask, the more positive responses they get and the more willing people are to come together for dialogue that ultimately leads to collective action for the benefit of all. This approach is contrary to problem solving approaches that involve searching for the root causes of problems, leading people to get stuck within the cause and effect and losing sight of innovations.

The approach emphasizes discovering good things about the present situation, understanding them, fostering innovation through collective action, and finally transforming human and social systems. The approach believes that there are lifegiving factors in all organisations and these factors stimulate people or organisations to move forward to meet the visions they have developed. The process follows a cycle of ' 4 Ds' - discovery (the best of what is), dream (what is the world calling for?), design (what should be the ideal?), and destiny (how to empower the team and achieve sustainability?). 
values and major achievements. Workshop facilitators assisted participants in identifying the features of collective action and in becoming informed about community forestry concepts and processes. The workshop then sought to identify potential roles for collaborative work among participating organisations and to develop a common understanding of the characteristics of good collaboration (see Table 3.1).

Table 3.1 Characteristics of and factors that promote good collaboration

\begin{tabular}{ll}
\hline Characteristics of good collaboration & $\begin{array}{l}\text { Factors that promote good } \\
\text { collaboration }\end{array}$ \\
\hline - Transparency, openness and honesty & - All parties involved benefit from the \\
- Commitment & collaboration \\
- Mutual respect & - All demonstrate commitment \\
- Feedback & are clear and well defined \\
- Effective communication and & - Flexibility \\
information & - Use of resources in an effective way \\
- Adopt and accept the changes made as & - Responsibility taken for \\
- P result of moving the time and process & communication, honesty, and \\
- Taking responsibility & transparency \\
- Positive thinking and support of the & Commitment of the staff working with \\
donors & organisation \\
- Common understanding, values and & - Forward looking plans \\
norms and common interest & Readiness for work, common \\
- Proper mobilization of the physical, & understanding and mutual sharing, \\
financial and human resources & supportive organisation, positive \\
& thinking \\
\hline
\end{tabular}

The participants worked together to develop action plans for each organisation that identified the tasks to be performed, the time frame, the methods to be used and organisations to provide backup support for the work. Finally participants organised a collaboration network. The network chairperson is also a member of the Federation of Community Forestry Users, Nepal.

Since the close of the workshop, a task force of the collaboration network has prepared a proposal for publishing a journal on collaborative efforts in resource management and circulated it among the organisations that attended the workshop. The journal will seek to promote the sharing of experiences and information among organisations and 
professionals involved in development work, as well as to improve local capacity for publication. The task force has also called for a follow-up workshop.

\section{IMPLICATIONS FOR IMPROVING MULTI STAKEHOLDER PARTICIPATION AND EMPOWERMENT}

In this section I examine these case studies in terms of what the NUKCFP has learned about the opportunities and limitations of each of the three platforms for enhancing stakeholders collaboration and learning. I also discuss what the Project has learned about facilitation in establishing effective multiple stakeholder involvement in communitybased resource management.

\section{Opportunities and Limitations of the Self-Evolved Network}

The Bokhim FUG network evolved out of collaborative reflections on the problems faced by many forest-user groups, and out of a need for a common platform from which to initiate innovative ideas. The opportunities created by such self-evolved FUG networks include the ability to control their own growth and to maintain ownership of the processes affecting their destiny. As self-evolved networks, they are well positioned to more democratically assess the legitimacy of management decisions and collaboration among network members.

Limitations for self-evolved FUG networks include a lack of incentives for leadership and membership due to a lack of resources. The amount of time a leader can afford to put into network activities depends on what incentives he or she receives for his or her efforts. Commitment to work counts a lot, but where does this commitment come from? Is success sufficient to motivate members to work without other benefits? As the chairperson of the network says "It's hard to give sufficient time for the work as all of us have to look after our own farms and other household business. We are therefore thinking to register the network as a local non-governmental organisation with the intention that we could at least get some financial profit from our work." This raises a debate about whether such an organisation would be able to provide free services to the groups. Even if they are willing to provide free services, social problems like gender, equity and participation may receive little consideration, unless the organisation is challenged and or made aware of the gaps in its practices. 
Back-up facilitation and support were critical to the success of the network. I discussed above that the Bhojpur DFO assisted the Bokhim FUG network to provide the district judge and land registration office with factual information on a land tenure case. Without this assistance, the Athaise FUG would have most likely lost its case and the community forest would have become private property. The capacity of such a network therefore needs to be assessed and developed as necessary.

Promoting and scaling up local initiatives also demands well-established vertical and horizontal communication and information-flow systems that are appropriate for the local context. These are presently limited, as in areas where most forest users are illiterate, communication systems cannot be based on the ability to read. Likewise, because of inaccessibility in areas where many people have to walk several days to get to the road head, dissemination of information at the local levels is not easy.

Solutions for easing these limitations may include locating the resources for communication through, for example, cross visits policies supportive of new initiatives. But there is always the risk that the communities will lose control over the process by seeking external support. Donors and other organisations supporting community development may seek to use self-evolved networks as vehicles for their own development and collaboration aims. Local DFO staff members may seek to use selfevolved networks to reduce their workload. Organisations supporting the communities may be tempted to take credit for the processes under their control. Yet collaborative efforts with externally-funded organisations may also be necessary to self-evolved networks for scaling up of local initiatives. The challenge will be for self-evolved networks to acquire facilitation that does not take control of the local process.

\section{Opportunities and Limitations of FUG Self-Monitoring and Participatory Planning Facilitated by an Outside Organisation}

The facilitation by NUKCFP enabled the FUG to access new information about monitoring. This realization was achieved through interactions with staff members from the Project, as well as the DFO. The facilitation by an outside group also probably made it easier to involved all users and empowered especially the disadvantaged (i.e. the poor and women). Resources were available from NUKCFP for each exercise. Role plays and games introduced by the facilitators were useful approaches for clarifying concepts and creating a participatory environment that would have 
otherwise not been available. The main constraints are that the monitoring and evaluation were introduced as a priority of an outside group and that the outside group drove information flow and the process. The purposeful shift to a more bottom-up process of monitoring, however, ultimately led to capacity of the FUG to assume control over the process.

\section{Opportunities and Limitations of the Workshop Approach}

The workshop approach was different from the network and facilitated-FUG process in that it focused on creating common understanding among workshop participants about where stakeholders could work in collaboration to enhance participation of users in community forestry. The major opportunity of the workshop was that it gave groups the chance to meet who might not have otherwise done so. The support of an external body also enabled the meeting to seek collaboration at a larger scale than might be possible by a self-initiated group.

The forward-looking approach of the workshop helped reduce conflict and tension and accommodate different interests and perspectives (cf. Acharya et al. 1998). The workshop also helped to create an environment of togetherness, thereby also encouraging a sense of common interests. Hence the overall approach of the workshop was useful for establishing partnerships. By emphasizing positive and constructive thinking, it created a process for exploring possibilities and opportunities for collaboration where all the parties benefit. However, the key to collaboration is getting good intentions translated into reality. What we really need is a process for identifying and promoting these factors in our partner organisations, which goes beyond the scope of a single workshop.

People generally tend to react positively in a workshop environment and are quick to make commitments. In real life however, the situation may be different because organisational behavioral change does not come easily and good working relations are not established so quickly (Fowler 1997). Critical differences in the institutions in terms of their origin, their less visible agendas, the backgrounds of the founder and staff members working with the institutions, and inter-personal relations of staff members are key factors that can have a significant impact on collaboration. A longer-term process of change is necessary, that most likely will involve some form of collaboration with other facilitating organisations. 
Because implementation of the actions decided on in the workshop has not started, it is not yet possible to comment comprehensively on the effectiveness of the workshop. For the time being, the continuity of the collaborative forum depends on backstopping from the collaborators and their leadership. A workshop can therefore be a useful platform for catalysing change in collaboration patterns, but to ensure long-term change, more sustained platforms are required.

\section{CONCLUSIONS}

FUGs are a necessary unit for organising community forest management in Nepal, but with time it has become apparent that additional types of social aggregations are needed, among FUGs themselves and with other organisations, to strengthen FUG internal capacities and build stronger interdependencies between FUGs and other groups.

Different types of platforms meet different types of objectives. The self-evolved network examined in this chapter was an active body that took on the ongoing needs of the operation of the FUGs. In contrast, the participatory planning and workshop were more immediately catalytic platforms. All three platforms accommodated a diversity of audiences among which collective action and learning occurred, within FUGs, among FUGs and with other organisations.

In each example, the platform likely had an impact on collaboration and empowerment of the FUGs. The platforms had immediate impacts on heightening awareness and understanding about interdependency among stakeholders and the opportunities for collaboration. Members of FUGs were empowered through the building of capacity and pressure was created for FUGs to be more accountable and responsive to their members. From these varied experiences, we found that collaboration was best initiated in informal settings where interpersonal relationships among the stakeholders could be established. Involvement of multiple stakeholders in specific issues affecting an ongoing concern was more practical and meaningful. Use of positive and forward-looking approaches appeared to stimulate institutions to move forward in planning collaboration with positive thinking. Interestingly, all the platforms also had an impact by leading to new platforms for collective action and learning, such as new workshops, the monitoring system, the journal and the collaboration network. 
The degree to which each platform involved outside facilitation seemed to affect the degree to which outside resources, knowledge and influence were brought to bear on a problem. For example, the use of games, exercises, pictures, and analogies, especially followed by discussion that help people to relate these games to their own context, were very effective tools for stimulating discussion and getting active participation. But local people did not have the capacity to use these tools by themselves. They benefited from the assistance of an outside facilitator. These advantages are gained, however, at the cost of possible loss of ownership and empowerment for the FUGs. Special measures need to be taken, such as the gradual transition to more bottom-up monitoring or the development of community facilitation skills, to ensure that ownership occurs. How to increase the capacity of local institutions as effective facilitators is therefore a major concern. The role of projects supporting community forestry (such as the NUKCFP) should not be as facilitators of FUG assemblies but as agents of growth assisting local people and institutions to grow stronger. Involving local people in these processes from the beginning and coaching them as needed can often be sufficient to achieve this goal (NUKCFP 1997, 1998a).

The sustainability of the impacts of the platform will ultimately depend on both the type of platform, the types of follow-up platforms that are generated and the dependence on a facilitator to maintain the process. Self-evolved platforms are likely to be more sustainable, whereas the sustainability of platforms introduced by outside facilitators depends on the commitment of the organisations, their objectives, leadership, relationships among collaborative organisations and with the outside sources of funding, availability of resources, and continuity of the people involved with the project. In addition, we found that continued communication and flow of information were the keys to promoting innovations, to enriching learning, to scaling up ideas, and to pressuring for policy change or support. Real learning occurred when this communication happened at the implementation level.

The three examples of platforms were initially selected to demonstrate that different types of social aggregations among FUGs and other organisations can enable collective learning that leads to greater multistakeholder collaboration. In the first case at least, collaboration led to new platforms for collective learning and vice versa. Learning can itself be empowering when it involves capacity building or building new alliances. Collaboration can itself be a learning process if it involves, among other things, developing a better understanding of each others' strengths and weaknesses. Rather 
than thinking of platforms as the starting point of a causal pathway, it may be more constructive to think of and use platforms as an arena for social interaction that can simultaneously enhance learning, empowerment and collaboration among multiple stakeholders. The type of platform and degree of outside facilitation required will then depend on the types of learning, empowerment and collaboration that exist and are desired.

\section{ACKNOWLEDGEMENTS}

I would like to express my sincere gratitude to the following: David Edmunds, Louise Buck, Sonja Brodt and especially Jefferson Fox for his intellectual and emotional support; June Kuramoto for the administrative and logistical assistance she provided; Mary Abo for her logistical support; Glenn Dolcemascolo; my colleagues Netra Tumbahangphe and Bharat Pokharel for their valuable advice prior to my coming to Hawaii; Nick Roche, NUKCFP Project Coordinator, and Hugh Gibbon, NUKCFP Project Area Leader; to my wife Shata Kafle and my children for their emotional support; and to the active members of field level networks: Krishna Pradhan, chairperson of Bokhim FUG network, Krishna Yonjan and Padam Lama, active members of the same network, and Ram Bahadur K. C., the coordinator of Baglung collaborative work. The two cases mentioned in the chapter are very much based on the information and materials I got from them.

\section{ENDNOTES}

${ }^{1}$ The Forest User Group (FUG) is an assembly of all forest users of a certain forest that is legally handed over to the group. The FUG committee is an executive body with fixed rights, authority and responsibility given to it by the group. In a group there are 60-70 households, whereas a committee usually comprises 7-11 members from those user households. The main role of the committee is to carry out the day-to-day work to implement the group's plan.

${ }^{2}$ The Forest User Group (FUG) is the assembly of all forest users of a certain forest legally handed over to the group. The FUG committee is the executive body with fixed rights, authority and responsibility given to it by the group. In a group there are 60-70 households, whereas a committee is usually comprised of 7-11 members from 
those user households. The main role of the committee is to carry out the day-to-day work to implement the group's plan.

\section{LITERATURE CITED}

Acharya, D. P., Shrestha, R. and Niraula, D. R. 1998 Community forestry for all forever. Report on the third community forestry national workshop. HMG, Ministry of Forest and Soil Conservation, Department of Forest, Kathmandu.

Fowler, A. 1997 Striking a balance: a guide to enhancing the effectiveness of nongovernmental organisations in international development. Earthscan Publications, London.

Maskey, R., Sharma, C.P. and Bania, S. 1999 Chhayamatako lagi shahakarya gosti (Collaboration workshop for capacity growth). Nepal/UK Community Forestry Project, Baglung.

Nepal/UK Community Forestry Project (NUKCFP). 1998a NUKCFP concept papers. NUKCFP, Kathmandu.

Nepal/UK Community Forestry Project. 1998b NUKCFP annual process report (1997/ 98). NUKCFP, Kathmandu.

Nepal/UK Community Forestry Project. 1997 NUKCFP annual process report (1996/ 97). NUKCFP, Kathmandu.

Ramírez, R. 1999 Stakeholder analysis and conflict management. In: D. Buckles (ed.) Conflict and collaboration in natural resource management, 101-126. International Development Research Centre/World Bank, Ottawa, Canada, Washington, USA.

Roche, N. and Gibbon, H. 1999 The Nepal/UK Community Forestry Project: Linking Practice with Theory in Nepal. Presentation at Natural Resource Advisors' Conference, NUKCFP, DFID Kathmandu, Nepal.

Röling, N. 1996 Towards an interactive agricultural science. European Journal of Agricultural Education and Extension, 2(4): 35-48.

Röling, N.G., and Jiggins, J. 1998 The ecological knowledge system. In: Röling, N.G. and Wagemakers, M.A.E. (eds.) Facilitating sustainable agriculture. Participatory learning and adaptive management in times of environmental uncertainty, 283311. Cambridge University Press, Cambridge, UK. 
Srivastva, S. and Cooperrider, D. 1990 Appreciative management and leadership: the power of positive thought and action in organizations. Jossey-Bass Publishers, San Francisco.

Social Action for Grassroots Unity and Networking (SAGUN) 1999 A study of collaboration and partnerships in Nepal. SAGUN, Kathmandu. 
PLATFORMS FOR LEARNING 


\title{
Chapter Four
}

\section{Seva Mandir: A learning organisation}

\author{
Rukmini Datta
}

\begin{abstract}
This chapter examines the experiences of Seva Mandir, a voluntary organisation working in rural development in Rajasthan, India, in the context of social learning theory. I identify six avenues for organisational learning and adaptation: feedback from fieldlevel workers, process documentation, research studies, training programmes, internal conflict and debate and interactions with the government. I then examine cases of each learning mode to illustrate the processes that led to crucial modifications in organisational perceptions, structure and strategy. Seva Mandir's experience suggests that some redundancies and apparent inefficiencies in organisational structure and function can actually enhance learning opportunities and, ultimately, the effectiveness of development interventions.
\end{abstract}

\section{INTRODUCTION}

Development planning and implementation in the last two decades have made extensive efforts to incorporate stakeholder participation. However, as Korten (1981: 176) notes, 
'... effective participation of the rural poor in the development process is more easily mandated in programming documents than achieved in the real world of programme implementation.' Such observations require us to examine how development organisations learn from their experiences to work with not only their clients, but also other stakeholders, and translate such learning into action.

The literature on organisational change provides useful insights on organisational learning loops (Maarleveld and Dangbégnon 1998). The outcomes of an organisation's planning and action are often evaluated according to how they contribute to the achievement of larger goals. Errors that emerge can be rectified through built-in mechanisms of the organisation which ensure that future performance continues to occur within the existing norms and values. This process has been labeled single loop learning. When feedback from experience starts to feed into the planning process such that the underlying assumptions are challenged, double loop learning takes place. Double loop learning requires examination of the purpose of the programme in light of its achievements and constraints such that the value of theoretical assumptions is clarified (Lee 1993; Maarleveld and Dangbégnon 1998).

Double loop learning necessarily involves organisational self-examination and, as a result, is often not attempted by organisations. Instead, any mismatch between planning and execution is often attributed to implementation failures alone (Lee 1993). Korten (1981) distinguishes between the self-deceiving organisation (which treats error as synonymous with internal failure), the defeated organisation (which assumes the source of error to be external and beyond its control) and the learning organisation (which treats error as an essential source of information).

Adaptive management and organisational understanding occur then in the context of an organisation's effort and success in incorporating double loop learning into its planning and actions. Knowing is not just the accumulation of objective knowledge, 'it is the effective action of an organism in its environment' (Maturara and Varela 1987: 248, cited in Woodhill and Röling 1998: 62). The accumulation of knowledge by an organisation is not useful until it results in adaptation of its policies and processes for further action. Furthermore, in a true learning organisation, this process is never really finished, as the organisation is always 'under construction' (Bruce and Wyman 1998: 250). 
The literature thus suggests that multiple stakeholder actions will be more successful when organisations follow the iterative process of learning outlined above and incorporate such learning into modifications in strategy. This chapter draws from the experience of Seva Mandir, an organisation engaged in rural and tribal development in Rajasthan, India, for the past three decades, to show how a mature organisation can progress through a continual process of learning and understanding, ultimately leading to adaptive management of projects and resources. As a district-level organisation with long years of experience and a diversity of personnel, the case of Seva Mandir may hold crucial lessons for similar organisations around the world. This chapter is based on the ground-level experience of the author during two years of working with village institutions and on the vast repository of knowledge gathered from documentation within the organisation and consultation with colleagues.

\section{ORGANISATIONAL BACKGROUND}

\section{Mission and strategy}

Seva Mandir is a voluntary organisation that has been working for community upliftment in the southern district of Udaipur in Rajasthan (western India), since 1969 (see Figure 4.1). Seva Mandir's work is spread over more than 500 villages. The villages in which Seva Mandir works constitute remote pockets of the district where most of the population is tribal and lives below the poverty line. Sharp structural constraints limit opportunities to improve livelihoods and achieve wellbeing in terms of health, education and gender equity.

The wellbeing of the rural and tribal people of Udaipur is intrinsically linked to the quality of the natural resources on which they depend for fuel, fodder and food. Udaipur is geographically defined by the Aravalli mountain ranges, which were at one time well-stocked with forests. Today, forests and common lands are more or less degraded. Only about $18 \%$ of the land is under cultivation, of which less than $14 \%$ is under some form of irrigation. Agriculture is primarily rain-fed with most of the cultivated area under single cropping for subsistence purposes. To counter the lack of food security, people migrate seasonally in search of employment. 
Figure 4.1 Position of Rajasthan in India and of Udaipur district in Rajasthan

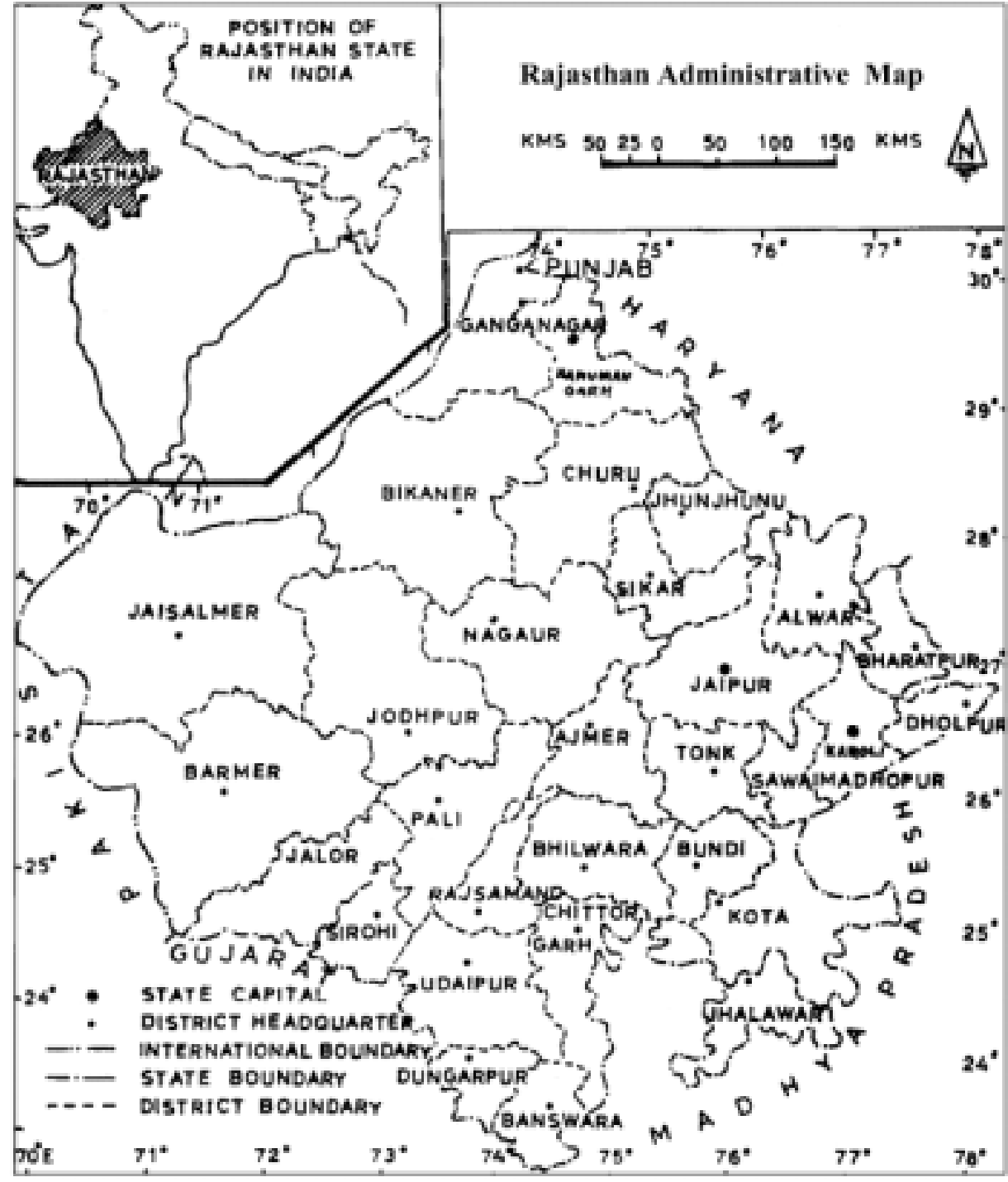

From the time of its inception, Seva Mandir's work has moved in phases. Every new phase has been prompted by lessons learned in the previous phase. The organisation began with the single point agenda of imparting education to poor peasants and has, today, evolved to work in three interrelated areas: 
- improving livelihoods of village communities through sustainable use of natural resources;

- building local capabilities to achieve wellbeing in terms of education, health and gender equity;

- creating autonomous village institutions.

The core of the organisational strategy, to empower the disadvantaged, has, however, remained unaltered over all these years. The ostensible change has been in implementation and operation and in identification of the need to change the way the organisation looks at the village group in relation to itself.

Seva Mandir's mission is twofold. It aims 'to make real the idea of a society consisting of free and equal citizens who are able to come together and solve the problems that affect them in their particular contexts' (Seva Mandir 1998: 14). It also works towards constituting 'the conditions in which citizens of plural backgrounds and perspectives can come together and deliberate on how they can work to benefit and empower the least advantaged in society'.

\section{Structure}

The organisation's head office in the city of Udaipur provides support to administrative and technical field staff. For the latter, subject matter specialists are appointed (in forestry, women and child development, etc.). The next rung of programme implementation in the organisation is the block level. Seva Mandir works in six administrative blocks of the district, but for the purposes of its operation it has divided its work area into five blocks ${ }^{1}$. The personnel at the block level comprise a team leader and subject matter specialists. Blocks are further divided into zones. At the zone level, team leaders work with forestry and health assistants. They are also assisted by village-level para-professionals ('paraworkers').

There is two-way reporting and feedback between the subject matter specialists in Seva Mandir's Natural Resource Development Unit and their block level unit. This two-way reporting is also used between the blocks and the zones, and is aimed at maintaining regular communication among all levels of the organisation. 


\section{THE INSTITUTIONAL LEARNING PROCESS}

This section identifies several modes of organisational learning and illustrates them with examples from Seva Mandir's history. All the learning processes are interlinked, and each feeds into the double loop learning process of the organisation. The success of Seva Mandir lies partly in being able to distinguish the various avenues for learning and in allowing each one adequate space to develop into a useful tool for the organisation.

\section{Learning through feedback from the field}

The organisation's commitment to making a positive impact on ground level circumstances means that investing a lot of energy in getting feedback from the field is critical. Of its 220 full-time staff, about $50 \%$ are stationed at the zone and block levels. These staff are in constant contact with the village group and implement Seva Mandir's programmes at the village level. They are the source of feedback about field realities and reactions. They attend village meetings year-round and are in touch with the residents of the village as well as with paraworkers (especially at the time of project implementation). The zonal and block staff are the key informants or the 'nerves' of the organisation and the paraworkers are its 'backbone'.

Most of the zonal staff belong to urban and rural areas in and around Udaipur and are products of modest economic and educational backgrounds. They begin working as young adults and already have an inherent sense of village-level dynamics and issues, which becomes fine-tuned with experience.

The paraworker cadre was given formal shape in the organisation in the second half of the 1980s. By then the organisation's strategy was based on the conviction that the State is not the best custodian of people's interests and that its monopoly on service provision in development must be challenged. Apart from enhancing its own capacity to provide the people with an institutional alternative for development services, it trained paraworkers from villages to provide services like forestry and health under the constant guidance of Seva Mandir staff. The paraworkers were paid a small stipend for their services by the organisation. Most of these paraworkers were those who had been in the frontline of the implementation of Seva Mandir's programmes in the field. At present nearly 750 paraworkers and 50 zone-level workers work with Seva Mandir (Figure 4.2). 
Figure 4.2 Paraworkers facilitating tree planting

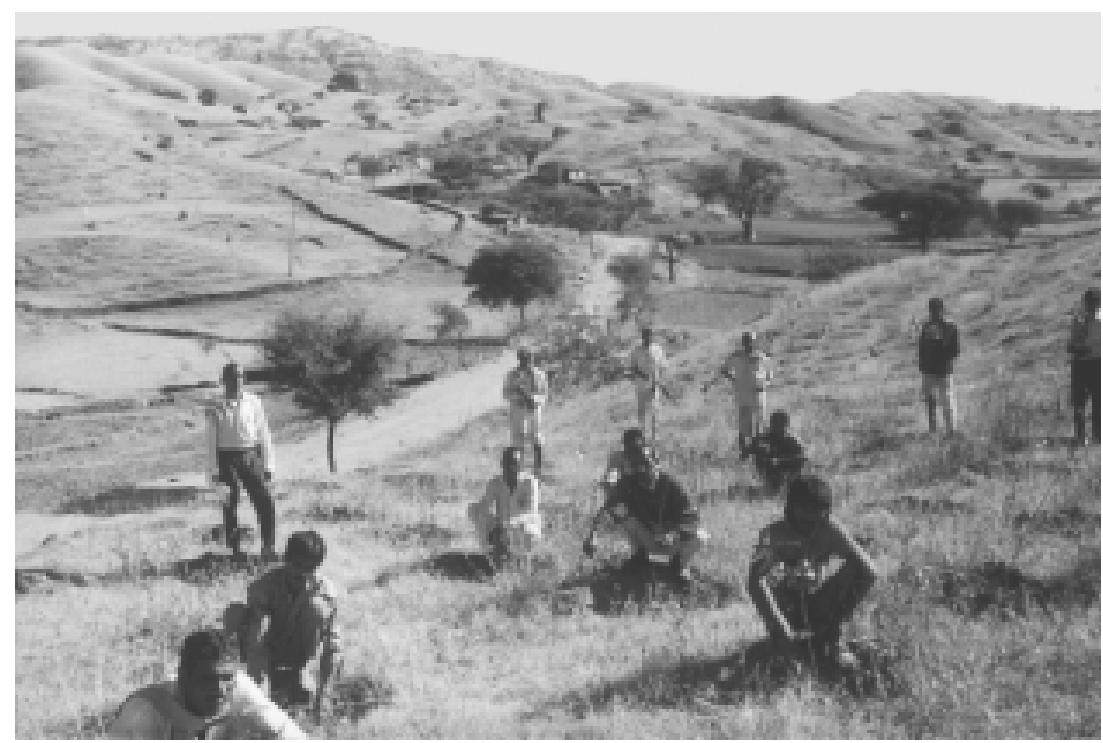

The reporting system for the zonal and block staff to subject matter specialists and team leaders is not rigid. It encompasses numerous forms of interaction-for example in village and organisation meetings and on field visits. This informal information system captures many nuances and dynamics that might be missed in a rigid system. On the other hand, not everything that is reported reaches a point where some action is taken. It often takes time before information leads to or is used in a decision. Another variable in the information system is the matrix structure of the organisation. All staff members located in the field report to two people above them in the hierarchy. The forestry worker at the zonal level, for instance, reports to the forestry supervisor at the block as well as to the team leader at the zone. Though this arrangement creates an apparent confusion over reporting lines, it has the inherent advantage of information not being suppressed by any one individual (if there is such intention). In addition, it is not the zonal team alone which is in direct touch with the village. Resource team members from the centre and, more frequently, members from the block team are in touch with the village groups as well. It is not uncommon, then, for a village group to give feedback about its dissatisfaction with the zonal staff to block and centre-level staff once a certain level of trust is built between them. 
Despite the importance of the field staff in the hierarchy, tapping information and feedback from them continues to be a challenge for the organisation. This difficulty is linked, to a large extent, to the level of motivation of field level staff. They are products of the local socio-cultural system in which being a part of a development agency is, perhaps, not a coveted profession. Many of them work with Seva Mandir for lack of choice; in most cases, they missed out on the opportunity to get a job with the government. This picture does not fit all field workers; some are highly motivated and have proven invaluable not only for their skills in community mobilisation and implementation of work, but also as key informants in the organisation's information system.

The case of Shyampura village (see Box 4.1) illustrates how a Seva Mandir team channelled a well-honed perception of events in the field to build a successful programme. It speaks of the need to gather information carefully from the field, to interpret it in a way that it can be used for the benefit of the programme and to incorporate it into subsequent planning.

\section{Learning from process documentation}

A more formalised method of information transmission within the organisation is through process documentation. Seva Mandir has evolved a fully fledged cell within its People's Management School (whose primary responsibility is capacity building) on process documentation. This cell is a manifestation of the organisation's recognition that in order to address its internal contradictions, it needs to invest a great deal in research and monitoring. Seva Mandir, like any other development agency, suffers from the danger of becoming self-serving and creating a patron-centric arrangement. Internal checks, therefore, are imperative to countervail this tendency. The process documentation cell has produced in-depth and analytical studies about the organisation's interventions in the field. The studies highlight the mismatch between the organisation's interventions and field level requirements, the concentration of benefits by those in leadership positions, the co-existence of poor relations and cohesion within village groups and inevitably the tendency for public action to be muted in cases of neglected duty on the organisation's part (Seva Mandir 1998). 
Box 4.1 Shyampura village

A proposal for Joint Forest Management (JFM) ${ }^{2}$ in Shyampura village was submitted to the Rajasthan State Forest Department and received their approval. This was the first village where JFM was undertaken by Seva Mandir (in JFM, the non-governmental organisation's role is envisaged as that of a facilitator). Paraworkers, block, zone and resource staff from the Centre were in constant contact with the village group, spreading awareness about the programme's objectives and benefits and the local people's roles and responsibilities. During their interactions, the staff realised that local people's understanding of the objectives of JFM was drawn, to a large extent, from their experiences of past government programmes. A typical programme would generate wage employment, initiate the creation of infrastructure and, on completion, disclaim any ownership in terms of maintenance or update. The people's perception of JFM focused on the labour that it generated at the physical works stage and the enhanced fodder availability due to soil and water conservation. It is still not unusual to find village groups approach Seva Mandir staff members with a request to initiate JFM activities to create employment opportunities within the village.

Partly due to the long gestation period of the forestry project and partly due to a lack of understanding and awareness, there was not much appreciation for the fact that the government wanted to share the responsibility for forest protection. This feedback from village groups was transmitted back to the resource unit in the organisation and incorporated in subsequent phases of planning.

Awareness building and training were strengthened through greater interaction and communication. To sustain the people's interest, some interim benefits were introduced in the project. JFM being restricted to degraded sites, the interim benefits from the land were few because of its decreased capacity to regenerate. Recognising this fact, Seva Mandir introduced some short-term programmes, undertaking non-forestry activities such as lift irrigation, pisciculture and the distribution of high-yielding varieties of seeds.

The process documentation illustration below indicates the value of documentation of organisational history. The story of Nayakheda (Box 4.2), for various reasons, can be considered a success in terms of Seva Mandir's efforts at building cohesive village institutions. A record of the processes that the village went through is, therefore, useful for drawing lessons for the future. 
Box 4.2 Nayakheda hamlet

Nayakheda is a hamlet comprising 30 households and is located about $25 \mathrm{~km}$ north of Udaipur. Despite Seva Mandir's efforts to create an environment for self-managed development, the group did not seem to make much headway due to the nature of local politics. The nexus of the local landlord, government officials and elected village council representatives was so powerful that it did not allow any avenue for the poor to undertake development activities, even with the help of Seva Mandir. A breakthrough came when the landlord was sent to prison on a murder charge. In his absence the village group, under the guidance of a committed and perceptive zonal worker, came together to take back some of the village commons that had been usurped by the landlord and to begin work on them. The zonal worker was able to mobilise the paraworkers (one of whom was eventually elected to the village council) as well as the rest of the community. He was in constant touch with the village as well as with the other staff of the organisation. Initially, cohesion of the people occurred primarily in relation to the development projects supported by Seva Mandir but, subsequently, the people's solidarity developed a life of its own (Mehta 1996).

Simultaneously, one of the staff members of the Process Documentation (PD) cell took up this village under the aegis of an agriculture project. She made regular visits to Nayakheda and was in touch with the people there. The zonal and other field workers talked to her about the political affairs of the village. Her documentation grew to comprise all aspects of village dynamics in an almost day-to-day time frame. Today, the story of Nayakheda stands out in the annals of Seva Mandir for the following reasons: the solidarity of the group in countering the landlord and the system, the commitment of the field staff in facilitating cohesion among the people even in the face of threat to life (by the landlord and his stooges) and the rich documentation upon which we can draw to learn from the unfolding of these events.

\section{Learning from research studies}

Seva Mandir has a tradition of carrying out research studies. The research programme draws heavily from the organisation's process documentation endeavour. However, it is distinct in that it begins with a predetermined objective of proving or disproving a hypothesis (very much like natural science research). The starting point of process documentation, on the other hand, is recording the operational course of a programme. 
Apart from in-house ventures, a large number of researchers and volunteers from other organisations have been encouraged to take up studies of their interest. In the next phase of its planning, the organisation proposes to initiate more in-house research. It has set up a Research, Monitoring and Evaluation Cell and looks forward to its input for organisational strategy planning and modification. Seva Mandir also utilises such efforts to learn about field realities and introduce mid-course corrections wherever possible.

Talai is one such village where the findings of an external research endeavour became the starting point for Seva Mandir to correct an uneven distribution of development benefits caused by concentration at some points of leadership. A recent study in Talai village conducted by a research scholar from the Institute of Development Studies, Sussex, UK, concluded that social capital in the village was organised around kinship lineage and that there was a concentration of benefits within certain lineage groups. The members of these groups had gained leadership positions through their associations with Seva Mandir.

Through ensuing discussions with the block and zone staff, it was decided that Seva Mandir needed to reinforce its presence in the hamlets that were being left out of the process of accessing benefits. The situation on the ground was assessed by the staff. They found, on establishing contact with these hamlets, that the problem was circular. Those who did not respond to Seva Mandir's effort to establish contact did not, as a result, get any benefits from interventions. Over time they stopped attending meetings organised by Seva Mandir because they harboured a grudge for being left out. At this point the organisation thought it critical to begin a dialogue directly with these people, rather than disturb the current leadership and risk the organisation's acceptance by the village as a whole.

\section{Learning from training programmes}

Training programmes are carried out by Seva Mandir for in-house staff and villagelevel functionaries from time to time on various subjects (Figure 4.3). While the ostensible function of training programmes is to build capacity of the participants, Seva Mandir has found that they also serve as excellent platforms for two-way information flows between the organisation and the trainees. Training for zonal staff, for instance, can be extremely rich in its feedback about the difficulties and constraints 
Figure 4.3 Training for village women

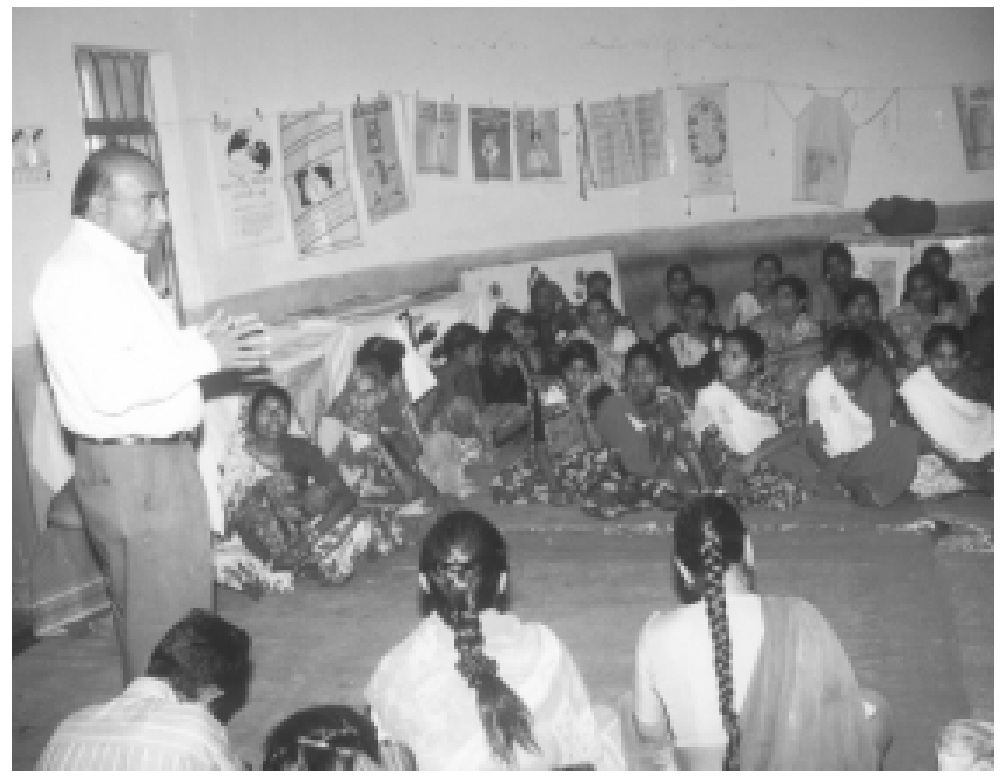

they face in implementing Seva Mandir's programmes in the field. Well-captured feedback can point towards strategies with sound potential and to those which may pose problems.

In the case of training programmes organised for village group members it has been observed that some groups, who are not used to being a part of discussions and training, take a long time to open up. Tapping the correct feedback requires some skill and perseverance. One reason for this is that villagers are often not clear about the destiny of their feedback and usually resort to saying the 'right' things. It is through frequent follow-up field visits and close interaction with the group that confidence is gradually built.

The training programme for women wardpanches (representatives in local government bodies) illustrated below was a vehicle that led to various areas of learning. While it was well-intended, it ended as a pointer to the faulty process of how training programmes were formulated (including the selection of trainers) and to the consequences that 
training programmes are destined to face if they do not examine and incorporate ground realities appropriately.

In the past year Seva Mandir was involved in a collaborative training programme for women members of twelve panchayats ${ }^{3}$. All these women had gained office as a consequence of a constitutional amendment that reserved a third of the seats in every panchayat for women. The result on the ground was that most of the women, who were illiterate products of a rigid patriarchal system, became dummy candidates for their powerful husbands and fathers-in-law.

The collaborating partner had designed the programme and a course module to encourage self-reflection and strengthen the identity of the women in order to build their confidence to participate in the panchayats. The paraworkers of Seva Mandir were first prepared for ten days to be trainers and in turn had to train women functionaries in a seven-day programme. The women's response was low to start with and dipped even lower during the course of the training. The paraworkers, too, were not comfortable with the training module, largely because they had never been trainers before.

The analysis of the project design pointed to the fact that the biggest failing of the programme was that it did not address any of the structural constraints that prevented women's participation in village politics in the first place. Training programmes are inadequate in empowering women when the wardpanches are the lowest rung of the village council structure and women among them are the weakest. Week-long training programmes do not address or resolve any of the day to day political and bureaucratic issues that these women must face.

\section{Learning from internal conflict and debate}

While the work on the ground provides rich feedback to the organisation, Seva Mandir has been alert to internal feedback as well. Senior managers invest time and initiative to ensure that they do not overlook the human resource aspect of development. Organisational conflict and debate has proven to be a potent source of input for strategy and planning. One of the missions of the organisation is to provide a platform for people from plural backgrounds to work together towards improving the conditions of the disadvantaged. This commitment has forced the organisation to look at changes 
not just at the community level, but also at modifications within the organisation triggered by those external changes. The multitude of backgrounds of the staff brings a diversity of skills to the organisation. The management's belief is that this abundance of expertise in different areas must not be lost by emphasising any one over any other. The organisation's experience speaks for itself in demonstrating the benefits of appropriate utilisation of skills, recognition of work and building of motivation.

The organisational transition recounted below points to the commitment to adapt to changing circumstances. It also demonstrates the senior management's recognition that in order for its staff to be motivated to better the lot of others, they must first feel secure in their own positions.

\section{Accommodating staff from plural backgrounds}

One of the drastic changes initiated within the organisation around the late 1980s was in the personnel structure. The organisation then (and largely now) was comprised of people from the local towns and villages. In the late 1980s, the organisation's field experience in trying to assist people in villages to gain entitlements pointed to the need to challenge the monopoly of the State in development work. As mentioned above, one of the responses to this insight was the decision to enhance the organisation's capacity to deliver development. To rise up to this need, Seva Mandir recruited people with professional degrees in rural management, engineering, social work and the like. Most of the new recruits were from renowned professional institutions in the country and were, by and large, products of privilege and opportunity. They had chosen to work in an organisation like Seva Mandir and could at any point exercise the option to work elsewhere. Due to the need to keep up with the market rates in terms of remuneration, the organisation decided to pay a higher salary to these young professionals than what many of the existing practitioners were earning.

These changes triggered a wave of redistribution of power and authority centres. The transition was not all smooth. The older people, some of whom had been with the organisation for nearly two decades, felt threatened by the introduction of a plurality of initiatives and authority centres. The senior management took these signals very seriously. It recognised the need to build the confidence of the staff who were expected, in turn, to empower people at the village level. The enthusiasm of the local staff, especially the field staff, seemed to wane when there was a threat of encroachment 
upon their authority. This was manifested in their unwillingness to cooperate with professional staff. Not all members of the staff could come to terms with the fact of having to share power with those who, until then, were strangers to the rural context.

With a view to assuaging such fear, the senior management held extensive and continual deliberations with the staff. The benefits of the new employees gradually became apparent and gained credibility with everyone in the organisation. The managers, in turn, gave credit to performance and integrity wherever it was due. Promotion norms were devised such that many people who had started from the level of community mobilisers and field supervisors moved up over the years and, today, occupy senior management positions in the organisation. Though some people in the staff still fondly look back to the time when there was less pluralism in the personnel composition, it is an accepted fact that this arrangement is supportive of furthering the agenda of empowering the local community (Seva Mandir 1998).

\section{Learning from interactions with government}

Seva Mandir has found that it can draw useful lessons not only from its own experience but also from that of other development agencies, including government. Seva Mandir studied the objectives and operationalisation of government experiments, such as Joint Forest Management, and found useful insights for its own institutionbuilding efforts. Wherever possible it has tried to affect policy by drawing on such lessons from the field.

The networking of Forest Protection Committees (FPCs) ${ }^{4}$ is an exercise triggered by many such experiences. Seva Mandir realised at some points of interaction with government that strong village-level institutions alone are sometimes inadequate. A 'higher order' institutional networking was deemed necessary.

The need to have a block level network of village Forest Protection Committees was recognised during the course of the organisation's work in JFM. Forest Protection Committees look upon the network as a higher level association that can deal more effectively with higher levels of the State Forest Department administration. Thus began Seva Mandir's efforts at organising the FPCs of one of the blocks into a blocklevel network called 'Van Utthan Sangh' (Forest Upliftment Federation). The role of 
the network is to show institutional support from the Forest Department through collective bargaining and negotiation, as in the incident reported below.

Some parts of the forest area of Bada Bhilwada had been encroached upon by people of the village as well as of the neighbouring village. The members of the FPC opposed this encroachment and visited the local forester to get action initiated against the offenders. The forester visited the site and convinced the encroachers to release the land. However, after a few days the encroachers returned. This time the FPC contacted the Van Utthan Sangh and with its support approached the Deputy Conservator to take action. He instructed one of the officers to visit the site along with the members of the FPC and the Van Utthan Sangh, and this time they successfully convinced the offenders to vacate the encroached lands for good. This case drives home the expressed need of village communities to have such a higher order institution.

\section{CONCLUSIONS}

Seva Mandir, in its 30 years of work, has had a variety of experiences, each with its potential to teach some lessons for the future. This chapter illustrates some of the ways in which Seva Mandir has tried to dissect these experiences into their causes and consequences. The organisation has been through a series of double loop learning processes, each leading to an enhancement of its ability to adapt and work with a range of stakeholders. Error, as defined in a learning organisation, has necessarily been treated as an essential source of information, as in the example of the distribution of benefits in Talai village or the training of women wardpanches.

Seva Mandir harbours a good deal of redundancy, in terms of its organisational and personnel structure, information system and performance standards. The organisation has been criticised for overlooking aspects of efficiency as management textbooks would define it. Perhaps, the experience of Seva Mandir suggests that efficient management in a conventional sense may not always be conducive to efficient learning. As Lee (1993: 102) states, 'Deliberately fostering diversity - learning in many different places, each supported in a different way, each pursuing its own mix of activities enhances the chance that important lessons can be learned somewhere'. Some functional ends have to be traded for others in the process. 
The fit among programmes, beneficiaries and the organisation as described by Korten (1981) is seen to emerge not only in the organisation's own functioning, but also in its constructive reaction to the government's development endeavour, especially in the case of Joint Forest Management. Seva Mandir has, however, not lost sight of the fact that the different stakeholders in the field must engage in open dialogue so as to be able to engender a more holistic approach. One of the reasons for initiating the Van Utthan Sangh was to facilitate such a dialogue among different players. Learning thus occurs not only about other stakeholders, but in collaboration with them. Collaboration also appears to be strengthened by taking such an approach.

Seva Mandir's learning process appears to have two distinct components built into it-one moving towards short-term learning and the other feeding into long-term paradigmatic shifts in the organisation. For instance, in the initial stages of the organisation's work, it assumed that a certain degree of social capital exists within village communities which could be used as a base for development. All activities and learning were located within this paradigm. Today, the organisation has learned from its experience that social capital is not necessarily present within a community and concerted effort is required to hone it. The paradigm within which the organisation works incorporates the mandate of building solidarity within village communities.

\section{ACKNOWLEDGEMENTS}

I would like to thank the East-West Center and the Center for International Forestry Research, especially Jefferson Fox, Louise Buck, David Edmunds and Sonja Brodt for their encouragement and academic assistance. Sonja, my supervisor, has been extremely supportive and has prodded me to give a semblance of order to my thoughts.

I thank Seva Mandir for giving me both the opportunity to participate in this workshop and for the experience to document the chapter. It is impossible to recount names of all those people who make a paper like this, right from village groups to staff members. The contribution of my team members - Neelimaji, Bhise Sb., Mamta and Neeraj-in terms of moral support, ideas and documentation assistance has been immense. I am immensely grateful to Ajay Sb. for his faith in my capabilities. The long distance assistance of Poonam and Bhatiji from Udaipur has been invaluable, especially at the last, panic moments. 


\section{ENDNOTES}

${ }^{1}$ A cluster of 5-7 zones, each comprising 10-15 villages.

${ }^{2}$ Joint Forest Management is the operational guideline of a change in forest policy issued by the Government of India in 1990 and adopted by various states, Rajasthan being one. The aim is to empower forest dwellers and increase their access to and control over the use and management of forest resources, which were once under the exclusive domain of the State. It also aims at ensuring the participation of local communities and at improving their livelihood options by giving them employment opportunities within the village (Natural Resource Development Unit n.d.).

${ }^{3}$ Local village council.

${ }^{4}$ The JFM guidelines lay down the constitution of Forest Protection Committees (FPC) on the basis of a revenue village, having rights over a particular patch of forest to meet its fuelwood, fodder and timber needs. Membership of the FPC is open to one adult of each household.

\section{LITERATURE CITED}

Bruce, R. and Wyman, S. 1998 Changing organizations: practicing action training and research. SAGE Publications, Thousand Oaks, California, USA.

Korten, D.C. 1981 Rural development programming: the learning process approach. In: Korten, D.C. and Klauss, R. (eds.) People-centred development: contributions toward theory and planning frameworks, 176-188. Kumarian Press, West Hartford, Connecticut, USA.

Lee, K. N. 1993 Navigational lore: expectations of learning. In: Compass and gyroscope: integrating science and politics for the environment, 136-160. Island Press, Washington D.C., USA.

Maarleveld, M. and Dangbégnon, C. 1998 Managing natural resources in face of evolving conditions: a social learning perspective. Paper presented at 'Crossing Boundaries', the seventh conference of the International Association for the Study of Common Property, 10-14 June 1998. Vancouver, Canada.

Maturara, H. R. and Varela, F. J. 1987. The Tree of Knowledge-The Biological Roots of Human Understanding. Boston: New Science Library.

Mehta, A. S. 1996 The micropolitics of development - anatomy of change in two villages. Seva Mandir, Udaipur, India. 
Natural Resource Development Unit. n.d. Experience of Seva Mandir JFM. Seva Mandir, Udaipur, India.

Seva Mandir. 1998 Third comprehensive plan, 1999-2002. Seva Mandir, Udaipur, India.

Woodhill, J. and Röling, N.G. 1998 The second wing of the eagle: the human dimension in learning our way to more sustainable futures. In: Röling, N.G. and Wagemakers, M.A.E. (eds.) Facilitating sustainable agriculture: participatory learning and adaptive management in times of environmental uncertainty, 46-71. Cambridge University Press, Cambridge, UK. 
SEVAMANDIR: ALEARNING ORGANISATION 


\title{
Chapter Five
}

\section{Institutional collaboration and shared learning for forest management in Chivi District, Zimbabwe}

\author{
Nontokozo Nemarundwe
}

\begin{abstract}
This chapter examines processes of collaboration among institutions for communal woodland management at the local level in Zimbabwe and explores how these processes influence sustainable resource utilisation. I discuss how institutions adapt to changing social and environmental conditions. Based on case study evidence, I argue that community-based natural resource management works best in a context of institutional collaboration and shared learning. I identify three requirements for collaboration: the need for effective facilitation of experimental learning, equal power in the learning process and the willingness to engage in a multi-stage process that can be costly.
\end{abstract}

\section{INTRODUCTION}

Failure to achieve sustainable natural resource utilisation has been attributed to the continued focus on management without consideration of the institutional framework within which that management is effected (Ostrom 1990; Sithole 1997). In this chapter, 
I examine the applicability of theories of common property resource management and adaptive management to institutional issues in the management of communal woodland resources in Chivi district, Zimbabwe. I examine two aspects of the growing literature on local institutions for natural resource management. First, I discuss the processes of collaboration among institutions for woodland management at the local level and how these processes influence sustainable resource utilisation in the context of communal lands. Many authors express an increasing interest in understanding conflicts over resource utilisation with regard to centre-local relationships (Fisher and Jackson 1998; Matose 1994; Matzke 1993; Moore 1993). While these relations are very important, it is easy to overlook how institutions operating at the local level collaborate before and after they interact with external agents. The consequences of this neglect are best illustrated in cases where external agents attempt to construct new local institutions, often following the principles of Ostrom and others, without understanding the potential relationships between these institutions and other, pre-existing local institutions, such as traditional authorities.

Second, I discuss how local institutions adapt to changing social and environmental conditions. Ostrom $(1990,1998)$ focuses on local level institutions in her design principles, which are explicit about the features of enduring institutions. Her design principles are not, however, very explicit about how institutions adapt to ever changing environments. Although Ostrom talks about constitutional change as a way of responding to changing circumstances, there are no clear guidelines as to how such change should take place. In this case, social learning theory (Röling and Wagemakers 1998) can be adopted to complement Ostrom's conceptual framework, as it contributes insights as to how local institutions can adapt to changes over time.

Based on case study evidence from Romwe in Chivi communal lands, southern Zimbabwe, this chapter argues that community-based natural resource management works best in a context of local level institutional collaboration and shared learning. I describe the changes in local level collaboration and learning introduced through use of the kuturaya approach, a participatory means of experimentation (Chuma et al. 1997; Hudson 1981). The case demonstrates that learning-by-doing is key to collaborative management. The focus for collaborative management, therefore, should not be on establishing institutions that endure, but on creating institutions that adapt. 


\section{BACKGROUND}

\section{Conceptual framework}

Two contending discourses have dominated the inquiry into Common Property Resource (CPR) management. The first contends that collective use of natural resources is a disincentive for investment in sound management. This viewpoint argues that common property is equivalent to open access tenure arrangements, and therefore people have little incentive to work for long-term productivity or environmental gains. Hardin's (1968) 'Tragedy of the Commons' idea has been very influential in the propagation of this view.

Identifiable groups of interdependent users of a given common property resource are assumed to have a strong stake in the collective management of the resource (McCay and Acheson 1987; Ostrom 1990; Lawry 1989). This view has informed democratised visions for sustainable management of natural resources, particularly in rural areas of developing countries where power over land and natural resources has been usurped by the state or its arms (Mandondo 1997).

In the common property literature, institutions are thought to shape human behaviour in relation to resource use. The term institutions is here used to refer to resource management organisations or authorities. In this chapter, organisations or authorities are defined, following North (1990), as governance structures that are established to manage human interaction. Rules and regulations are treated as institutional arrangements. Institutional arrangements often form the basis for guiding the activities of an organisation, though they may also be informal, and not associated with any specific organisation. The rules and regulations in use by a community determine who has access to common pool resources, what use-units authorised participants can consume, at what times and who will monitor and enforce these rules (Ostrom 1998). This study covers both formal and informal institutions and institutional arrangements.

The CPR literature pays scant attention, however, to collaboration among local institutions. Yet throughout Africa, a variety of traditional institutions exert influence on decision making at the local level (Berry 1989). Traditional institutions also often co-exist with introduced institutions. Understanding the conditions under which these local institutions collaborate or compete with each other and with new institutions 
working at the local level will improve the chances of sustainable forest management in areas where the institutions share responsibility.

One such condition of collaboration might be a shared approach to learning and adaptation. While much of the CPR literature provides insights on how local level institutions may be constituted and sustained, it is not explicit about how they adapt to new situations (McCay and Acheson 1987; Ostrom 1990). As Cleaver (1999) argues, most of the CPR literature treats institutional issues in a static perspective and not as a living tradition. Mandondo $(1997,1998)$ has also questioned the lack of dynamism in much of the literature on local institutions. He argues that the issue of appropriateness of institutions appears to have been driven by the quest to attain enduring institutions. He further stresses that 'in the context of variegated and ever changing resource use contexts, it may be more useful to aspire to adaptive institutions instead of those that simply endure' (1998:18).

Social learning theory becomes relevant in this context as it can enrich the CPR approaches to institutional analysis. It provides insights about how institutions can evolve to deal with changing circumstances (both social and environmental). Social learning is a 'framework for thinking about knowledge processes that underlie social adaptation and innovation' (Woodhill and Röling 1998:64). Where interest groups are interdependent and environmental chance is uncertain, the effects of management may be unpredictable for all groups concerned. An adaptive or learning approach enables an iterative approach to dealing with uncertainty that minimises risks based on matching actions to the information available. The social learning framework highlights the importance of group learning for collaborative natural resource management. Meaningful interaction and communication between individuals and groups (including different local level institutions) is central to the social learning process.

\section{The study area}

The study was conducted in the Romwe Catchment located in Chivi District, Southern Zimbabwe (see Figure 5.1). The catchment is about $4.5 \mathrm{~km}^{2}$ in size and home to about 50 households. Chivi District is characterised by low rainfall, poor soils for agricultural production and seasonal droughts. Being quite dry, it is not very conducive for agricultural production, creating competition for woodland resources such as fruit, honey and wood 


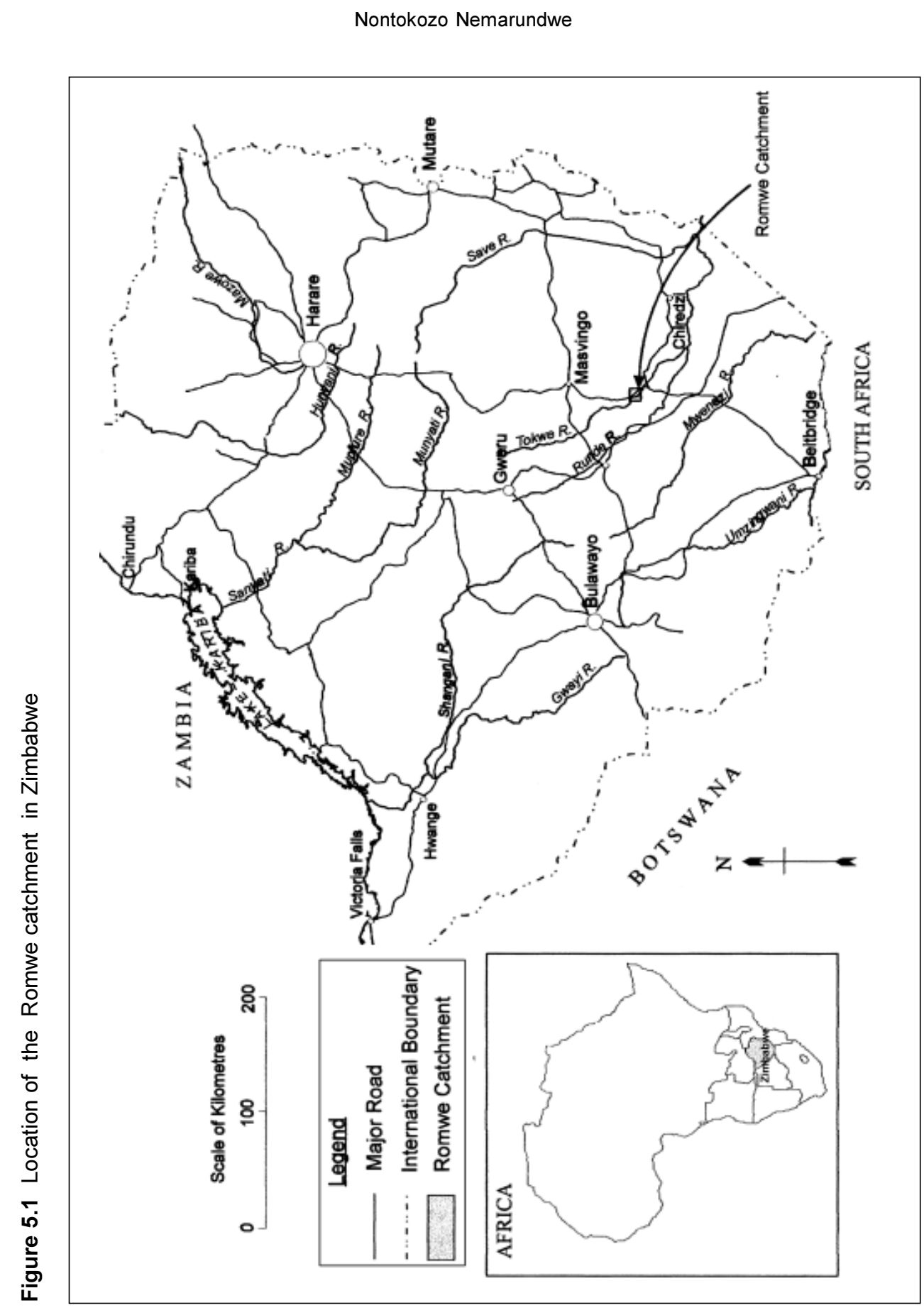


for carving. The resulting uncertainty associated with resource use suggests the need for a flexible, adaptive approach to management.

Changes over time in population and land pressure in the area add complexity to community-based resource management and the related local resource management institutions. The district was a site for forced in-migration during the early 1950s as a result of the designation of some land as commercial farming areas. The current population comprises Shona- and Ndebele-speaking people with different ethnic backgrounds. The different ethnic groups have different belief systems and patterns of resource use. In-migration and ethnic diversity pose challenges to collaborative resource management at the local level, and suggest the need for institutions that can adapt to changing social conditions.

Administratively, the catchment area lies in Wards 23 and 25 of Chivi District. The administrative, traditional authority, and the resource use boundaries do not coincide with one another. Three villages ( $k$ raalheads) fall under the Romwe catchment, namely Dobhani (Ward 25), Sihambe (Ward 23) and Tamwa (Ward 23). Two of the three kraals are only partly contained within the catchment: Sihambe, situated on the northern side, and Dobhani, on the southern side. Such administrative overlap indicates both the difficulty and necessity of effective collaboration among local institutions (Table 5.1).

At the local level, there is a multiplicity of institutions involved in woodland management. These include state-supported extension organisations or parastatals, local government structures and the traditional authority. Non-governmental organisations (NGOs) and research groups are also identified by the community as relevant institutions. The various roles and responsibilities of these institutions have evolved at different times. Figure 5.2 illustrates the relationships among the woodland management institutions found operating in the study village.

The existence of multiple institutions for woodland management makes collaboration at the local level difficult. Their changing mandates, interests and power to influence resource management also suggest that no one form of collaboration can remain viable for long. Mechanisms are required to enable the process of collaboration itself to be flexible. 
Table 5.1 Women's ranking of importance of institutions operating in the Romwe catchment area

\begin{tabular}{|c|c|c|}
\hline Institution & Rank & Reason for the rank \\
\hline $\begin{array}{l}\text { Sabuku/ } \\
\text { chiefs }\end{array}$ & 1 & $\begin{array}{l}\text { Set rules that guide people on resource use; they are generally } \\
\text { respected; they allocate land; resolve disputes which enable the } \\
\text { community to live in harmony; owners of the land }\end{array}$ \\
\hline $\begin{array}{l}\text { Councillors/ } \\
\text { VIDCO }\end{array}$ & 2 & $\begin{array}{l}\text { Spearhead development by forwarding village members' requests } \\
\text { to the Rural District Council }\end{array}$ \\
\hline Health services & 3 & $\begin{array}{l}\text { Provide treatment, midwifery and immunization services, although } \\
\text { people have to pay for some of the services especially at the } \\
\text { hospital; health services are provided throughout the year }\end{array}$ \\
\hline $\begin{array}{l}\text { CARE } \\
\text { International }\end{array}$ & 4 & $\begin{array}{l}\text { Provides tools for rehabilitating dams through the food for work } \\
\text { programme-these benefit people and improve water supply for } \\
\text { livestock; they are based outside the village but come frequently }\end{array}$ \\
\hline Church & 5 & $\begin{array}{l}\text { Teaches people good morals; helps keep families together; gives } \\
\text { moral support during illness and when death occurs in the family }\end{array}$ \\
\hline Teachers & 6 & Provide education to children which is vital \\
\hline Agritex & 7 & $\begin{array}{l}\text { They are always in the area; they assist in fields and gardens; } \\
\text { have effective extension; work well with people; peg fields; have } \\
\text { open interaction with people and cover a wide area }\end{array}$ \\
\hline Researchers & 8 & $\begin{array}{l}\text { Carry out research in small areas; deal with a few people, e.g., } \\
\text { field trials in few fields; provide the community with transport }\end{array}$ \\
\hline $\begin{array}{l}\text { DNR } \\
\text { Jengetavhu }\end{array}$ & 9 & $\begin{array}{l}\text { Has a local representative who is supposed to work with the } \\
\text { kraalhead police. Rarely enforces fines, e.g. for starting fires, which } \\
\text { is considered a serious offence in the village }\end{array}$ \\
\hline $\begin{array}{l}\text { Zimbabwe } \\
\text { Farmers Union }\end{array}$ & 10 & $\begin{array}{l}\text { Not well known in the area; come during the growing season only; } \\
\text { sell seeds-only a few people benefit; membership fees have to } \\
\text { be paid }\end{array}$ \\
\hline ZINATA $^{1}$ & 11 & $\begin{array}{l}\text { Visits to ng'ngas (ZINATA) are made secretly; they are not open; } \\
\text { make claims that cannot be proved, e.g., that they can cure AIDS; } \\
\text { very few people still rely on or visit ng'ngas }\end{array}$ \\
\hline
\end{tabular}


INSTITUTIONAL COLLABORATION AND SHARED LEARNING

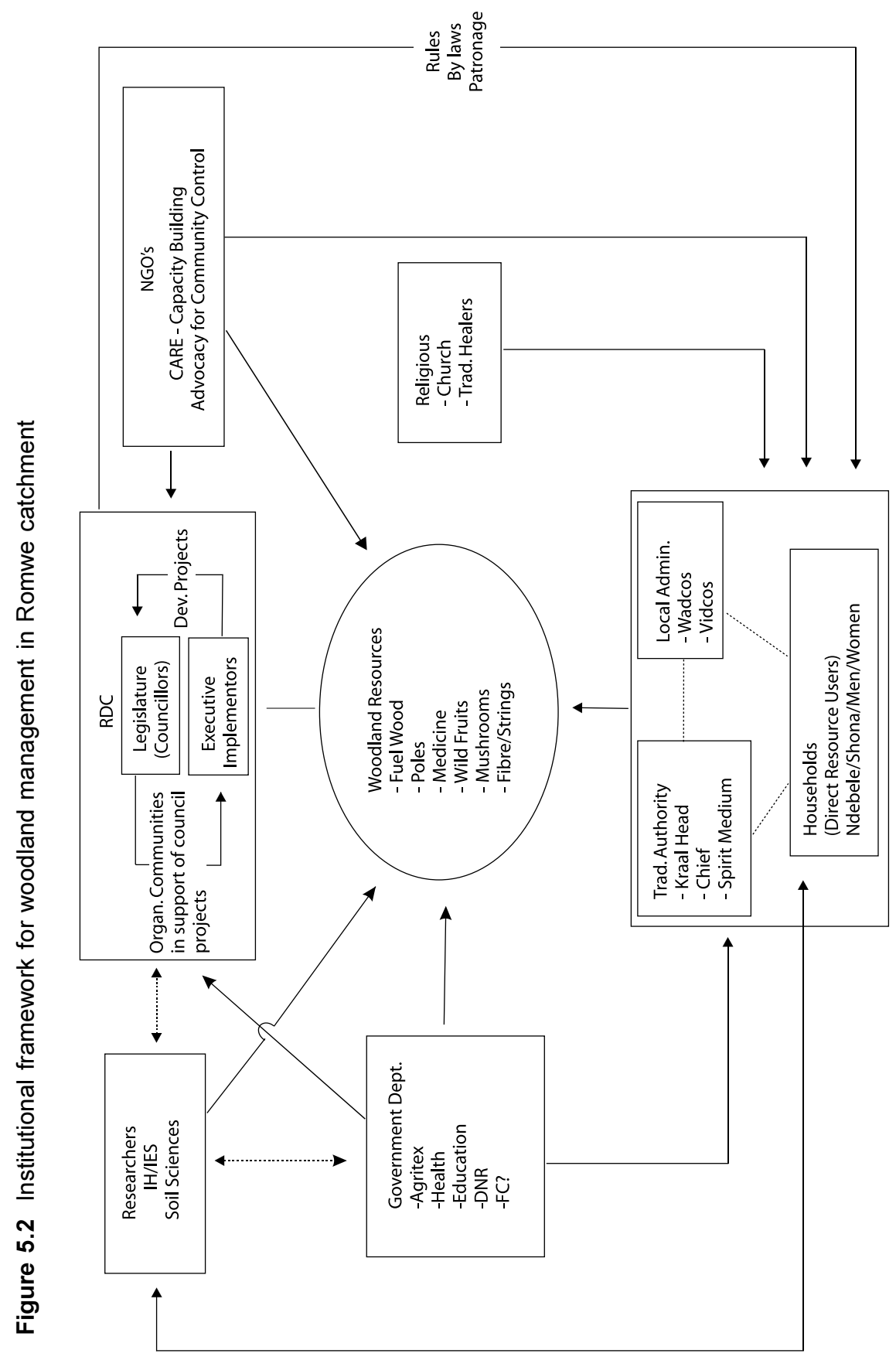




\section{THE ROMWE CATCHMENT CASE STUDY}

I participated in the processes described below as a researcher, with an interest in both participatory research methods and participatory natural resource management techniques. I have been working in the area for one year and am affiliated with the Institute of Environmental Studies, a research institute with a long-term commitment to the Romwe Catchment. Working with a team of four researchers, data collection methods included literature reviews, key informant interviews and participatory rural appraisal techniques. The study was undertaken from July 1998 to July 1999.

This section presents the case from Romwe to illustrate attempts at centre-local collaborative management that have worked and attempts that have not worked. I explain the reasons for their outcomes. The case demonstrates that an absence of collaboration among local institutions can lead to unsustainability. Even where local institutions, both traditional and newly created, embody many of the design principles described by Ostrom $(1998,1999)$, the Romwe case suggests that a social learning approach to management is one way to overcome current differences in institutional priorities, sources of support, legitimacy and culture, and to encourage effective collaboration.

In Romwe, both traditional institutions and newly created village development committees (VIDCOs) and ward development committees (WADCOs) match most of Ostrom's criteria for enduring institutions. ${ }^{2}$ Such institutions should have a good chance of sustainably managing common property woodland in the catchment. Traditional authorities, VIDCOs and WADCOs have their boundaries clearly established, even if these are not the same boundaries for the different institutions. Though the distribution of costs and benefits related to woodland management in each is not perfect, it is reasonable compared with other local institutions discussed in the literature (Dzingirayi 1997). Traditional authorities, VIDCOs and WADCOs all have monitoring and conflict resolution mechanisms in place, as well as methods for making collective choices about management practices. Traditional authorities are not as clearly nested within larger government structures as VIDCOs and WADCOs, but they are recognised to some extent by government. While both the VIDCO/WADCO structure and the traditional leadership, especially the sabuku (kraalhead), meet many of Ostrom's design principles, in the absence of collaboration, resource management efforts at the local level have not been successful. 
INSTITUTIONAL COLLABORATION AND SHARED LEARNING

\section{Management that failed: The case of settlement in grazing areas in Romwe}

During the 1950s and 1960s, three traditional authorities were concerned with resource management: the sabukus of the Ndebele and Shona, Shona headmen and a Shona chief $^{3}$. These traditional authorities were generally effective in the distribution of resources such as land and in resolving disputes such as boundary friction occurring at the household level. The traditional authorities also governed the use and management of woodlands. According to local people, cases of norm breaking were very limited. Although traditional authorities had some interaction with extension workers and the district administrator, they had autonomy in management at the local level. This reduced the incidence of offenders, as the control system was clearly defined. Many villagers, for example, claim that during that time, everyone respected sacred areas of the Shona, even recent Ndebele-speaking in-migrants, for whom these sacred areas were not culturally important.

During the peak of the war of liberation in the 1970s no other institution had control over resource use except the guerillas. The traditional authorities were weakened. The absence of strict control over resources such as the woodlands and grazing areas encouraged some people to settle in grazing areas. Extension workers were not operating in the area during this time. The period immediately after independence is referred to by local people as mazvakemazvake (each person for him/herself). During this time, no institution existed to govern woodland resource use. Much deforestation occurred, which spurred the government to create a central forestry authority and corresponding regulations.

As part of the government's subsequent decentralisation process, however, and in an effort to better control forest use, new local government structures were created in 1982. These were the popularly elected village development committees (VIDCOs) and ward development committees (WADCOs), which are legally mandated to monitor resource use. Forestry and agricultural extension agents, for example, consult with these committees to resolve the problem of woodland conversion into arable land. On the ground, however, some traditional leaders still have more respect from community members and have their own rules and regulations, although these are not on paper. Although the traditional authorities were weakened during the war, and continue to lack legal recognition, they have retained much of their legitimacy after independence 
(Government of Zimbabwe 1994; Mandondo 1998). They continue to exert significant influence over resource management, including over issues such as the conversion of woodlands to grazing areas. In fact, many offenders have ignored VIDCO/WADCO rules on conversion of woodland because they pay more allegiance to traditional authorities.

The presence of multiple local authorities has led to conflict over the use of common pool lands. Box 5.1 presents a case of individual privatisation of a common pool land resource that has traditionally been used by community members for woodland products such as firewood, poles, fruit and fibre. This privatisation occurred partly as a result of overlapping authority of resource management institutions.

\section{Box 5.1 Mr. Jonasi Dube's case ${ }^{4}$}

My father settled in the area in 1963 when land was abundant. When I got married in 1989, he gave me part of his crop fields. The land had been overworked and was barren, so I felt I could not live on such poor soil. I went to work in South Africa as a migrant worker and when I came back in 1995 I asked my sabuku to allocate me a piece of arable land. The sabuku referred me to the VIDCO chairman, who gave me permission to clear part of Barura hill as a crop field. The area is rocky and sloping, so last year I went back to the sabuku to ask for better land to establish a vegetable garden in the grazing area and explained to him that the VIDCO chairman had given me land with very poor soils. The sabuku said if it was for the welfare of my family I should go ahead. So I fenced off a small piece of land in the grazing area which was being used as a road for carts. I opened up a detour which the carts could use to go around my garden. I dug a well in the middle of the garden so that I could have a reliable source of water all year round. At the present moment (July 1998), the well is more than $5 \mathrm{~m}$ deep and produces about 400 I of water every two days. Other villagers cannot collect water from my well. I want to use it to grow vegetables to sell to big supermarkets in Masvingo. Other villagers are complaining that I fenced off an area which they used in the past and they are not getting water from my well. The case was reported to the sabuku, but he said the councillor should resolve such issues. Nothing has been done and I continue to use my garden. 
This case is one of many in which young land seekers liase with one of the local institutions to get land in the absence of consensus. Although there has been a slow process of encroachment on common lands since independence (1980), the incidence of such cases rose dramatically in 1993-4. This increase may have been stimulated by a decrease in urban employment after many companies closed down as a result of economic hardships partly caused by the economic structural adjustment. A high level of woodland conversion occurred as a result of the ensuing settlement in grazing areas and lack of control over grazing. The availability of many woodland products has since declined. The existence of the traditional authorities (chiefs and sabukus) and statutory institutions (VIDCOs and WADCOs) without well-defined mandates and artculation processes, and their reliance on contrasting sources of legitimisation (customary versus state) have caused conflicts that have undermined the scope for coordinating land use decisions. These sorts of conflicts have persisted over time, indicating that the VIDCOs and WADCOs have not effectively learned how to work with other local authorities. Other conflicts that villagers have identified as resulting from a lack of institutional collaboration include cultivation of fragile areas such as stream banks and a lack of respect for sacred areas that traditionally served to protect diverse tree species.

The decentralisation process therefore lacked mechanisms to allow for the government institutions to learn about and coordinate with an existing key institution at the local level, the sabuku. Even if they recognised the existence of the sabukus, government and extension agents had no mechanism or incentive at the time to involve the sabukus in the planning, action, monitoring and evaluation necessary for group learning (Gilmour and Fisher 1997). It took more than ten years, from the early years of independence to the time of the Land Tenure Commission in 1994, for extension agents and local government to recognise the need to involve the traditional authority in natural resource management initiatives and to learn from their shortcomings. If the agents and other government officials had established a system to help them learn and reflect on their actions, they probably would have been better able to recognise the influence of traditional authorities earlier and might have avoided many years of chaotic woodland conversion. 


\section{Management that worked: Adopting the kuturaya (experimentation) approach}

It was in this context that in 1999 villagers from Romwe, together with traditional leaders, VIDCOs and extension workers, adopted an experimental approach for tree and grass planting for rehabilitating an area that was traditionally used for woodland resources. This approach was taken up after a group look and learn visit to a neighbouring village, where an experimental approach to soil and water conservation, known as kuturaya, had been adopted.

Kuturaya is a Shona term for 'trying out'. It is a participatory research and experimentation approach introduced in Chivi District, Ward 25 by extension agents after a realisation that conventional extension methods were not effective (Chuma et al. 1997; Chuma et al. 1998). It operates under the philosophy that farmers need to understand and share their views about the dynamics of their environment and the biophysical processes at work in order for them to have a higher capacity to generate land husbandry solutions. Farmers must have access to a variety of ideas and technical options so that they can experiment with and identify the strategies most suitable for their own context.

Key elements of the kuturaya approach include:

1) Enhancing farmers' creativity and their capacity to use technical principles, elements and ideas to arrive at a solution appropriate to the situation.

2) Reducing farmers' dependence on the knowledge of extension agents and promoting information sharing.

3) Encouraging farmers to learn by doing by being involved in action and debate. People learn more in a process of action, reflection, self-evaluation and new action.

4) Motivating various interest groups to analyse their situation together.

5) Using a facilitator, especially during the initial stages of the project.

Various strategies have been used to encourage the group social learning process. These include: 
Resource management experiments. In the kuturaya case, farmers engage in a number of soil and water conservation experiments. One example is the simple paired design experiments for comparative purposes (Chuma et al. 1998). In this case, conventional practice and new ideas are compared by placing them side by side in the field. Both sites are monitored closely and the farmers analyse what they see. This leads to an understanding of the processes and factors that influence the performance of technologies and is referred to, by Chuma et al. (1998:33), as learning by experimenting.

Community workshops. Conservation awareness is raised through debate and joint analysis of change during community workshops. The social learning process creates shared visions formulated by the group and makes plans for working towards those visions. This form of learning focuses mainly on evaluating the impacts of a management practice on the resource being managed. Community workshops also increase interaction among the various interest groups, however, which helps institutions to build trust and to learn about how to collaborate with other institutions.

Use of metaphors and folklore. A key feature of both Shona and Ndebele cultures is the use of figurative language and folklore. Traditional leaders, especially, have found metaphors and folklore to be useful during joint analysis meetings to communicate the concept of learning-by-doing. One sabuku told the following story: 'Once upon a time, there was an old lady from Chivi. During a year of hunger, the lady searched for fruits, small game and tubers, but could not find any. Finally she decided she should cook stones, maybe they could become edible. So she cooked the stones and to her joy, they produced a tasty soup' (Chuma et al. 1998:31). This story was used as an illustration of the idea that trying out seemingly far-fetched things is not a new concept, but has been known and encouraged in their traditional society. This lesson has motivated the villagers in Romwe to participate in experimentation with tree and grass planting in the most degraded parts of the grazing areas. Other metaphors and stories have been used to create shared understanding among different interest groups about the importance of access to firewood, fruit, fibre, fodder, honey and medicinal plants found in the woodlands, and how various management activities affect different interest groups. 
Group look and learn visits. Woodhill and Röling (1998) argue that village-to-village interactions are a platform for learning for villagers that increases the chance of local level collaboration. Learning across communities can also enable institutions to adapt to change. The Romwe group look and learn visit described below supports Woodhill and Röling's argument.

Look and learn visits involve travel to a site by representatives of diverse local institutions to exchange ideas with others confronting similar resource management problems. The visits can provide insights about specific technical solutions to management problems, but are perhaps most useful as a platform for 'double loop' learning (Maarleveld and Dangbégnon 1998). Double loop learning occurs when institutions change not only their actions, but also their assumptions on which practices have been based, as a result of some feedback mechanisms (Maarleveld and Dangbégnon 1998:5; Datta, this volume). Creating such platforms for double loop learning can help institutions adapt to changing circumstances by facilitating periodic and systematic evaluation of their fundamental principles and work habits. Look and learn visits can act as such a platform by exposing institutions to others operating under different assumptions and strategies.

\section{Trying out the kuturaya approach in Romwe: Tree and grass planting in the degraded parts of the grazing areas}

As described above, random settlement in grazing areas and uncoordinated grazing have resulted in the degradation of areas traditionally used as a source of woodland products, and for controlled grazing. Early attempts by extension agents to prevent degradation were not successful. Having seen the kuturaya case in the neighbouring village, extension workers and some researchers organised a look and learn visit to the project for Romwe representatives in early 1999. The goal was to help them in thinking about how to solve their own environmental problems, especially in the grazing areas. The group that visited the project included traditional authorities (represented by sabukus), the VIDCO chairperson, government councillors, Agritex workers, NRB representatives and some researchers from the University. 
During the visit, discussions were held with the farmers participating in kuturaya who shared their experiences with the experimentation process. They described both successes and problems they experienced during the process (see Box 5.2). Field visits had the most visual impact on the visitors. The Romwe group expressed surprise at the progress the kuturaya farmers had made. They were motivated and determined to engage in a similar experimentation process in the context of woodlands and grazing management.

Box 5.2 Successes and challenges of the kuturaya project

The kuturaya project has largely been considered a success. However, the experimental approach has created new challenges for the people involved, especially the villagers, related to their time and labour inputs for experiments and to managing information about the project within the community. Following is a quote from Mr. Isaac Siziba. 'Prior to independence, we were forced to construct contour ridges. We were told that this would prevent soil erosion in our fields. We didn't really understand why we had to dig the contours and this was very labour intensive as well. At independence most people deliberately destroyed the contour ridges because we saw this as one of the ways of the oppressors. During the mid 1980s, we were taught by agricultural extension workers new cropping methods such as planting in lines which they said will assure us of good yields. We did not understand these and we were also hesitant to adopt them. Now, after having engaged in the experimentation process, together with extension workers, we have discovered ways of conserving our soils, we get higher yields than before and we have a better understanding of our environment. We have discovered that building check dams in rills, leaving grass strips and creating small barriers to prevent concentrated flow from anthills are more effective than the standardised mechanical designs such as the contour ridges. We now understand better the causes and effects of soil erosion and we are able to monitor the experiments ourselves. This has also given us a chance to interact with people from all over the world as they come to visit our project.

Despite all this we have also faced some challenges here and there. I remember the first time we made the small barriers to prevent concentrated flow from anthills, they were too small and they got washed away when heavy rains fell. We had to reconstruct these and it takes a lot of time, labour inputs and patience. Although it is a good thing that we have many visitors coming to see our project, it is also time consuming because we have to spend some time with them. Jealousies also arise, for instance when some people feel that external agents interact more with the community representatives. We try to guard against this by being open and holding regular meetings so that people are kept informed.' 
After returning to the village, a meeting was called and representatives that had visited kuturaya shared their experiences. After some lengthy discussions, the community decided that its members should begin experimenting by planting trees and vetiver grass in one degraded area of the village (Figures 5.3, 5.4 and 5.5). Some community members have been chosen for monitoring to ensure that livestock does not destroy the seedlings. Since the project is in its initial stages, no formalised monitoring and evaluation plans have been put in place. There is therefore a need for both internal and external agents to develop monitoring tools and techniques and for community representatives to implement them. Currently the process is being facilitated by extension agents and researchers from the University of Zimbabwe. Other institutions involved include the traditional authority, VIDCOs and WADCOs, members of the community and CARE International. Some of the tools and techniques used in the kuturaya project, such as community workshops, the use of metaphors, folklore and role plays, field days, look and learn visits and other participatory resource management tools will be adopted as appropriate.

Figure 5.3 Degraded gully to be reclaimed

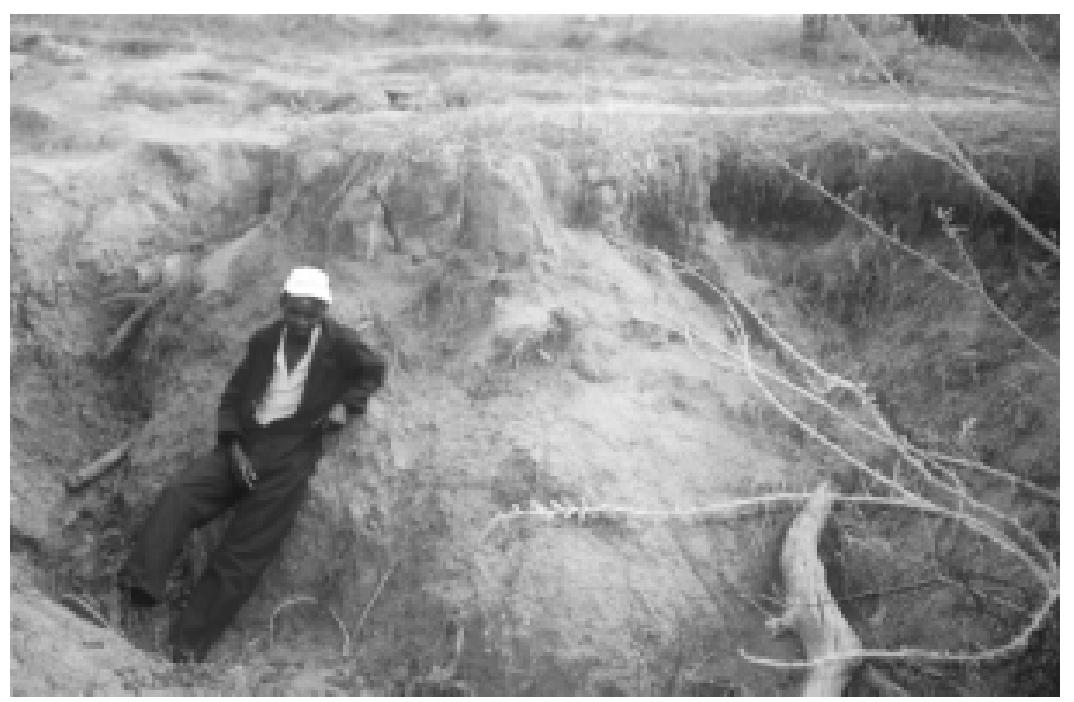


Figure 5.4 Grass donated after the visit to Kuturaya project

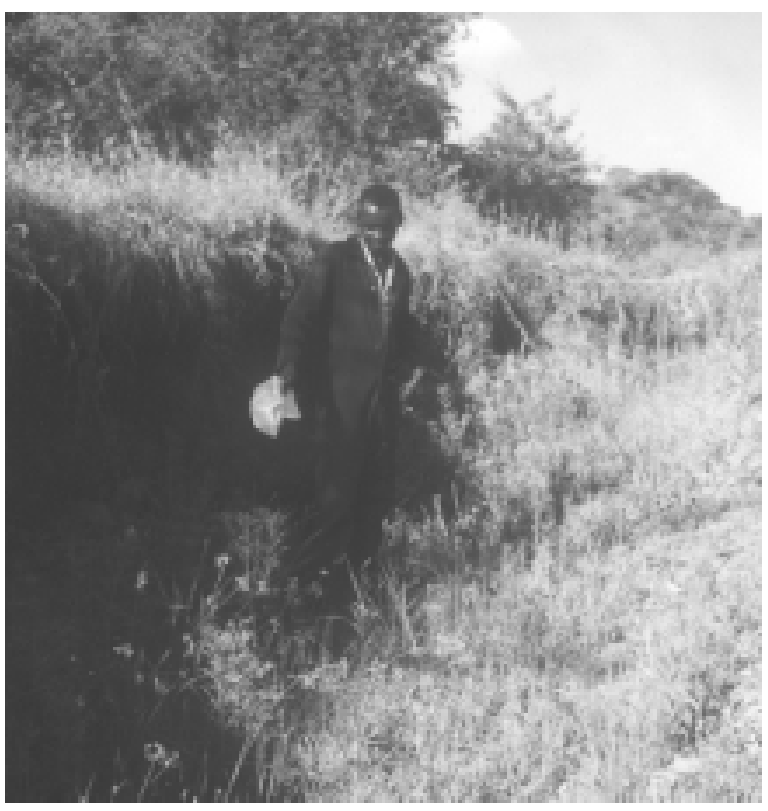

Figure 5.5 Attempts to reclaim gully with vetiver grass

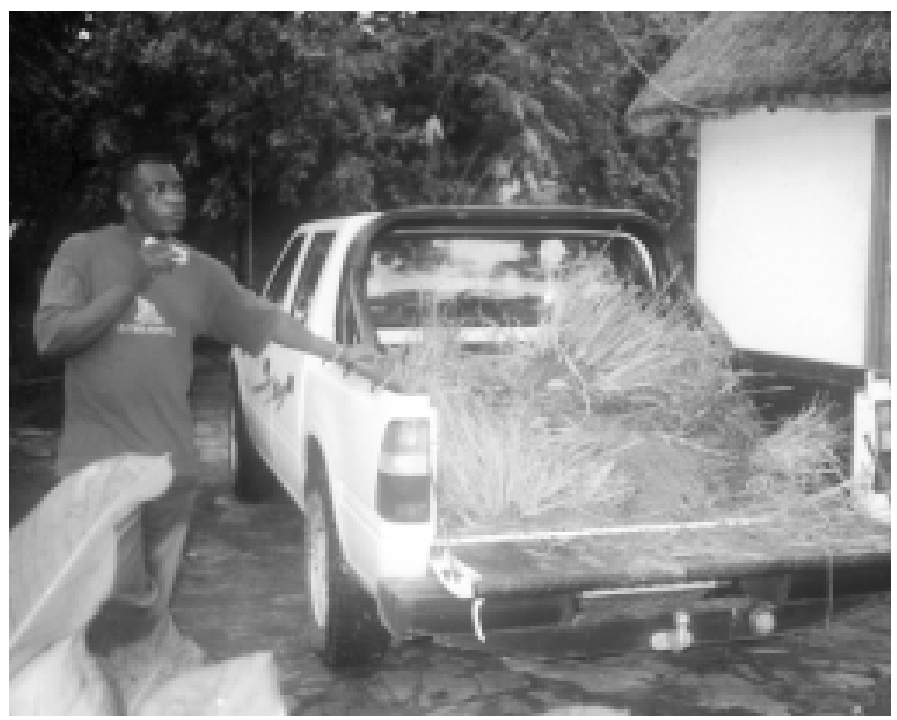


The organised look and learn visit to the kuturaya project helped people and institutions operating in the area to collaborate in resource management based on sharing of experiences in the experimentation process. Joint participation in community workshops, field days and look and learn visits has helped to build trust among institutions and to develop shared understanding of the problems facing different interest groups. The experimental approach has also helped form the basis for joint monitoring and evaluation of different types of management, and may lead to more collaborative decision making. Although the approach is still new, the impact on improved collaboration can already be felt.

The adoption of kuturaya illustrates the importance of organised interaction for group learning. The kuturaya process has been ongoing for more than five years now in the village next to Romwe catchment. Individuals from Romwe have previously had interactions with farmers involved in kuturaya without adopting the approach. It was only after the group look and learn visit to that village that the Romwe institutions really learned from kuturaya. Much of the degradation of Romwe's woodlands could perhaps have been avoided if a collaborative learning approach had been adopted earlier.

\section{CONCLUSIONS}

This chapter has argued that in the context of ever changing woodland resource use, it may be more beneficial for community-based resource management programmes to strive for adaptive resource management institutions instead of those that simply 'endure'. The concept of 'enduring' raises connotations of static situations, yet no institution is permanent (Berry 1993). The chapter also highlights the need to develop group learning and experimentation processes and to increase institutional collaboration at the local level in order for participatory natural resource management to be successful.

A number of key issues arise from the Romwe case. Several of these relate to questions of how to bring about effective social learning. I focus on three aspects of collaboration and group learning: the importance of good facilitation, equal power in the learning process and the fact that social learning is a multi-stage process that can be costly, a fact that needs to be taken into account during the planning stages. 
It has been argued that collaborative social learning may be difficult to implement as this requires a lot of technical (especially for facilitation) and financial support (Chuma et al. 1998; Röling and Jiggins 1998). Effective facilitation of learning involves making things visible and helping people to reconstruct their realities through experimentation, observation and meaningful experience (Woodhill and Röling 1998: 68). Based on the kuturaya approach, I would argue that the key to success of a learning-by-doing approach is good facilitation, especially during the initial stages of the experimentation process. In this case the facilitation was done jointly by extension agents and researchers from the University of Zimbabwe.

While the facilitation role may be undertaken by external agents such as extension agents or personnel from non-governmental organisations, initially these bodies are never neutral and may not always reflect local village's priorities. Over time local institutions may want to develop the capacity to facilitate the process themselves through the provision of training. The current external facilitators therefore need to impart facilitation and coordination skills to local institutions.

The facilitation process should also aim at bringing together the various resource management institutions involved because their jurisdictions do not neatly coincide with resource use boundaries, posing a major challenge to institutional collaboration. It is worth noting that Zimbabwe's current models for community-based natural resource management have tended to focus mainly on the centre-local interface. Developing and promoting similar initiatives in the communal lands context is a challenge that requires attention from various interest groups.

Because social learning is a multi-stage process (Korten 1984; Kemmis and McTaggart 1998) and involves the investment of time and effort over long periods of time, it may be costly. The kuturaya experimentation process illustrates the multi-stage processes involved. Farmers, together with the external agents, agree on the management issue at stake, discuss and agree on some management approach to be tested, make a plan of action, implement the plan, review and reflect on the outcome and use this outcome as a basis for further planning and action. The need for agreement at each stage requires frequent consultation among interest groups and significant inputs and information management, all of which can be costly. Also, in a collaborative experimental approach, mistakes are common, as can be seen from the challenges faced in kuturaya described in Box 5.2. As a result, both material and human resource inputs may be high. 
In the beginning of the process, as noted from the early stages of the Romwe case study above, it is important to identify all the key institutions that need to be involved. Grimble et al. (1995) note that after identifying the various interest groups, a process of verification is necessary to confirm that all groups are represented. After the key institutions have been identified, they all have to be involved in such a way that they all feel ownership of and equal power in the learning process. In the Romwe case, for example, key institutions such as the traditional authority, local government structure, non-governmental organisations, researchers and extension agents need to be fairly involved in the learning process. If some institutions do not feel that they are fairly represented, problems similar to those described in Box 5.1 may arise.

A social learning approach helps us to address two of the principle shortcomings of current theories on local institutions. First it adds needed emphasis on the importance of collaboration among different local institutions. Second, it provides insights on how local institutions can adapt to changing environmental and social conditions. As such, if most of the challenges discussed above can be addressed, a social learning approach has great potential to promote more effective collaboration among local institutions, and, ultimately, more sustainable forest management.

\section{ACKNOWLEDGEMENTS}

Funding for this research was provided by the Center for International Forestry Research (CIFOR) and the Department for International Development-funded MicroCatchment Management Project. Guidance during fieldwork was received from Bruce Campbell of the Institute of Environmental Studies, University of Zimbabwe and Wil de Jong from CIFOR. I would also like to acknowledge insightful comments from David Edmunds from CIFOR. The East-West Center provided an excellent writing environment. Last but not least thanks to Witness Kozanayi for his professional research assistance. 


\title{
ENDNOTES
}

\author{
${ }^{1}$ Zimbabwe National Traditional Healers Association. \\ ${ }^{2}$ Ostrom's criteria are: i) that there should be clearly defined resource use boundaries; \\ ii) congruence - fair distribution of benefits and costs; iii) collective choice arrangements; \\ iv) monitoring; v) graduated sanctions; vi) conflict resolution mechanisms; vii) minimal \\ recognition of rights to organize and for CPRs that are part of larger systems; viii) \\ nested enterprises (Ostrom, 1990). \\ ${ }^{3}$ The traditional authority structure is made up of the sabuku (kraalhead) who is at \\ the bottom of the hierarchy. The sabuku reports to the headman who in turn reports \\ to the chief (who is at the top of the hierarchy). \\ ${ }^{4}$ Names of individuals have been changed to maintain confidentiality. \\ ${ }^{5}$ Names have been changed to maintain confidentiality.
}

\section{LITERATURE CITED}

Berry, S. 1989 Social institutions and access to resources. Africa 59(1): 41-55.

Berry, S. 1993 No condition is permanent: The social dynamics of agrarian change in Sub-Saharan Africa. University of Wisconsin Press, Madison.

Chuma, E., Chiduza, C. and Utete D. 1997 Training Manual: Soil Fertility management for smallholder farmers in Zimbabwe. IES Report Series, Paper number 4. Harare.

Chuma, E., Hagmann, J. and Gundani, O. 1998 Supporting farmers' land literacy: tools for learning about soil and water conservation. The Zimbabwe Science News. 32(2/3, April/September): 30-34.

Cleaver, F. 1999 Moral ecological rationality, institutions and the management of common property resources. Paper presented at the African environments conference, 5 7 July 1999, St Anthony's College, Oxford, UK. (forthcoming in Development and Change)

Datta, R. This volume. Seva Mandir: A learning organisation. In: Wollenberg, E., Edmunds, D., Buck, L., Fox, J. and Brodt, S. (eds.) Social Learning in Community Forests, pp.65-84. CIFOR and East West Center, Indonesia.

Dzingirayi, V. 1997 Take back your CAMPFIRE: A case study of the communal areas management programme for indigenous resources in Binga District, Zimbabwe. University of Zimbabwe - CASS, Harare. 
Fisher, R.J. and Jackson, W.J. 1998 Action research for collaborative management of rotected areas. Paper presented at the workshop on Collaborative Management of Protected Areas in the Asian region. Sauraha, Nepal, 25-28 May 1998.

Gilmour, D and Fisher, B. 1997 A project or a process? In: Borrini-Feyerabend, G. (ed.) Beyond social fences: seeking social sustainability in conservation, 103-106. Volume 2: A resource book. IUCN, Gland, Switzerland.

Government of Zimbabwe. 1994 Report of the commission of inquiry into appropriate agricultural land tenure systems. Government Printers, Harare.

Grimble, R., Chan, M.K. Aglionby, J, and Quan, J. 1995 Trees and trade-offs: a stakeholder approach to natural resource management. Gatekeeper Series No. 52. International Institute for Environment and Development, London.

Hardin, G. 1968 The tragedy of the Commons. Science 162: 1243-1248.

Hudson, N.W. 1981 Social, Political and Economic aspects of soil conservation. In: Morgan, R.P.C. (ed.) Soil Conservation: Problems and Prospects, 45-54. Wiley, Chichester.

Kemmis, S. and McTaggart, R. 1998 Introduction: the nature of action research. In: Kemmis, S. and McTaggart, R. (eds.) The action research planner, 1-13. Deakin University, Victoria, Australia.

Korten, D.C. 1984 Rural development programming: the learning process approach. In: Korten, D. C. and Klauss, R. (eds.) People-centered development: contributions toward theory and planning frameworks, 176-188. Kumarian Press, West Hartford, Connecticut.

Lawry, S. 1989 Tenure, policy and natural resource management in Sahelian West Africa. Land Tenure Centre, University of Wisconsin, Madison, Wisconsin.

Maarleveld, M. and Dangbégnon, C. 1998 Managing natural resources in face of evolving conditions: A social learning perspective. Paper presented at the seventh conference of the International Association for the Study of Common Property. Vancouver, Canada, 10-14 June, 1998.

Mandondo, A. 1997 Trees and spaces as emotion- and norm-laden components of local ecosystems in Nyamaropa communal land, Nyanga District, Zimbabwe. Agriculture and Human Values 14: 353-372.

Mandondo, A. 1998 The concept of territoriality in local natural resource management, and its implications on livelihood in Nyamaropa communal land. WWF Programme Office, Harare.

Matose, F. 1994 Local people's uses and perceptions of forest resources: an analysis of a state property regime in Zimbabwe. Unpublished MSc thesis. Department of Rural Economy, University of Alberta, Edmonton, Alberta. 
Matzke, G. 1993. Resource Sharing Schemes for state owned land in Zimbabwe: A discussion of conceptual issues needing consideration in the development and planning of co-management regimes. CASS, University of Zimbabwe. Occasional Paper Series number 54/93. Harare.

McCay, B. J. and Acheson, J. M. 1987 Human ecology of the commons. In: McCay, J.B. and Acheson, J.M. (eds.) The question of the commons: the culture and ecology of communal resources, 1-34. University of Arizona Press, Tucson.

Moore, D. 1993 Contesting the terrain in Zimbabwe's Eastern Highlands: political ecology, ethnography and peasant resource struggles. Economic Geography 69 (4): 380-401.

Murphree, M. W. 1991 Communities as institutions for resource management. Centre for Applied Social Sciences, University of Zimbabwe, Harare.

North, D. C. 1990 Institutions, institutional change and economic performance. Cambridge University Press, Cambridge, UK.

Ostrom, E. 1990 Governing the Commons: the evolution of institutions for collective action. Cambridge University Press. New York.

Ostrom, E. 1998 The institutional analysis and development approach. In: Loehman, E.T. and Kilgour, D. M. (eds.) Designing institutions for environmental and resource management, 68-90. Edward Elgar, Cheltenham.

Ostrom, E. 1999 Self-governance and forest resources. Occasional Paper no. 20. Centre for International Forestry Research, Bogor, Indonesia.

Röling, N. G. and Wagemakers, M.A.E. (eds.) 1998 Facilitating sustainable agriculture: participatory learning and adaptive management in times of environmental uncertainty. Cambridge University Press, Cambridge, UK.

Röling, N.G. and Jiggins, J. 1998 The ecological knowledge system. In: Röling, N.G. and Wagemakers, M.A.E. (eds.) Facilitating sustainable agriculture: participatory learning and adaptive management in times of environmental uncertainty, 283311. Cambridge University Press, Cambridge, UK.

Sithole, B. 1997 The institutional frameworks for the management and use of natural resources in communal areas of Zimbabwe: village cases of access to and use of dambos from Mutoko and Chiduku. CASS, University of Zimbabwe, Harare.

Woodhill, J. and Röling, N. G. 1998 The second wing of the eagle: the human dimension in learning our way to more sustainable futures. In: Röling, N.G. and Wagemakers, M.A.E. (eds.) Facilitating sustainable agriculture: participatory learning and adaptive management in times of environmental uncertainty, 46-71. Cambridge University Press, Cambridge, UK. 
Chapter Six

\title{
Rethinking the role of consensus in pluralism: Learning from community- based forest management in Yunnan, China
}

\author{
Cao Guangxia and Zhang Lianmin
}

\begin{abstract}
This chapter contributes to an understanding of pluralism and social learning in community-based forest management by examining three cases of village forest management in Yunnan, China. The authors question the current trend in the literature to dismiss the value of consensus and endorse open conflict (FAO 1999, Rescher 1993). An analysis of the three cases suggests that cultural values about consensus can be equally important in generating learning that leads to successful forest management strategies. The analysis also demonstrates the significance of informal communication and the importance of influential leaders as insider facilitators, for successful negotiation and compromise to reach consensus, and we thereby question the emphasis on formal mechanisms in discussions on pluralism. We show that through negotiation and compromise, even communities that encompass diverse interests in forest resources can be effective in uniting under a common cultural value system and thus develop successful mechanisms for managing interests.
\end{abstract}




\section{INTRODUCTION}

In discussions on community-based forest management, the current literature on pluralism maintains that diverse interests among stakeholders are inevitable, both on a material level as well as on the level of cultural values (FAO 1999, Rescher 1993). Therefore, argue some authors, no single view of forest management can be preeminent, and consensus is unattainable (Anderson et al. 1999, Daniels and Walker 1999). A process of formal negotiation with a neutral or powerful outside facilitator is often required. Social learning theory (Lee 1993) also emphasizes the importance of bounded or manageable conflict as a primary basis for social learning and adaptive management. While this emphasis on overt and presumably constructive conflict may be useful in many management situations, it seems inappropriate in the context of village-based forest management in present-day China, where consensus building is regarded as an essential cultural value (Faure and Rubin 1993).

The literature on pluralism and forest management places considerable emphasis on formal processes, such as those involving the roles of official, outside facilitators in multistakeholder negotiations. Though informal communication is discussed, it is often not accorded prominence in explaining stakeholder relations, nor does the discussion shed much light on how informal channels work. Our study, as well as others in China, found that informal communication is essential for people to come together to negotiate, compromise and to identify agreed-upon strategies.

Using case studies of community forest management in Yunnan Province, China, we demonstrate first that the Chinese cultural context requires a heavier emphasis on initial, overall consensus building, often based on fundamental cultural values, before diverging or conflicting interests can be handled effectively. Second, we show how informal processes of negotiation and compromise, facilitated by the strong influence of village leaders, play crucial roles in consensus-building processes. Insights on the interplay of consensus and conflict, and of formal and informal negotiation mechanisms, may shed light on the dynamics of community forest management in other cultures within Asia and beyond. 


\section{CONCEPTUAL FRAMEWORK}

Lee (1993), Korten (1984), and Röling and Jiggins (1998) suggest that collaborative adaptive management involves social learning. Actors involved in forest management learn together about ecosystems and about institutional innovations and reconfigurations that support effective learning. This learning approach leads to an improved understanding of relationships among:

- The status of the natural resources (forests and forest resources)

- Institutions governing human activity that affect the status of the natural resource

- Learning (knowledge and information) systems for improving technical innovational capacity for managing the natural resource (Maarleveld and Dangbégnon 1999).

Here we will examine how the management of diverse interests in resource use by communities in Yunnan addresses all three of the above elements. The term 'interests' here refers mainly to the material interests of the community members, although some essential spiritual interests are also included. We assume that in addressing different user interests, communities formulate a consensus that can in principle be accepted by community members. Rescher (1993:13), referring to Jürgen Habermas, refers to this as a rational consensus, the 'product of people implementing the norms of reason', which is to be distinguished from a de facto consensus. In the process of coordinating their interests, local people continuously institutionalise basic, agreedupon values and norms via enforced community rules that can serve as the basis for negotiating further disputes. Thus, consensus is achieved through active negotiation and compromise among community members. Conflict is managed behind the scenes rather than overtly. The community's power to negotiate with outside stakeholders in adaptive management is, in turn, determined by the degree of consensus reached among stakeholders within the community.The purpose of negotiation within the community is to facilitate understanding of different interests among members. Community members carry out negotiation processes according to the cultural value that face-to-face agreement and harmony is important. Compromise arises out of a need for some members to forgo fulfilling some of their individual interests in favour 
of community-wide interests and values. This is facilitated by leaders working informally with individual or small groups, encouraging the development of a consensus before open public discussions.

\section{BACKGROUND AND METHODS}

Yunnan Province, located in southwestern China at N $21^{\circ} 9^{\prime}-29^{\circ} 15^{\prime}$ and E $97^{\circ} 39^{\prime}-$ $106^{\circ} 12^{\prime}$, covers a total area of about $390000 \mathrm{~km}^{2}$, of which over $90 \%$ are mountainous (see Figure 6.1). The Province has a population of 40000000 . Forest land throughout China is divided into two types, state forest land and community forest land. The latter accounts for $61 \%$ of the total. By law, each village community in China has its own forest land exclusively for meeting its basic needs. The policy on usufruct of village forest land was implemented in the early 1980s and assigned a forest area to each household for particular uses. The assigned forest land was categorized into

Figure 6.1 Location of three villages in Yunnan province, China. 1. Dongda village, 2. Beida village and 3 . Tangdui village

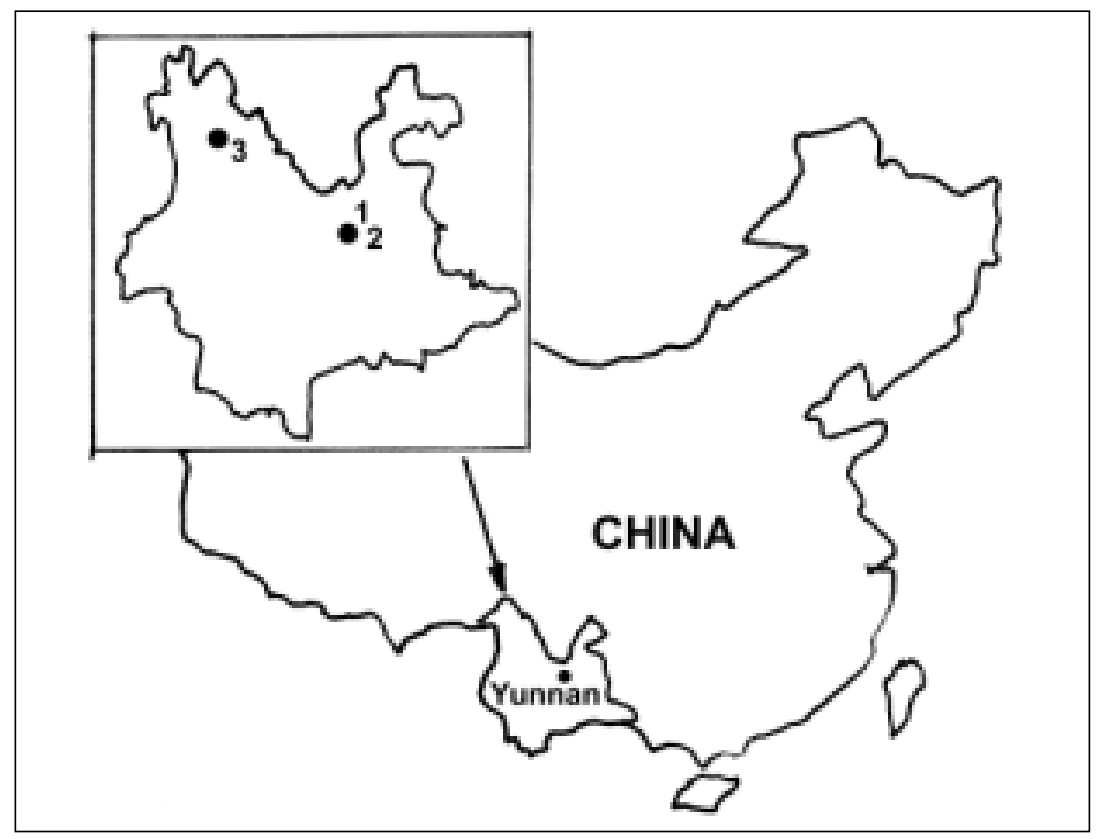


two types: freehold forest land (Ziliushan), which is intended for meeting household needs such as firewood and is primarily managed and utilized by individual households, and contract forest land (Zerenshan), which individual households have the duty to manage for the whole village. In implementing the policy, some adjustments have been made by local communities to facilitate management. For example, contract forest land in many villages has been collectively managed and utilized. Regarding the use of collective forests, the volume of wood extraction is controlled and authorized by the county forestry bureau based on villagers' requests.

To illustrate how local communities manage their diverse interests, we document the experiences of three villages. Two villages with contrasting experiences of good and poor management were selected on the basis of having a similar ethnic composition, being near each other, and having access to relatively good transportation and market opportunities. A third village was selected in a relatively remote location with less direct contact with authorities and poor access to markets. We have been working with local villagers as researchers and facilitators for over four years using participatory rural appraisal and participatory observation. Village leadership at each site consists of a committee composed of one headman, one deputy headman, one accountant and one woman leader. Table 6.1 presents additional information about the context of forest management in each of the three villages (Cao and Zhang 1997).

Table 6.1 Location, population, and forest information for three case study villages in Yunnan Province

\begin{tabular}{|c|c|c|}
\hline Village & Location and Population & Forest Condition and Ownership \\
\hline Beida & $\begin{array}{l}\text { Near provincial capital }(20 \mathrm{~km}) \text {; } \\
\text { population: } 210 \text {; Han majority }\end{array}$ & $\begin{array}{l}\text { Forest area: } 2000 m u^{*} \text {, no large trees present Main } \\
\text { tree species: Pinus yunnanensis, } P \text {. armandi } \\
\text { Ownership: collective, but with contract and freehold } \\
\text { assigned to individual households }\end{array}$ \\
\hline Dongda & $\begin{array}{l}\text { Near provincial capital }(20 \mathrm{~km}) \text {; } \\
\text { population: } 225 \text {; Han majority }\end{array}$ & $\begin{array}{l}\text { Forest area: } 3000 m u \text {, large trees present } \\
\text { Main tree species: } P \text {. yunnanensis, } P \text {. armandi } \\
\text { Ownership: collective }\end{array}$ \\
\hline Tangdui & $\begin{array}{l}\text { Northwest Yunnan, nearest } \\
\text { town } 30 \mathrm{~km} \text { away; population: } \\
\text { 752; Tibetan majority }\end{array}$ & $\begin{array}{l}\text { Forest area: } 30000 \text { mu, large trees present } \\
\text { Main tree species: } P \text {. densata, } P \text {. armandi, Picea sp, } \\
\text { Arbies sp. Ownership: collective }\end{array}$ \\
\hline
\end{tabular}

*15 mu = 1 hectare 


\section{CASE STUDIES}

\section{Beida}

Beida village consists of diverse groups, including agriculturists, livestock raisers, fruit tree cultivators, vegetable cultivators, and other small business owners. The village has experienced a steady decline in forest area until recently. As early as the 1960s, owing to political reasons affecting most of China, agriculture production failed and severely affected the villagers' basic livelihood. Although the community wanted to conserve its forest for future use and formulated regulations and assigned a guard to do so, the forest was not conserved. Because of the lack of effective measures to deal with the food shortage, villagers were forced to cut their trees to trade for food. Due to the dire circumstances and lack of alternatives for procuring food, the village forest guard did not prevent the illegal cutting.

Dissatisfied with the deforestation problem they had created, the villagers changed their leadership. Deforestation continued nevertheless, so they changed their leadership again. This pattern was repeated again and again until nearly every adult man had been posted as the headman. With most of the forest already gone, it was left to regenerate naturally. This regeneration was threatened again in the early $1980 \mathrm{~s}$, when a new forest policy was implemented to encourage more individual control of forest lands. The villagers met at the time. Without much discussion before the village meeting, the villagers generally voiced support for more individual control of forest lands in the meeting. However, no effective, community-wide control mechanisms were worked out. Further deforestation followed soon after the allocation of forest lands. Individual ownership may have contributed to deforestation, but we suggest poor consensus building and a weak learning process could have been equally or more important.

Despite the deforestation, a few hectares of watershed forest have been relatively well conserved, although there are no big trees. Villagers attribute this success to the area's importance for their water resources, as well as its location in direct view of the village settlement.

The primary lessons learned from this case can be summarized as follows:

- The villagers' needs and interests were not well-coordinated toward the good maintenance of forest area, even though villagers had clear interests in managing their forest resources well. 
- No effective social learning occurred. Adaptation was not channelled into social learning, but rather to the superficial change of leadership.

- The information flow was largely random, therefore social learning was not well-coordinated.

In contrast, in the following cases of good management, the above shortcomings were overcome.

\section{Dongda}

Dongda village still has some of the old forest plantations established in 1947 during the Guomingdang period. During the past 50 years, Dongda has experienced steady growth in forest cover with more than half of the forest land having been reforested. In the past, nearly all villagers depended on diverse aspects of agriculture for their livelihood, such as livestock raising, crop cultivation, medicinal healing, crafts and others (Figure 6.2). As the economy developed, more diverse economic interests among villagers also developed. For example, most farmers now cultivate different kinds of vegetables. Some are busy in mushroom and Myrica sp. collection activities for cash,

Figure 6.2 The village forest addresses villagers multiple needs. A farmer's hourse grazing in the forest Dongda

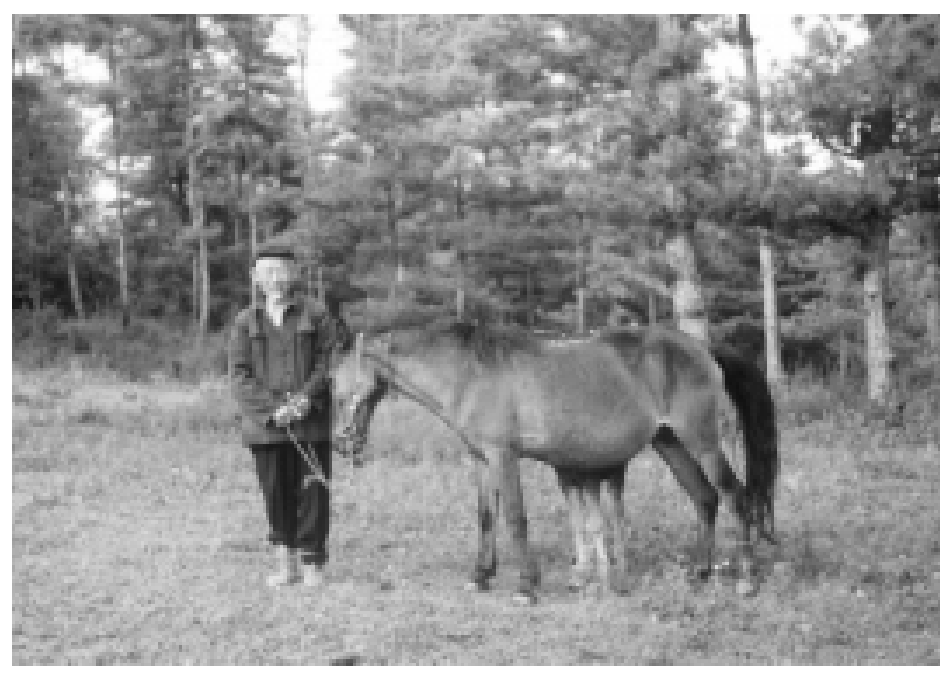


while others are involved in small non-agricultural businesses. Some people rely more heavily on forest resources for their livelihood. These differences have not strongly affected forest management, however, nor has the fact that forest resources are not crucial economic resources for the village as a whole.

The villagers all agreed that the forest provides them with many forest products and provides clean water for them. Their drinking water comes from a hill covered by dense scrub woodlots. When asked about the rationale for conserving forests, one villager answered:

a forest is always better than barren land, because barren land arouses bad feelings and monotony in one's heart. To have a forest nearby means that the site's fengshui [meaning harmony in the environment, mystically referring to the effect of a particular site on one's fate and the good of the future generations - a prevalent way of thinking among Chinese] is good and it implies good living...

In the 1960s, the village leadership developed a strategy to address the multiple needs of villagers, through enrichment of the forest with fast growing bamboo. The forest was not allowed to be cut individually for sale, only collectively.

At a later period, from 1981 to 1989 , the headman in Dongda village led the community through the critical years of shifts in national forest policy. He said:

the national forest policy was incomplete and thus could be easily operationalised in a way to suit our needs....we adjusted the general policy to our village's condition and made it effective. The principle was that we used the rational content in the policy to facilitate local forest management. For example, the 1980 s forest policy regulated that the collective forest should be divided into two parts before being assigned to individual households, namely the 'contract hill', the Zerenshan, and the 'freehold hill', the Ziliushan. Considering that our forest condition was good and farmer households did not have enough money to buy the 'freehold hill', we decided to allocate only the contract hill to farmer households and stipulated the appropriate rules to monitor management activity based on informal discussions with some villagers. When this was announced in the village meeting, most villagers supported the option and no one openly opposed. 
The plan was submitted to the local forest department, which supported it.

The village headman added 'If you want to conserve the forest well, the key to its management is the word "dare", i.e., you dare to prevent offenders and potential offenders. If you are afraid of creating "opposition" and try to be good to everyone, do not talk about forest management.' However, he also said, 'Daring forest management cannot function on its own without the exchange of ideas and opinions and talking about the problems. One needs to talk to the person who commits the wrong and let him fully realize the necessity of the decision.' Therefore, while conflict is acknowledged, the manner of dealing with it points towards a greater cultural emphasis on consensus, in the sense that even an offender is expected ultimately to see the situation from the point of view of the larger group.

The village meeting was the site where much of this discussion took place. These meetings enabled a high proportion of the village to be involved in the decisions taken about their future. The village leadership was well aware of the importance of these meetings. When new forest action was initiated, the community's ideas and opinions were probed in these meetings and the responsibility divided among members. The process before the village meeting was, however, equally important. It was before the meeting that informal consensus would be negotiated. As one headman said, he would often release messages through friends and family regarding future management to test the feedback from the villagers. Gossip and different opinions often suggested that a new plan was not feasible and needed adjustment. According to the village headman, good management cannot rely upon the punishment of the offenders all the time, but on the control of misbehaviour beforehand. The most efficient way to achieve this is to discuss and publicise new regulations in the village meetings.

The lessons learned from the Dongda case are that:

- Coordination of interests through effective leadership under a common value system results in good forest management, even if some villagers are not heavily dependent upon forest resources for their livelihood.

- To reach overall consensus within the community does not mean a complete absence of conflict. Rather, the village committee tries to reduce the severity 
of conflict and move the community as a whole toward consensus as much as possible.

- Learning occurred through an effective leader who engaged in active informal information exchange.

\section{Tangdui}

The occupational interests within Tangdui village are diverse, including agriculturists, mushroom collectors, livestock owners, pottery makers, transporters, retailers and craftsmen. Forests play an important role in supporting daily living needs, providing resources such as firewood and timber. Tangdui's village committee is composed of experienced people. According to local culture, elders are respected. Communication and decision making occurs through formal and informal means. For example, pottery makers once proposed an expansion of their pottery business, which required more consumption of firewood, but also provided more employment. They made their proposal first through informal channels and then to the village leadership, until it was finally accepted by the village community.

The Tibetan villagers' spiritual life is closely linked with the surrounding forest resources (Figure 6.3). According to their Buddhist religion, people should behave in such a way that nature will not be seriously violated. In the village, two opposite hills in the surrounding mountains are their sacred hills, where no tree is allowed to be cut and the forest condition is better than elsewhere.

Every morning, each household burns branches and leaves of Pinus densata as incense in its own special stove for traditional worship. The village has traditionally set rules to manage the pine species, and these rules have been voluntarily observed by the village households. Religious beliefs and use of tree leaves have created a common base for all villagers' concern about the forest. In village meetings, this common value system is often referred to as the reason for better forest management.

The villagers in Tangdui harvest their timber through selective logging from relatively distant spruce and fir forests. Elders and others discussed management options informally among themselves and then formulated a regulation for the rotation of cutting. This regulation has been continually announced in the village meetings. In the 


\section{Cao Guangxia and Zhang Lianmin}

Figure 6.3 The local worship under the divine hill in Tangdui village

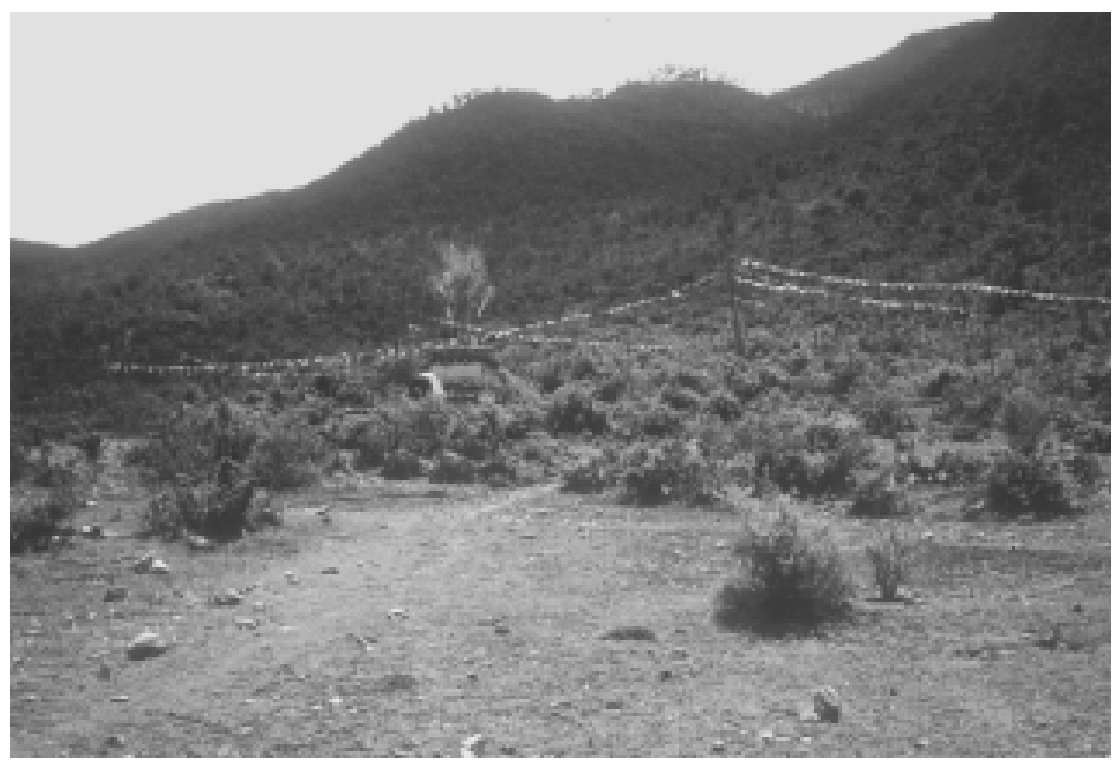

words of the village headman, it is necessary to constantly remind people of certain regulations to avoid open charges and offences. He said that so far everybody has voluntarily observed the rule.

The local people also organised themselves collectively to protect their exclusive rights to collect a valuable mushroom-matsutake. This move was initiated by the collectors and communicated to other groups in the village to gain their acceptance. Finally the consensus was publicised in the village meeting: outsiders are not allowed to enter the village forest freely to collect mushrooms; rather, a gate fee will be charged to these outsiders.

Between 1996 and 1998, a social forestry project was launched by the government. Local villagers convinced the forest department to help them to build an irrigation system (SFET [Social Forestry Evaluation Team] in press). They also successfully negotiated with the local forest department for a controlled grazing arrangement, in which animals could be grazed in an otherwise closed forest. The successful management of this project with external agents such as the forest department 
demonstrates the importance of internal consensus in strengthening the village's negotiating power.

The lessons from this case study are:

- Common cultural values regarding forest resources gave villagers a shared incentive to protect the forest.

- Local communication processes were facilitated by local elder groups.

- Effective adoption was possible through the coordination of interests internal to the community and efficient information flow through informal channels.

\section{ANALYSIS}

\section{Negotiation and Compromise}

The importance of informal negotiation and compromise is clearly illustrated in all three cases. In Dongda and Tangdui, common shared values created a strong basis for successful negotiation and compromise, which led to effective forest management. Beida illustrated that common values alone may not be enough. Without effective leadership in informal processes of consensus building, efforts at forest management can fail.

Although spiritual needs contributed to a common value system in Tangdui, community members were most concerned with their essential livelihood needs, i.e. their material interests, which should therefore serve as a basis for further negotiation. The Beida case demonstrates that, because the community was not able effectively to address its basic needs without overusing the forest, its ideas for forest management could not be institutionalised, and were, in fact, finally abandoned by the villagers. On the other hand, in Dongda and Tangdui villages, the adequate handling of basic needs issues ultimately resulted in more effective management. This analysis suggests that effective internal negotiation should begin when certain crises, such as food shortages or policy changes, are foreseen. 
The benefits of consensus building, grounded in informal communication and organised by strong leaders, were clearly perceived by local communities in our two successful forest management cases. Even in the case of Beida, the community wanted to institute a better process, as is evident in their repeated trials with new leadership. These cases suggest that successful forest management requires social learning, effective leaders, and informal communication.

\section{Social Learning}

Conflict and consensus are both outcomes and causes of social learning, greatly facilitating its process. When either conflict or consensus continually dominates, effective social learning is less likely to happen. Conflict prevailed in Beida village, thus adaptive management was hindered by poor social learning. For effective management, conflict should be bounded and at least a temporary consensus should be established as a basis for management (Lee 1993). As the conditions change, old consensus is broken away by new conflict, forming further consensus in an iterative upward spiral. The cases of Dongda and Tangdui show that such iterative formations of consensus out of conflict resulted in effective social learning about forest management problems.

Different cultural and political contexts suggest different points of balance between conflict and consensus. In contexts such as Western democracies, for example, where people value individual freedom and the political competition it fosters as fundamental human rights, conflict may be viewed as a prominent and even essential tool for social learning (Lee 1993). Proponents of this view admit that dissonance should be restrained, although no clear demarcation from consensus is provided (Rescher 1993). On the other hand, in cultures such as China, where people place a high value on group solidarity and where open debates and serious disagreements are considered to be disgraceful situations that should be avoided, consensus plays a relatively more important role in facilitating social learning. This importance of consensus is clearly indicated in these three cases, where local people attempted to manage their villages' essential interests without jeopardising their potential for future cooperation with one another. Even in Beida village, we can still see the urgent needs of local people to identify an effective way of social learning with a minimum of open conflict by choosing a different leader. 


\section{Leadership}

To make social learning in forest management possible, the cases suggest that a good leader acting as an inside facilitator is important. A good leader should be able to coordinate the social learning process and use it as a channel to reach acceptable management choices. This type of leadership can encompass efforts to convince villagers of new views and discourage those who try to overemphasise their own stakeholder group's interests, all in the interests of reaching a final consensus. Examples of this type of leadership are evident in the case of Dongda's handling of changes in forest policy in the 1980s and Tangdui's manipulation of an external social forestry project. In Beida village, no individual seemed capable of performing this role of coordinating learning, and consequently, forest management was unsuccessful.

\section{Communication and Information Flow}

Good communication within a group facilitates effective social learning. In the case studies, local communication occurred largely through informal means. Daily chatting during casual, but frequent, visits between friends and relatives promoted rapid information flow. The effectiveness and desirability of informal communication was illustrated in the case of Dongda, where the headman hesitated to institute new management plans before receiving feedback through informal channels. Informal information flows also were used by local leaders to persuade others to help implement decisions, and to accommodate special interests (such as the Tangdui mushroom collectors and pottery makers).

The strength of informal communication rests on two premises: the Chinese cultural setting and openness. In rural China, local people avoid openly contrasting views and regard them as a threat to their personal relationships and efforts at building social capital. Therefore, more informal and seemingly casual information channels are preferred for exchanging contrasting ideas. The openness of informal channels allows for a more democratic exchange and equitable weighting of different ideas. Good leaders and facilitators should be able to understand and use informal information channels to test and communicate major decisions regarding resource use. Other documentation in China also demonstrates the use of informal channels to negotiate interests (Xu et al. 1998). 
Cao Guangxia and Zhang Lianmin

\section{CONCLUSIONS}

The cases in this study demonstrate that through successful coordination of their diverse internal interests, local communities are able to manage forest resources effectively. Forest management is enhanced when responsive leadership in combination with effective, but informal communication processes facilitate social learning. Based on a set of common cultural values about the desirability of agreement, especially in informal or public settings, this learning leads to effective consensus building. An analysis of this process suggests a revision of pluralist theory with regard to its views on the roles of conflict and consensus and the means to achieve consensus. We suggest viewing conflict and consensus as a linked pair, in which the balance shifts according to appropriate cultural context; neither is more prominent and both can contribute to social learning. Understanding the cultural differences in how social groups manage conflict and value consensus will lead to a more complete understanding of how social learning can be achieved. Managing conflict may thus require settings beyond the formal negotiation table, and these settings may require specific skills and types of people to manage them. More attention should be given to the importance of these other processes, such as the role of local leaders in building consensus prior to formal decision making. As the concept of social learning is applied in increasingly diverse settings, we can expect to see more of these value-related and informal-processrelated modifications of the concept and the assumption underlying its use.

\section{ACKNOWLEDGEMENTS}

The fieldwork for this study was sponsored by the FAO Forests, Trees and People Program and the WWF Russell Train Education Program. We would like to express our gratitude toward local farmers for their patience and cooperation. The writing of this paper was made possible by a well-structured and informative workshop at the East-West Center, for which the organisers and facilitators are acknowledged. The efficient administrative work of June Kuramoto and Mary Abo made the first author's participation possible and enjoyable. Acknowledgements particularly go to Sonja Brodt for her patience and detailed instructions on help in focusing and structuring the paper, and to David Edmunds for his continuously helpful discussions and input in refocusing the paper. The following people are acknowledged for their useful comments and help 
during the preparation of this paper: Jeff Fox, Louise Buck, Glenn Dolcemascolo, Wenpin Lin, Christian Asanga, Bishnu Upreti and Ron Ayling.

\section{LITERATURE CITED}

Anderson, J., Clement, J. and Crowder, L. V. 1999 Pluralism in sustainable forestry and rural development - an overview of concepts, approaches and future steps. In: Food and Agriculture Organization (FAO). Pluralism and sustainable forestry and rural development. Proceedings of the fourth biennial conference on communication and environment, 28 July 1997, 17-26. Cazenovia, New York. Food and Agriculture Organization, Rome.

Cao, G. and Zhang, L. 1997 Innovative forest management by the local community in Dongda village, Yunnan Province. Forests, Trees and People Newsletter 34: 32 38.

Daniels, S. E. and Walker, G. B. 1999 Rethinking public participation in natural resource management: concepts from pluralism and five emerging approaches. In: Pluralism and sustainable forestry and rural development. Proceedings of the fourth biennial conference on communication and environment, 28 July 1997, 29-48. Cazenovia, New York. Food and Agriculture Organization, Rome.

Food and Agriculture Organization (FAO) 1999 Pluralism and sustainable forestry and rural development. Proceedings of the fourth biennial conference on communication and environment, 28 July 1997. Cazenovia, New York. Food and Agriculture Organization, Rome.

Faure, G. O. and Rubin, J. Z. (eds.) 1993 Culture and Negotiation: the resolution of water disputes. Sage Publications, Newbury Park.

Korten, D. C. 1984 Rural development programming: the learning process approach. In: Korten, D. C. and Klauss, R. (eds.) People-centered development: contributions toward theory and planning frameworks, 176-188. Kumarian Press, West Hartford, Connecticut, USA.

Lee, K.N. 1993 Compass and Gyroscope: integrated science and politics for the environment. Island Press, Washington, D.C.

Rescher, N. 1993 Pluralism: against the demand for consensus. Clarendon Press, Oxford.

Röling, N. G. and Jiggins, J. 1998 The ecological knowledge system. In: Röling, N. G. and Wagemakers, M. A. E. (eds.) Facilitating sustainable agriculture. Participatory 
learning and adaptive management in times of environmental uncertainty, 283311. Cambridge University Press, Cambridge, U.K.

Maarleveld, M. and Dangbégnon, C. 1999 Managing natural resources: A social learning perspective. Agriculture and Human Values 16 (3). Pp. 267-280.

Social Forestry Evaluation Team (SFET) 1998 Evaluation Report on Rational Utilization of Forest Land Trail and Pilot Project in Yunnan Province. Evaluation Group for Rational Utilization of Forest Land Trail and Pilot Project in Yunnan Province.

Xu G., Cao, G., He, P., Li, W.J.Y., Lin, Xie. 1998 Community Forestry. Chinese Forestry Press. 
RETHINKING THE ROLE OF CONSENSUS IN PLURALISM 
Chapter Seven

\title{
External donors and community-based management of Mgori Forest, Tanzania: What happens when the donors leave?
}

\author{
Edward Massawe
}

\begin{abstract}
Rapid forest degradation and the inability of the government to police the forest prompted Tanzania to attempt community-based forest management. In this chapter I describe initiatives to set up village-based management institutions among several villages around the Mgori forest. I focus on the roles played by villagers, foresters, international donor agencies and expatriate advisors. External funders and advisors have provided crucial resources, including transportation and communication assistance, influence in convincing higher levels of government to lend support and third party facilitation to help foresters gain the trust of villagers. To achieve the sustainability of collaborative management efforts once expatriate donors and advisors withdraw, there will need to be more capacity building for Tanzanian foresters and local villagers, better technical and policy support from all levels of government and a system of funding for local institutions derived from the sharing of benefits from forest and wildlife management.
\end{abstract}




\section{INTRODUCTION}

Collaborative management of forests has been receiving increasing attention in recent years, because governments cannot afford to police forests, and because many foresters have taken up a participatory approach as people living near forests have demanded a larger role in forest management (Joshi 1998). Collaboration can be very complex, however, and there is much to learn about how to encourage collaboration among different groups interested in forests. Many people now writing on the subject mention the key roles of convenors and facilitators in helping different groups manage resources collaboratively (Ramirez 1999; Röling and Jiggins 1998; Grimble et al. 1995; Margoluis and Salafsky 1998; Borrini-Feyerabend 1997). Convenors and facilitators can play a crucial role in helping to identify who should be involved in collaboration (Grimble et al. 1995; Gilmour and Fisher 1997), in helping to build trust among different groups (Asanga, this volume), in levelling the playing field among groups (Ramirez 1999), and in calling groups together to discuss issues (Grimble et al. 1995; Ramirez 1999). Facilitators can also help groups to develop shared definitions of problems, plans for action, standards of evaluation and approaches to problem solving (Ramirez 1999; Röling and Jiggins 1998). The roles of convenors and facilitators can therefore be extremely important where many different groups have strong interests in the forest and where the potential for misunderstanding and conflict is high.

In many cases, however, it seems to be taken for granted that highly skilled, third party convenors and facilitators are available and can be paid for. This may not be true in many parts of the world, including most of Tanzania. Many of the processes needed take 10 to 20 years to achieve some stability (Ingles et al. 1998). It is therefore necessary to take a close look at exactly what roles these people play and to make plans for filling those roles if funds are short and external help is not available. In this chapter, I suggest where some of the key problems are and ways to address them.

The Mgori Forest in Tanzania was being severely degraded through improper management when it was under government control. Now, with the country's first ever attempt at collaborative forest management, the area of the forest is increasing and flora and fauna are flourishing. The five villages located on the Mgori Forest perimeter protect and manage parts of the forest as Village Forest Reserves in collaboration with local authorities and international advisors. Through trial and error, all parties to this effort, including myself as a participating forest officer, have gained 
experience in organising participatory activities. This project can act as an important baseline and model for other developments in the management of natural resources in Tanzania (Wily 1996).

This collaborative approach, however, is not yet institutionalised in Tanzania, which still lacks sufficient money and people skilled in facilitation and technical matters to carry on the work effectively. There are also many government officials who are not yet fully aware of the advantages of this approach, and external assistance may still be needed to convince them of the benefits. In this chapter, I examine the role of donors, expatriate advisors and government foresters in facilitating the development of community forestry in Mgori. I also discuss some of the difficulties faced by local institutions preparing to facilitate community forestry development when donors and expatriate advisors eventually leave, and how these might be overcome. I examine how communities and foresters can prepare to cover costs, develop the necessary technical and facilitation skills, assure follow-up and pressure government for support of community forestry.

\section{BACKGROUND}

The Mgori Forest is about 40000 ha of miombo ${ }^{1}$ woodland, lying on the Great Rift Valley escarpment in the northeast corner of Singida District, Tanzania (see Figure 7.1). Annual rainfall ranges from 700-1000 $\mathrm{mm}$ and occurs from November to March. Soils are sandy to sandy loam. The forest has valuable tree species such as Pterocarpus angolenesis, Afzelia quenzensis and Dalbergia melanoxylon. Fortythree per cent of the Mgori Forest has been categorised as forest, although it is only of medium to low density and rarely even reaches $20 \mathrm{~m}$ in height. The remainder is thicket, scrub or bush of about 8-10 $\mathrm{m}$ in height with Combretum, Terminalia and Acacia species dominant. Wildlife is abundant in Mgori Forest, but suffers from overhunting. Many species of animals are present, including the rare ground pangolin. Native residents are farmers cultivating maize, sorghum, finger millet and beans. Beekeeping is also widely practised. Many farmers keep livestock, but the area is infested with tsetse flies, so the numbers are not large. Five years ago, this forest was becoming severely degraded through clearing for charcoal burning, shifting cultivation, overexploitation of timber tree species and illegal hunting of both small and big game. Today, it is a relatively healthy forest that villagers value highly. 
Figure 7.1 Location of Mgori Forest in Singida regions (Tanzania) UNITED REPUBLIC OF TANZANIA.

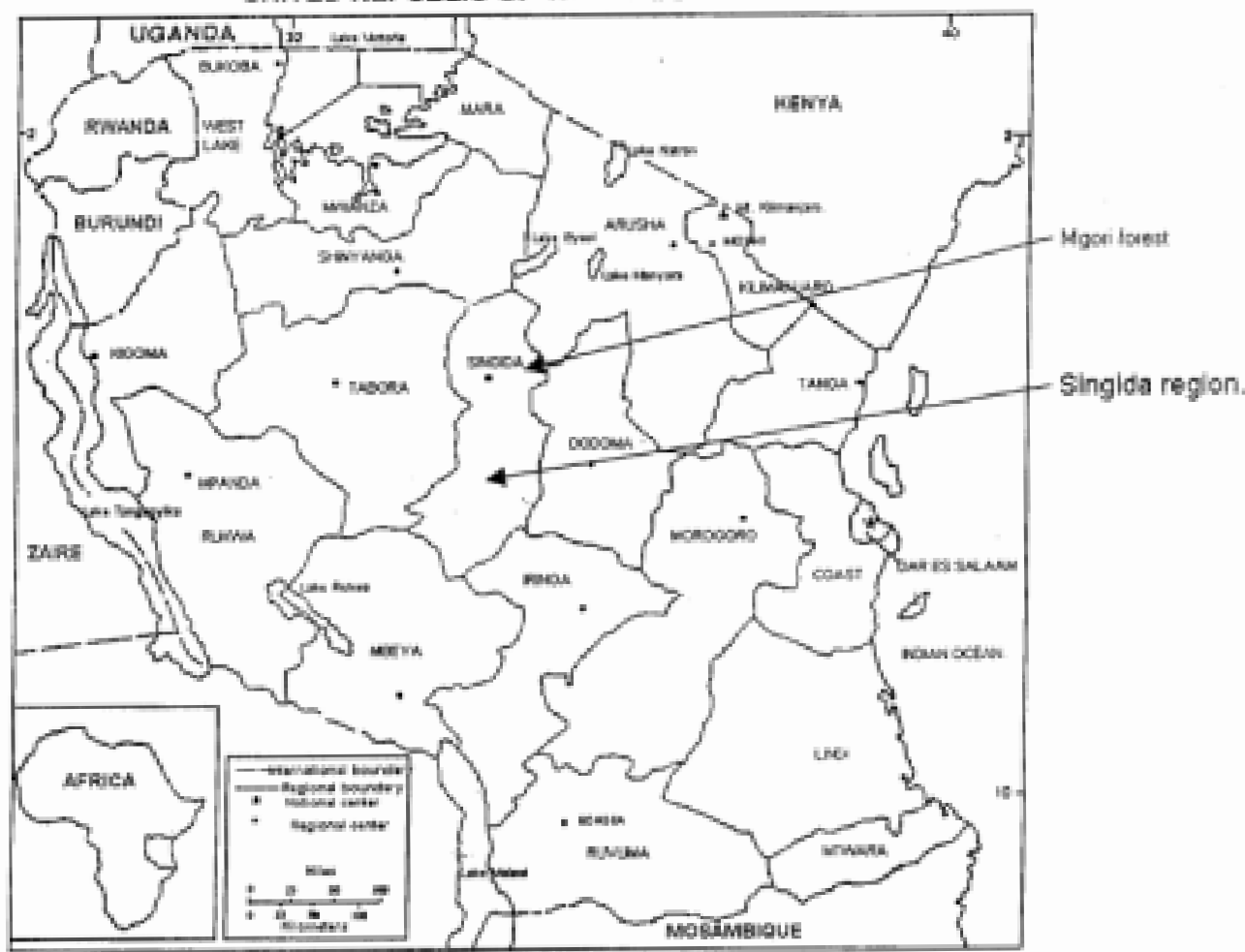

The conflict between the government and the villagers began when the government was planning to make the forest a government reserve. Survey and inventory teams preparing a $10 \mathrm{~m}$ cut-line (to demarcate the intended government forest reserve) met with rejection in the field, as the villagers feared losing the forest-based goods and services that they had been enjoying for some time. Villagers valued the forest and feared that if the government took it, there would be tighter rules and conditions on their use of the forest. The villagers complained through their leaders- the councillors to the Chairman of the Council and the District Commissioner-about losing their land. Legally, only one-third of the forest fell within the areas recognised as their respective villages. Two-thirds was considered open public land, but still the local people felt it belonged to them. The villagers struggled to get from the forest whatsoever was available for use before the government could take it. Thus, the forest was heavily degraded. It was obvious that the process of gazetting this 
forest could not work if the two parties could not come to compromise. The government halted the process pending further investigation of how the problem could be solved.

Two field technical advisors ${ }^{2}$ from an external agency were called in to try to find a solution, assisted by the Regional District and Divisional Forest Officer. The consultants found that the government was unable to manage the forest together with other scattered forest reserves, as it did not have enough staff, funds and other inputs. The only solution was to involve the communities in forest management. The critical questions remained of who could do what, and how?

This chapter focuses on three stakeholder groups and their roles in the process of developing the community management programme: villagers, government officials (local and central) and expatriate donors and advisors. The villagers live near the forest and use it for many things, including daily necessities. The government wants to manage the forest for protection. The donor, working through the consulting agency it hired, hopes to facilitate negotiation between various stakeholders, and provides technical and financial support for sustainable development. I show below how these stakeholders were brought together and then worked together with the assistance of convenors. I show how these third parties have also played a critical role in negotiations. I then ask how Tanzanian institutions can begin to take on the convening role to accomplish these multiple functions.

\section{THE PROCESS OF BRINGING STAKEHOLDERS TOGETHER}

At Mgori Forest, the donors and their expatriate advisors helped significantly in bringing the three main stakeholders on how to reduce or manage conflict among villagers, and between villagers and the government. The first task was to visit all the five villages that shared the boundaries with the intended government forest reserve, namely Pohama, Ngimu, Unyampanda, Mughunga and Nduamghanga (see Figure 7.1). The aim was to discuss whether they were willing and able to take on the responsibility of looking after the forest. All the villages agreed. The process was good for the villagers as it was the first time they had ever been consulted. All the meetings were well attended by the required stakeholders-villagers, District/Divisional Forest Officer and the expert technical advisor. 
Only the expatriate advisors could do this work at first because the vollagers did not trust the government foresters. The history of tension between villagers and government, and the poor management of the forest prior to the start of the project, meant that an outside third party — in this case, the expatriate advisors - was needed. The process was also costly. Several meetings with each village were required for villagers to understand the concept. This involved very high travel and communication expenses. The donor covered all these costs. The presence of the Divisional Forest Officer was also important as he was the only forester living close to the community and was able to show that the government was serious about the consultation underway. He also acted as a watchdog when things went wrong from the villagers' side.

\section{ESTABLISHING SHARED DECISION MAKING}

Once the donors, advisors and foresters had established some trust with the villagers, a number of other processes were undertaken to help the stakeholders work together to manage the Mgori Forest. Each process addressed specific problems of community forest management and each demanded inputs of time, skills or financial support from donors, expatriate advisors and government foresters. These processes are discussed briefly below.

\section{Formation of Village Forest Committees}

The villagers formed Village Forest Committees (VFCs) of about six to twelve members, including an elder who knows the forest very well and a woman to take on gender issues. It was important to have a committee that could be responsible for this new form of forest management as villagers had never been consulted on forestry matters before, and this degree of protection or technical forestry had not previously been undertaken under their traditional authority. The donor supported the committees by providing funding for nearly all their activities. Advisors and the Divisional Forest Officers together helped to design the committees, as well as to specify the roles of committee members and how they should report to the village government. Initially, the advisors and the foresters helped to run the meetings, though the villagers now run them on their own. 


\section{Demarcation of the village forest reserves}

The villagers, after agreeing with their neighbours, marked the boundaries between their village forest reserves using paint on trees and rocks (Figure 7.2). This was important because each village could be responsible for a known, specific area and could be accountable for that area to the Divisional Forest Officer. Later the government surveyors came back and marked boundaries with permanent beacons. These beacons give the villagers a sense of secure ownership and the legal and political basis to protect something that is known as 'our village forest'. The villagers respect these border marks and there are no conflicts over them. Donors provided the funds to cover costs of beacon installation (including transport, night allowances, map drawing and applying for title deeds), which were very high. Expatriate advisors and the Divisional Forest Officer provided guidance on all technical issues on village entitlements, and went to the District Land Office to speed up map preparation.

Figure 7.2 Boundary marker between two villages - Nduamughanga and Mughunga

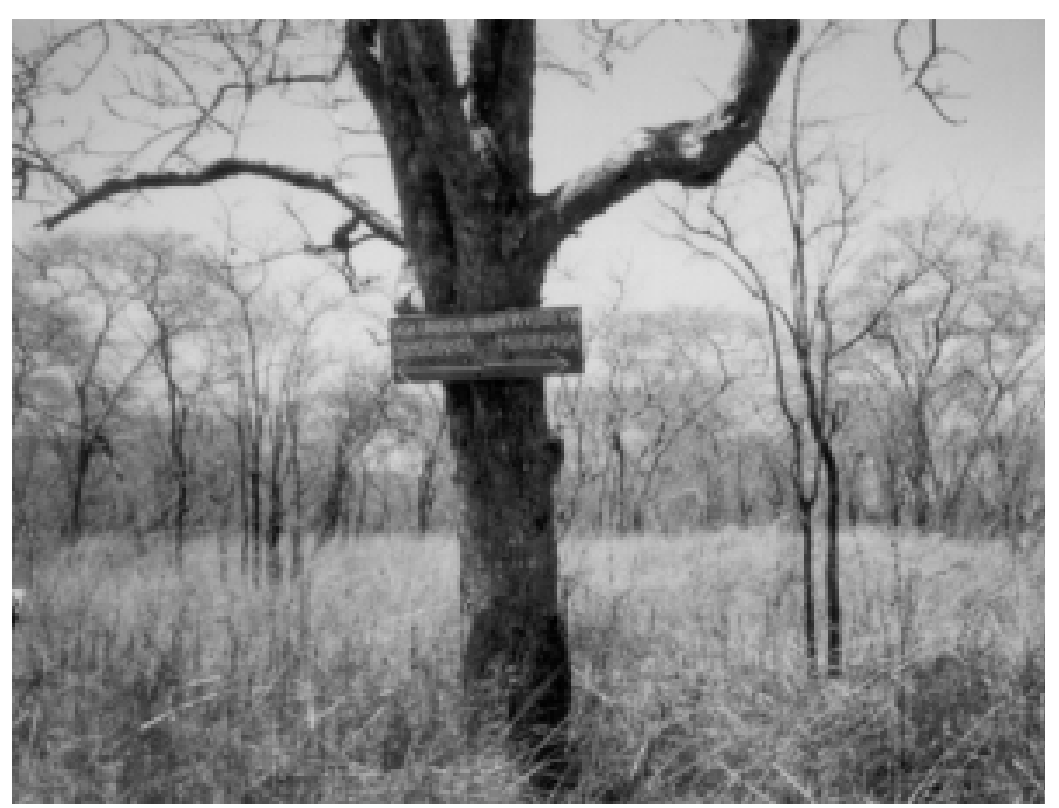




\section{Preparation of Village Forest Management Plans and bylaws}

The donor and the Forest Department staff sat together with the villagers and prepared the Village Forest Management Plans (VFMPs) that will guide them in their daily work in managing their forest reserves. At first, the emphasis of the VFMPs was on protection, as villagers already had abundant resources around their homesteads. However, the VFMP also indicates that villagers can harvest some products from reserves under the guidance of technical officers. The management plans describe the village forest reserve location and boundaries with neighbouring villages. They also describe the way villagers have zoned their forest, e.g., for the collection of dry wood, fruits, poles or timber, or for hanging beehives. The VFMP also states where to report an offender who has been caught, delineates the fines to be imposed and outlines cooperation with the District Council and other villages. In addition, the VMFP states the reason for protecting the forest. Again, donors supported all costs (for five two-day meetings with villagers, documentation and translation, and distribution of the plans). The advisors and the government forester helped define what should be in the management plan to assure protection and sustainability. These advisors also helped present the plan to the District Council, assuring speedy approval. Now, villagers can draw up plans on their own, in consultation with the forester.

\section{Opening bank accounts}

All five villages have opened Village Forest Banking Accounts to store a percentage of the fines imposed on offenders, after a part has been given to the patrolmen. It was important to establish the accounts to ensure transparency, so that the villagers would not suspect that the committee members were pocketing the money for their own use. Here, the donor did not support the villagers because they had already accumulated some money from the fines. Nor did the expatriate advisors play a significant role. Instead, the Divisional Forest Officer helped to guide them to the Treasury (the local authority) for endorsement, then later to the bank. As a government officer, he also signed forms and cards to certify that he knew the villagers and the programme they were working with. The drawing and depositing of money is done by the villagers themselves. No village has withdrawn money yet, because the amounts saved are still small, ranging from US\$50 to US\$150. Since the number of offences has declined over time, these sums are not growing either. For now at least, the funds cannot support the Mgori Forest management activities on their own. 


\section{Formation of a Mgori Forest Coordinating Committee}

The villagers themselves formed the Mgori Forest Coordinating Committee to coordinate the activities of the five villages in matters relating to forestry. The Committee consists of members from each village, has about 25 members in total and is chaired by a local councillor. A representative from the District Council also attends. Usually the Committee meets once every three months (Figure 7.3). Many problems are resolved at this meeting, such as dealing with forest dwellers or corrupt Village Forest Committees. The Committee also organises field visits to collect the information necessary to make joint decisions on managing the Mgori Forest. The Divisional Forest Officer calls for the meetings and the advisors to date have played no significant role. The donor has, however, provided funds for the meetings and the technical advisors receive the reports of progress and problems regarding Mgori Forest management. Donor funds are especially important for providing transport, as many members are old and cannot walk $40 \mathrm{~km}$ or more back to their respective villages. Donors also provide stationery for keeping minutes and a small per diem for meal allowances. The proceedings from the meeting are sent to the District Council for action and information.

Figure 7.3 Mgori Forest coordinating committee meeting, including project technical advisor

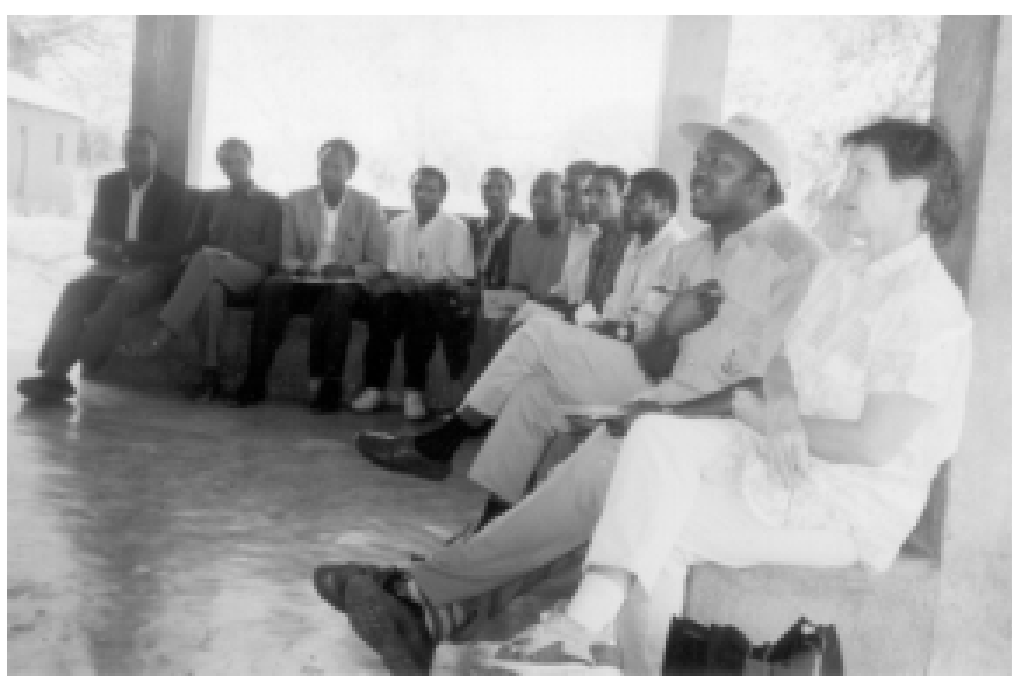




\section{Monitoring the condition of the forest}

Monitoring is essential for planning sustainable management (Margoluis and Salafsky 1998) and helps villagers to know how much can be harvested of any forest product without causing damage to the forest. Monitoring can, however, be costly and technically complicated. Support for villagers near the Mgori forest to monitor the forest was provided by donors, expatriate advisors and government foresters: the donor helped to fund much of the monitoring that has taken place so far, including data processing and analysis. The advisors helped to design the monitoring plan and gave guidance on interpreting and using the results for the management of the Mgori Forest and its villages. For example, advisors helped develop plans for a felling coup in two villages to try to generate income to support other management activities. The Divisional Forest Officer provided technical support in the field to implement the monitoring programme. Villagers would have had difficulty in undertaking these tasks without the help of donors and government foresters.

Three forms of monitoring have been undertaken in Mgori Forest: sample plots, patrols and fire management.

\section{Sample plots}

In February 1996, the central government and the donor sent an inventory team to set up 17 visible sample plots, and, for each one of these, four blind sampling locations for monitoring changes in, for example, growth or damage. This type of monitoring is highly technical and experienced technicians were required. The government facilitated the operation by sending the inventory team, while the donor covered the costs. Villagers helped nevertheless to number trees and install metal reference tags. They also assisted the inventory group in giving traditional names and uses for unidentified species, so that they could easily be found in the checklist. For the future, there are plans to involve the villagers more fully in monitoring operations that they are capable of carrying out. Villagers and foresters participated in the analysis of the findings together. After data processing at the headquarters, the information is sent to the District and to the Divisional Forester. The forester provides a simple translation and sends it to the villagers to inform them of what has been done. Some seem to understand, some do not, though those who understand share the information with their fellow villagers. From the first round of analysis of data from the plots, the villagers concluded that 
their efforts at patrolling these areas were working, as only one tree was cut over the three-year monitoring period.

\section{Patrols}

Villagers appointed patrolmen to patrol the village forest reserves (Figure 7.4). At first, 166 were appointed, but some were dropped along the way due to their inefficiency. Now there are about 100 patrolmen. Some villages also felt that there was no need to have so many, as the number of offences decreased sharply once daily patrols began. Due to the forest's extent, the villagers adopted at their Village Forest Committee meetings a process of concentrating on sensitive areas with timber, water for wildlife and beehives. The decision to change the patrolling regime came after the patrolmen experienced difficulties in covering large areas of their respective Village Forest Reserve-some of which were not attractive to offenders. The Committee secretaries organised the patrols. Advisors have helped devise forms for recording information on wildlife and forest resources. To encourage the patrolmen to do their work, they are exempted from village development activities such as road construction and school

Figure 7.4 Local patrolmen with their traditional weapons

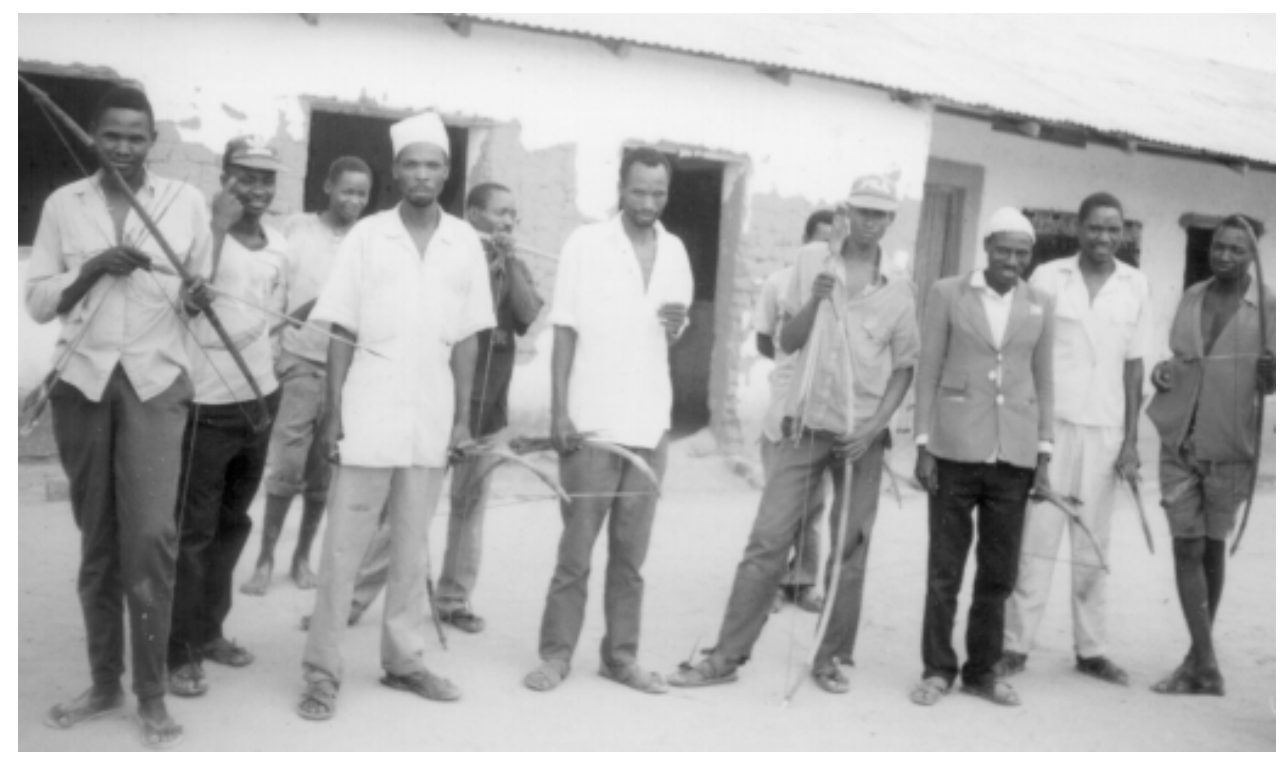


building and other contributions to the village. The donor has provided money for boots, caps, raincoats and antisnake bite kits for the patrols, but the District has blocked the distribution of these provisions for reasons that are not clear. The patrolmen also get support for upkeep from the fines obtained, though this source has decreased significantly as offenders are no longer going to the forest as before. Now villages are looking for other sources of support for the patrolmen. Villagers are considering a small tax on forest produce obtained in the Mgori Forest. For now, they have not given up patrolling, as most of them are beekeepers and need to inspect their beehives for theft or honey anyway.

\section{Fire management}

Fires damage the forest every dry season. Most of these fires start outside the Mgori Forest in the neighbouring Hanang and Kondoa districts, which do not practice this type of collaborative forest management. After several discussions at the Village Forest Committee and Mgori Forest Coordinating Committee levels, the latter decided to initiate early burning before the grasses become dry. This decision was supported by the expatriate advisors who consulted other experts in Zimbabwe and Zambia concerning fire prevention in miombo woodlands. Fire setting is planned at Village Forest Committee meetings and the patrolmen and some Committee members actually set the fires. Fires are set from April to June. After that anyone setting a fire is an offender and is liable for fines. This system has worked and the forest is no longer being damaged by fire (see Box 7.1).

In sum, villagers can be trained to monitor some aspects of forest management, such as beekeeping. Such training has not yet been organised. For other aspects of management, such as fire control, villagers may need assistance from technical advisers such as government foresters. How these will be arranged when the donor and expatriate advisors leave is not yet clear.

\section{PROBLEM SOLVING FOR INSTITUTIONS - LEARNING BY EXPERIENCE}

Foresters, expatriate advisors and donors have played crucial roles in facilitating problem solving negotiations among villagers themselves, and between villagers and government. 
Box 7.1 Improving fire management in Mgori Forest

In 1995, the Mgori Forest Coordinating Committee brought members of the individual Village Forest Committees together and all agreed that fire was a serious problem. Uncontrolled fires had damaged forests and beehives and scared wildlife, and had even spread to crops in some years. It was agreed that burning would be banned to avoid these problems. In the first year of the ban, we managed to put fire under control within the Mgori Forest. Grasses grew tall and biomass accumulated. During 1996, however, fires from the neighbouring districts spread to the Mgori Forest and burnt all of it, including big trees.

The individual VFCs all submitted reports that fire had damaged their forest. First, the MFCC thought of going to neighbours to ask them to stop their burning. But that would not work because fire could be started by anybody, such as traditional hunters, who are difficult to trace. The villagers also considered digging a fire line. That was rejected because it was too tough a job. In the miombo, such a line would have to be very wide and demand lots of hard work, and hunters and others could still jump the line and start fires inside the line and would be difficult to trace. Therefore, they decided that fires in miombo cannot be stopped; they can only be planned for. The VFC members discussed the tradition of setting small fires for harvesting beehives that reduced the amount of fuel in the forest and kept fires small.

Villagers were setting their small fires without organisation. With the MFCC, the villagers could coordinate their small fires and make sure they did not get out of control. The MFCC therefore decided that fires should be started two months before the grasses start to dry, in April and May. Fires should be set by the VFCs and their patrolmen. Anybody else starting fires in April and May would be liable for punishment. Anyone, even VFC patrolmen, starting fires after May would be liable for fines from the VFC.

Initial attempts started small. The next year, 1997, each VFC burned along its boundary within the forest, to make sure to control fires within Mgori. The two villages bordering other districts also burned on the border with those districts to keep fire from outside from spreading to Mgori. They also burned small patches of grasses within VFC areas to reduce the risk of fire. This procedure is followed the same way each year and has worked thus far.

Monitoring by patrolmen and in the sample plots indicated that small trees were reviving after the bad burn of 1996. Patrolmen also found wildlife concentrated in areas with grasses sprouting from early burns. They also found that elephants had more grass from early burning, so they did not disturb crops so much. 


\section{Box 7.1 Continued}

To be sure, the MFCC asked Dr. Liz Wily, one of the technical advisors, to check with her colleagues about the value of early, controlled burning. Liz suggested that only VFC and patrolmen set the fires to keep it properly managed. At an MFCC meeting, the VFC representatives themselves suggested that all those inspecting or harvesting beehives should report to the secretary of the VFC for a permit (even those who come from other villages), and second, should carry a matchbox rather than other sources of fire. They also should make sure that after the work is done, all fires are extinguished. Dr. Wily's suggestions thus reinforced decisions already reached by the MFCC.

Donors have provided the funds needed to support such negotiations, and advisors have offered skills and experience in dealing with institutional problems. Government foresters, expatriate advisors and donors have acted as watchdogs over villagers and other government officials, quickly stepping in to address inefficiency or corruption in any of the forest management institutions. Donors and expatriate advisors, in particular, often have used access to higher-level government officials to solve problems more quickly than other groups could. In contrast, the government forester was critical for follow-up, as donors and their advisors did not stay in the villages. Descriptions of some of the specific problems addressed follow.

\section{Corruption and inefficiency}

There were several incidences of corruption and inefficiency that the villagers needed to resolve. In one case, a local councillor was allowing shifting cultivators from neighbouring districts to operate illegally in the reserve. The Mgori Forest Coordinating Committee appointed a team to inspect these issues in the field after receiving reports from different individuals that cultivation was underway. The team included the Divisional Forest Officer, District Forest Officer, District Game Officer and a District Council representative. They found that the offenders included a powerful man that the VFC was afraid to report on. Through the Coordinating Committee, supported by the Regional Commissioner, the VFC was dissolved and a new one elected by the villagers. The new VFC is working well. The field visit and the meetings were funded by the donor, but organised by the forester. 
There were also cases of inefficiency on the part of VFC members in two villages. Several meetings were called by the Coordinating Committee to warn them, but there was no change. Finally, the Divisional Forest Officer went, together with the expatriate advisors, to the District Executive Director who, through another official, dismissed these members. Some of these cases can be tackled by villagers themselves through monthly VFC meetings, Coordinating Committee meetings and other informal discussions. Some of the crucial issues, however, need external assistance. Without donor pressure, for example, it would have been difficult to change the VFC.

\section{Finance}

Finance has not yet been much of a problem, due in part to the fact that the Divisional Forest Officer helped the VFC set up the Village Forest Banking Accounts and regularly inspects the books for those accounts. The role of the officer assured transparency in all financial matters. The VFC also is required to report accounts to the Village Government and to the Village Assembly. The fact that the officer is considered an honest third party, and one who is in turn watched by the donor, gives villagers confidence that the books are in order and that the Committee members are working for everyone and not for their own benefit.

\section{Slowness of the District Council in passing the management plans and bylaws}

Each management plan was developed by the villagers with help from the donors, expatriate advisors and foresters. With the help of the donors and advisors, the first plan was approved quickly. After working under the first plan for 18 months, the villagers found they needed a change, based on discussions in their regular VFC meetings. Fines for violations under the first plan were not high enough to cover the damage or to punish leaders who abused their position by committing offences. The revised plans have been prepared and sent to the District, but have not been approved. The villagers are now making rules without legal backing and run the risk of outsiders violating their plans without fear of punishment. Foresters, donors and advisors need to continue to put pressure on the District to approve the new plan. 


\section{Institutional support from the Department of Forestry}

Initially, there was very little support for the Mgori Forest initiative from the then Director of Forestry, who railed against what he called 'wrong, new-fangled foreign notions' and who wanted to keep the forest for foresters (Msitu Newsletter, December, 1995). In addition, the laws and policies governing forestry dated from the colonial era in the 1950s, and though they did not expressly forbid people's participation, they also did not expressly allow it. The Project was thus started without any workable official policy. Shortly thereafter, a new Director was appointed who quickly came to the field. This was a key moment in the Project, as the Director was able to see directly the state of the forest and observe the management activities of the villagers. He gave the villagers the go-ahead for their management activities. The new Director also called a meeting of all Regional Forest Officers to discuss with them a need to change the forest policy. At the time of writing, the first draft of a new forest policy has been prepared and is under review, and is expected to receive parliamentary approval. The Mgori Forest initiative would not have gone to the extent it has without a Director who was willing to meet with and listen to villagers, and make decisions according to what he learned in the field.

\section{Game policy}

Both Regional and District Game Officers were also very supportive of the Mgori initiative, after a meeting with donors, advisors and the Division Forest Officer. The reserve was initially an area for public hunting, but the officers stopped issuing permits for hunting in this area to support the Mgori initiative. The project is now working with the Game Officers to develop a game policy that will benefit villagers through ecotourism. Currently, policies benefit central government and leave local people emptyhanded. The expatriate advisors helped assure the cooperation of the Game Officers by visiting with them, explaining the programme and asking for their support. They were probably more successful than the Divisional Forest Officer would have been acting alone. Donors, advisors and district officers are also needed to help the villagers influence government policy in Dar Es Salaam, encourage the Game Department to provide more assistance with more scientific monitoring of wildlife and help advertise locally and internationally the Mgori Forest as a place for ecotourism. 


\section{Boundary issues}

Initially, many boundary conflicts occurred among the five villages. These were resolved in meetings among VFCs, facilitated by donors, advisors and the Divisional Forest Officer. Now, however, there are new boundary conflicts with neighbouring districts, Hanang and Kondoa. No cut lines mark the Mgori boundaries with these two districts, thus there is confusion about where the boundaries lie. These boundaries are the responsibility of the respective District Commissioners, yet two District Commissioners have come and gone without resolving the problem. The matter has since been taken to the Regional Commissioner and there have already been exchange visits for fact finding between the districts by the District Commissioners and surveyors.

\section{Traditional hunters}

The donor facilitated transport for Mgori Forest villagers to travel to neighbouring districts to talk with the elders of hunting peoples. The Divisional Forest Officer then organised a meeting with the elders and helped to convince them to stop traditional hunters from coming to the Mgori Forest. The hunters listened as the forest was now under the villagers' management. The donors and expatriate advisors had no significant role in this activity.

To resolve the institutional issues above, it was necessary to involve villagers in discussions with other stakeholders, to have transparent processes so that villagers could build confidence in their advisors and their plans, and to have access to and support from higher levels of government. Funding was essential to support these activities. Foresters played an important role in keeping an eye on how the plans were working in practice.

The forester should be able to continue his work after the donor and advisors leave, now that he has experience. The villagers have also gained experience in forest management, and can solve many technical and institutional problems themselves. The question remains, how will the remaining roles of the donors and expatriate advisors be filled? Who will guide the process, who will solve the more complex technical and institutional problems with which villagers are unfamiliar, and who will be able to pressure government to support the Mgori Forest programme with new services and 
policies? How will management tasks be funded? At this point, the forester and the villagers are not ready to take on these tasks.

\section{CONCLUSIONS: WHAT IS NEEDED BEFORE THE DONOR AND EXPATRIATE ADVISORS LEAVE}

This chapter has shown that the role of facilitating collaborative forest management in the Mgori Forest is complex, and shared by several institutions. Facilitation can be costly and time-consuming. It requires certain skills and needs the support of government officials. I now examine what needs to happen for Tanzanians to pick up the facilitation tasks previously carried out by donors and expatriate advisors, and how they can deal with the issues of costs, skills and obtaining government support for collaborative forest management on their own. On the basis of my own involvement in the project and analysis of stakeholders' roles, it is my conclusion that stakeholders in the Mgori Forest can take five steps to assume responsibility for conducting the facilitation role.

First, there should be capacity building for forestry staff so that they can take up the work of involving the communities in managing their resources once the donors and advisors leave. Already the advisor working for Mgori, Liz Wily, has initiated a forum, consisting of a team of experienced foresters who have been working with the communities in the management of the forests (see Box 7.2). Funds are, however, provided by Orgut Consulting AB. The Director of Forestry is aware of the initiative and has given it the go-ahead. A change in the syllabus at various forestry teaching institutions to include a participatory approach is also needed. This could be started now while the donors and the advisors are present so that they may assist and advise the Forestry Department.

Second, local authorities should give support to villagers and their bylaws. The local authorities must encourage villagers in their tiresome work by playing their part in approving management plans and bylaws. These important documents are used as a compass to guide proper management and implementation of the work and as the legal basis for enforcement.

Third, government support should be secured for local ownership of land. The new Land Law Act of 1998 clearly states that villages will manage all the land belonging to 
Box 7.2 Establishing a forum for community-based forest management in Tanzania

By the year 2000, the government expects about 9000 Village Forest Reserves to be operational. The new forest policy and the new land act of 1998 give villagers the right to identify and manage natural resources for village development (Wily 1999). There is a need for experienced foresters to assist with this kind of community-based management.

To date, there has been little effort to train Tanzanian foresters to take up many of the facilitation roles needed to make Village Forest Reserves work. The forestry institutes train in traditional forestry: the syllabus takes no account of the new demands on foresters made by community-based forest management. Donors occasionally train foresters. For example, this author benefited from a donor-sponsored visit to study community-based forestry in Chiang Mai, Thailand. However, this is an expensive way to provide training and is unlikely to be available to a large number of foresters. How then can a large number of foresters learn about community-based management, and refresh that learning on a regular basis, so that they can work more effectively in the field?

In June of 1999, the first meeting of the Forum for Community-based Forest Management in Tanzania was held in Arusha. With the help of the Director of Forestry, Orgut Consulting and Dr. Liz Wily, the Forum brought together 13 foresters involved in implementing community-based management across the country. This meeting is meant to be the first of an ongoing series of meetings, with the next one scheduled for September. The purpose of the Forum is to create a platform on which experienced foresters can discuss problems and successes in implementing community-based management. Foresters learn how to play a facilitation role by sharing experiences with one another. They document their experiences in a book of guidelines that outlines techniques and strategies for dealing with problems faced in community-based management. This book includes a step-by-step outline of how to get started. For example, it presents discussions on how to build trust with villagers, how to set up Village Forest Committees, how to organise field visits with villagers to determine boundaries, how to prepare Village Forest Management Plans with villagers, and how to deal with conflicts among villagers and government officials, among other things. The guidelines are open-ended, however, and will be revised as new problems, and new approaches to solving them, arise. The Forum also is an opportunity for foresters to influence policy. The Forum has been approved by the Director of Forestry and he is planning to attend the regular Forum meetings. Foresters can influence the Director by exposing him to field 


\section{Box 7.2 Continued}

experiences. The Forum is more effective than individual reports from the field because it involves face to face communication and the opportunity to interact with many foresters at once. The Forum can also be more efficient because it is possible to get immediate responses to questions or requests. The Forum is currently in an introductory phase. One donor has recognised its importance and has agreed to finance the Forum. But for how long? And what will happen once the donor leaves? At that time, the Director of Forestry will have to find another way to support the Forum. As the Forum is an efficient way to train foresters in practical field work, the government should consider supporting the Forum itself. The Forum already has addressed how foresters can take up two roles that have been filled thus far by expatriate advisors. First, the Forum helps Tanzanian foresters develop skills and share experiences that help villagers set up committees, develop monitoring plans and pursue other activities necessary for collaborative forest management. Second, because the Forum is a recognisable entity, foresters will have more power to implement community-based management without interference from politicians and traditional foresters. The Forum, therefore, offers a concrete opportunity for the government and its foresters to make a positive impact on the growth of community-based forest management around the country, independent of external assistance.

them, which includes forests, in a sustainable way. This Act now gives the villagers a chance to plan and develop their resources without fear that they will be taken by government, provided they fulfil the conditions of the Act, particularly the surveying of village lands. So villagers can now confidently invest their time and energy in developing their land.

Fourth, there is a need for more in-country technical support, especially for monitoring. The Mgori Forest case is meant to be a model of sustainable utilisation of forest resources, and this involves some technically sophisticated monitoring. Proper monitoring of forests and wildlife could also help the villagers benefit financially, by indicating how much of a valuable resource can be harvested. This could lead the villagers to greater self-reliance in their management, so that they would not depend on donor funding. Now is a good time to use the presence of the donor and expatriate advisors to train local villagers to carry on the monitoring so that they can manage and facilitate more sophisticated monitoring by forestry and game officials. 
Fifth, there is a need for a system that ensures that the benefits of forestry and wildlife management from the Mgori Forest go to the villagers and the local authorities. This would again lead to greater self-reliance on the part of villagers and the local authorities managing Mgori. If the donors leave before such a system is in place, the Mgori programme will not be able to continue for lack of funds.

If the stakeholders can make these changes before the donors and advisors leave, the outlook for collaborative forest management at Mgori Forest will be bright. Villagers would be able to take up more of the tasks of funding their own management activities. Together with local foresters, they would be able to solve more of the complex technical and institutional problems faced at Mgori. They would have a stronger legal basis for pressuring the government to provide them with the services and policies they need to continue. The roles that outside facilitators have played will be replaced by new forms of collaboration. This evolution in the role of facilitation is likely to occur elsewhere where new initiatives occur. The ability of the facilitation functions to be taken on by others, however, and the flexibility of the collaborators to do this will be the keys to assuring the long-term sustainability of these initiatives.

\section{ACKNOWLEDGEMENTS}

I am grateful for the assistance provided by CIFOR and the East-West Center which enabled me to attend the workshop. Also many thanks to staff at the Center: Jeff Fox, June Kuramoto, Mary Abo, Sonja Brodt. I am glad for their courtesy during our stay at the Center. Also, David Edmunds provided great assistance and guidance in writing this chapter. Our one-month stay at the Center has improved our skills and we hope to be change catalysts at our work places.

\section{ENDNOTES}

${ }^{1}$ Miombo is a colloquial term used to describe dry forests south of the equator in Africa, usually dominated by the genera Brachystegia, Julbernadia or Isoberlinia. The importance of miombo for forest product use and wildlife is increasingly recognized. Refer to Campbell (1996). 
${ }^{2}$ Dr. Liz Wily, an international development consultant based in Nairobi, Kenya, and Mr. Håkan Sjöholm, a natural forest management advisor based in Dar Es Salaam, Tanzania, have acted from the outset as the main facilitators of these developments on behalf of Orgut Consulting AB. This Swedish-based consulting group has been providing technical assistance to natural resources and land management programs in Tanzania on behalf of the Swedish International Development Agency (SIDA) and in conjunction with the Tanzanian Government.

\section{LITERATURE CITED}

Asanga, C. This volume. Facilitating viable partnerhips in community forest management in Cameroon: the case of Kilum-Ijim mountain forest area. In: Wollenberg, E., Edmunds, D., Buck, L., Fox, J. and Brodt, S. (eds.) Social Learning in Community Forests, pp. 21-44. CIFOR and East West Center, Honolulu and Bogor, Indonesia.

Borrini-Feyerabend, G. (ed.) 1997 Beyond fences: seeking social sustainability in conservation. Volume 2: a resource book. World Conservation Union (IUCN), Gland, Switzerland.

Campbell, B. (ed.) 1996 The Miombo in transition: woodlands and welfare in Africa. Monograph. Center for International Forestry Research, Bogor, Indonesia.

Gilmour, D. and Fisher, B. 1997 A project or a process? The story of Chaap al Danda. In: Borrini-Feyerabend, G. (ed.) Beyond fences: seeking social sustainability in conservation. Volume 2: a resource book, 103-106. World Conservation Union (IUCN), Gland, Switzerland.

Grimble, R., Chan, M., Aglionby, J. and Quan, J. 1995 Trees and trade-offs: a stakeholder approach to natural resource management. Gatekeeper series No. 52. International Institute for Environment and Development, London.

Ingles, A., Musch, A. and Qwist-Hoffman, H. 1998 The participatory process for supporting collaborative management of natural resources: an overview. Draft discussion paper prepared for the Community Forestry Unit. The Food and Agriculture Organisation, Rome.

Joshi, A. 1998 Progressive bureaucracy: an oxymoron? The case of Joint Forest Management in India. Rural Development Forestry Network paper, 24a. Overseas Development Institute, London. 
Margoluis, R. and Salafsky, N. 1998 Measures of success: designing, managing, and monitoring conservation and development projects. Island Press, Washington, DC.

Ramirez, R. 1999. Stakeholder analysis and conflict management. In: Buckles, D. (ed.) Conflict and collaboration in natural resource management, 101-126. International Development Research Centre/World Bank, Ottawa, Canada and Washington, USA.

Röling, N. and Jiggins, J. 1998 The ecological knowledge system. In: Röling, N. and Wagemakers, M. (eds.) Facilitating sustainable agriculture: participatory learning and adaptive management in times of environmental uncertainty, 283-311. University of Cambridge Press, Cambridge, UK.

Wily, L. 1996 Collaborative forest management, villages and government: the case study of Mgori Forest, Tanzania. Forest, Trees and People working paper. Food and Agriculture Organisation, Rome.

Wily, L. 1999 The evolution of community-based forest management in Tanzania. Unpublished document presented to the Ministry of Land, the Republic of Tanzania. 
EXTERNALDONORS AND COMMUNITY-BASED MANAGEMENT 


\title{
Chapter Eight
}

\section{Model forests: A partnership-based approach to landscape management}

\author{
Ron D. Ayling
}

\begin{abstract}
This chapter examines the potential of model forests as new institutions for a scaledup, landscape-based approach to resource management. The Model Forests Programme was established in Canada in 1992 in response to growing public concern over forest management practices, future timber supplies and the long-term conservation of forests. The programme has grown into the International Model Forest Network, currently spanning seven countries around the globe. While a diversity of resource base, ownership and governance structures characterises the model forests in the network, each model forest ideally comprises a partnership among micro-level stakeholders, such as local communities, and macro-level stakeholders, such as government agencies and national organisations. The chapter examines the successes and shortcomings of current model forests in promoting adaptive management and in defining and addressing stakeholders' values and conflicts over resource use. It concludes that, while the programme provides a framework for innovation, adaptive management and collective learning and decision making, it is as yet too early to demonstrate concrete progress and results.
\end{abstract}


'We have not realised all of our initial goals and objectives; however, we have developed a framework which allows us to debate contested issues in an atmosphere of trust and good will'

\section{Dr. Louis LaPierre, Chairman, Fundy Model Forest, Canada ${ }^{1}$}

\section{INTRODUCTION}

In 1992 Canada redefined its forest management objectives in a strategy statement, Sustainable Forests: A Canadian Commitment. This strategy emphasised the importance of forests as ecosystems and not only as sources of timber. It was a direct response to the 1987 Brundtland Commission Report. The Strategy was the result of an extensive and open process of public consultation on the future of the nation's forests and recognised the presence of multiple and often conflicting values associated with forest resources. Despite the political commitment to support the shift in forest management from sustained yields to sustainable management, the knowledge and tools to support an ecosystem management approach were unknown (Brand et al. 1996). Furthermore, as Röling and Jiggins (1998: 296) observed "only few institutions have emerged to support sustainability...yet careful studies of the management of complex ecosystems or of common property resources reveal the immense importance of new institutional arrangements.'

The Model Forest Programme was established to assist in the search for the new development path called for by the National Forest Strategy. The programme is considered a series of ecosystem-level experiments to devise, test and accelerate the implementation of sustainable development based on forest resources. Each model forest is a physical, geographical entity that can be illustrated on a map and examined on the ground.

The first five-year phase began in 1992 with the approval of the Canadian Council of Forest Ministers and the financial support of the Canadian Forest Service (CFS). Following the United Nations Conference on the Environment and Development (UNCED) held in Brazil in 1992, Canada invited other countries to participate in building an international network of model forests (see Figure 8.1). The oldest model forests are the original ten of the Canadian network, the Calakmul and Chihuahua Model Forests in Mexico, and the Gassinski Model Forest in Russia's Far East. Other members in the current network include Argentina, Chile, Japan and the United States. 


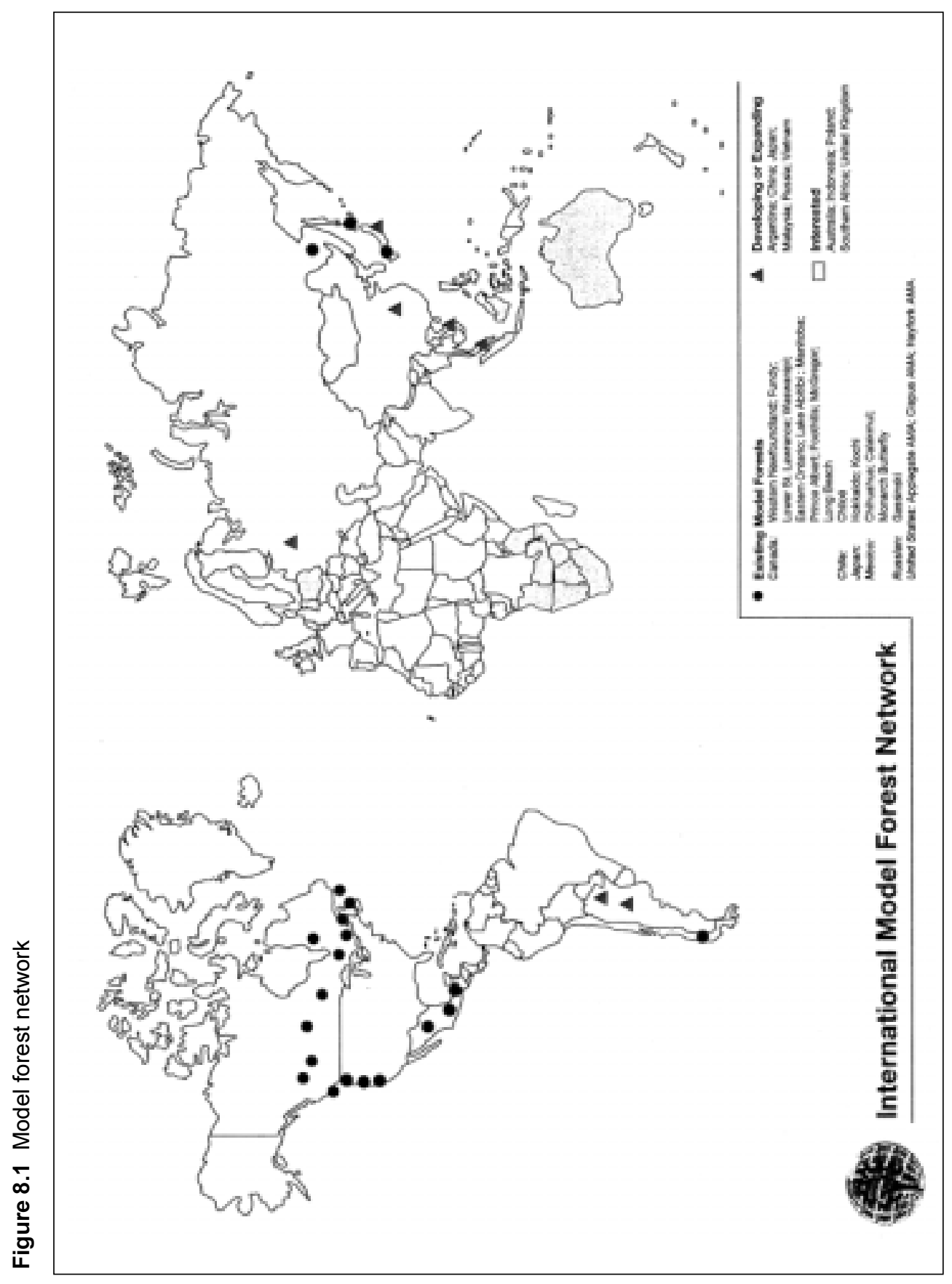


Each model forest is unique in terms of its biological resources, ownership or responsibility patterns, benefits and value systems, knowledge, management skills and options available and above all, the composition of its stakeholders - those involved directly or indirectly in management decisions. This diversity is a major strength of the programme and allows for learning about forest management under varying conditions.

The purpose of this chapter is to examine the potential of model forests as institutions for ecosystem-based management. The chapter is based on a limited, but growing literature on model forests, particularly several studies supported by the Manitoba Model Forest, as well as interviews provided by key informants. ${ }^{2}$ Special attention is given to the Network's experience in developing partnerships and constructive stakeholder relationships across large landscapes.

\section{BACKGROUND}

A 1989 national survey of Canadian public opinion on forestry found that $75 \%$ of those surveyed considered forests to be a national treasure that should be held in trust for future generations. Almost as many disapproved of clearcut harvesting and the use of chemicals in forest management, and half considered forests more important for wildlife protection and as wilderness areas than for other forest values (Carrow 1999). Increasing concern over future timber supplies, recognition of the multiple values of forests, and public pressure, including highly publicised resource-use conflicts over old-growth forests, were common in Canada in the early 1990s. Forest management as perceived by the public was clearly out of phase with society's emerging values of ecological sustainability, biodiversity and integrated planning as well as institutional issues relating to stakeholder participation in planning and decision making. The Model Forest Programme was designed to respond to these concerns by establishing a series of representative situations within which these values and issues could be addressed at a local and regional level (Sinclair et al. 1998a). 


\section{A MODEL FOREST DEFINED}

A model forest may be considered a social experiment in innovative learning. It is 'a consensus-driven partnership, working with shared decision making to achieve social, environmental and economic sustainability in forest management' (Bouman and Kulshreshtha 1998: 255).

The nature and composition of each model forest partnership is unique, differing according to the history of the area and its social, economic and ecological characteristics. At a minimum the partnership consists of landowners and/or organisations, institutions and individuals directly dependent on, or de facto managers of, land and resources, referred to by Grimble et al. (1995) as micro-level stakeholders. Other partners might include macro-level stakeholders such as government officials, academia and national organisations not directly dependent on the particular forest resources. The managing partnership of Mexico's Chihuahua Model Forest includes, for example, private owners and representatives of the peasant communities or ejidos (micro-level stakeholders) and macro-level stakeholders such as the Ministry of Environment and state and local governments. A second group of macro-level stakeholders are collaborating partners, including representatives of national institutions, universities and even the US National Parks Service, who provide technical assistance when required. The Eastern Ontario Model Forest, an area of some 1.5 million ha of fragmented forest in east-central Canada, claims a partnership mix of micro- and macro-level stakeholders of over 100 organisations, individuals and enterprises, although many are clearly more active than others.

Model forests are expected to be inclusive and represent as much as possible the complete range of interests and values (both utilitarian and aesthetic) for the area, particularly those of micro-stakeholders. Members agree to work together towards a common vision and a common set of forest management objectives. They also agree to demonstrate progress towards sustainable forest management.

The creation of a model forest does not supersede the rights, interests and responsibilities of individual land owners and managers. Individual partners continue to manage the land-base; the model forest provides support and contributes to improving knowledge on how management may best be carried out. 
Sinclair et al. (1998a: 2) summarise clearly that the 'multistakeholder aspect of the model forest programme is particularly significant since the model forests themselves have no decision-making authority regarding the use of the forest resource. Each model forest, therefore, relies on its multistakeholder partners to take up and implement the good ideas that result from the studies undertaken. This means that each model forest must not only have a broad array of stakeholders on their respective Partnership Management Board, but also that these stakeholders communicate the results of studies undertaken to a wider constituency' (emphasis added).

The landscape scale of a model forest is distinct from two common patterns of forest management that many countries use to involve micro-level stakeholders. The first, co-managed forests, displays a range of management arrangements between local resource users and government. These range from those that merely involve local participants to those where local communities have considerable authority and responsibility. In Canada, co-management is most commonly represented by agreements between aboriginal communities and federal or provincial governments. The second common pattern is community forests, which are relatively new to North America but have existed in different forms for generations in many countries (Beckley 1998). Model forests are invariably larger than co-managed and community forests, but more important is the diversity of landscape units, ownership patterns and management regimes that determine the partnership composition and the values and resource-use issues of the model forest. What makes an ecosystem large is not its size but the degree of interdependent use (Lee 1993).

Co-management and community forests show attributes of model forests: community-based management of multiple forest resources and decisions made by consensus among stakeholder groups. However, they differ in two important ways. Co-management and community forests define the community as a placespecific group of forest users. In contrast, the community of a model forest is inclusive and includes a full spectrum of stakeholders - those with either a direct or indirect, or a mandated interest in how resources are used and managed. A second difference is that 'theoretical models of community forestry often involve or assume that some institutional body exists to determine management objectives for community forests' (Beckley 1998: 738), whereas with model forests, prior 
institutional arrangements do not exist and have to be created. The need to create effective institutional arrangements for landscape-scale management is precisely the challenge of the model forest system.

\section{KEY ATTRIBUTES OF A MODEL FOREST}

Sustainable resource management is the common goal of each model forest and is based on three fundamental constructs: the sustainable management of a diverse resource base, collaboration through a partnership among stakeholders and the use of a learning process. This last construct implies that management activities of the model forest should be experimental (if not on the entire area at least on significant portions of it). They should also be diverse and flexible enough to adapt to the changing needs, interests and values of the partnership and society at large, the uncertainties of biological systems and the unfolding complexities of sustainability.

\section{Diversity of the resource base}

All model forests presently in the international network are a minimum of 100000 ha and include a variety of elements such as natural forest, plantations, farmland, villages and small municipalities, rivers, lakes and the greenbelt areas around large urban centres. Boundaries are based on existing political or administrative boundaries, one or several watersheds, or other considerations such as forest types. The critical point is that a model forest is a mosaic of elements across a landscape. The Manitoba Model Forest, for example, consists of provincial land licensed to a paper company, provincial forests and multiple-use parklands, a provincial wilderness area, numerous municipalities and town sites, privately-owned agricultural land and woodlots and the reserve lands of four aboriginal groups (Waldram 1998). The Bas Saint Laurent Model Forest, in a densely-populated region of eastern Quebec is, on the other hand, entirely privately-owned. The 112 000 ha landscape is composed of two large tracts owned by a timber corporation and a third controlled by hundreds of small woodlot owners. The McGregor Model Forest on the western edge of the Rocky Mountains is comprised of a single 180,000 hectare tree farm leased by the provincial government of British Columbia to one entity, a large timber corporation. 
MODEL FORESTS

\section{The partnership structure}

The key innovation that the Model Forest Programme is testing is the development of partnerships across diverse and often large numbers of stakeholders. The effectiveness of the partnership structure has been crucial to the success of the programme (Sinclair et al. 1998a). An effective partnership provides its members and their constituencies with opportunities to experiment with new approaches to resource management, recognising and sharing the risk of failure. At the same time, for individual stakeholders, such as a timber company, environmental organisation or aboriginal community, there can be risks attached to shifts in power and influence, to becoming more transparent in negotiating or to accepting and learning from criticism. The partnership seeks to overcome these risks by experimenting with new forms of communication, interaction and decision making among stakeholders. Often, time and the trust built up through working together over years have been the most important factors. A 1996 evaluation of the Canadian programme noted that the creation of the partnerships was a major accomplishment and a more difficult and time-consuming task than expected (Gardner-Pinfold 1996).

In the formative early stages of development, a model forest may benefit most from the input of an external facilitator to bring this rich assortment together and to ensure that the process is kept on track; an initiative led by a key stakeholder may have the disadvantage of the appearance of ownership and give the perception of a controlled agenda. The facilitator needs to be neutral (in actuality and in others' perceptions) in order to ensure equity and fairness, especially where stakeholders may be unequal in power and knowledge. In the Canadian network of model forests, for example, the Canadian Forest Service provides an 'enabling environment' whereby stakeholders of different strengths can come together, exchange views and information, share experiences and begin to work together on resource management at an ecosystem level.

To be effective, the partnership must be representative of the key interests and values among both the micro and macro stakeholders. According to Bouman and Kulshreshtha (1998: 257), 'private sector companies took, in most cases, the lead in the development of the original model forest proposals for those sites that had been admitted to the programme.' This was the process for the Prince Albert Model Forest and likely others such as British Columbia's McGregor Model Forest, the 2.5 million ha Foothills Model Forest in west-central Alberta, and the Lake Abitibi Model Forest in northern 
Ontario. However, with the onset of the second five-year programme in late 1997, most partnerships increased their diversity of participation. The Foothills Model Forest brought in additional stakeholders such as aboriginal communities, the Alberta Forest Products Association and the Canadian Association of Petroleum Producers. One feature of the Model Forest Programme that has enabled the partnerships to increase their effectiveness is that the partnerships are dynamic and evolving associations, non-restrictive, and open to growth and change.

One of the advantages to including such a broad range of stakeholders is that it enables a discussion of the complex relationships and values found across the landscape (Figure 8.2). Model forest partnerships provide institutional structures for negotiation and social learning to address the need for scaling up decision making to the higher level of the landscape.

The model forest experience suggests that there is no one institutional recipe for fostering this scaling up. Each arrangement is responsive to the interests in the landscape. However, a few features are shared at a very broad level. Each model forest is a registered 'not-for-profit' organisation or corporation, and each has a volunteer governance structure labelled as Board of Directors, Partnership

Figure 8.2 Partnerships can be rich associations of personalities, and are dynamic and evolving relationships (Waswanipi Cree Model Forest)

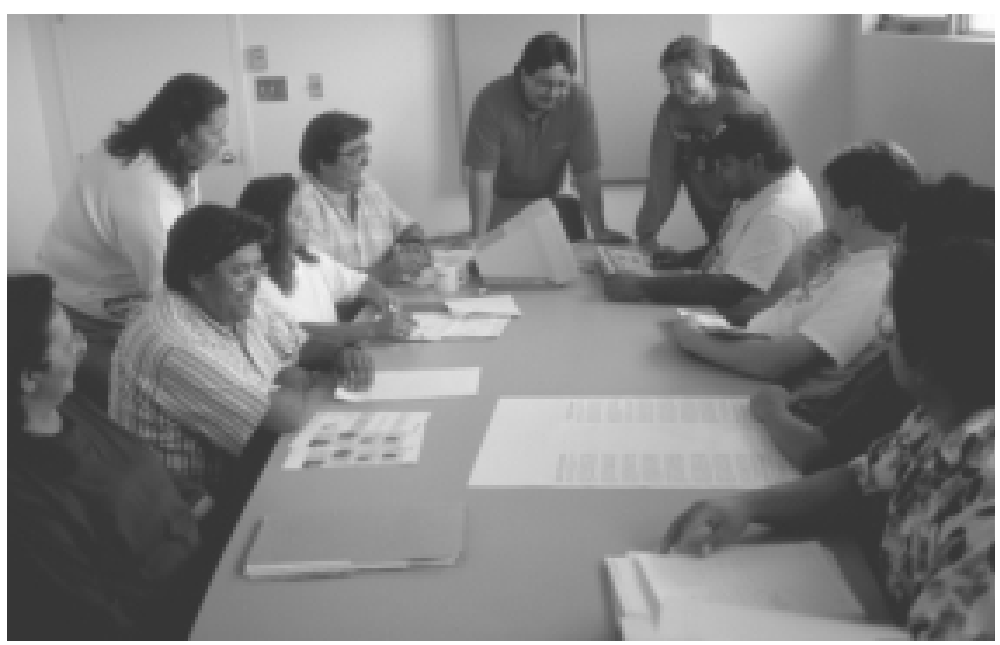


Management Board or Management Committee. Some or all members of these governing bodies are elected by the general membership of the partner organisations, while others are permanent positions reserved for key stakeholders. Aside from these general commonalities, the partnerships formed by the different model forests vary widely from tightly knit organisations where decision-making authority is concentrated among a small number of partners, to relatively broad-based organisations involving many people (Gardner-Pinfold 1996). In some cases, such as the Manitoba Model Forest, the governing structure is made up of all the partners; in contrast, the Fundy Model Forest has a 10-member Management Committee answerable to a 28-member Partnership Group. The Eastern Ontario Model Forest also has a 10-member Board of Directors, with six positions elected by the general membership of over 100 organisations, enterprises and individuals. Sinclair and Smith (1995) found that the more traditional interests (timber) were consistently well-represented on smaller boards. For example, Sinclair et al. (1998b) suggested at the time that the 11-member Board of the Foothills Model Forest was the least diverse with six positions held by the provincial government and industry officials. As Board size increases, so generally does the diversity of interests at the table, although exceptions exist.

Respondents to a survey of four model forests by Sinclair et al. (1998b) suggested that one of the most positive changes the model forest structure could bring about would be to identify ways of involving more stakeholders in decision making. Ironically, the authors noted that none of the four model forests included in the study ${ }^{3}$ considered stakeholder involvement an important research topic. Nevertheless, most model forests are continually trying to widen the partnership base with an emphasis on local groups, especially aboriginal communities (Mike Waldram, Manitoba Model Forest; personal communication). The Chihuahua Model Forest in the Sierra Madre Mountains in Mexico presents an interesting lesson in the development of a more representative board through targeted efforts to reduce mistrust (see Box 8.1).

\section{The learning process}

Because of the inherent diversity of the resource base and complexity of the partnership structure, a learning process approach must be taken to achieve both sustainable landscape management as well as effective partner collaboration. 
Box 8.1 Development of a Representative Board for the Chihuahua Model Forest, Mexico

The model forest area includes eight ejidos, diverse peasant communities where forested lands are communal and management decisions are made by the community. More than $97 \%$ of the model forest land base is owned by the ejidos. However, owing to a falling-out among the original three partners at the time the proposal was being developed, the concept of community representation was lost and ejidos were not represented on the Board for the first four years of model forest operations. The Board consisted only of federal and state government representatives. The development of the second five-year phase specifically took up the challenge of engaging community leaders in the programme, a slow and difficult task in order to overcome past misunderstandings and build trust. More than 20 workshops were organised, including workshops on specific topics like ecotourism. One of the most important ways of overcoming mistrust was to support small projects which involved the community. These small projects were trying to solve some immediate basic needs like food and housing. The current six-member Board has two ejido representatives and two representatives of large private landowners. The role of the government agencies has diminished.

(Source: Gustavo Heredia, CMF; personal communication).

\section{Adaptive management of resources}

The concept of adaptive management involves continual learning facilitated by the rapid acquisition of knowledge, effective information flow and processes for creating shared understandings (McLain and Lee 1996). It often involves 'the use of systems models and an iterative hypothesis testing process to enhance knowledge acquisition rates' (McLain and Lee 1996: 443). In some model forests, adaptive management of resources has been implemented through scenario-based techniques and modelling.

For example, adaptive management by the Fundy Model Forest uses a 'what if' scenario planning approach to predict future landscapes and resource values affected by management practices (MacLean et al. 1999). Their 'management planning loop' is similar to the steps for adaptive management set out by Kemmis and McTaggart (1998): design; act; monitor and observe; and reflect and revise. It begins with partnership input to identify issues of concern, then moves to public consultation to add to or refine issues and results in a range of management scenarios for evaluation and revision (Figure 8.3). 
Figure 8.3 Public participation and sharing of information are essential ingredients of an effective model forest (Western Newfoundland Model Forest)

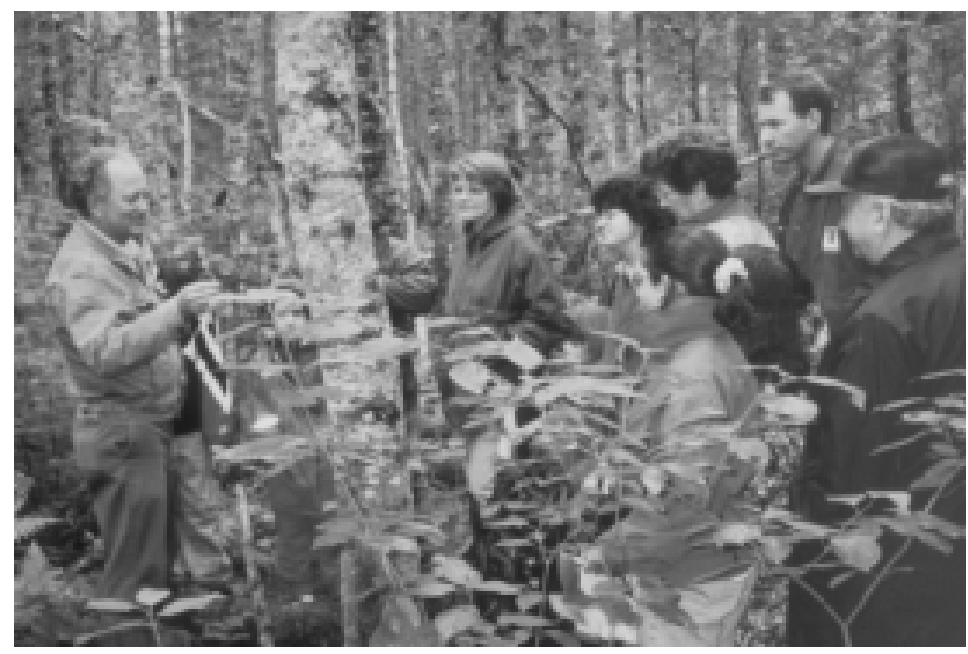

In another example, wildlife habitat modelling of the pine marten in the Western Newfoundland Model Forest is using adaptive management methods to determine where and how timber harvesting should be conducted. The process follows a cyclical framework to continually re-evaluate assumptions and modify actions based upon new information until forecasts mirror the results of the actions (Sean Dolter, Senior Planner, Western Newfoundland Model Forest; personal communication).

\section{Adaptive management for institutional design}

In addition to adaptive resource management techniques, there has been a parallel use of adaptive management in the partnership building process. 'The adaptive management concept stresses the importance of social interaction and consensus building in reaching management decisions' (McLain and Lee 1996: 446), and will fail unless fora for creating shared understanding about values, goals, objectives and management options among stakeholders are created. In practice, attention is rarely given to the type of institutional structure and the processes required for adaptive management to work on a large scale. 'Essentially the problem is one of creating an institutional framework that promotes the coordination of management activities undertaken by many loosely connected but interdependent institutions' (McLain and Lee 1996: 446). 
The partnership structures of the model forests can provide insights about what is necessary for such large-scale management to work. Partnerships in large-scale landscapes cannot afford to exclude any one group of stakeholders (Beckley et al. 1995; Sinclair and Smith 1995; Sinclair et al. 1998a, 1998b). They may have to absorb significant costs and allow long periods of time to bring all groups on board. In the Manitoba Model Forest, partly because of misunderstandings, communication problems and a long history of mistrust, aboriginal communities did not participate in the first five years of the partnership. The Board recognised that this lack of participation was a critical issue and set about to change it through community presentations, workshops and the involvement of aboriginal communities in project design and implementation. This was a time-consuming but necessary process. Direct, verbal communication instead of correspondence through letters, faxes and electronic mail was found to be important, perhaps more so than with non-aboriginal groups (Mike Waldram, MBMF; pers. comm.). The Gassinski Model Forest experience (see Box 8.2) shows that this type of experience in partnership-building is not limited to Canada.

Box 8.2 Experimenting with partnership building in the Gassinski Model Forest, Russia

The Gassinski Model Forest in Russia's Far East is primarily managed for timber. There was originally one stakeholder, the government, with subsets of stakeholders all funded and supported by the central government. Although they appeared to have similar interests, conflict was not uncommon due to strongly-held views and a history where collaboration was largely unknown. There was an overall feeling of unease because of problems with the economy, and mistrust and reluctance to bargain in good faith. Over time, however, through discussions and interactions often occurring at an individual level, the process of working through the model forest programme created opportunities for building trust, respect and confidence. It was also clear that the projects were trying to solve several important local problems affecting everybody, such as high unemployment. Political agendas and self-promotion were overcome. Trust and confidence building came through such simple things as freely sharing information. The investment in time, money and energy in building an effective, working partnership has been considerable, and some conflicts still exist. But the bottom line is that the partners have learned that they can accomplish more together than separately. Source: Evgeny Zabubenin, administrator, GMF; personal communication. 
MODEL FORESTS

\section{Appreciating stakeholder values}

Once partners agree to work together, how can groups of such diverse and often large numbers of stakeholders learn to appreciate each other's values and interests? An effective working partnership implies an awareness, but not necessarily acceptance, of each partner's attitudes, perceptions and values. Yet, according to Beckley et al. (1995: 17) 'systematic assessments of stakeholder values are rarely done in Canada,' let alone any the development of any process for stakeholders to become aware of each other's values. An evaluation of the Canadian Model Forest Programme noted that actual forest management involving stakeholders' values during Phase I was scarce (Gardner-Pinfold 1996).

The Model Forests have worked to identify values and an appreciation for values through a variety of mechanisms. Surveys of four model forests ${ }^{4}$ by researchers from the University of Manitoba (Sinclair et al. 1998a, 1998b) indicated that board-level discussions, public workshops, commissioned studies, presentations, strategic planning initiatives and specific projects had been undertaken at one time or another, sometimes in combination. In all four model forests, the majority of respondents indicated that the best means for groups to understand each others' values was through board-level discussions, and in fact it was due to the consideration of the partners' values that changes in the decision-making process occurred regularly. Regular face-to-face meetings in small groups with a mandate to make decisions was a critical element of this mechanism's success.

In the Fundy Model Forest, a series of consultations and workshops involving the partnership group in addition to workshops for the general public were found to enhance the degree and quality of public participation in identifying resource-use issues. Here, getting forest managers to meet face-to-face with other stakeholders and discuss with them their concerns enabled more effective communication of people's values. Studies of the resource values and interrelationships of the three main stakeholders of the Prince Albert Model Forest in northern Saskatchewan (Bouman and Kulshreshtha 1998) helped to explain the partnership's limited progress with integrated management. The timber sector was primarily interested in timber production while the national park's interests related to its mandate to protect and enhance biological diversity and wildlife habitat. The aboriginal partners held the widest range of forest values with the strongest psychological and spiritual attachment to the forest. These studies, while 
perhaps involving a lengthier period for learning about stakeholders' values, nevertheless served a purpose in identifying more entrenched biases that had hindered the partnership. In addition, they can provide a relatively 'neutral' view that all stakeholders can be more open to than they might otherwise be in face-to-face meetings.

Among many of the Canadian model forests, these mechanisms for eliciting and learning about values have resulted in a consistent trend towards greater recognition of aboriginal values. For example, aboriginal values have played a critical role in the development of the Long Beach Model Forest on Vancouver Island (Norma Dryden, LBMF; personal communication). With more than half the population of the area comprising aboriginal people, and a majority of those under the age of 25 , a youth representative was included on the Board and the values and interests of young native people became an integral part of the design and delivery of the programme. The other partners also agreed that all forest management should be ecosystem-based and driven by aboriginal values and traditional knowledge of resource management. In Ontario, aboriginal values of the Mohawk community are key to the functioning of the Eastern Ontario Model Forest (Barkley et al. 1997; Story and Lickers 1997). Partners have agreed to the Mohawk concept of 'planning for seven generations' and to decision making by consensus.

\section{Values of the wider community}

In order to address the goal of sustainable forest management more effectively, an appreciation of values held by the community, beyond the Board level and the partnership group, is essential, as shown by Sinclair et al. (1998b). Three model forests in their study had started research on community values through formal workshops and surveys and, somewhat significantly, most respondents accepted that research on values could lead to creative solutions for influencing the decision-making process. They concluded that these model forests were just beginning to consider forest values, but questioned whether the importance of research on values in challenging status quo forest management was fully acknowledged.

It should not always be assumed that stakeholders' values and interests are the equivalent to those of the wider public. As noted previously, there have been and continue to be highly publicised examples of resource-use conflict in Canada and in a number of other industrialised countries. Beckley et al. (1995) note that the forest products industry in 
Canada has been largely influential in determining the direction of public policy, and other stakeholders such as aboriginal groups, environmentalists and the public in general have been noticeably absent. As a result, they contend that 'a fractious community exists $1 / 4$ and there is great deal of unresolved conflict throughout the Canadian forest sector' (Beckley et al. 1995: 33).

\section{Values and resource conflicts}

An analysis of the values and of the interactions between and amongst stakeholders and the community can reveal much about the potential for conflict over management choices. With natural resources, 'each stakeholder group can be expected to have rational but different interests $1 / 4$ and these differences may be fundamental' (Grimble et al. 1995: 3). Conflict is a normal and even desirable element in society (Grimble et al. 1995) and, according to Lee (1993: 10), "necessary to detect error and to force corrections.' However, unbounded conflict will destroy the long-term cooperation required for sustainability, and therefore a degree of conflict bounded by legitimate restraint is beneficial. Both adaptive management and bounded conflict are essential for social learning in the Model Forest Programme. In a resource policy context, conflict itself is not the problem; rather, the way it is managed can be problematic. Conflict may result from different interpretations of information or different sets of information, from differences in underlying social values, or from different perceptions of who wins and who loses. If institutional structures fail to address the underlying causes, conflict may go unresolved and will ultimately lead to high social, political and managerial costs.

Within the Model Forest Programme, conflict or even minor disagreements over resource management decisions are largely unrecorded in the available literature. If conflict is actually lacking, it may be due to any number of reasons: a narrow stakeholder base in which there are few differences in resource values; the implementation of non-controversial projects or the failure to analyse the significance of project results; and/or the fact that forest management practices and policies have yet to be influenced to any degree by model forests. The failure to record and analyse conflict management is also another possibility.

The apparent lack of conflict over resource management issues may also be due to the ability of individual model forests to manage and resolve conflict, reach consensus, 
make decisions and move forward. Barkley et al. (1997:2) suggest that the Eastern Ontario Model Forest 'has gained substantial practical experience in dealing with multi-value management of the forest resource in a private land tenure system and has developed a respected conflict avoidance approach to working with diverse groups.'

The conflict that does exist appears to be related to governance within the model forest. In their review, Sinclair et al. (1998b) reported that most conflicts were related to the allocation of programme funding, the type and direction of projects and the structure of the Boards. Issues were dealt with through discussions and resolved or held over for further discussion. Both the Manitoba and Foothills Model Forests operated on the basis of a modified consensus process, discussing issues thoroughly and then voting using Roberts' Rules (a protocol commonly used for running meetings). The Lake Abitibi and Long Beach Model Forests were experimenting with consensus building based on communication and discussion.

The wider literature provides very little insight on cooperation or conflict management when a large number of stakeholders with different interests is involved in using the resource (Grimble et al. 1995). Clearly, the preceding discussion barely reflects the rich social dynamics that are taking place within model forest partnerships as they develop and mature. All model forests have an important contribution to make in this area of social research by documenting and sharing their experiences of institutional learning.

\section{CONCLUSIONS}

The concept of 'sustainable development' still lacks precision. One of the benefits of the Model Forest Programme is to give this concept form at a local level. Although each model forest is unique in terms of its resource base and partnership structure, the programme provides the framework for flexibility and innovation, and for experimentation and risk-taking in adaptive management at the broad landscape level. The composition, values and interrelationships of a rich assortment of stakeholders makes for a fascinating experiment in collective learning and decision making.

To manage large, complex landscapes, model forests draw from three approaches: an appreciation and understanding of the diversity of land uses and their relationships, 
partnerships based on both micro- and macro-level stakeholders, and a learning process to adjust assumptions, objectives and management techniques. Among these elements, the partnerships have proved by far the most time-consuming and challenging to implement, and have affected progress on understanding diverse land resources and on shared learning.

In developing partnerships for landscape management, the Network has had to craft institutional arrangements among diverse interests and types of organisations. Comprehensive representation of these interests, communication with interest groups and the building of trust among them have been the greatest hurdles. A trade-off seems to occur between being able to deal with large numbers of interests and yet having quality face-to-face interaction between them. Two factors are essential: sufficient time to develop the partnerships and the capacity to be flexible and respond to changing interests and organisational imperatives.

While the model forest concept is sound and the processes followed are dynamic and evolving, the 'programme' is not without challenges. A certain amount of risk is involved, for example, for an entrenched bureaucracy or corporate institution in opening up to public scrutiny and to processes which might have aspects of 'give-and-take'. Local communities, particularly those marginalised by culture or economics, also face risk. To be successful, then, model forests require risk-taking and innovative leadership, and, some might say, tireless visionaries unbounded by conservative traditions.

Demonstrating progress and results is also a challenge. There is considerable expectation that the programme will result in on-the-ground change and influence forest policy. Therefore each model forest is expected to show evidence that management practices are different and are leading to sustainable resource management. The evaluation of the Canadian Programme after five years, while acknowledging achievements, noted that there was little evidence of this 'on-theground' change. Carrow (1999) stated that if change did not occur, public credibility of the programme will be lost. However, the introduction, evaluation, modification and adoption of new concepts requires time. Experimentation by a partnership of diverse interests needs time, goodwill and much effort. As Lee (1993:14) noted 'the crucial test will be learning over time scales of biological significance-learning that lasts long enough to sense the long-run response of the ecosystems we use. Since long- 
term learning is the acid test of whether a policy (or a concept) is in fact headed towards sustainability.'

\section{ACKNOWLEDGEMENTS}

I would like to express my sincere appreciation to the following: the Secretariat of the International Model Forest Network, particularly Peter Besseau, programme officer for Asia/Europe and Kafui Dansou, programme officer for Latin America; Evgeny Zabubenin, administrator of the Gassinski Model Forest; Gustavo Heredia, General Manager of the Chihuahua Model Forest; John Hall of the Canadian Network; Sheila Robinson and Sean Dolter of the Western Newfoundland Model Forest; Norma Dryden of the Long Beach Model Forest; Mike Waldram, General Manager of the Manitoba Model Forest; the workshop team at the East-West Centre, in particular Sonja Brodt; and the workshop participants.

\section{ENDNOTES}

${ }^{1}$ Dr. Louis LaPierre, 1995/96 FMF Annual Report; as noted in MacLean et al. 1999.

${ }^{2}$ Informants included Dr. John Hall, General Manager of the Canadian Model Forest Programme of the Canadian Forest Service, Evgeny Zabubenin, administrator of the Gassinski Model Forest, Russia and Sr. Gustavo Heredia, General Manager, Chihuahua Model Forest, Mexico.

${ }^{3}$ Manitoba Model Forest, Long Beach Model Forest, Foothills Model Forest and Lake Abitibi Model Forest.

${ }^{4}$ Manitoba Model Forest, Long Beach Model Forest, Foothills Model Forest and Lake Abitibi Model Forest. 
MODEL FORESTS

\section{LITERATURE CITED}

Barkley, B., Patry, M., Story, P. and Virc, S. 1997 The Eastern Ontario model forest: acting locally, connecting globally. The Forestry Chronicle 73(6): 1-4.

Beckley, T.M. 1998 Moving towards consensus-based forest management: a comparison of industrial, co-managed, community and small private forests in Canada. The Forestry Chronicle 74(5): 736-744.

Beckley, T.M., Boxall, P.C., Just, L.L. and Wellstead, A.M. 1995 Forest stakeholders' attitudes and values: a review of social science contributions. MBMF 95-2-25.

Bouman, O.T. and Kulshreshtha, S.N. 1998 A case of integrated development in the boreal forest of Saskatchewan, Canada. Commonwealth Forestry Review 77(4): 254-261.

Brand, D.G., Bouman, O.T., Bouthillier, L. Kesslet, W. and Lapierre, L. 1996 The model forest concept: a model for future forest management? Environmental Review 4: 65-90.

Carrow, R. 1999 Canada's model forest program: challenges for phase II. The Forestry Chronicle 75(1): 73-80.

Gardner-Pinfold. 1996 Evaluation of the Canadian model forest program. Gardner Pinfold Consulting Economists Limited, Halifax.

Grimble, R., Chan, M-K., Aglionby, J. and Quan, J. 1995 Trees and trade-offs: a stakeholder approach to natural resource management. Gatekeeper Series 52. International Institute for Environment and Development, U.K.

International Model Forest Network (IMFN) 1999 Model forest development guide. IMFN Secretariat. May, 1999.

Kemmis, S. and McTaggart, R. 1998 Introduction: the nature of action research. In: Kemmis, S. and McTaggart, R. (eds.) The action research planner, 1-13. Deakin University Press, Deakin, Australia.

Lee, K.N. 1993 Taking measures. Pages 7-17; Gyroscope: negotiation and conflict. In: Lee, K.N. Compass and gyroscope: integrating science and politics for the environment, 87-114. Island Press, Washington, D.C.

MacLean, D.A., Etheridge, P. Pelham, J. and Emrich, W. 1999 Fundy Model Forest: partners in sustainable forest management. The Forestry Chronicle 75(2): 219227.

McLain, R.J. and Lee, R.G. 1996 Adaptive management: promises and pitfalls. Environmental Management 20(4): 437-448. 
Röling, N.G. and Jiggins, J. 1998 The ecological knowledge system. In: Röling, N.G. and Wagemakers, M.A.E. (eds.) Facilitating sustainable agriculture. Participatory learning and adaptive management in times of environmental uncertainty, 283311. Cambridge University Press, Cambridge, U.K.

Sinclair, J. and Smith, D.L. 1995 Multi-stakeholder decision making and management: Manitoba model forest. MBMF 95-2-95.

Sinclair, J., Smith, D.L. and Bidinosti, A. 1998a Results of the survey of views on Manitoba model forest activities at achieving sustainable forest management. MBMF 96-2-25.

Sinclair, J., Smith, D.L. and Bidinosti, A. 1998b Canada's model forest network: How individual model forests are working together to achieve sustainable forest management. MBMF 96-2-45.

Story, P.A. and Lickers, F.H. 1997 Partnership building for sustainable development: A First Nations perspective from Ontario. Journal of Sustainable Forestry 4(3/4): 149-162.

Waldram, J.M. 1998 Manitoba model forest: a diversity of land and people. In: Model forests for field-level application of sustainable forest management, 190-195. Proceedings of an International Workshop, 10-12 March, 1998. Tokyo, Japan. 
MODEL FORESTS 


\title{
Chapter Nine
}

\section{Learning how to devolve: The Social Forestry Project, Malakand, North-West Frontier Province, Pakistan}

\author{
Haider Ali Khan
}

\begin{abstract}
The past several decades have seen a worldwide increase in the recognition of the need to involve civil society in the management of natural resources by devolving management authority from government agencies to local civil groups. In Pakistan, efforts are being made to develop working relationships among civil society and public sector actors. We have learned that the devolution of authority to local groups is not a simple linear process, but rather a continuously changing process involving many stakeholders. This chapter describes the evolution of learning about this process as it has been occurring since 1987 in the Social Forestry Project of the North-West Frontier Province. This project has succeeded in developing structures for collaborative resource management by incorporating the Forest Department, local communities, and non-governmental organisations. The establishment of these 'partnership arrangements' involved a period of learning after which adjustments were made and the approach applied on a larger scale. While all stakeholders in the project are continuing to learn about and adjust to new institutional roles and responsibilities, lack of widespread support from the communities and the Forest Department raises questions about the sustainability of the collaboration.
\end{abstract}




\section{INTRODUCTION}

Government agencies, local communities, NGOs and other civil society actors have been part of a global trend to devolve power from centralized management agencies to community-based resource management groups. In Pakistan's North-West Frontier Province (NWFP), we have gained considerable experience in establishing and strengthening community-based natural resource management organisations. Through this experience, the NWFP Department of Forestry, Fisheries and Wildlife has learned that the rehabilitation of degraded natural resources requires an active partnership between civil society actors (non-governmental organisations and local communities) and public sector players (Department of Forestry). This civil society/public partnership can improve policy development, strengthen the enforcement of legislation and assist the management of state forests, research and extension. But, perhaps, primarily we have learned that the devolution of management authority to local groups is not a linear process - it is neither 'top to bottom' nor 'bottom to top.' Instead it is a continuous conversation among the various stakeholders. It is always messy and usually contested. Problems continuously appear threaten the process.

This chapter describes how the Malakand Social Forestry Project has used learning to facilitate the involvement of civil society organisations with public sector agencies in the management of natural resources. Korten (1984) writes that a learning organisation learns from its mistakes. Rather then treating error as a defeat, error is treated as an essential source of information, discussed candidly to identify the lessons learned and possible corrective actions. The chapter delineates what the project has learned about the stakeholders (the Forest Department, a non-governmental support organisation and local communities) and how it is using this knowledge to assist stakeholders to adjust to their new roles and responsibilities. Finally, the chapter discusses how we are using our knowledge of the past, and our past mistakes, to improve the future of community-based resource management in the project area.

I have been involved in the project for several years in different positions. I was initially involved for approximately two years as a Divisional Forest Officer of the Forest Department. For the last year and a half, I have been manager of the support organisation and a natural resource management consultant. 
Haider Ali Khan

\section{THE EVOLUTION OF LEARNING}

The traditions of forestry in Pakistan are old, especially in the North-West Frontier Province, which has most of the country's best timber producing forests. Forests cover only $5.4 \%$ of the country's area, with an even smaller area (3\%) considered commercially productive.

Forestry in Pakistan focused for many years on conservation and timber harvesting. Attempts to increase forest cover, including the production of seedlings and afforestation, started in the mid 1960s. Large-scale afforestation projects were launched under a watershed management programme in the late 1970s. The objectives of these programmes were to meet people's energy requirements and to rehabilitate watershed areas above large dams. The Forest Department made considerable progress in terms of raising awareness, improving technical knowledge and skills and rehabilitating denuded hills and farmland. However, with the area under afforestation increasing, the Department was faced with the problem of effectively protecting and maintaining this growing area.

Problems associated with conserving state forests, as well as forests on private and community lands in the custody of the Forest Department, continued to escalate with a growing population and dwindling resources. Concurrently, decision makers were learning that community involvement was critical for long-term resource management. This knowledge stimulated interest in people's participation, village organisation, local capacity building, local ownership, cost effectiveness and cost sharing. These issues steadily became more popular among major rural development projects seeking to find new approaches to their work.

It was in this context that in 1987 the NWFP Forest Department started the Social Forestry Project in Malakand Agency (see Figure 9.1), with financial and technical assistance from the Royal Netherlands Government. During the last 12 years, project activities have included organising communities to raise village plantations on communal lands, growing trees on farmlands and degraded hillsides, institutional development of the Forestry Department, developing extension methods, managing rangeland and involving village women in natural resource management activities. The programme was implemented and managed by the Forest Department. Through this process a more bottom-up approach to resource management evolved. 


\section{LEARNING HOWTO DEVOLVE}

Figure 9.1 Social Forestry Project in Malakand Agency

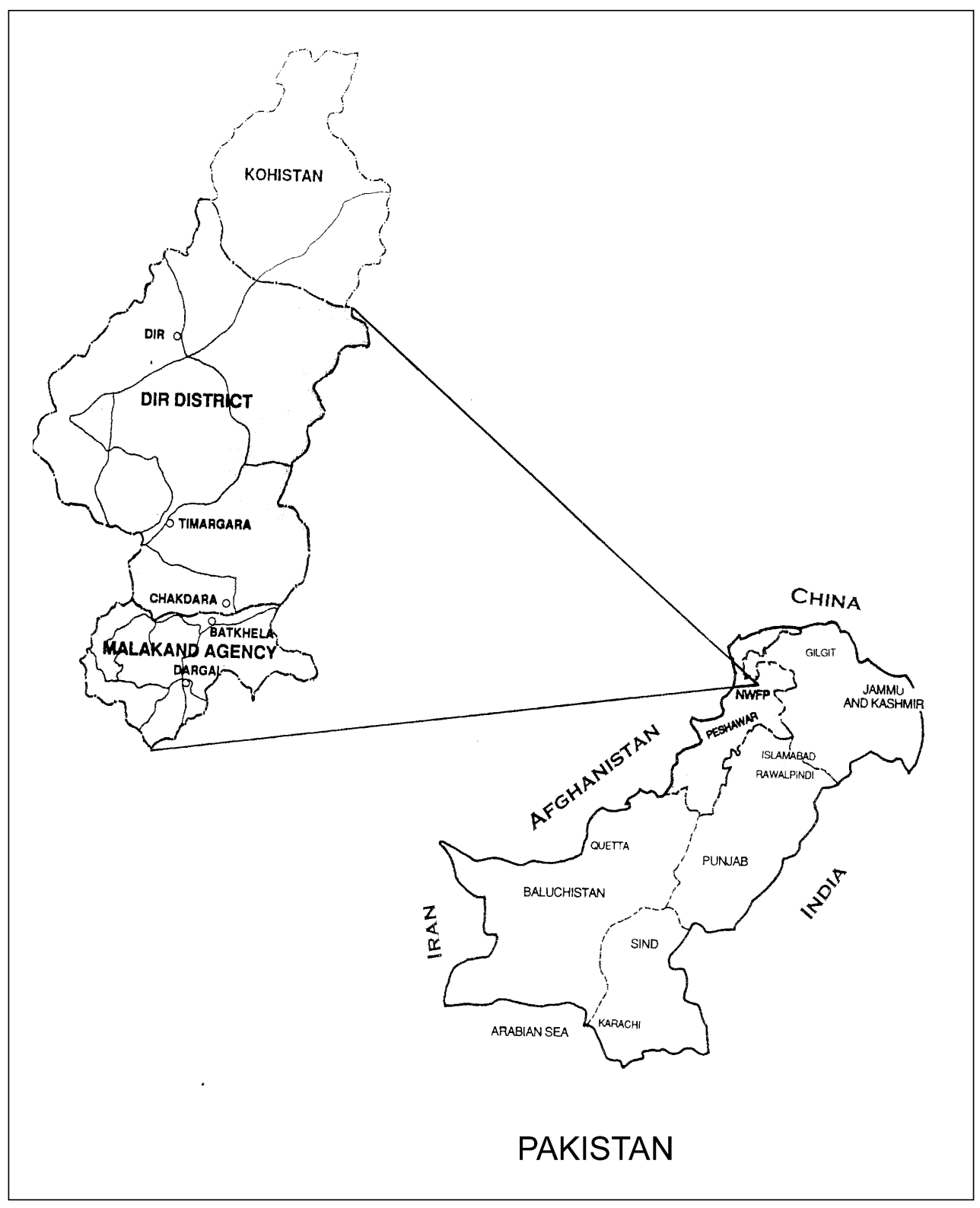


Phase I, and, in the beginning, Phase II, proceeded from the usual perspective of a government line agency, with the Forest Department implementing natural resource management activities in the field. By the end of Phase II, however, a shift had occurred in the project's orientation from a supply-driven approach to a demand-driven approach with a focus on meeting the natural resource requirements of the communities. A start had also been made towards sharing management responsibilities with local community organisations. The project initiated programme implementation through partnership arrangements among local communities, support organisations (NGOs) and Forestry Department staff. This change in orientation and the devolution of management responsibilities to the village organisations and NGOs are the prominent features in Phase III of the project (1999-2002).

How did this change in the project's orientation happen? I think it occurred as the project was finishing Phase II in June 1997 and awaiting approval for Phase III. To link the two phases, the Forest Department and the funding agency agreed to a bridging arrangement that would begin to test collaborative management in the field. Both parties felt that it was necessary to prepare all the partners for their new roles and responsibilities before launching a full-scale programme. Over a six-month period (July to December 1997), Forest Department staff members worked to create a better understanding with local communities and appointed a manager for the new support organisation. With support for the bridging arrangement approved by the government and the funding agency, partnership management was initiated in a few villages in March 1998. The institutionalisation of a public/civil society social forestry approach had been an objective of the project in 1992.

The project began this process by focusing first on the village level and on the development of management plans facilitated by the Forestry Department. One of the lessons incorporated from the first phase of work was the need to go beyond the forestry sector and address villagers' needs from an integrated land use perspective. A second lesson learned from the first phase was the need for villagers to organise themselves to manage their land resources.

Thus, the concept of Village Land Use Planning, which considers the whole village area as one unit of planning (van den Hoek and Werter 1994), was developed. Central to the concept is social cooperation within the village. Different stakeholders in a village (land owners and users) are brought together in a village development committee 
(VDC) to work as a social unit. The end product of Village Land Use Planning is a management plan for the village's natural resources, which is implemented by the community with the assistance of the Forest Department (Figure 9.2).

Figure 9.2 Village plantation on communal hillside

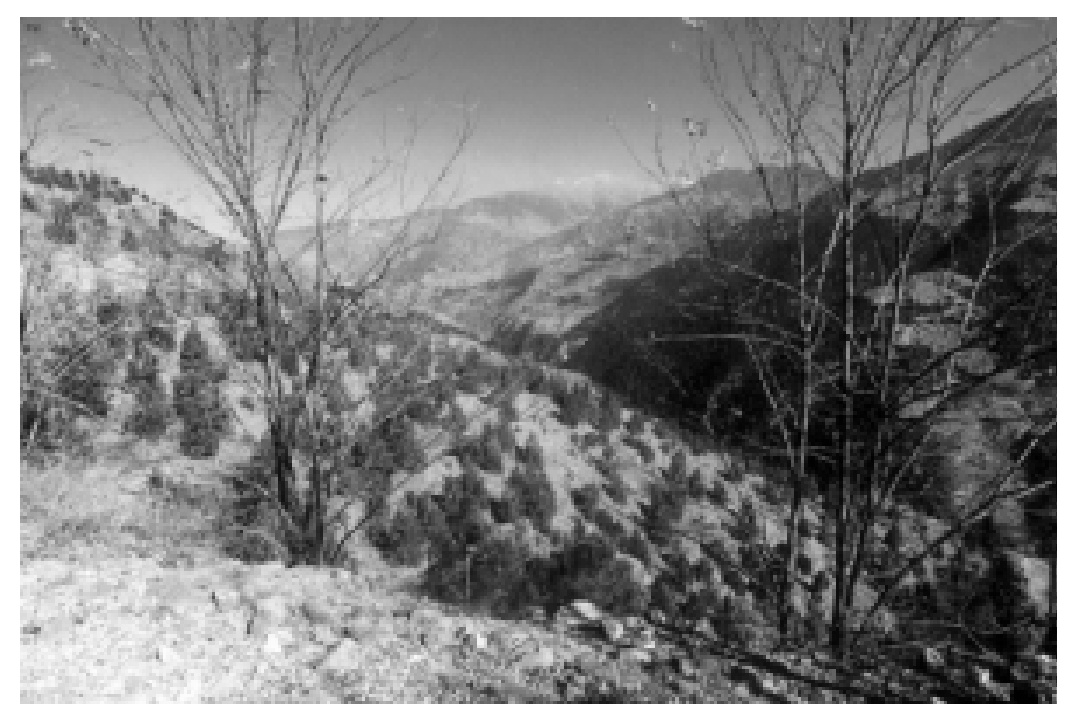

As these village planning processes proceeded, learning about what worked or did not work often occurred at a small scale before being promoted in other areas. For example, the raising of seedlings by women started as a small pilot activity, but after learning about the demand for different species, acquiring the technical knowledge for growing these species, and learning about contractual arrangements, the project applied the activity on a larger scale.

\section{Partnership arrangements}

In 1998, the project took a step towards further formalising and expanding the collaboration between villages and the Forest Department by initiating 'partnership arrangements', which included NGOs as an additional stakeholder, and the fund manager from the donor. The Forest Department saw these more formal partnership arrangements as an efficient way of mobilising local resources and reducing 
government expenditure, while also encouraging local entrepreneurship and improved access by village communities to private sector services. The main objectives of partnership arrangements include:

1. Assisting the village development committees (VDCs) and women's organisations (WOs) in organising, building capacity, forming capital and gaining technical skills for self-help.

2. Assisting VDCs/WOs in developing their natural resources through sustainable management that can be continued without assistance from outside.

3. Regulating investment and inputs from the partners within the logical framework of the project.

The partners (stakeholders), which now included VDC/WO members (landowners, non-owners and tenants residing in the village), Forest Department staff, support organisation/NGO staff and the fund manager/chief technical advisor, were jointly responsible for preparing and implementing the village management plans. The arrangements specified that programme implementation is the responsibility of the VDC/WO. The Forest Department staff are responsible for extension, technical assistance and monitoring. The support NGO is a catalyst for the social mobilisation of communities, development of village organisations, communication and extension, and networking with other service delivery agencies. The fund manager/chief technical advisor provides funds for programme implementation to the VDCs/WOs through the support organisation and to the Forest Department for seedling production, extension, and technical training. Although new partners were taken on, the roles were predetermined by the donor and the Forestry Department.

\section{Partnership implementation}

The VDCs and WOs began implementing the Social Forestry Project in their villages in March 1998. Their Terms of Partnership agreements were developed by the support organisation after negotiating with Forest Department staff members, as well as members of the VDCs/WOs. To prepare VDCs/WOs for this purpose and to explain the new strategy, basic training in accounting and record keeping was arranged. In addition, VDC/WO members were taken on excursions to other projects and community-based organisations to study how village organisations could work 
independently, generating their own resources and developing administrative and accounting procedures.

The project introduced partnership arrangements on a small scale in order for the partners to learn about the process. After more than a year, the approach was adjusted and applied on a larger scale. During the test period, communities learned about their strengths and weaknesses. Forest Department staff members learned about their new roles, and the support organisation staff members learned how to transform a support organisation into a NGO which could work with the government agencies. Members of the support organisation also learned about organisational development and capacity building. The learning process was a continuous activity that plays an important role in the devolution of management and responsibility.

The relatively rapid process of scaling up was made possible because of the longer period phase of village-level planning. It was also a government and donor-driven process that took advantage of existing organisational infrastructure and lines of decision making. The project selected nine initial villages in the Malakand and Dir districts based on an assessment report of VDCs prepared by a monitoring and evaluation specialist. After the agreements were successfully initiated in these villages, the approach was introduced to 14 other villages in the Malakand and Dir districts in July 1998. By July 1999, Terms of Partnership agreements had been initiated in all 60 villages. The programme package includes afforestation (planting and sowing) on hillsides, controlled grazing, maintenance of afforested areas and village infrastructure schemes. Table 9.1 shows the timing and details of the Terms of Partnership agreements during different stages of the project (Figures 9.3 and 9.4).

Table 9.1 Stages of terms of partnership agreements

\begin{tabular}{lccrrrrrr}
\hline Stage & \multirow{2}{*}{$\begin{array}{l}\text { Number of } \\
\text { villages }\end{array}$} & $\begin{array}{c}\text { Number of } \\
\text { agreements }\end{array}$ & & \multicolumn{3}{c}{ Activities } & & \multicolumn{2}{c}{$\begin{array}{l}\text { Cost in } \\
\text { Rupees }\end{array}$} \\
& & & A & B & C & D & \\
\hline Mar-June '98 & 9 & 11 & 2974 & 0 & 18 & 0 & 353990 \\
July-Dec '98 & 23 & 45 & 4364 & 302 & 45 & 2 & 2452961 \\
Jan-June '99 & 23 & 49 & 4453 & 320 & 50 & 2 & 2367273 \\
Total & 23 & 105 & 11792 & 621 & 113 & 4 & 5174224 \\
\hline
\end{tabular}


Figure 9.3 WO members also contribute in the preparation of village management plan

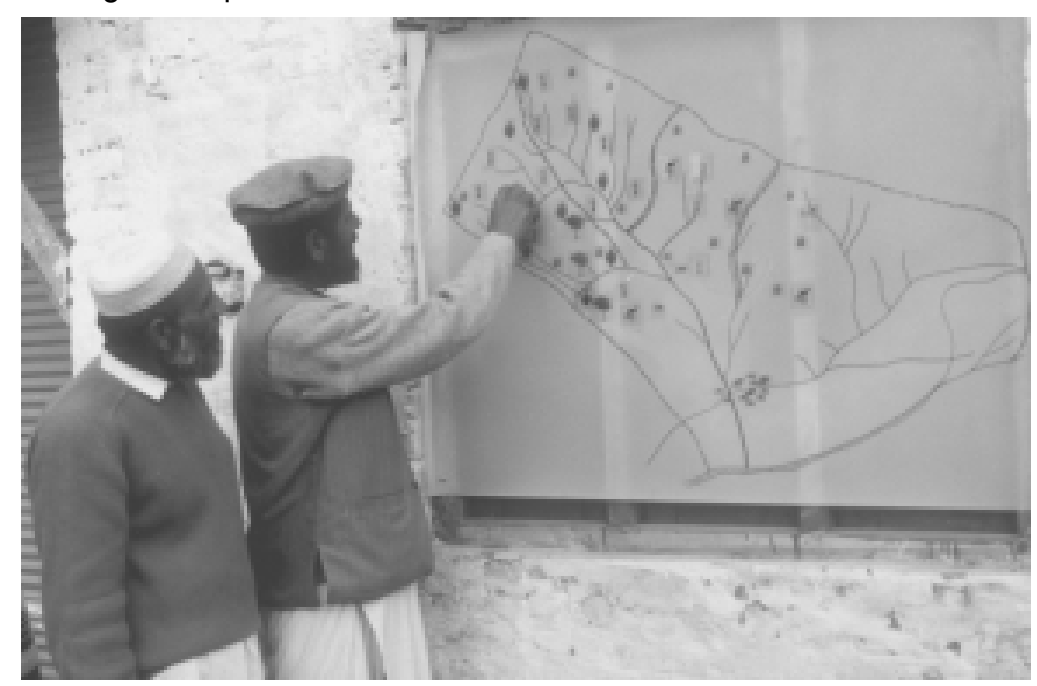

Figure 9.4. VDC members prepare village management plan

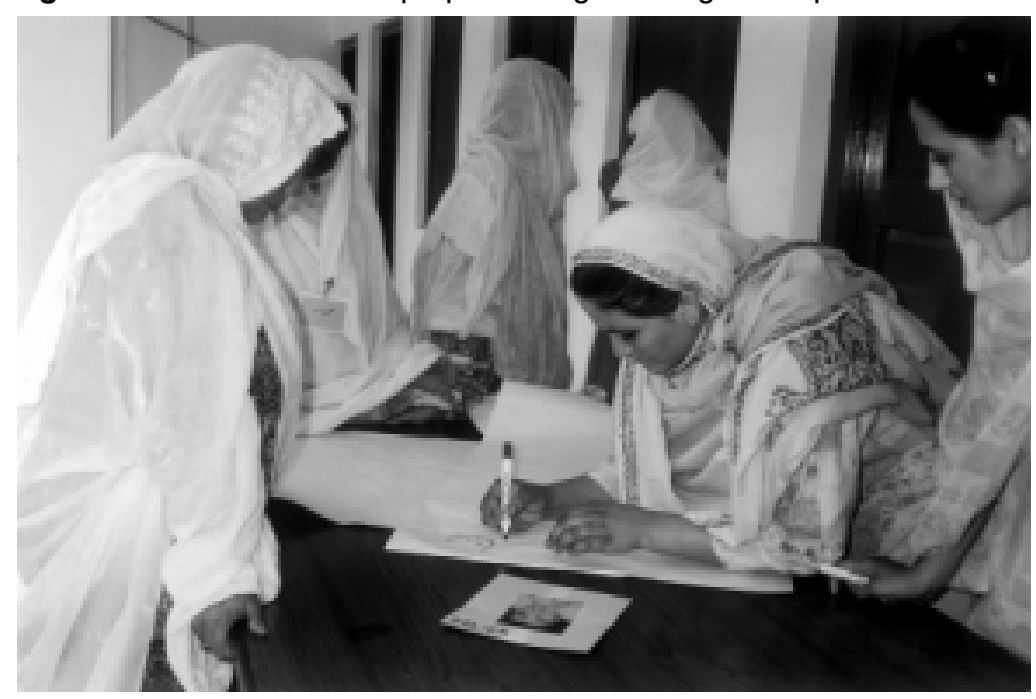


To maintain financial accountability, the fund manager/chief technical advisor controlled the flow of funds on the basis of periodic evaluations, releasing $40 \%$ of the estimated project cost as a first instalment to the VDC/WO upon the signing of the partnership agreement by all the partners. After the first evaluation, up to $40 \%$ of the remaining funds were released. The remaining $20 \%$ (the last instalment) was released after the final evaluation. The funds were released to the VDC/WO accounts, which are operated jointly by three nominees of the VDC/WO. The Evaluation Committees comprise representatives from the Forest Department, the concerned VDC and support organisations. The partnership is based on consensus among all the partners and trust building.

Project activities include A) maintenance of afforestation areas (in hectares); B) afforestation (planting and sowing in hectares); C) controlled grazing (number of herdsmen hired); and D) infrastructure development schemes (number). Separate agreements are signed for each activity in a village.

Based on the experiences so far, this approach will be further improved and extended to 66 new villages during the next two and a half years.

\section{LEARNING BY THE STAKEHOLDERS}

The Forest Department, the support organisation/NGO and the communities are currently trying to adjust to their new roles and responsibilities. Underlying the formal structure of the partnership there is still a degree of mistrust as well as some confusion about the respective roles in the partnership. Each partner perceives collaborative management from its own point of view and hence the identification of key issues with respect to different stakeholders is important. The project staff have developed a better understanding of these issues over time. This learning has been slow and largely reactive on the part of all the stakeholders. It has focused on learning by project staff about how to improve operations through joint learning among stakeholders. Grimble et al. (1995:3) suggest that stakeholder analysis can help us to better understand the objectives and interests of the various stakeholders managing and using the environment, the potential trade-offs between objectives, and the benefits of change and intervention at both macro and micro levels. However, the project has developed an understanding 
of the stakeholders more through its 12 years of experience than by any formal method of analysis. Below we describe the major lessons we learned about collaboration and conflict among the partners.

\section{The communities}

In the project area, we knew already that the land use rights of tenants and users with respect to landowners was the major issue affecting collaboration among members of the local communities. Historically, villagers in Pakistan had free rights to collect timber and firewood and to graze livestock on public and private lands within the village. In the decade between 1970 and 1980, however, social and political circumstances led to conflicts between landowners and land users that resulted in the collapse of local governing systems and institutions. These circumstances led to an escalation of serious conflicts between the landowners and non-owners. As a result, the landowners became more cautious about their ownership rights.

We have learned in the last several years that collaboration in the project area depends on constant negotiation and persuasion by extension workers to create an understanding between owners and non-owners. When conflicts between landowners and users are particularly deep and based on old enmities, we have also learned that compromise may not be possible.

As mentioned above, project activities tended to channel information 'upward' towards project staff. One example of this is that most people in the communities were not informed about the partnership agreements and the responsibilities of the village development committees. This lack of information may be caused by poor communication between the community and the leaders of the VDC. Insufficient communication can create misunderstanding among the community and its leaders. The project has learned that transparency is a tool for developing mutual trust among community members as well as between the community and other partners. But we have also learned that transparency can only work if everyone is actively involved in project activities. From the project evaluation in Haryankot village, we found that when the participation of members is weak and communication with the local leadership is poor, there is a tendency for village leaders to hijack the project. The lack of widespread participation by community members can thus affect communication and have implications for the ownership and the sustainability of collaborative management. 
We have also learned that local capacity for social organisation, management, and natural resource management is an important element in the partnership arrangement. The capacity of some VDCs to manage a social forestry programme and technical aspects of related natural resource management activities is not sufficient.

Local people are also uncertain about the continuity of management after the project ends. People who do not own land are concerned about whether or not the landowners will continue to follow the system agreed to for distributing benefits and for a controlled grazing system. They also question the sustainability of the village development committee and its management practices.

\section{The Forest Department}

We have learned about conflicts among Forest Department staff members during the partnership arrangement process. Like the villages and other organisations, the Forest Department is not a homogeneous institution. It has efficient professionals devoted to the improvement of forest resources and it has bureaucrats who persistently oppose new ideas that conflict with their personal interests. Some staff members support the new approach of community empowerment, while large numbers oppose it—particularly to losing control over financial inputs into projects. This conflict exists from the top to the bottom of the Department.

Forest Department staff members perform two types of functions. Regular staff are responsible for the routine activities of policing legally declared forests, while temporary project staff initiate and manage new community-based resource management projects. Eventually, regular staff members are supposed to assume responsibility for communitybased projects. These staff, however, are not trained for community-based management and can negate the trust and confidence established between the communities and the Forest Department by the project staff. The greatest constraint on the Forest Department in managing community-based programmes may be its current lack of capacity for such work and its rigid top-down planning and monitoring processes that continue to prevail in place of the bottom-up village level planning required by communitybased programmes.

Fortunately for the project, the institutional reform process within the Forest Department will formalize new roles for Forest Department staff members. Under the new NWFP 
forest policy, the Forest Department is to be reorganised and the job descriptions of the staff will be changed. Responsibility for programme implementation will shift from the Forest Department to local communities. The new policy will also emphasize the involvement of NGOs and community-based organisations and the private sector in natural resource management.

\section{The NGOs}

The Malakand Social Forestry Project needs to select an NGO with the capacity and the expertise to work in the partnerships established by the project. The purpose of the NGO is to provide additional support to both the Forest Department and communities. An important question facing the project is what kind of NGO is prepared to assist in the partnership arrangement? Furthermore, who should prepare the criteria for selecting this NGO, the Forest Department or the donor?

Many new NGOs are being established in the area with different objectives and programmes. Many of them want to assist government institutions and would like to be funded to work with government agencies to establish community-based resource management. Other NGOs find it is more convenient to work according to their own rules and regulations instead of those of the government, often becoming advocacy groups. Some of these NGOs are dominated by charismatic personalities, while others only exist on paper. This situation has created a bad reputation for the NGOs, with many politicians and religious leaders criticizing them for advocating agendas that are against local traditions and government policies. The government has recently begun to scrutinize NGOs and develop rules that will affect working relationships between NGOs and government departments.

Because of the difficulty of finding an appropriate NGO, the project has yet to work with a formal, independent organisation. Instead, it has created an informal support organisation to temporarily fulfil the same functions. It is anticipated, however, that the support organisation will evolve to become a locally-based, development-oriented nonprofit NGO. The formation of the support organisation was initiated in early 1998 by assisting non-governmental project staff members to set up their own group. The support organisation has since taken steps towards forming an NGO, such as developing membership criteria, preparing a constitution, registering with the government and establishing a board of directors. 
As long as the project continues to be funded, the support organisation can successfully perform its role as the NGO as it has staff members with expertise in the relevant subjects and who are familiar with the area, the village organisations and Forest Department staff. Since, however, the support organisation continues to include the nongovernmental staff members of the project, and these staff are not employees of the support organisation, the organisation cannot function independently. The project's current support organisation has gained experience and it should be utilised to serve the needs of the public sector and local communities. However, it needs an internal and external assessment of its institutional capacity and resources before adapting to an independent role. An important question facing the support organisation is, therefore, at what stage in the project should it become an independent NGO.

In addition, the Forest Department would like to engage locally-based NGOs to facilitate the new approach of collaborative resource management. For a smooth working relationship, the Forest Department and donors should jointly develop criteria for selecting the NGOs to work with the project. The NGOs should be engaged by the Forest Department, which will provide legal support.

\section{Learning for the future}

The important lessons that the project has learned about the partnership arrangements include: (1) reaching beyond local VDC leaders to engage all members of the communities, (2) using negotiation as a constant part of the partnership process, while understanding that some conflicts are persistent and beyond the influence of the project, (3) recognizing that both the will and capacity of Forest Department staff need to be developed for them to take on new roles in working with the communities, and (4) ensuring that the role of 'third parties' like NGOs is clear, as is the process for selecting them. Clear communication, regular interaction and transparency of decision making have been key factors underlying each of these insights about how to make collaboration work.

The partnership arrangements remain, however, very much imposed structures on existing relationships. The support NGO, for example, was formed from existing project staff and was therefore not truly independent. Widespread support from the Forest Department is still not guaranteed. These conditions raise questions about the sustainability of the project and the collaboration. 
A lack of legal support for the new approach also threatens the long-term sustainability of the project. A VDC is a self-organised village body that presently has no official recognition or decision-making power. In Dheri Jolagram village, for example, while local people supported the decisions of their VDC, the local government administration opposed these decisions to please a few influential people in the village. Local people are also uncertain about sustainability of the village development committee and its management practices.

A final problem is that the government of NWFP and external donors may reduce subsidies for improving hillsides and other natural resource management interventions. Direct benefits to the communities from natural resource management may be insufficient to motivate them to invest in social organisation and community-based management. This raises another question mark regarding the sustainability of the new system. Project policy in Phase III requires village communities to contribute in cash or in kind to natural resource management activities in their communities. Project personnel proposed this change on the basis that cost sharing would create selfreliance and ownership in these communities. The communities, on the other hand, not used to cost sharing in the past, may not respond well. Cost sharing in natural resource management activities is an idea that needs to be tested.

Thus, perhaps the major challenge facing the project in the future is the maintenance of sustainable relationships among the Forest Department staff, NGOs and communities when the donor leaves the project.

\section{CONCLUSIONS}

Learning has played a key role in the design and implementation of the Malakand Social Forestry Project since its startup in 1987. Learning experiences have provided the project with insights necessary for adjusting the planning, implementation and monitoring of field activities so as to make it possible for the project to overcome seemingly impenetrable difficulties. The project minimizes the cost of this learning by initially introducing smallscale applications of programme activities under the principle of learning by doing. After an activity proves successful, it is applied on a larger scale. Partnership arrangements, for example, were introduced on a small scale to allow the partners to learn about the process. The approach was subsequently adjusted and 
applied on a larger scale. The test period gave communities the opportunity to learn about their strengths and weaknesses, and Forest Department staff members about their new roles. Support organisation members not only learned about organisational development and capacity building but also about how to transform a support organisation into an NGO which could work with the government agencies. The learning process was a continuous activity that plays an important role in the devolution of management and responsibility.

The new NWFP forest policy will provide substantial support for collaborative management through partnership arrangements, despite the limitations. Local communities are also showing great willingness to implement the programme. The Forest Department has limited skills for social mobilization and social organisation and cannot cover each and every village of the province. It has to outsource such types of activities to local NGOs who can perform this role more cost-effectively. To make this happen, the Social Forestry Project has initiated a process that should aim to eventually expand the learning experiences for all the partners. Learning from both our successes and our failures will provide guiding principles for adapting new strategies.

\section{LITERATURE CITED}

Government of NWFP 1999 Pak-Dutch follow-up (phase-III) of social forestry project in Malakand Division, NWFP. Department of Forestry, Fisheries and Wildlife, Peshawar, Pakistan.

Grimble, R., Chan, M., Aglionby, J. and Quan, J. 1995 Trees and tradeoffs: a stakeholder approach to natural resource management. Gatekeeper Series No. 52. International Institute for Environment and Development, London, U.K.

van den Hoek, A., and Werter, F. 1994 Manual for village land use planning. Training series: 5A SFP. Department of Forestry, Fisheries and Wildlife, Peshawar, Pakistan.

Korten, D. 1984 Rural development programming: the learning process approach. In: Korten, D. (ed.) People-centered development: contributions toward theory and planning frameworks, 176-188. Kumarian Press, West Hartford, CT, USA. 
Chapter Ten

\title{
Beyond rhetorical success: Advancing the potential for the community forestry programme in Nepal to address equity concerns
}

\author{
Bishnu Upreti
}

\begin{abstract}
The Community Forestry Programme in the hills of Nepal is transforming the way forest management is practised and is becoming institutionalised as progressive strategies, policies and legislation evolve. Community-based forest management has demonstrated appreciable success with respect to biophysical achievements. Despite these advances, it is not yet able to fully ensure equitable, gender-sensitive and povertyfocused outcomes. A major factor responsible for this inability is the lack of appropriate methods to effectively translate policies into practices. By examining characteristics and the applicability of social learning approaches to community-based forest management in Nepal, this chapter argues that social learning can fill this gap.
\end{abstract}

\section{INTRODUCTION}

Community forest management is increasingly recognised as a suitable approach to the sustainable management and utilisation of forest resources. This approach is 
grounded in the philosophy of participation by users in management activities, which forms the basis of the current Community Forestry Programme of Nepal.

Despite the advances that have been made in government community forestry programmes in Nepal since the late 1970s, Nepal's experience to date does not go far enough in accounting for the complex social dynamics underlying community-based approaches to ensure equitable, gender sensitive and poverty-focused outcomes. This contention is supported by evidence from recent research. The level of participation of women on Forest Users' Committees (FUC) is only 19\% per cent of the total membership (Shrestha 1997). A study of users' expectations from community forestry carried out in seven districts shows that women and the poor feel marginalized and lack information about users' rights to community forest resources (WATCH 1995). Evidence is emerging that the poorest and low caste people are beginning to withdraw from Forest User Groups (Pokharel and Tumbahamphe 1999). The second National Workshop for government forest officials, held in August 1999, explicitly concluded that current forest management is not addressing equity concerns (Kantipur Daily National Newspaper 1999). Appendix 1 illustrates some of the problems confronting poor and disadvantaged forest users. These shortcomings suggest a need for alternative approaches to bridge the gap between policy and practice. It is the thesis of this chapter that the achievement of the desired social outcomes requires a deeper understanding and appreciation of the ecological interdependence, social embeddedness, complexity and uncertainty (Röling 1997) that characterise the activities and discourse relating to community-based forest resources.

In community-based forestry, there are different types of resource users, having different economic and social status, perspectives, knowledge systems, values, understandings and objectives (Anderson et al. 1998). Their coping strategies and actions determine the success or failure of community-based forest management. Successful community-based forest management promotes equity and improved standards of living for users. A social learning approach that facilitates collective learning and collaborative action among the different users at group, community, regional and national levels has great potential to contribute towards this ultimate goal.

Social learning is an approach to collaborative learning and collective action that enables people to assess past events jointly, to modify their accustomed behaviour and to develop new forms of adaptive behaviour. It promotes interaction among stakeholders 
who may have different interests, beliefs, values, knowledge systems, management styles and perspectives (Röling and Jiggins 1998; Upreti 1998; Wilson and Morren 1990) to construct shared knowledge, to agree to act, to actually act, and to monitor the effects of acting upon that knowledge (Röling 1992, 1994).

I use a case study from Dolakha District in the Middle Hills of Nepal to explore the opportunities for social learning and advancing social equity in community forest management in Nepal. The case highlights how community forests can be managed at the local level based on collective learning and adaptive action. The paper concludes that the current gap between the rhetoric and the reality of social equity in community forestry can be substantially reduced by systematically incorporating social learning into the sustainable management of community-based forest resources.

\section{BACKGROUND TO COMMUNITY FORESTRY IN NEPAL}

Nepal has been one of the pioneers in promoting community management of forests. Realizing the management abilities of local users, His Majesty's Government of Nepal in 1978 amended the Forest Act of 1961 to provide for the handover of degraded forest to panchayats $^{1}$, in the form of Panchayat Forest and Panchayat Protected Forest. These forests were collectively termed 'community forest' (Tuladhar 1998). Over the next 20 years, forest policies, laws, regulations and operational guidelines were revised, the participation of users and non-governmental organisations (NGOs) was encouraged and donors changed their funding priorities. In 1989, the Master Plan for the Forestry Sector gave top priority to the community and private forestry programmes and prescribed a legal and organisational framework for increasing the participation of local communities. This plan was supported by the Forest Act of 1993 and the Forest Regulations of 1995 (Belbase and Regmi 1998), as well as by the Forestry Sector Coordination Committee created at the central level. The policy guidelines focus on decentralisation, participation of local people in decision making, meeting basic needs, utilising forest resources sustainably and encouraging gender equity and social peace (NSCFP 1997). The resulting Community Forestry Programme explicitly recognises social equity and poverty alleviation as fundamental objectives. However, the translation of policies into practices that address these issues remains weak. Table 10.1 summarises the current status of the Community Forestry Programme in Nepal, based on detailed reviews by academics and NGOs working in the country. 
BEYOND RHETORICAL SUCCESS

Table 10.1 Overview of the strengths, weaknesses, opportunities and challenges of community forestry in Nepal

Strengths Weaknesses

- Awareness raised and experiences gained

- User's access to forest resources increased

- Conflict management skills developed

- Emerging and recognised local institutions and platforms

- Women's workload reduced

- Natural regeneration increased

- Forest fire incidences decreased

- Leadership at grassroots developed

- Feeling of ownership increased

- Private planting practices increased

- Decentralisation started

- Community forest area increased

- Accountability of users increased

- Deforestation rate in hills decreased
- Social equity issues are in question (gap between policy and practice)

- Focus on quantitative targets

- Elite domination of Forest Users' Groups (FUGs)

- Increasing gap between rich and poor

- Authority to grant or revoke community forest status lies with bureaucracy

- Lack of transparency

- Donor-driven

- Lack of representation of disadvantaged groups of people in the planning process

- Difficult to scale up from hills to Terai

- Lack of technical knowledge among FUGs

- Protection oriented approach

- Weak post-formation support to FUGs

- Insufficient and contradictory policies

- Lack of political commitment

- Autocratic bureaucrats

\section{Challenges}

- Globalisation and privatisation

- Bureaucratic resistance

- Timber Corporation of Nepal has sole rights to harvest the timber of 33 districts

- Resistance to change

- Vested interests of powerful stakeholders

- Corruption and corruption network

Sources: Shrestha 1999; Poudel 1997; Shrestha et al. 1995; Sinha et al. 1996; Poudel et al. 1998; Shrestha 1997a, 1997b; Balbase and Regmi 1998; Joshi 1997; and author's observations. 
Figure 10.1 Community managed forests: hope for future

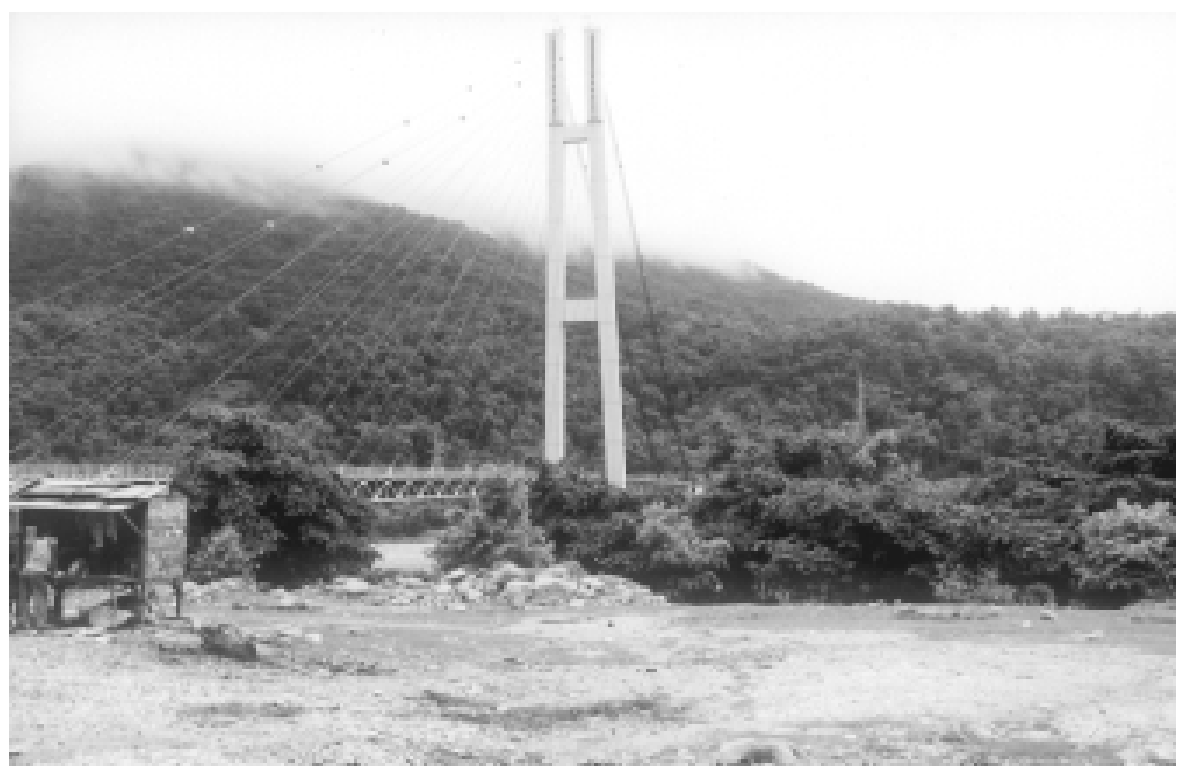

\section{LEARNING FROM COMMUNITY FORESTRY IN THE CENTRAL} HILLS OF NEPAL

\section{Methodology}

Information for the case presented here was developed through focus group discussions, life histories, secondary data, informal discussions, researcher observation and semistructured and key informant interviews ${ }^{2}$.

\section{Study area}

Figure 10.2 depicts the case study areas. Dolakha district is situated in the mountain belt, $160 \mathrm{~km}$ northeast of Kathmandu. Geographically, it ranges from $763 \mathrm{~m}$ to 7183 $\mathrm{m}$ asl with a total area of $2143 \mathrm{~km}^{2}$. Within this area, $94400 \mathrm{ha}$ are covered by forest. The total population of the district is 173836 (NSCFP 1998). The prevalence of indigenous forest management is a unique feature of this district. The Community Forestry Programme is one of the major development projects in Dolakha district. 
Khahare-Katunje forest, with an area of approximately 800 ha, is situated in the Pawoti Village Development Committee area in the belt of the Tamakosi River. It has been the major forest system used by more than 650 households in this area for 700 years. Matarkopakho is a fragmented section of this larger forest system and comprises about 50 ha now used by about 50 households. It is a uniquely managed forest in this area and illustrates how local people learned to respond to changing situations and to adapt their management system for a better future.

Figure 10.2 Location of the research area

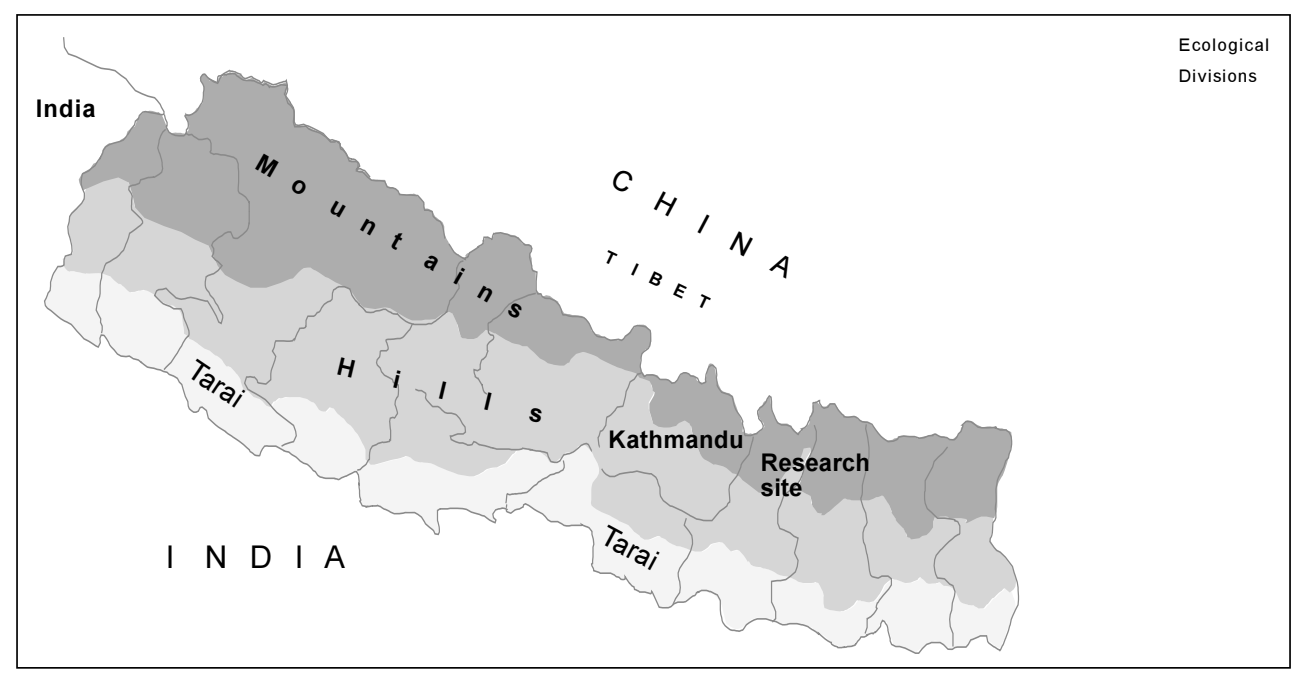

\section{The development of local management initiatives}

In about 1910 a powerful landlord encroached for the first time on the dense natural forest of Matarkopakho. The following year, due to a bad dream ${ }^{3}$, the landlord left the land and it came under community ownership. Thereafter, Matarkopakho was used mainly for grazing, collection of fodder, alignment for public irrigation canals and worshipping. In the late 1960s, Matarkopakho was encroached upon again, this time by a powerful politician and Mukhiya ${ }^{4}$. The users decided to protest the invasion. Without critically assessing the risks and possible negative impacts, they filed a case with the mobile judge (Badahakim) against the invasion. Due to unfavourable power relations, they suspected that the forthcoming decision would most likely be in the landlord's favour. That was the turning point for users to seek informal negotiation. 
The invader began cropping the land and reacted negatively toward the protesters, causing the conflict to escalate. The protesters faced severe fodder and grazing problems for more than two years. Then they began to search for other alternatives. They discussed the severity of the problem, analysed the situation, reviewed their past approach to protection and finally in 1968 formed a Protection Committee to negotiate the conflict. The committee discussed the issue with the local community. It mobilised parents and other relatives of the invader, the religious leader (purohit) and social workers to exert strong social pressure, rather than proceeding further with legal action. The family of the invader welcomed negotiation as a way of maintaining relations with the larger community. Ultimately, the conflict was resolved through informal negotiation. The facilitation role of elderly people as opinion leaders was crucial in bringing the conflicting parties into negotiation. In this process, all users had to think, rethink, express opinions, share their ideas and develop common understandings and reoriented action plans. The Protection Committee called periodic meetings of all forest users, including women and poor villagers, to review their activities and draw lessons for further improvement. Users provided feedback to the committee to improve action processes. In this way they learned from their mistakes. The emergence of a self-facilitation process is a unique characteristic of this case.

Following successful negotiation, the villagers sought collaboration with agencies to regenerate the forest to assure the fulfilment of their future forest needs. In 1984, the Swiss-funded Integrated Hill Development Project (IHDP) agreed to support their initiatives. In addition, the Panchayat (village council) provided legal and organisational support to the collaborative venture to develop and manage this forest area. Following the IHDP, an NGO known as the Environment and Population Awareness Program (ENAP) supported the villagers in implementing community development activities.

Subsequently, in 1990 the Protection Committee was reorganised into the Matarkopakho Forest Conservation Committee 5 . Committee members were selected through a mass meeting of the users to represent women, disadvantaged and poor people and social workers. The elders and the elected head of the Village Development Committee were nominated by consensus as advisors. With the support of ENAP, the Forest Conservation Committee participated in training activities, meetings and discussions organised at district headquarters and elsewhere and gained knowledge and experience on resource management approaches and participatory planning processes (Figure 10.3). Committee members observed the effective income 
generation and community development activities carried out by other groups and organisations. Learning from these cases, they decided to begin resource utilisation and management activities such as provision of community drinking water, non-formal education, post-harvest processing, kitchen gardening and other income generating activities. Continued monitoring of progress by both committee members and users, combined with joint review and reflection, helped them to achieve success. By this learning and action process people demonstrated their management abilities and learning capacities.

Figure 10.3 Community members are planning a community forestry activity

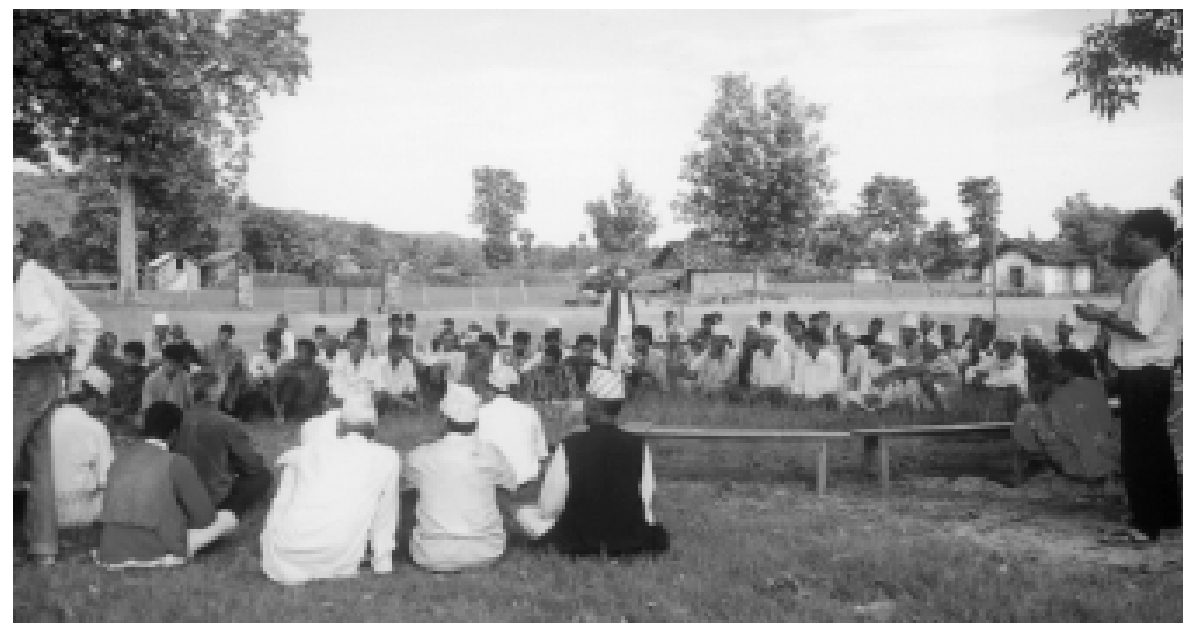

Presently, the Forest Conservation Committee is sharing information regularly with other Forest User Groups, government and non-governmental organisations and communities. Participatory diagnosis of problems is a strong element of their management style. Grazing, for example, became a serious problem when the practice was prohibited to protect the planted forest. Poor people especially suffered from such protection measures. To overcome the problem, the committee opened a few sections of forest at a time for rotational grazing. Linkages were established with other stakeholders to help manage and monitor the plan. Rules and regulations were implemented, refined, re-refined and amended by the users themselves and executed, thereby enhancing the adaptive nature of learning and action. 
During the period between 1984 and 1999, the Matarkopakho Forest Conservation Committee, in collaboration with other stakeholders, used this adaptive approach to develop innovative practices. These practices included alternate fodder harvesting, thatch grass management, green manuring, and harvesting of minor forest products. In the later years, the committee initiated action research on some high value nontimber forest products (NTFPs). Organised rotational surveillance of the forest by members of the committee ensured the prevention of illegal activities.

This forest management approach contains several elements of social learning and is an example of adaptive community-based management grounded in local initiatives. Women are members of the Forest Conservation Committee and participate in training, meetings and decision making (ENAP 1998). Gender roles in the community are changing and gender sensitivity has increased. The forest has become a symbol of cultural and social change in this remote hill area. Learning from this approach, the people of neighbouring areas also planted forest on barren public lands. Fifteen ha of barren public land known as Masanedanda and 20 ha of barren public land known as Rukhinikopakho are now also being converted into dense forest. In many cases, ENAP strategically facilitated the awareness-raising process to develop the capacity of users to conserve their forest.

\section{Analysis and reflection}

Evidence from the case study suggests that gender and other equity concerns may be substantially addressed by incorporating measures such as the following into management systems: 1) facilitation of planning processes to include potentially marginalised people in decision making from the very beginning; 2) the use of Protection Committees as an institution to negotiate informally on behalf of the community; 3) representation of the poor, women and other disadvantaged groups in Forest User Groups and ensuring that they are informed about their roles, responsibilities and authority regarding community forest resources; 4) assessment of the fairness and efficiency with which forest resources are distributed (Figure 10.4).

The case reflects conditions similar to those analysed by Maarleveld and Dangbégnon (1998), in which learning through experience, observation and interaction within particular social contexts over time results in the creation of recognisable social platforms 
Figure 10.4 Women are the principal user of forest. Therefore their involvement is utmost essential

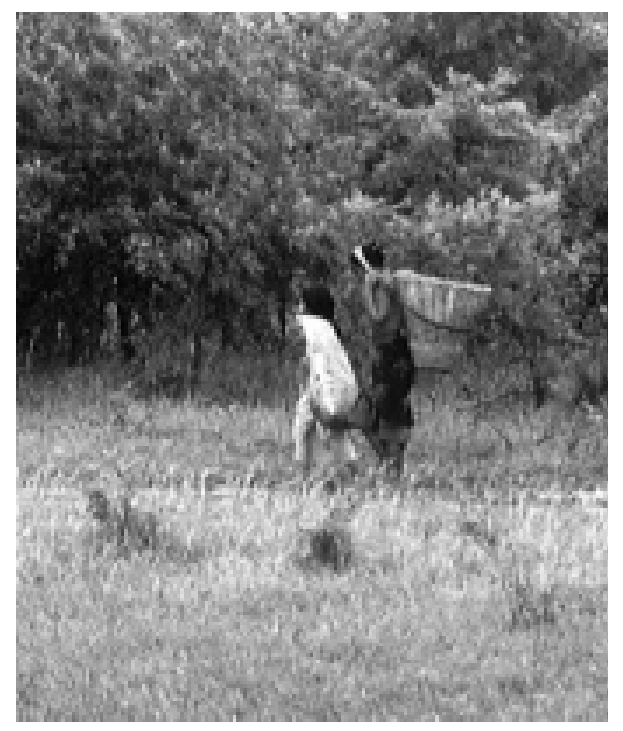

for collaborative action. Social learning as a methodological approach provides alternative ways of gaining insights into and predicting actions that affect communitybased forest management. This section aims to demonstrate how social learning can help fill the gap between the rhetoric and the reality of the Community Forestry Programme.

\section{Collective learning and collaborative action}

Collective learning promotes collaborative action. Characteristics observed in the case that enhance learning and thus collaboration include the following: 1) the willingness of the actors to cooperate; 2) the positive influence of local power elites such as elders or priests; 3) effective communication among the actors; 4) the practical significance to the community of the issues under consideration; 5) the participation of skilled facilitators; and 6) complementarity in the roles of supporting organisations.

The case shows that collective learning enhances community-based forest management. Such learning is not limited to scientific-academic knowledge, but occurs principally 
among the actors and involves both 'finding out' and 'taking action'. The case also demonstrated that collective learning is a reflective process of adjusting to the changing circumstances in which people come to perceive, interpret and act upon their interests. Stakeholders learned by action and experience and developed new ways of thinking.

Equitable access of disadvantaged groups of people to forest resources and their influence in policy formulation can be increased through facilitated social learning. This process brings people of different status and cultures together on a common platform to negotiate issues of access and, ultimately, to decrease the elites' domination of decision making in the Forest User Group. This process also creates awareness among the users themselves of their rights and responsibilities with respect to community forest resources. Through facilitation of effective communication, organised monitoring, collective learning and collaborative action, the existing mechanisms of 'equal' benefit sharing can be changed to address the needs of those who are totally dependent on forest resources for their survival and are too poor to pay access fees.

Effective facilitation of the four phases ${ }^{6}$ of the Forestry Programme should ensure sensitive and equitable processes, not necessarily just neutral or 'equal' ones. To achieve better equity for the poor, community-based forest management may require tradeoffs (Grimble et al. 1995). The process of making trade-offs is itself a politically sensitive process that requires an inductive approach (Gunderson et al. 1995; Lee 1993) to bring observation and experience together in understanding the responses of different stakeholders.

Ownership and accountability are other important variables for collaborative learning and action. Imposed participation and lack of involvement of all users in decision making cannot generate feelings of ownership and accountability. Community-based forest management can only succeed when all users participate in the decision-making process (Shrestha 1997a), as is demonstrated in the case study. Democratic decisionmaking processes help to develop feelings of trust, ownership and self-confidence. Unless disadvantaged groups of people develop the confidence to assert their rights to forest resources, powerful members of user groups dominate the whole process, which then becomes feudalistic (Sinha et al. 1996). The appropriate way to break such an impasse is to develop common understanding and agreement through effective communication among the actors. 
Similarly values, beliefs and trust also affect learning. The values associated with the vertical social stratification created by the Hindu caste system in Nepal exert enormous influence on community forestry and inhibit sensitivity to issues of social equity. In the case, a long-term interactive process and facilitation support helped to raise awareness and weaken the intensity of cultural resistance. In this particular case, collaborative work was enabled by feelings of trust, group identity and positive intention that occurred among the individual stakeholders despite caste differences.

The case demonstrates double loop learning, through which people reflect on and amend not only their actions, but also their action strategies. Double loop learning requires valid information, free and informed choice and internal commitment (Hamilton 1998). In the case study, stakeholders obtained valid information through their actions and made informed choices to adapt. People also, over time, learned to learn, which might be considered 'triple loop learning'.

\section{Information and communication}

Understanding the generation, transformation and use of knowledge helps to facilitate collective learning and joint action. Institutionalisation of feedback and communication mechanisms and rewards for learning by doing (Lee 1993) increases the effectiveness of multistakeholder forest management. A lesson from the case is not to control information flows, but to monitor, adapt and learn continuously through ongoing information exchange and trust building (Gilmour and Fisher 1997).

In the Matarkopakho case, action research (for example rotational grazing) generated knowledge and information which served as a basic starting point for planning and adaptation of further collaborative activities. Valid and reliable information is important for decision making. The communication strategies used in the case were effective in establishing a platform for bringing multiple stakeholders into the decision-making process.

\section{Platforms for negotiation}

The dependence of a group of people on a resource is a condition upon which common platforms for resource use negotiation can be created. Such platforms provide crucial opportunities to work together in agreeing on joint action plans and collective 
implementation. The Matarkopakho Forest Conservation Committee is a concrete example of such a platform. The functioning of a platform is governed by content, power structure, local context and the culture of a society. Platforms, as places for social learning, help to develop networks between individuals and institutions for collaborative action. The case shows that social networking can be a powerful way of achieving common objectives, especially when actors are united by a common problem and a common culture. The creation of social networks through facilitation promotes shared commitment (Ramirez 1999) and helps to develop institutional capacity for collaborative action, without which community-based management is difficult to achieve (Gilmour and Fisher 1997).

\section{Monitoring and adaptation}

Monitoring frameworks in adaptive forest management help participants to learn from the ongoing process and to adapt as needed. In this case, monitoring played a significant role in improving the management process. For example, the size of fragments allocated for grazing in the dry season was increased after the committee realised the excessive pressure of animals on forest land. An effectively organised monitoring system is essential to tracking representation and equitable benefits distribution for poor and disadvantaged people.

\section{Facilitation}

Facilitation can improve the performance of the implementation, monitoring and evaluation of any development interventions (Engel 1995). Facilitation focuses on the process of making things visible, and it was crucial in the case in orienting awareness and activities toward social equity concerns. Facilitation minimises later conflict by ensuring that planning processes are effective in identifying real users, their roles, commitments, and authority over forest resources.

One of the main challenges in community forestry is to create mechanisms and procedures to involve disadvantaged groups of people in decision making and to minimise the influence of the powerful elite. Facilitation can help to meet this challenge through awareness raising as a non-coercive means for change. Such change, however, does not happen immediately; continuous efforts are essential to promote effective, efficient and expandable social learning (Korten 1984). In the study case, for example, gender 
sensitisation was an external concept that was contradictory to the customary norms for the majority of users (Upreti 1995). Even so, the case shows evidence that women are gradually emerging as active members in forest management and other development activities and are participating in meetings, discussions and learning processes, mainly because of coordinated facilitation. Facilitation need not always be from outside. It can emerge from within the communities, whose insights and adaptive skills of resource use are derived from many years of experience and cultural traditions that have coevolved with local circumstnces.

\section{LESSONS LEARNED AND IMPLICATIONS FOR COMMUNITY FORESTRY IN NEPAL}

The availability of progressive acts and regulations is a necessary but not a sufficient condition to ensure community forestry's responsiveness towards social equity issues. The case study in this paper shows that the internal social structure and disposition of power to manipulate acts and regulations, local knowledge systems, the donor's role and procedures and institutional arrangements all play influential roles as well. They also demonstrate that a social learning approach supports institution building and can make positive impacts on the Community Forestry Programme in Nepal.

The case showed that local people are capable of making sound judgements in managing the forest resources available in their communities. Therefore, community-based forest management should be built primarily upon their abilities. However, it is essential to develop the capacity of local people and their institutions (such as the Matarkopakho Forest Conservation Committee) through awareness-raising activities and support. The case showed that conflict and negotiation are integral parts of the community management process. Conflict is not always dysfunctional, as it can lead to innovation and therefore has great transformational potential. It is essential to create favourable structural mechanisms, such as the involvement of poor, disadvantaged people and women in planning and decision-making processes to ensure their proper representation and to realise their authority, responsibility and accountability in community forestry. Such a mechanism can be found in a sound learning process. In particular, facilitation and platform establishment encourage the involvement of marginal groups. 
The innovative and successful approaches and methodologies developed by individual projects and institutions need to be shared with other organisations working in communitybased resource management. Institutionalised forums are essential to share and 'scale up' such experiences. Otherwise, there is a risk of creating an island effect, with large disparities between districts where community management projects have been implemented and districts without such projects.

\section{CONCLUSIONS}

This paper has highlighted that the implementation of Nepal's Community Forestry Programme has not adequately addressed social equity concerns, but that the situation may be improved by incorporating social learning activities into the programme. Collective learning and collaborative action can lead to greater transparency about equity concerns and help mobilize less powerful stakeholders. Platforms for communication and negotiation play crucial roles in promoting these processes of learning and action. From the case study, it is clear that other aspects of social learning that are key to making the Community Forestry Programme successful are: the needs and the willingness of stakeholders to learn effective facilitation, regular monitoring, sharing of valid knowledge and information, effective feedback and feelings of ownership and trust among the actors. The Nepalese community forestry policy is progressive and comprehensive in comparison to the policies of other development programmes. However, their translation into practice, especially in addressing social equity concerns, could be stronger. If we learn from our experiences and respond appropriately, we will be that much closer to achieving the goals of the policy.

\section{ACKNOWLEDGEMENTS}

I would like to express my gratitude to the East-West Centre (EWC) and CIFOR, especially June Kuramoto, Louise Buck, Jefferson Fox, David Edmunds, Sonja Brodt and Glen Dolcemascolo. In the process of preparing this paper I have received reference materials, ideas, and encouragement from K. P. Siktel and Brahma Dhoj Gurung (NSCFP), Laxman Gautam and Narayan Shrestha (DFO, Dolakha), Sita Ram Basnet and Apsara Chapagin (FECOFUN), Saroj Upreti (ENAP) Bikram Raj Tuladhar (DOF), 
Balaram Kandel-Hill Leasehold Forestry Project, Bimala Poudel Rai and Ramesh Khadka (Action Aid-Nepal), Ghanendra Kafle, (NUKCFP), Kalpana Neupane, Bishnu Prasad Pokharel, Raju Raj Pande, Kabi Raj Neupane, Khem Sharma and Lini Wollenberg. I wish to pay special tributes to all of them. The continued support of Yamuna Ghale Upreti, Natural Resource Management Specialist, Asmita and Aaiyush to carry out this study is highly appreciated. Last but not the least, I express my sincere thanks to all participants of the workshop on 'Sharing Innovations: Methods for Multiple Stakeholder Management of Community Forests' for their comments and suggestions.

\section{ENDNOTES}

${ }^{1}$ Panchayat is a local governing body. After the restoration of democracy in 1990, the name 'panchayat' was replaced by 'Village Development Committee' (VDC), the smallest political unit.

${ }^{2}$ In this research, I have a dual role: as an independent researcher, and, as a resident and forest user of one of the districts in which the project is being implemented, as a beneficiary of the project.

${ }^{3}$ A white cow kicked his faced in the dream. According to local legend, when a cow kicks the face of a person in a dream something bad will happen. To prevent such misfortune, part of the land should be kept for cows to graze on.

${ }^{4}$ A local land tax collector appointed by the Land Revenue Office. Only a few powerful people who have good relations with the government have this position.

${ }^{5}$ In Dolakha district, forest protection committees are common management structures created to develop and conserve forest not formally handed over by the government to users (NSCFP 1997: 10).

${ }^{6}$ The Community Forestry Program identifies four phases: investigation, negotiation, implementation and review. 
Bishnu Upreti

\section{LITERATURE CITED}

Anderson, J., Clement, J. and Crowder, L. V. 1998 Accommodating conflicting interests in forestry: concepts emerging from pluralism. Unasylva 194 (49):3-10.

Belbase N. and Regmi, D. C. 1998 Comparative analysis of decentralization and (community) forestry legislation. International Center for Integrated Mountain Development, Kathmandu.

ENAP 1998 Annual report 1997-98. Charikot, Nepal. (Nepali version)

Engel, P. G. H. 1995 Facilitating innovation: an action-oriented approach and participatory methodology to improve innovative social practice in agriculture. Ph.D. Dissertation. Wageningen Agricultural University, Wageningen, The Netherlands.

Gilmour, D. and Fisher, B. 1997 A project or process. In: G. Borrini-Feyerabend (ed.) Beyond fences: seeking social sustainability in conservation, 103-106. IUCN, Gland, Switzerland.

Grimble, R., Chan, M,K. Aglionby, J. and Quan, J. 1995 Trees and trade-offs: a stakeholder approach to natural resource management. Gatekeeper Series \#52. International Institute for Environment and Development, U.K.

Gunderson, L.H. Holling, C. S. and Light, S.S. (eds.) 1995 Barriers and bridges to the renewal of ecosystems and institutions, 428-460. Columbia Press, New York.

Hamilton, G. 1998 Co-learning tools: powerful instruments of change in South Queensland, Australia. In: Röling, N. and Wagemakers, A. (eds.) Facilitating sustainable agriculture. Participatory learning and adaptive management in times of environmental uncertainty, 172-188. Cambridge University Press, Cambridge, UK.

His Majesty's Government of Nepal 1989 Master Plan for the Forestry Sector. Ministry of Forests and Soil Conservation, Kathmandu.

Kandel, P. N. 1999 Development of community forest: diminishing livestock. Sahabhagita 12: 2055. (Nepali version)

Kantipur Daily National Newspaper 1999. 4 August.

Korten, D.C. 1984 Rural development programming: the learning process approach. In: Korten, D.C. and Klauss, R. (eds.) People-centred development: contributions toward theory and planning frameworks, 176-188. Kumarian Press, West Hartford, Connecticut, USA. 
Joshi, A. L. 1997 Community forestry evolution, concept and policy. International Training Course (15 Sept.-5 Oct. 1997). Participatory Process, Tools and Techniques in Community Forestry Field Tested Innovations. Regional Community Forestry Training Center/HMG Nepal, Kathmandu.

Lee, K. N. 1993 Compass and gyroscope: integrating science and politics for the environment. Island Press, Washington, D.C.

Maarleveld, M., and Dangbégnon, C. 1998 Managing natural resources in face of evolving conditions: a social learning perspective. Paper presented at the seventh conference of the International Association for the Study of Common Property, 10-14 June, 1998. Vancouver, Canada.

Nepal-Swiss Community Forestry Project (NSCFP) 1997 Nepal-Swiss Community Forestry Project Document Phase III July 1996-June 2000. HMG/N and Swiss Development Corporation, Kathmandu.

Nepal Swiss Community Forestry Project 1998 Nepal-Swiss Community Forestry Project Annual Report 1998. HMG/N and Swiss Development Corporation, Kathmandu.

Poudel, B. R., Siktel, K. P. and Bhattarai, U. R.. 1998 Proceedings of the community forestry strategy development workshop. Action Aid Nepal, Kathmandu.

Poudel, D. 1997 Impact assessment of Nepal-Swiss Community Forestry Project NSCFP, Kathmandu.

Pokharel B. and Tumbahamphe, N. 1999 Community forestry development action: a synthesis of NUKCFP reports and publications. Nepal-UK Community Forestry Project, Kathmandu.

Ramirez, R. 1999. Stakeholder analysis and conflict management. In: Buckles, D. (ed.) Conflict and collaboration in natural resource management, 101-126. IDRC/ World Bank, Ottawa, Canada, Washington, USA.

Röling, N. 1992 The emergence of knowledge systems thinking: a changing perception of relationships among innovation, knowledge process and configuration. Knowledge and Policy: The International Journal of Knowledge Transfer and Utilisation Spring 5(1): 42-64.

Röling, N. 1994 Creating human platforms to manage natural resources: first results of research program. In: Proceedings of the International Symposium on Systems Oriented Research in Agriculture and Development, 391-395. Montpellier, France. Röling, N. 1997 The soft side of land: socio-economic sustainability of land use systems. Paper presented at the conference on Geo-Information for Sustainable Land 
Management. Enschede 17-21 Aug. 1997. International Institute for Aerospace Survey and Earth Science (ITC), The Netherlands.

Röling, N. and Jiggins, J. 1998 The ecological knowledge system. In: Röling, N. and Wagemakers, A. (eds.) Facilitating sustainable agriculture. Participatory learning and adaptive management in times of environmental uncertainty, 283-311. Cambridge University Press, Cambridge, UK.

Shrestha, N. K. 1999 Community forest in danger in Nepal. Forest, Trees and People Newsletter 38, March. Food and Agriculture Organization and University of Agricultural Sciences, Sweden, Uppsala.

Shrestha, K. B. 1997a Community forestry: policy, legislation and issues. First national workshop on community forestry and rural development: potential role of I/NGOs. 24-26 July, 1997. Godawori, Lalitpur, p. 9-16.

Shrestha, K. B. 1997b Policy implementation lecture notes. International training course: Participatory process, tools and techniques in community forestry field-tested innovations. 15 Sept.-5 Oct., 1997. Regional Community Forestry Training Center/ HMG/Nepal, Kathmandu.

Shrestha, M. L., Joshi, S. P., Bhuju, U. R., Joshi, D. B. and Gautam, M. 1995 Community forestry manual. DANIDA and International Center for Integrated Mountain Development, Kathmandu.

Sinha S., Shrestha, N. K., Kuechli, C. and Shrestha, M. L. 1996 Of trees, careers and capacity development: evaluation of the Dolakha Ramechhap Community Forestry Development Project. HMG/N and Swiss Development Corporation. Kathmandu.

Tuladhar, B. R. 1998 Community forestry in integrated participatory watershed management. Paper presented in People and Resources Dynamics Project workshop. March, 1998, Almora.

Upreti, B. R. 1998 Searching for an alternate approach for community level natural resource management in Nepal: a case study on natural resource use negotiationa knowledge systems perspective. M.Sc. thesis submitted to the Wageningen Agricultural University, The Netherlands.

Upreti, B. R. 1995 Women's participation in development activities: a case study of Mechi Hill Development Progr am in Ilam District. M.A. Thesis submitted to the Department of Sociology/Anthropology, Tribhuvan University, Kathmandu, Nepal.

Wilson, K. and Morren, G. E. B. 1990 Systems approaches for improvement in agriculture and resource management. Macmillan Publishing Company, New York.

WATCH 1995 Developing an understanding on users' expectations from community forestry. Nepal-UK Community Forestry Project, Kathmandu. 
BEYOND RHETORICAL SUCCESS

\section{APPENDIX 1. EVIDENCE OF THE NEED FOR ALTERNATIVE APPROACHES FOR ADDRESSING SOCIAL EQUITY CONCERNS IN COMMUNITY FORESTRY}

Example 1. Female-headed households In one village, there was a poor, femaleheaded household that depended on goat keeping for its livelihood. The woman of the household obtained all necessary goat fodder from the nearby forest. After control of the forest was handed to the local community, the Forest User Group decided to close the forest to all access for some years. Eventually, the woman could not obtain enough fodder for her goats and her enterprise collapsed, thus threatening her livelihood. (Source: Poudel et al. 1998: 10).

Example 2. Community forestry jeopardizes livestock in Humla In 1995, Forest User Groups in neighboring districts decided to block the pathway for the sheep of the Humli people via their community forest area. Sheep are the main source of transportation for goods and materials in Karnali Zone. To protest the decision of these Forest User Groups, Humli people appealed to the district court and obtained an order to open the pathway for sheep. The Forest User Groups did not respect the court's decision. Representatives of all political parties and people of Humla then came to Kathmandu to register complaints with the Ministry of Forest and Soil Conservation. The ministry did not take the problem seriously and ultimately, Humli people stopped their sheep farming. Presently the population of sheep in Humli is rapidly decreasing and the livelihood of many sheep farmers is threatened. (Source: Kandel 1999: 16-19).

Example 3. Poor people are marginalised Some of the poorest Mushahar families are unable to thatch their small houses due to the lack of thatching materials (thakal/khar), since the Forest User Groups who control the forest are protection-oriented and do not allow the collection of thatching materials. (Source: Poudel et al. 1998: 10).

Example 4. Forest resources are exploited by the elite In Suspa, 558 ha of dense forest have been managed by a Forest User Group for 6 years. This year, a few members extracted personal profit from the forest. They drew up a plan for selling timber and secured approval from the forest users' committee. Then they sold 
wood for 2 million Nepalese rupees (about US\$29 400 at an exchange rate of 68 rupees $=$ US $\$ 1$ ) to traders from Kathmandu. At the same time, they drew up legal documents for expenditures of that amount, so that the total expenditure was shown equal to the total income. In this way money was misused by a few people at the cost of other users. (Source: primary data collected from informal discussion). 